UNIVERSIDADE DE SÃO PAULO

INSTITUTO DE QUIMMICA

\title{
REAÇÕES DE IONS DE COMPOSTOS OXIGENADOS EM FASE GASOSA ESTUDADAS POR ESPECTROSCOPIA DE RESSONÂNCIA CICLOTRÔNICA DE ÍONS
}

PETER WILHELM TIEDEMANN

Tese de Doutoramento Orientador :

Prof. Dr JOSÉ MANUEL RIVEROS 


\begin{abstract}
Gostaria de expressar meu profundo agradecimento ao Professor José Manuel Riveros, não apenas pela orlentação segura e pelo incentivo constante que recebi durante a execução desses trabalhos, mas prin. cipalmente pelo esforço dispen dido para o meu desenvolvimen to cientifico.
\end{abstract}




\section{AGRADECIMENTO}

Agradeço

ao Professor John D. Baldeschwieler e ao Professor Robert T. McIver, Jr., em cujos laboratórios estagiei, respecti vamente, na Universidade de Stanford (California, USA) e na Uni versidade da California em Irvine (California, USA). O agradecimento se estende ao Professor Paschoal Senise e ao Dr. Wesley Copeland por terem possibilitado os estágios.

ao Dr. Larry K. Blair, por Inümeras sugestões feitas. aos colegas de laboratór 1o, Sônia Maria José Briscese, Keiko Takashima, Ana Maria Garcia da Costa, Paulo Celso Iso lani, Antônio Celso Breda e José Fernando Faigle pela colabora ção continuamente prestada.

ao Sr. Geraldo Ayrosa, de cujo auxilio constantemente nos valemos para reparos e modificaçōes no espectrômetro de ressonância ciclotrônica de Ions.

ao Dr. Fernando Galembeck e ao Dr. Yoshlo Kawano por inümeras discussões bastante proveitosas.

aos.laboratōrios de Física do Estado sōlido (Instituto de Fisica), do Acelerador Van de Graaff (Instituto de Fỉsi ca), de Espectroscopia Molecular (Instituto de Química) e de Es pectropolarimetria (Instituto de Química), que em épocas diver sas forneceram nitrogênio líquido.

à Biblioteca' do Conjunto das QuImicas pela impressão da tese.

à National Academy of Sciences (USA), ao Conselho Nacional de Pesquisas e à Fundação de Amparo à Pesquisa do Estado de são Paulo pelas bolsas concedidas. 
PÅG.

1. INTTRODUÇÃO 1

2. PRINCIPIOS DA RESSONANCIA CICLOTRONICA DE IONS 4

2.1. O ciclotron 4

2.2. Absorção de potência 10

2.3. Operação continua 16

2.3.1. O omegatron 17

2.3.2. A cela de Wobschall 19

2.3.3. A cela de três regiões 21

2.3.4. Técnicas de ressonância ciclotrônica de lons 28

2.3.4.1. Ressonância simples 28

2.3.4.2. Ressonância dupla 33

2.3.4.3. Ejeção de Ions 35

2.3.5. Constantes de velocidade de reação 37

2.3.5.1. O método a pressão alta 38

2.3.5.2. O método a pressão baixa 42

2.3.5.3. Métodos mais completos 47

2.3.5.4. Medição experimental do tempo de residência 49

2.4. Operação pulsada 52

2.4.1. A cela de aprisionamento 53

2.4.2. Sequência de pulsos 55

2.4.3. Curvas cinéticas 58

3. REAÇÕES ENTRE IONS E MOLECULAS 61

3.1. Reações em fase gasosa 62

3.2. Modelos para reações entre lons e moléculas em fase gasosa 64

3.2.1. Modelo de polarização 65

3.2.2. Modelos estatísticos 73

3.2.2.1. Teoria do quase-equilibrio 73

3.2.2.2. Teorta do espaço de fase 83

3.2.3. Modelos diretos 90

3.2.4. Outros modelos 99

4. REAÇס̃ES DE ACETILAÇÃO 102

4.1. Espectros de massa de cetonas 103

4.2. Reações entre Ions e moléculas de cetonas 105

4.3. O espectrômetro de ressonância ciclotrônica de Ions 111 
4.4. Compostos usados 128

4.5. Frequências de colisão elástica 130

4.6. Reações de acilação 144

4.6.1. Cetonas sem hidrogênios $\gamma \quad 147$

4.6.2. Cetonas com hidrogênios $\gamma$

4.6.3. Mecanismo das reações de actlação 162

5. BASICIDADE DE ACIDOS, ALCOOIS E ESTERES SIMPLES

5.1. Afinidade protônica 170

5.2. Basicidades relativas 174

5.3. Parte experimental 178

5.4. Resultados 181

5.5. Afinidade protônica e potencial de ionização 200

6. REAÇÕES DE ESTERIFICAÇÃO 206

6.1. Reações em solução 207

6.2. Parte experimental 211

6.3. Reações dos ácidos 213

6.4. Reações dos älcoois 216

6.5. Reações dos ésteres 222

6.6. Reações de esterificação 225

6.7. Reações de transesterificação 235

6.8. Um novo tipo de reação 235

6.9. Termoquímica e mecanismos 244

7. ESPECTROSCOPIA DE RESSONANCIA CICLOTRONICA DE IONS PULSADA 259

7.1. A cela de aprisionamento 260

7.2. Circuitos de pulsos 261

7.3. Espectros e curvas cinéticas 269

$\begin{array}{ll}\text { SUMARIO } & 276\end{array}$

SUMMARY 280

REFERENCIAS 284 


\section{INTRODUÇÃO}

o estudo de reações de íons gasosos com molēculas neutras gasosas é de suma importância para a compreensão dos fatores fundamentais de que. depende a reatividade química. A maior parte da informação a respeito de mecanismos de reação provém de investigações realizadas em solução. Muitas relações interessan tes entre reatividade e estrutura dos compostos foram descober tas, mas a interpretação em termos de propriedades intrínsecas dos compostos envolvidos é dificultada, pelo fato de os reagen tes iônicos estarem solvatados. Deve-se esperar que uma espēcie quimica se comporte de maneira diferente, se uma atmosfera de solvente a circunda. En fase gasosa, a pressões baixas $110^{-5}$ Torr), ions podem ser formados por impacto de elétrons sobre moléculas neutras, sem serem solvatados, reagindo em processos bimoleculares simples com moléculas neutras. Desta maneira, mecanismos de reação deduzidos a partir de resultados experimentais. de reações de ĩons com molēculas em fase gasosa, bem como constantes de velocidade de reação calculadas a partir desses resultados, refletem as propriedades estruturais intrinsecas das espécies participantes.

Num espectrômetro de massa convencional os ions permanecem por um tempo multo reduzido na fonte do mesmo $\left(10^{-6} \mathrm{~s}\right) \mathrm{e}$, nas pressões balxas reinantes, a probabilidade de colisão entre İons e molēculas é desprezivel. Contudo, modificações apropriadas possibilitam o estudo de reações de fons com molèculas. Porēm, existe um instrumento especlalmente desenvolvido para esses estudos: o espectrômetro de ressonāncia ciclotrônica de ions, 1,2 capaz de manter os lons por tempos superiores a $10^{-3} \mathrm{~s}$ numa cela 
metálica. Este espectrômetro é extremamente versátil, permitindo a identificação inequivoca dos reagentes e produtos iônicos e a elucidação de mecanismos de reação; as possibilidades experimentais estendem-se desde estudos a respeito da termodinâmica das reações (calores de reação), até estudos cinéticos, visando a ob tenção de constanteses de, velocidade de reação. Uma sērie de artí gos de revisão de ressonância cicłotrônica de íons foi publica da ${ }^{1-11}$ e um livro está sendo preparado, ${ }^{12}$ o que certamente mostra o grande interesse despertado por essa técnica. o número to tal de publicações na literatura aberta jā ultrapassa duas centenas, devendo-se mencionar que os primeiros artigos apareceram depois de 1960.13

Nesta tese serão discutidos inicialmente os principios fundamentais da ressonância ciclotrônica de ions; necessaria mente requer esta discussão a dedução de algumas equações que relacionam grandezas observāveis com parâmetros instrumentais. Ad mite-se que algumas das deduções sejam apresentadas de forma demasiadamente longa e detalhada, mas acredita-se que isto possa levar em alguns casos a uma compreensão mais profunda de certos aspectos da ressonância ciclotrônica de íns.

Existem alguns modelos teóricos que permitem tratar reações de ions com molēculas, considerando a colisão dos reagen tes ao nivel de particulas e, a dissoctação do complexo de colisão eventualmente formado. Esses modelos permitem em geral o cálculo de certas grandezas cinêticas ou dinâmicas envolvenào produtos de reação. No capitulo 3 desta tese os aspectos mais salientes desses modelos serão mencionados $e$, se bem que na tese só um deles seja empregado e de modo muito superficial para cálculos quantitativos, eles serão frequentemente invocados em outras partes da tese. 
Nos três capitulos seguintes $(4,5$ e 6$)$ será relatada a parte experimental deste trabalho. Como foram realizados estudos relativamente independentes, cada um será tratado num capítulo próprio, constando cada capítulo de uma revisão bibliogrāfica pertinente ao assunto, de uma descrição dos métodos experimentais empregados, de uma apresentação dos resultados, seguida de discussão dos mesmos. Assim, o capitulo 4 refere-se a reações de acilação de compostos carbonillicos, o 5, à medição de afinidades protônicas relativas de alguns compostos oxigena dos e, o capitulo 6 , a reações de esterificação e transesterifi cação.

Finalmente, consta do capĩtulo 7 uma breve descrição de algumas modificações instrumentais realizadas no decorrer dos trabalhos. 


\section{PRINCIPIOS DA RESSONANCIA CICLOTRONICA DE IONS}

Um espectro de ressonância ciclotrônica de îons, que na da mais è do que um espectro de massa no qual aparecem produtos de reações entre ions e, moléculas, requer a aplicação de certas correções para obter correntes iônicas a partir das alturas dos picos no espectro. Para compreender a natureza dessas correções è necessārio conhecer as características do movimento dos íons na cela de ressonância ciclotrônica, atravēs das equações que descre vem tal movimento. Para a melhor compreensão das experiências rea lizadas no presente trabalho, será apresentada neste capítulo uma discussão dos princípios físicos da ressonância ciclotrônica de Ions e das diversas possibllidades experimentals. A discussão não é exaustiva e diflcilmente o poderia ser, pois continuamente são sugeridas experiênclas novas; mas justamente isto mostra a potencialidade da técnica.

\subsection{O clclotron}

A força que atua sobre uma particula, de carga g e velocidade $\underline{\mathrm{v}}$ num campo magnētico $\underline{\mathrm{H}} \mathrm{e}^{-}$

$$
\vec{F}=\frac{g}{C}(\vec{v} \times \vec{H})
$$

A força è sempre perpendicular à velocidade instantânea, de modo que, se o campo magnētico é uniforme, a trajetōria da partícula é clrcular, num plano perpendicular ao campo magnético. Nenhuma for ça age sobre a partícula na direção paralela ao campo magnétí co. São usadas untalades do sistema CGS; por isso aparece a velocidade c da luz. A força magnética è igual à força centrifuga: 
$\frac{\mathrm{q}}{\mathrm{c}} \mathrm{vH}=\frac{\mathrm{mv}}{\mathrm{r}}$

Logo, o raio da órbita da partícula de massa $\underline{m}$ é:

$r=\frac{\mathrm{mvC}}{\mathrm{qH}}$

e a velocidade angular do movimento é

$\omega_{\mathrm{C}}=\frac{\mathrm{v}}{\mathrm{r}}=\frac{\mathrm{qH}}{\mathrm{mc}}$

sendo a quantidade $\omega_{C} / 2 \pi$ denominada de frequência ciclotrônica. Um conjunto de ions de dada massa, produzidos por impacto de elé trons, tem certa distribuição de velocidades e, portanto, esses ions descrevem örbitas de raios diferentes (equação 2.2.), mas todos têm a mesma frequência ciclotrônica (equação 2.3.), que não depende da velocidade dos Ions. $1,2,3$ Um ion monovalente de massa atômica 1 , num campo magnético de $100 \mathrm{G}$, tem uma frequência ciclotrônica $\omega_{c} / 2 \pi$ de $153,56 \mathrm{kHz}$.

E possivel colocar no campo magnético um par de placas paralelas, de tal modo que se possa aplicar um campo elétrico al ternante $\vec{E}(t)$ de frequêncla $\omega_{1}$ perpendicularmente a $\vec{H}$. Se $\omega_{1}=\omega_{c}$, os ĩons absorvem energia desse campo elētrico e são acelera dos a velocidades e örbitas maiores. A energia absorvida pelos ions tem que vir da fonte de $\vec{E}(t)$. Se essa fonte for um oscilador, sendo que as placas paralelas constituam parte do elemento capacitivo do circuito de ressonância (IC) do mesmo, a absorção de energia pelos lons será equivalente a uma impedância adicional em paralelo ao condensador, o que fará com que a amplitụ de de oscilação se reduza, desde que o oscllador seja sensivel

a pequenas variações de Impedâncla do circuito LC. Desta propriedade goza o oscilador marginal, um oscilador que pode ser operado em condições que são "marginais" para oscilação contínua. Este circuito, desenvolvido iniclalmente para uso em ressonância magnética nuclear (onde a potência é absorvida na indutância) , 


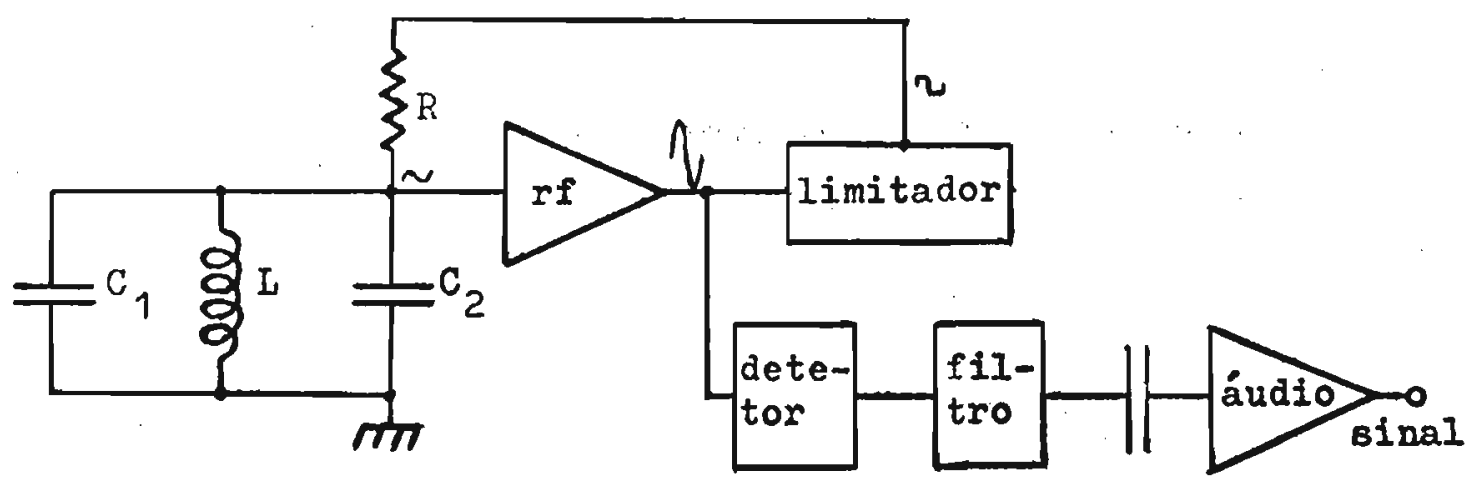

FIGURA 2.1. Esquema simplifioado do oscilador marginal. $C_{1}$ é a cela.

Uma oscilação no circuito de ressonância é amplificada num ampli ficador de rádio-frequência e realimentada através de um limita dor ao circuito LC. Isto constitui um oscilador. O limitador corta a onda senoidal de rádio-frequência, fornecendo uma onda quadrada de amplitude constante, mesmo que a da onda senoidal se reduza. Esta tensão constante, aliada à resistência $\underline{R}$ de valor muito alto, constitui uma fonte de corrente constante. Se o con densador $\mathrm{C}_{1}$ estiver num campo magnētico e se entre suas placas houver íons de frequência ciclotrônica igual à do oscilador, os ions absorverão potência do circuito; como a corrente no circui to LC è constante, a tensão precisa diminuir. Pode-se mostrar que a queda de tensão è proporcional à absorção de potência; assim, registrando a tensão, sabe-se a potência absorvida. Apōs - amplificador de rădio-frequência, o sinal val a um detetor e a um filtro, obtendo-se uma tensão continua. Como serā visto abaixo, é conveniente modular de alguma forma a absorção de potên cia, geralmente numa frequência de áudio, isto é, fazer com que alternadamente haja e não haja absorção de potência. Então, 
havendo condições de ressonāncia em $C_{1}$, a amplitude da rádio-fre quência será alternadamente maior ou menor (modulação) e a tensão depois do filtro não será mais contínua, mas variará na frequência de modulação, podendo ser amplificada por um amplifica dor de áudio. Se em $C_{1}$ não houver condições de ressonância, não haverá absorção de potência em instante algum, a amplitude de rạ dio-frequência permanecerá constante no valor máximo e após o filtro ter-se-ã uma tensão continua, que não chega ao amplificador de ãudio, do qual não sairá sinal algum.

Sob condições usualmente empregadas em ressonância ciclotrônica de ions, um ion monovalente de massa atômica 50 , sendo o nivel de oscilação no circuito LC do oscilador de $100 \mathrm{mV}$, a sorve uma potência de $4 \cdot 10^{-8} \mathrm{erg} \cdot \mathrm{s}^{-1}$ (ver fōrmula 2.33..). Num oscilador marginal típico isto corresponde a uma variação de 5. $10^{-8} \mathrm{~V} \cdot$ ion $^{-1}$. ? O ruído no circuito LC é tipicamente 7 . $10^{-7} \mathrm{~V}$. Portanto, o oscilador marginal tem em principio sensibi lidade suficlente para 14 ions na cela já serem detectáveis. ${ }^{7}$

A equação 2.3. mostra que, mantendo a frequência $\omega_{1}$ do oscilador fixa e varrendo o campo magnéti.co $\underline{H}$, a condição $\omega_{1}=$ $\omega_{C}$ será sucessivamente satisfelta para Ions de diversas relações massa/carga (m/q). Então, um grăfico de tensão contínua após o filtro no oscilador marginal em função do campo magnético, é o espectro de ressonância ciclotrônica da mistura de fons de vārias massas, com uma escala linear em massa. Assim tem-se um es pectrômetro de massa.

A tensão continua mencionada acima precisa obviamente ser amplificada para poder alimentar um registrador. Mas o processamento de sinajs contínuos sempre está sujeito a deslocamento de I1nha base, 1sto é, a uma variação no sinal, devido a 
uma variaçễo na tensão de referênqia (zero) do sistema. Por isso deve-se "zerar" frequentemente o sistema lequivale, por exem plo, a fazer medida com um "branco" em colorimetria). Quanto mais frequentemente o sistema for "zerado", mais certeza podese ter de que a linha base não se está deslocandoi ${ }^{15}$ um modo de fazer isso é modular o sinal como mencionado acima; no caso, o perĩodo em que não há absorção de potência corresponde ao "zerar". Dessa maneira a tensão contínua è transformada essencial mente numa tensão alternada de amplitude proporcional à tensão continua, e que pode ser amplificada convenientemente (amplifica dor de áudio, no esquema do oscilador marginal), por um amplificador que deixa passar apenas uma banda de frequências ao redor da de modulação, de mođo que o ruỉo não seja amplificado em extensão igual à do sinal. A frequêncla de modulação mais apropriada para ressonância ciclotrônica de lons situa-se na faixa de āudio (tıpicamente $27 \mathrm{~Hz}$ ), mas deve situar-se longe de "frequências do ambiente", tais como os $60 \mathrm{~Hz}$ da linha de energia elétrica, por razões que serão vistas abaixo. A maneira de conseguir periodos de absorção de potêncla seguidos de períodos em que não hã absórção (modulação), serã apresentada seção 2.3.4.1. Dépots que o sinal fol amplificado, è necessārto retificā-lo, pạ ra recuperar novamente o sinal original. Isto poderia ser feito com um retificador de onda completa, que deixa passar o sinal, se este vem com certa polaridade e o inverte, se vem com polaridade oposta, de modo que o sinal de saída tenha só uma polarida de, não sendo, porém, uma tensão continua pura; os componentes aI ternados restantes podem ser removidos por filtros. Um retifica dor de onda completa pode ser considerado um engenho "operado pe lo sinal", isto é, seu modo de operação (1nverter ou não inver ter) depende da polaridade instantânea do sinal alternado. 160 
problema è que ruỉdo tambēm opera o retificador, isto è, faz com que produza um sinal retificado. Um instrumento especialmente de senvolvido para aumentar relações sinal/ruỉdo é o detetor de fase, que è um demodulador sỉncrono, "operado por uma referência", ou seja, seu modo de operação depende da polaridade de uma onda de referência, que tem a mesma frequência que a modulação e uma fase fixa em relação a esta. Na realidade a própria onda de referência è usada para modular o sinal. A fase é ajustada de modo que o sinal passe, se a onda de referência estiver com dada polaridade, e seja invertido, se a onda de referência estiver com a polaridade oposta. O detetor de fase pode ser visto como uma chave de duas posições, acionada na frequência de referēncia,e que liga o sinal de entrada à saída com dada polaridade,e inverte as Iigações quando a polaridade do sinal de entrada inverter, de modo que o sinal tenha sempre a mesma polaridade na salda. Desta maneira consegue-se que só a componente fundamental de modula ção seja retificada; ruído ao acaso, não sincronizado com a onda de referêncla, não produz na saỉda uma tensão continua (a não ser que haja sincronização acidental; por exemplo, se a frequência de modulação for $60 \mathrm{~Hz}$ e no sinal houver ruído vindo da linha de energia elétrica, este será retificado; por isso essa fre quência deve ser evitada); o ruido aparece na saída, com a mesma frequência que antes, mas pode ser atenuado até o ponto desejado (com o chamado controle de constante de tempo) por um ampli ficador que deixa passar apenas sinais continuos.

Até aqui fol descrito como aparece o sinal de ressonân cia ciclotrônica de ions e como é processado, mas nada foi men cionado a respelto do sinal em si, ou espectficando melhor, respeito da forma da linha de absorção de ressonância clclotrôni ca de ions. Isto serā felto na seção segulnte. 
2.2. Absorção de potência

A força que atua sobre uma particula carregada quando, além do campo magnético, existir um campo elétrico alternante, $E(t)$, perpendicular ao magnētico, è dada pela equação de Lorentz.

$\vec{F}=m \frac{d \vec{v}}{d t}=q \vec{E}(t)+\frac{g}{c}(\vec{v} \times \vec{H})$

Esta equação é aplicãvel ao movimento dos ions no ciclotron, quando este è usado como espectrômetro de massa, como visto acima. Mas como tal, não tem vantagens, apesar da sensibị lidade e da resolução, que è razoável. o aparelho torna-se inte ressante, quando, alēm dos ỉons, tambēm houver um número muito grande de moléculas na cela. Então o movimento ciclotrônico coe rente dos íons è de vez em quando interrompido por colisões com moléculas neutras, levando a espalhamento dos Ions. Nestas ocasiões a absorção de potêncla pelos lons é sustada e um termo de amortecimento precisa ser adicionado à equação 2.4. para descrever o movimento dos Ions. 1

$m \frac{d \vec{v}}{d t}=q \vec{E}(t)+\frac{g}{c}(\vec{v} \times \vec{H})-m \xi \vec{v}$

$\underline{\xi}$ è a velocidade de relaxação da quantidade de movimento do ion, tambēm chamada frequêncla de colisão reduzida do Ion e que se re laciona com a frequência de colisão entre Ions e molèculas, $\underline{v}$. atravēs de

$\xi=\frac{M}{m+M} \nu$

onde $\underline{m}$ é a massa do íon e $\underline{M}$ a da molécula neutra; esta relação vale só para colisões elásticas. 17 A equação fenomenolögica 13 de movimento de um Ion mëdio, quimicamente não reativo, num ciclotron, equação 2.5. fol deduzida ${ }^{18}$ a partir da equação de Boltzmann aplicada a proprledades de transporte em gases loniza 
dos. Ela é válida se $\underline{\xi}$ é independente da velocidade do ion e is to só ocorre se o potencial de interação do lon com a molécula for do tipo carga-dipolo induzido, ${ }^{19}$ isto é, for do tipo $\mathrm{r}^{-4}$, sendo $\underline{r}$ a distância entre o ion e a molécula (vide seção 3.2.1.). Isto nem sempre é o caso, mas a equação 2.5. deve ser uma aproxı́ mação boa se $\underline{\xi}$ variar monotonicamente com a velocidade. $13,17,20$

o Ion absorve a potência $A(t)$ do campo elétrico e esta é dada pelo produto escalar da força elétrica $\mathrm{qE}(t)$ sobre o ion e a velocidade do Ion.

$A(t)=q \vec{E}(t) \cdot \vec{v}$

Para obter $A(t)$ é preciso portanto resolver a equação 2.5. para $\overrightarrow{\mathrm{v}}$.

Tome-se um sistema de coordenadas $x, y, z$, com vetores unitários $\overrightarrow{1}, \vec{j}, \vec{k}$, tal que o vetor campo magnético seja parale lo ao eixo $z$ e o vetor campo elétrico oscile paralelo ao eixo $\underline{x}$. $\overrightarrow{\mathrm{H}}=\mathrm{H} \overrightarrow{\mathrm{K}}$ $\vec{E}(t)=E_{1} \operatorname{sen} \omega_{1} t \vec{I}$

$\underline{H}$ è o módulo dọ campo magnētico e $E_{1}$ è a amplitude da rádio-frequência $\omega_{1}$.

o Ion executa movimento ciclotrônico no plano $x y$.

o campo elétrico alternante línearmente polarizado pode ser decomposto em dols campos circularmente polarizados, girando em sentidos opostós.

$\vec{E}(t)=\vec{E}^{+}(t)+\vec{E}^{-}(t)$

$\vec{E}^{+}(t)=\frac{E_{1}}{2}\left(\operatorname{sen} \omega_{1} t \vec{I}+\cos \omega_{1} t \vec{J}\right)$

$\vec{E}^{-}(t)=\frac{E_{1}}{2} \quad\left(\operatorname{sen} \omega_{1} t I-\cos \omega_{1} t J\right)$ 
- campo elétrico só perturba o movimento circular do ion próximo às condições de ressonância; nesta situação só a componente do campo elétrico que gira no mesmo sentido que o ion é capaz de acelerá-10. Seja $\mathrm{E}^{+}(t)$ esta componente; $\overrightarrow{\mathrm{E}}^{-}(t)$ é desprezado.

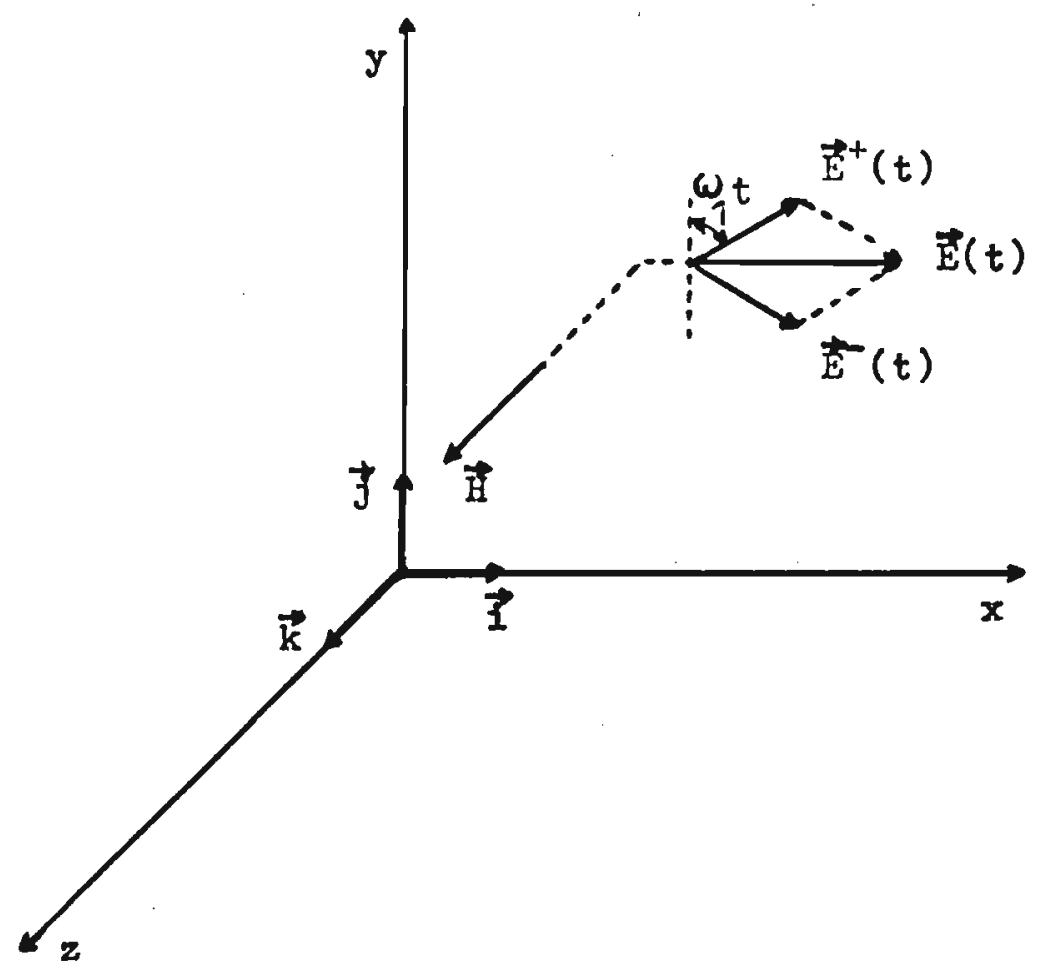

FIGURA 2.2. Sistema de coordenadas fixo à cela de ressonância ciclotrônica de íns.

Decompondo a equação 2.5. nas componentes $x, y, z$, subs tituindo a expressão 2.8. e usando a 2.3., resulta o sistema de equações :

$\frac{d v_{x}}{d t}=\frac{q E_{1}}{2 m} \operatorname{sen} \omega_{1} t+\omega_{c} v_{y}-\xi v_{x}$

$\frac{d v_{y}}{d t}=\frac{q E_{1}}{2 m} \cos \omega_{1} t-\omega_{c} v_{x}-\xi v_{y}$

$\frac{d v_{z}}{d t}=-\xi v_{z}$ 
A equação em $\underline{z}$ não precisa ser considerada, pois os campos elétr co e magnêtico não exercem nenhuma força na direção $\underline{z}$. A solução completa destas equações diferenciais foi apresentada por Comisarow: ${ }^{19}$

$v_{x}=B \cos \omega_{1} t+C \operatorname{sen} \omega_{1} t+\left(D \cos \omega_{c} t+F \operatorname{sen} \omega_{c} t\right) e^{-\xi t}(2.9$.

$v_{y}=c \cos \omega_{1} t-B \operatorname{sen} \omega_{1} t+\left(F \cos \omega_{c} t-D \operatorname{sen} \omega_{c} t\right) e^{-\xi t}(2.10$.

onde

$B=\frac{q E_{1}}{2 m} \frac{\omega_{C}-\omega_{1}}{\xi^{2}+\left(\omega_{c}-\omega_{1}\right)^{2}}$

$c=\frac{q E_{1}}{2 m} \frac{\xi}{\xi^{2}+\left(\omega_{c}-\omega_{1}\right)^{2}}$

$D=v_{0} \operatorname{sen} \gamma-B$

$F=v_{0} \cos \gamma-c$

$\Upsilon$ è a diferença de fase da rádlo-frequência (vetor campo elétrí co girando) e a velocidade inicial do Ion, no instante em que o Ion começa a absorver potêncla. Retomando a equação 2.7. e subs tituindo a equação 2.8. e depols as equações 2.9. e 2.10., resulta:

$$
\begin{aligned}
A(t) & =q \vec{E}(t) \cdot\left(\vec{v}_{x}+\vec{v}_{y}\right) \\
& =\frac{q E_{1}}{2}\left(v_{x} \operatorname{sen} \omega_{I} t+v_{y} \cos \omega_{1} t\right) \\
& =\frac{q E_{1}}{2}\left\{C+e^{-\xi t}\left[D \operatorname{sen}\left(\omega_{1}-\omega_{c}\right) t+F \cos \left(\omega_{1}-\omega_{c}\right) t\right]\right\}
\end{aligned}
$$

E possivel simplificar essa expressão, lembrando que a fase $\underline{y}$ pode tomar todos os valores entre o e $2 \pi$ com Igual probabilidade, de modo que em média a contribulção dos termos senr e cos $\gamma$ é 
zero; assim chega-se a uma potência absorvida média.

$$
\begin{aligned}
A(t)= & -\frac{q^{2} E_{1}^{2}}{4 m\left[\xi^{2}+\left(\omega_{1}-\omega_{c}\right)^{2}\right]}\left\{\xi+e^{-\xi t}\left[\left(\omega_{1}-\omega_{c}\right) \operatorname{sen}\left(\omega_{1}-\omega_{c}\right) t-\right.\right. \\
& \left.\left.-\xi \cos \left(\omega_{1}-\omega_{c}\right) t\right]\right\}
\end{aligned}
$$

Esta equação descreve a absorção de potência instantãnea média por um ion. Na condição de ressonâncla, $\omega_{1}=\omega_{c}$, obtēm-se a absorção de potência instantânea em ressonância.

$A\left(\omega_{1}=\omega_{c}\right)=\frac{q^{2} E_{1}^{2}}{4 m \xi}\left(1-e^{-\xi t}\right)$

Dunbar 20 tratou esse problema de maneira ligeiramente diferente, não decompondo o campo de rảdio-frequência em duas componentes circularmente polarizadas, de modo que o sistema de equações diferenciais en $\underline{x}$ e $y$ ficasse:

$\frac{d v_{x}}{d t}=\frac{q E_{1}}{m} \operatorname{sen}\left(w_{1} t+r\right)+w_{c} v_{y}-\xi v_{x}+\frac{q E}{m}$

$\frac{d v_{y}}{d t}=-\omega_{c} v_{x}-\xi v_{y}$

A fase $Y$ foi introduzida já neste ponto. 0 termo $\mathrm{qE} / \mathrm{m}$, onde $\underline{E}$ ē um campo elétrico estático (seção 2.3.3.), não contribui para a absorção de potência e fol depois desprezado, tendo sido colocado na equação, para que seja completa. Estas equações foram resolvidas, fazendo uso de transformadas de Laplace. Basta encontrar uma solução para $v_{x}$, pols como agora o campo elétrico é linearmente polarızado na direção x, é só esta a componente da velocidade que entra na equação 2.7. A expressão obtida ${ }^{20}$ para 
a absorção de potência ınstantânea é:

$$
\begin{aligned}
A(t)= & \frac{q^{2} E_{1}^{2}}{4 m\left[\xi^{2}+\left(\omega_{c}{ }^{-\omega_{1}}\right)^{2}\right]}\left\{\xi+\frac{{ }^{2 \omega_{c}\left[\xi^{2}+\left(\omega_{c}-\omega_{1}\right)^{2}\right]}}{\left[\xi^{2}+\left(\omega_{c}+\omega_{1}\right)^{2}\right]^{1 / 2}} e^{-\xi t} x\right. \\
& \left.x \operatorname{sen}\left[\left(\omega_{c}-\omega_{1}\right) t+t^{-1} \frac{2 \xi \omega_{c}}{\xi^{2}-\omega_{c}{ }^{2}+\omega_{1}{ }^{2}}+\pi\right]\right\}
\end{aligned}
$$

Na condição de ressonância, $\omega_{1}=\omega_{c}$, e fazendo a aproximação de que a frequência de colisão è muito menor que as frequências ciclotrônicas geralmente encontradas, isto $\bar{e}, \xi<<\omega_{c}$ esta equação se reduz à 2.12 .

Quando o espectrômetro de ressonância cicloțônica. é operado de forma continua (seção 2.3.), os Ions ficam expostos ao campo de rädio-frequência por um intervalo de tempo t; logo, - que se observa é uma potência absorvida média no intervalo de tempo $\underline{t}$.

$$
\begin{aligned}
& \langle A\rangle=\int_{0}^{t} A\left(t^{\prime}\right) d t^{\prime} / \int_{0}^{t} d t^{\prime} \\
& =\frac{q^{2} E_{1}^{2}}{4 m\left[\xi^{2}+\left(\omega_{1}{ }^{2 \omega_{c}}\right)^{2}\right] t}\left\{\xi t-\frac{\xi^{2}-\left(\omega_{1}-\omega_{c}\right)^{2}}{\xi^{2}+\left(\omega_{1}-\omega_{c}\right)^{2}}+\right.
\end{aligned}
$$

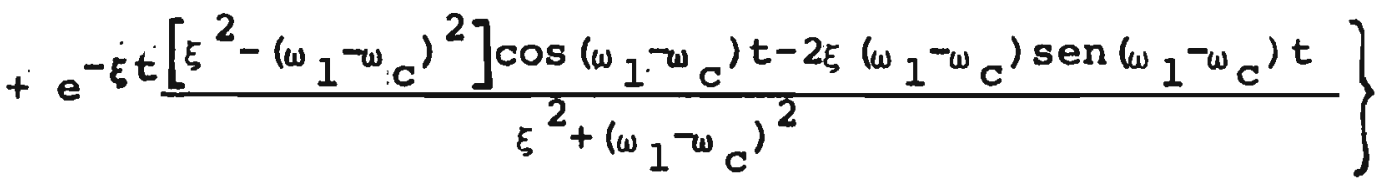

Esta expressão é geral e fol deduzida por Comisarow: ${ }^{19}$ antes de surgir esta equação, foram usadas equações que valem em con- 
dições extremas, ou melhor, que valem ou só a pressões muito ba xas, ou só a pressões muito altas. A pressões baixas os íns não sofrem colisões, o que equivale a fazer $\xi=0$ na equação $2.13 ., 0 \underline{b}$ tendo-se

$$
\langle A\rangle=\frac{q^{2} E_{1}^{2}}{4 m t} \frac{1-\cos \left(\omega_{1}-\omega_{C}\right) t}{\left(\omega_{1}-\omega_{c}\right)^{2}}
$$

Esta equação havia sido deduzida anteriormente, ${ }^{21}$ começando já com a equação 2.5. truncada, sem o termo de amortecimento. Nes te caso a potência absorvida é limitada pelo tempo que o ỉon fica sob ação do campo de rãdio-frequência. A equação para o limí te de pressão alta è obtida, considerando $\underline{\xi}$ muito grande.

$$
\langle A\rangle=\frac{q^{2} E_{1}{ }^{2}}{4 m} \frac{\xi}{\xi^{2}+\left(\omega_{1}-\omega_{c}\right)^{2}}
$$

Vê-se que $\langle A\rangle$ não é mais função de tempo, pois colisões com trans ferência de quantidade de movimento são tão frequentes, que a absorção de potência se torna constante no tempo. Esta expressão fol anteriormente deduzida, 18 não usando a solução completa do sistema de equações diferenciais. ${ }^{2}$

Um gráfico de potência absorvida, $\langle A\rangle$, em função da frequência do oscilador marginal, $\omega_{1}$, usando a expressão 2.13., ou as expressões simplificadas, 2.14. ou 2.15., representa a forma do pico de um ion de massa m num espectro de ressonância ciclotrônica, de Ions. Usando a expressão de potência absorvida li mitada por colisões, 2.15., a linha obtida é lorentziana, que é o que se observa a pressões elevadas.

\subsection{Operação continua}

Fo1 visto que o espectrômetro de ressonâncla clclofrô- 
nica de ions serve basicamente como espectrömetro de massa, obtendo-se um espectro ao registrar potência absorvida do oscila dor marginal pelos ions em ressonância, em função da frequência de observação $\omega_{1}$, ou, do campo magnētico H. Tambēm foi visto que é possivel calcular a forma de cada pico no espectro de massa. Para obter esses espectros, o instrumento é geralmente operado de modo que os íons sejam produzidos continuamente, havendo uma corrente iônica continnua através da cela. Esta descrição não é perfeitamente correta, pois como mencionado, é preciso modular a absorção de potência e, dentre as vārias possibilida des de modulação, existem as que interrompem periodicamente a produção de Ions (seção 2.3.4.1.). Porēm, o termo "oper ação con tínua" será empregado a fim de distinguir de "operação pulsada", na qual um punhado de ỉons è formado e seu comportamento observa do no decorrer do tempo, registrando-se potência absorvida em função do tempo. Este tipo de experiência será descrito na seção 2.4 .

Antes de discutir as técnicas de ressonâncla ciclotrônica de lons małs empregadas hoje em dia, far-se-á menção a dois instrumentos que foram importantes na evolução do instrumen to atual: o omegatron e o espectrômetro de Wobschall.

\subsection{1. o omegatron}

Neste espectrômetro, descrito por Sommer, Thomas e Hip ple, 22 ions são produzidos por um feixe de elétrons paralelo ao campo magnētico, dentro de uma cela aproximadamente cúbica. A rádio-frequência è aplicada entre as placas superior e inferior, e também a anẻis dentro da caixa, através de um conjunto de resistores para garantir um campo elëtrico uniforme. Uma dada 


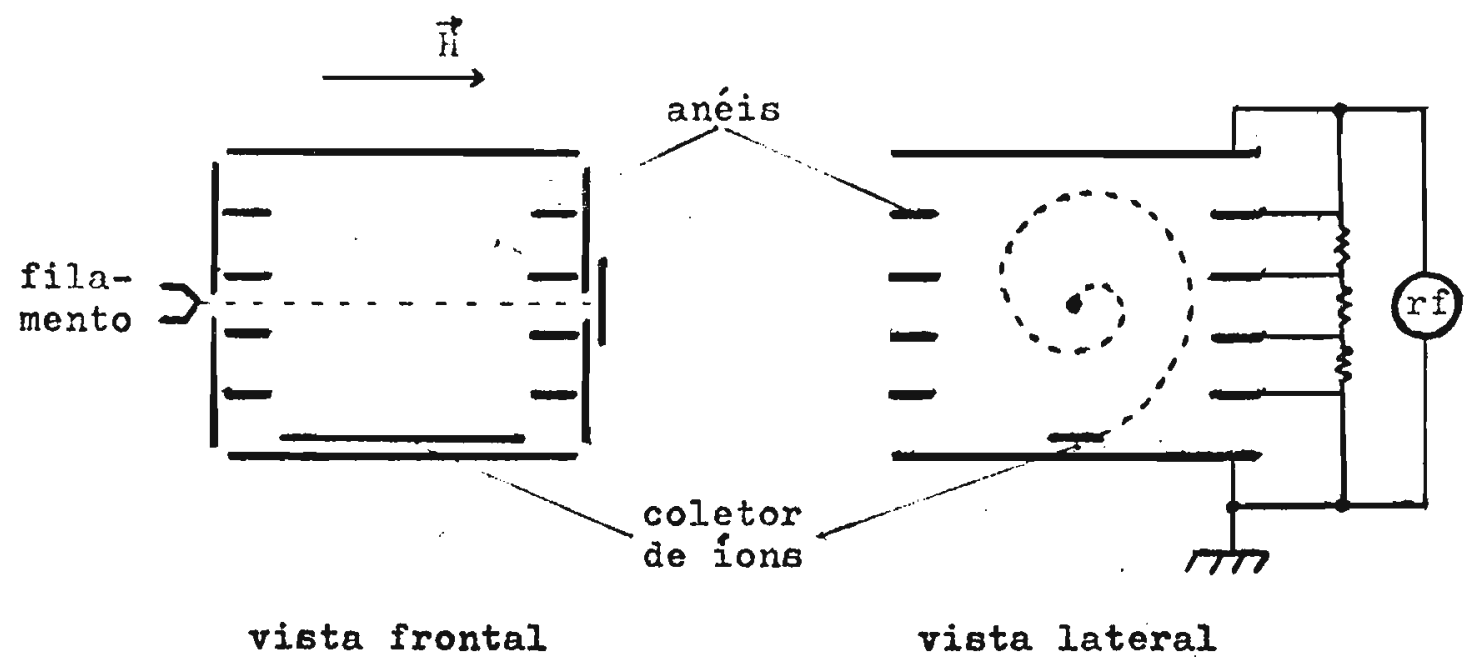

FIGURA 2.3. Diagrama simplificado do omegatron.

frequência faz com que íons de dada massa adquiram uma quantidade constante de energia em cada revolução, de modo a descreverem uma espiral de Arquimedes. Estes íons em ressonâncla podem ser. coletados num eletrodo que passa atravēs do eletrodo de rádiofrequência inferior e a corrente resultante pode ser medida num cịrcuito externo. Varrendo a rádı-frequência, ions de massas diferentes são coletados ao entrarem em ressonância. A ressonân cia também foi detectada através da potência absorvida pelos ions do oscilador de rádio-frequência. ${ }^{23}$ calculou-se que o aumento na relação sinal ruido seria de 50 , se a técnica de coletar dire tamente os ions fosse substituida por essa, envolvendo absor ção de potência.

Foram deduzidas expressões ${ }^{22}$ para a resolução do instrumento, para o caminho percorrido por um Ion até o coletor, pạ ra o tempo que ele leva para 1sso, para o raio máximo que um Ion 
que não estā em ressonância atinge e tambēm para o deslocamento da frequência de ressonância devido a um potencial positivo apli cado nos anēis da cela e que reduz a perda de ions na direçăo do campo magnético. Por exemplo, ions $\mathrm{N}_{2}^{+}$(massa 28) percorrem em 67 us a distância de $36 \mathrm{~cm}$ do feixe iônico até o coletor, num omegatron em que essa dịstância ē $0,7 \mathrm{~cm}$ em linha reta, sendo a tensão da rādio-frequência de $1,0 \mathrm{~V}$ (eficaz) e o campo magnētị co 4300 G. 24

Inicialmente ${ }^{22}$ o omegatron não foi empregado como espectrômetro de massa propriamente dito, mas para obter grandezas físicas, tais como o momento magnético do prōton, a relação carga/massa do pröton, o valor do faraday, a relação massa do próton/massa do elétron. Atualmente è usado como medidor de pressões parciais (como è um espectrômetro de massa, permite separar os componentes de misturas gasosas quanto à massa); tem a vantagem de ser relativamente simples, principalmente na parte eletrônica; ${ }^{25}$ além disso ralos $x$ não constituem um problema,pois são gerados só fora da cela. ${ }^{24}$ Neste tipo de aplicação geralmen te não são usados anēis, e o coletor cobre praticamente uma face inteira da cela. o limite superior de pressão, até a qual pode ser usado, è de $10^{-5}$ Torr, quando o caminho livre médio dos Ions se torna comparável ao comprimento da espiral que descrevem. A sensibilidade do eletrômetro 1 igado ao coletor de ions permiti ria em principio medidas até um limite inferior de $10^{-13}$ Torr,mas há indícios de que esse limite é $10^{-11}$ Torr, em virtude de ralos $X$ refletidos nos eletrodos da cela e que acabam atingindo o cole tor de Ions. 24

\subsubsection{A cela de Wobschall}

o espectrômetro de ressonância clclotrônica de ions de Wobschal1 13,26 jā fol desenvolvido com a finalidade de observar 
colisōes entre Ions e moléculas.
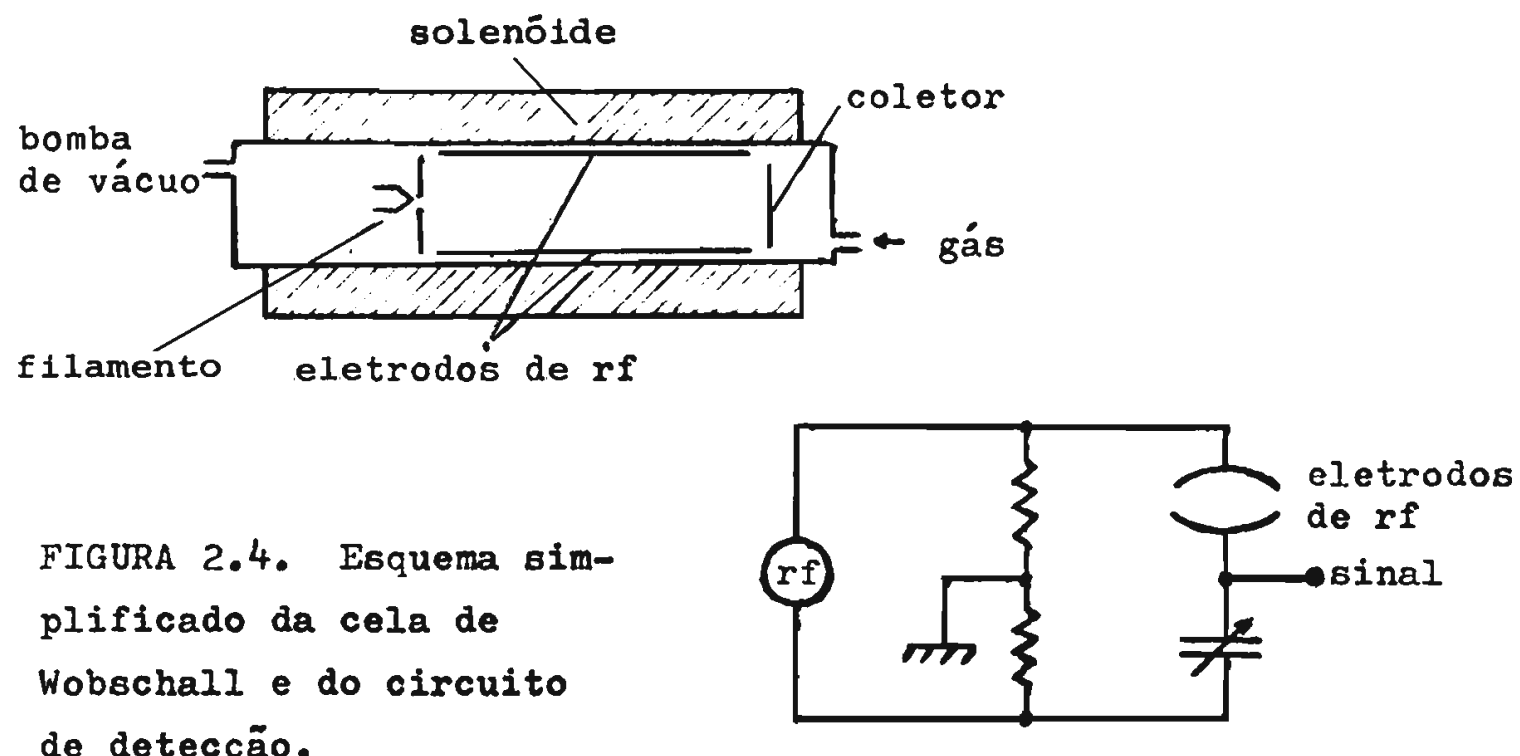

A cela consiste de um tubo de vidro com dois eletrodos de ouro de positados internamente. Os eletrodos devem ser consideravelmente mals longos que o caminho livre médio dos Ions na pressão de operação, para reduzir a perda de íons na direção paralela ao campo magnético, na qual não existem forças agindo. o tubo de vidro é evacuado e existe uma entrada para a amostra gasosa a ser estuda da. A fonte de Ions consiste basicamente de um filamento que pode produzir elétrons de balxa energia (1 - $8 \mathrm{eV})$ para formar ions negativos na câmara de medição ou, elétrons de alta energia $(70 \mathrm{eV})$ para formar ions positivos. Foi usada também uma fonte de difusão, que produz Ions positivos por meio de um feixe de elē trons numa câmara separada da de medição; nesta fonte um coletor pára os elētrons, permitindo, porém, que uma fração considerável dos lons difunda para a reglão analisadora. 0 campo magnético è produzido por um solenótde capaz de gerar un campo magnético de 1500 G. O par de eletrodos forma um braço de uma ponte de rádio- 
frequênaia; o sinal de absorção é detectado pelo desbalanceamei.-to dessa ponte. o campo magnético é modulado na frequência de $11 \mathrm{~Hz}$ e o sinal de absorção é processado por um detetor de fase. Com esse sistema, o número mínimo de ions detectāvel entre os eletrodos è 30 .

o instrumento' descrito não permite a separação de íons positivos e negativos; por exemplo, $\mathrm{O}_{2}{ }^{+}$não ē distinguido de $\mathrm{O}_{2}{ }^{-}$. Mas como uma particula negativa num campo magnëtico gira no sentido oposto ao de uma positiva (equação 2.1.), um campo elëtrico circularmente polarizado, girando em dado sentido em torno' do vetor campo magnētico, acelera sô um dos ĩons. Consegue-se o cam po elëtrico circularmente polarizado, colocando, perpendicular mente aos eletrodos de deteç̧ão, dois outros eletrodos, eletro dos de quadratura, ${ }^{27}$ nos quais se aplica uma rādio-frequência que esteja atrasada ou adlantada por $90^{\circ}$ em relação a aplicada nas placas de detecção. E possivel, escolhendo adequadamente as amplitudes das râdio-frequências nos dois pares de eletrodos, fazer, por exemplo, com qùe a absorção de $\mathrm{O}_{2}{ }^{+}$seja zero e obser var só a de $\mathrm{O}_{2}^{-}$.

Wobschall usou seu instrumento principalmente para medir frequências de colisão entre lons e molẽculas e calcular mobilidades iônlcas em gases. 28

\subsubsection{A cela de três regiões}

A Varian Associates (Palo Alto, California, USA) produ ziu durante alguns anos um espectrômetro de ressonância ciclotrô nica de ions sob o nome comercial de syrotron, conforme o princí pio desenvolvido por Baldeschwieler e colaboradores. $1,2,5,29$ A cela deste espectrômetro tem as dimensões dadas na FIGURA 2.5., onde os potencla1s indicados são os aproprlados para examinar 


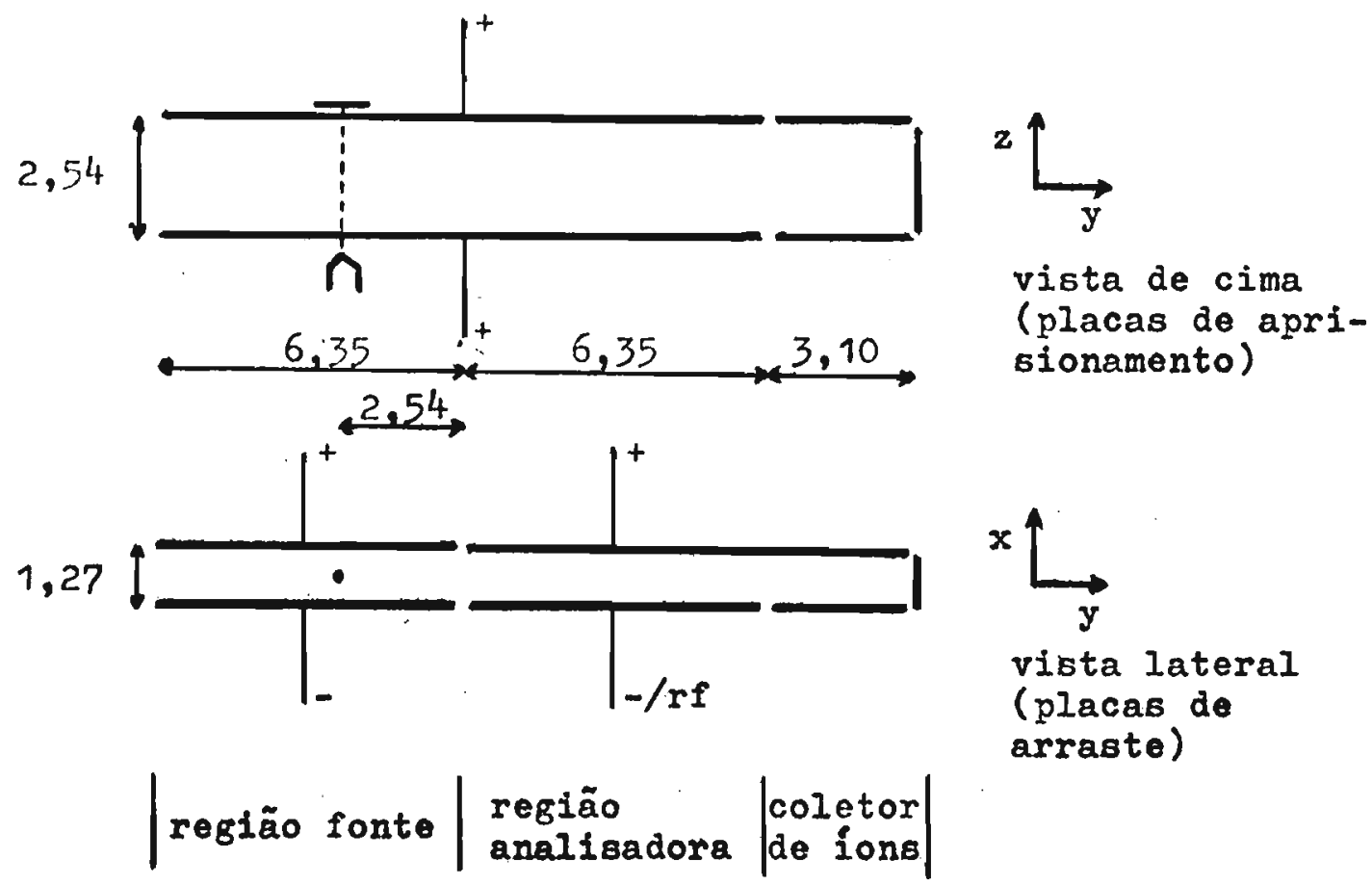

FIGURA 2.5. Cela de ressonância ciclotrônica de fons. Escala 1:2, dimensões em centímetros.

Ions positivos (para Ions negativos, são invertidos). Difere a cela da de Wobschall, primeiro, por serem aplicados potenciais nas placas às quals é ligada a rádio-frequência; como será visto, estes potenciais fazem com que os lons, além de executa rem o movimento ciclotrônico, adquiram uma velocidade na direção da maior dimensão da cela. Além disso é aplicado um potencial de aprisionamento (positivo para ions positivos, negativo para Ions negativos)num par de placas tal que os ions teinham seu movimento restringido na direção do campo magnético, direção na qual, apenas com campos magnētico e elétrico cruzados, nenhu ma força age (equações 2.1. e 2.4.). Wobschall fizera essa d1mensão paralela ao campo magnético muito maior do que as outras dimensões da cela, de modo a evitar perda de lons nessa direção. ${ }^{26}$ Este campo elétrico cria certos problemas mas por outro 
lado possibilita experiências adicionais, como será visto abaixo. Torna fäcil a separação de Ions positivos e negativos: os ions de sinal oposto ao da polaridade das placas são neutralizados.

A cela consta na realidade de três regiões distintas,que serão descritas posteriormente. Ela è colocada entre os polos (23 cm de diâmetro) de um eletro-ímã, capaz de gerar campos magnẹ ticos entre 0 e $14000 \mathrm{G}$ com a uniformidade necessāria. A cela en contra-se numa câmara de vácuo de aço inoxidável e que pode ser aquecida e evacuada até $10^{-8}$ Torr para fazer a limpeza do sistema.

o campo elétrico estático aplicado na direção x, parale la ao campo de rádio-frequência (veja a figura da cela), faz com que os Ions sejam arrastados ao longo da cela, na direção Y. A fim de tratar o problema matematicamente, parte-se da equação 2.4, sendo que $\vec{E}$ é agora ındependente do tempo. Não é preciso considerar o termo de amortecimento, pois o movimento resultante se dá atravēs de uma distância muito curta, não sendo responsável por um nūmero apreciável de colisões. Então, decompondo a equação 2.4. nas componentes $x, y, z$, resulta:

$$
\begin{aligned}
& \frac{d v_{x}}{d t}=\frac{q E}{m}+\omega_{c} v_{y} \\
& \frac{d v_{y}}{d t}=-\omega_{c} v_{x} \\
& \frac{d v_{z}}{d t}=0
\end{aligned}
$$

E é o campo elētrico estātıco na direção x. 10 campo de aprisionamento não é considerado e a equação em $\underline{z}$ è desprezada). A solução desse sıstema é

$$
v_{x}=A \cos \omega_{c} t+B \operatorname{sen} \omega_{c} t
$$


$v_{Y}=B \cos \omega_{C} t-A \operatorname{sen} \omega_{C} t+\frac{C E}{H}$

A velocidade média do ín nas direções $x$ e $y$ num período completo do movimento ciclotrônico é 30

$\bar{v}_{x}=0$

$\overline{\mathrm{v}}_{\mathrm{Y}}=\frac{\mathrm{CE}}{\mathrm{H}}$

Portanto, o ion, além de descrever uma trajetōria circular no pla no $x y$, desloca-se na direção $Y$. Dadas as dimensões da cela, a equação 2.16. permite calcular o tempo de permanência do íon na ce la, o que possibilita obter dados cinéticos na experiência de res sonância ciclotrônica de íons (seção 2.3.5.)..

o potencial aplicado nas placas de aprisionamento (não considerando o potencial de arraste) dā origem a um campo quadru polar próximo ao centro da cela, que pode ser aproximado por 31 $\mathrm{v}=\mathrm{v}_{\mathrm{o}}+\mathrm{c}\left(\mathrm{z}^{2}-\mathrm{x}^{2}\right)$

onde $v_{\circ}$ é o potencial no centro da cela e $\underline{C}$, uma constante. $\mathrm{V}_{\mathrm{O}}=\frac{1}{2} \mathrm{~V}_{\mathrm{T}}$

$\mathrm{V}_{\mathrm{T}}$ é a tensão de aprisionamento aplicada nas placas. A origem do sistema de coordenadas é o centro da cela; o eixo $\underline{z}$ è perpendicu lar às placas de aprisionamento, a distância entre as quais è di - eixo x é perpendicular às placas de arraste. No ponto da cela $z=d / 2, x=0$ tem-se $v(z, x)=V(d / 2,0)=v_{T}$ e isto fornece a constante $\underline{C}$; logo

$V=V_{T}\left[\frac{1}{2}+\frac{2}{d^{2}}\left(z^{2}-x^{2}\right)\right]$

As componentes do campo elêtrico são:

$$
\begin{aligned}
& E_{x}=-\frac{d V}{d x}=\frac{4 V_{T}}{d^{2}} x \\
& E_{y}=-\frac{d V}{d y}=0
\end{aligned}
$$


$E_{z}=-\frac{d V}{d z}=-\frac{4 V_{T}}{d^{2}} z$

Substituindo esse campo elētrico na expressão 2.4. e desdobrando esta nas componentes $x, y, z$, obtém-se o sistema de equações

$\frac{d v_{x}}{d t}=\frac{4 q v_{T}}{m d^{2}} x+\omega_{c} v_{y}$

$\frac{d v}{d t}=-\omega_{c} v_{x}$

$\frac{d v_{z}}{d t}=-\frac{4 q v_{T}}{m d^{2}} z$

Valem aqui considerações anālogas às feitas no caso da tensão de arraste. Porém, os dois campos elétricos não deveriam ser considerados separadamente, pois existe uma componente do campo de aprisionamento na direção $x$ que precisaria ser somada ao campo de arraste na direção $x$. Contudo, como o primeiro depende da coordẹ nada x e como, trabalhando a correntes iônicas baixas, os íons de vem concentrar-se no centro da cela, o campo de aprisionamento não deve influir mutto no de arraste. Um gráfico de linhas equipoten ciais numa cela de ressonância ciclotrônica de íons em condições típicas de operação, fol apresentado por Futrell. 32 Diferenciando em relação ao tempo a equação em $x$ e substituindo a em $y$, resulta:

$\frac{d^{2} v_{x}}{d t^{2}}=-\left(\omega_{c}^{2}-\frac{4 q v_{T}}{m d^{2}}\right) v_{x}$

Dıferenclando a equação em $\underline{z}:$

$\frac{\mathrm{d}^{2} \mathrm{v}_{z}}{d \mathrm{t}^{2}}=-\frac{4 q \mathrm{~V}_{\mathrm{T}}}{\mathrm{m} \mathrm{d}^{2}} \mathrm{v}_{\mathrm{z}}$

Estas equações representam movimento harmônico de frequência $\omega_{\text {ef }}=\left(\omega_{C}^{2}-\frac{4 \mathrm{qV}_{\mathrm{T}}}{\mathrm{md}^{2}}\right)^{\frac{1}{2}}$ 
e

$\omega_{T}=\left(\frac{4 \mathrm{qV}_{\mathrm{T}}}{m \mathrm{~d}^{2}}\right)^{\frac{1}{2}}$

respectivamente. A primeira equação mostra que a tensão de aprisionamento, $V_{T^{\prime}}$ desloca a frequência ciclotrônica do ion de massa $\underline{m}$ de um valor $\omega_{c} / 2 \pi$ para uma frequência efetiva $\omega_{\text {ef }} / 2 \pi$. A segunda mostra que os ions executam um movimento oscilatōrio de fre quêncla $\omega_{T} / 2 \pi$ na direção $\underline{z}$. Este fenômeno tem grande utilidade prátıca, a qual será vista na seção 2.3.4.3.

Foi mencionado que a cela de ressonância ciclotrônica de ions consta de três partes: uma região fonte, uma região analisadora e uma região coletora de ions.

Os Ions são produzidos na região fonte por um feixe de elétrons paralelo ao campo magnétıco e proveniente de um filamen to aquecido. Os elētrons atravessam a cela, ionizam algumas das moléculas do gãs presente e chegam a um coletor, ao qual é ligado um amperimetro para medir a corrente de elétrons (corrente de emissão), que geralmente não excede $1 \mu \mathrm{A}$, sendo usuais correntes entre 0,01 e 0,20 $\mu$ A. Este feixe de elētrons dá origem a uma carga espacial que provoca um deslocamento na frequência da resso nâncla dos Ions ${ }^{26}$ e é por isso que produção e detecção dos ions são feitas em seções distintas da cela. A tensão de aprisiona mento na região fonte faz com que os ions de mesma polaridade que esta tensão sejam aprisionados na cela, enquanto que os de polar 1 dade oposta sejam neutralizados. A tensão de arraste faz com que os ions passem da região fonte para a região analisadora. Nesta região a tensão de aprisionamento é a mesma que na região fonte (os eletrodos se prolongam de uma região à outra), mas a de arraste difere geralmente em módulo (mas não em sinal). Todas estas tensões são na malor 1 a das vezes ajustadas emplricamente, de maneira 
a obter sinal máximo para um ion qualquer. Na placa de arraste inferior da região analisadora è aplicada a rádio-frequência de observação (a placa superior forma um "terra" para rádio-frequên cia, mas não para tensão continua); desta forma este par de ele trodos da região analisadora forma um condensador que faz parte do elemento capacitivo do circuito LC do oscilador marginal, permitindo a deteç̧ão de ions em ressonância. Em seguida os Ions vão para a região coletora de ions, onde não hā mais tensão de aprisionamento, de modo que os ions são recolhidos nestas placas, numa placa final que fecha a cela e nas placas supe rior e inferior; todos estes eletrodos são ligados a um eletrômetro, podendo-se ler assim a corrente iônica total na cela. A placa de arraste superior da região analisadora estende-se na realidade até a região coletora, o que deve facilitar a chega da dos ions no coletor; no entanto a utilidade prática disto é questionável. Em algumas celas a placa final não existe, estan do a cela aberta, o que permite certas experiências, como a introdução de um feixe de luz. 33-35

Os eletrodos da cela são feltos de aço inoxidãvel ou de cobre prateado. A estrutura da cela é feita de cerimica ou de Vespel, uma poli-imida da DuPont. o bloco do filamento é de cerâmica ou de nitreto de boro. São em geral usados filamen tos de rênio, com seção retangular. (A corrente que passa pelo filamento normalmente não excede 4 A.) As conexões elētricas com os eletrodos são feltas através da base da cela (cerâmica ou Vespel) e saem da câmara de vácuo, indo a dois conectores de oito pinos. A rādio-frequência e a tensão de arraste da placa Inferior da analisadora vêm atravēs de um cabo blindado de baixa impedância, e entram na câmara através de um conector blinda do (TNC); daI chegam até a cela por um flo localizado dentro de 
um tubo metālico (blindagem). De maneira idêntica são ligadas as placas do coletor de íons ao eletrômetro externo.

A amostra gasosa a ser estudada é introduzida inicial mente numa antecâmara, que pode ser evacuada até $10^{-5}$ Torr por meio de bomba mecânica e peneira molecular. No instrumento do nosso laboratório fol adíclonada uma bomba de difusão de óleo. Da antecâmara o gás entra na câmara de alto vácuo, onde está a cela, através de uma válvula de controle fino (safira movendose sobre um anel de cobre). Trata-se de um sistema em fluxo: o gās entra e é continuamente bombeado por uma bomba iônica (Vaç Ion, Varian, $8 \mathrm{l} / \mathrm{s}$ ). Veja a seção 4.3 . para uma descrição mais completa.

\subsubsection{Técnicas de ressonância ciclotrônica de Ions}

Há vārios tipos de experiências que podem ser realizą das em espectroscopia de ressonância ciclotrônica de Ions; expe riências, que permitem desvendar as reações que ocorrem num sis tema gasoso submetido a impacto de elétrons. Serão descritas a seguir algumas das técnlcas desse tipo de espectroscopia, dando mals ênfase às empregadas no presente trabalho.

\subsubsection{Ressonância simples}

O espectro de ressonância simples de baixa pressão $\left(10^{-7}\right.$ Torr $)$, nada mais é do que o espectro de massa da substância introduzida, e è importante tê-lo, a fim de certificar-se da pureza do composto em estudo. Elevando a pressão, aparecem pro dutos de reação, geralmente de massas mais elevadas. Conhecen 
reagem e, obtendo a partir do espectro as massas dos produtos,já è frequentemente possivel inferir a natureza química destes ūltimos e a reação que ocorre. Estudos em função de pressão são importantes na elucidação de mecanismos de reação (ver seção 4.6.1.). Como se apresenta o espectro de ressonāncla simples?

A intensidade de um pico de ressonância simples è dada pelo produto da corrente iônica parcial na cela, correspondente ao Ion em questão, $P(t)$, e a potência instantânea absorvida por um ion dessa espec̃ie, $A(t)$ (equação 2.11.), e Integrada sobre o tempo de observação, t.

$I=\int_{0}^{t} P\left(t^{\prime}\right) A\left(t^{\prime}\right) d t^{\prime}$

Supondo que a corrente iônica seja constante na região analisado ra, pode-se fazer $P\left(t^{\prime}\right)=P(0)$ (no caso de se tratar de um ion primārio, $P(0)$ é a velocidade de formação do Ion no feixe eletrônico). Tomando a equação 2.11. no limite de ba1xa pressão $(\xi=0)$ ', integrando, e impondo a condição de ressonância, $\omega_{1}=\omega_{c}$ (intensi dade māxima do sinal), obtēm-se

$I=\frac{P(0) q^{2} E_{1}{ }^{2} t^{2}}{8 m}$

O tempo de observação $t$ é o tempo que o Ion permanece na região analisadora, dado pela velocidade de arraste (equação 2.16.) e o comprimento dessa região.

$t=\frac{l H}{c E}$

Logo:

$I=\frac{P(O) q^{2} E_{l}{ }^{2} l^{2} H^{2}}{8 m c^{2} E^{2}}$ 
No caso de dois íns de massas $m_{1}$ e $m_{2}$ obtém-se a seguinte relação de intensidades:

$\frac{I_{1}}{I_{2}}=\frac{P_{1}(O)}{P_{2}} \frac{\mathrm{H}_{1}^{2}}{\mathrm{H}_{2}^{2}} \frac{\mathrm{m}_{2}}{\mathrm{~m}_{1}}$

Quando a frequência do oscilador marginal é mantida constante e - campo magnético varrido, todos os Ions entram em ressonância na mesma frequência, isto $\bar{e}, \omega_{1}=\omega_{c} e$, pela equação 2.3. :

$\frac{\mathrm{m}_{1}}{\mathrm{~m}_{2}}=\frac{\mathrm{H}_{1}}{\mathrm{H}_{2}}$

Logo,

$\frac{I_{1}}{I_{2}}=\frac{P_{1}(0)}{P_{2}(0)} \frac{m_{1}}{m_{2}} \quad$ ou $\quad \frac{P_{1}(0)}{P_{2}(0)}=\frac{I_{1}}{I_{2}} \frac{m_{2}}{m_{1}}$

Portanto, para obter correntes iônicas relativas, as Intensida des observadas precisam ser divididas pelas massas dos respectivos Ions, pelo fato de Ions mais pesados ficarem mais tempo no campo de rādio-frequêncla e portanto absorverem mals potência. 30 Quando o campo magnético é mantido constante e a frequência do oscilador marginal varrida, pela equação $2.20 ., t_{1}=t_{2} e$, toman do a equação 2.19 ., resulta:

$\frac{I_{1}}{I_{2}}=\frac{P_{1}(0)}{P_{2}(0)} \frac{m_{2}}{m_{1}} \quad$ ou $\quad \frac{P_{1}(0)}{P_{2}(0)}=\frac{I_{1}}{I_{2}} \frac{m_{1}}{m_{2}}$

Neste caso o Ion mals leve absorve mais potência, mas esta técni ca não é usada, pois é difícil construir um oscilador marginal de sensibilidade independente da frequência.

Fol mencionado na seção 2.1. que é preciso modular a absorção de potência para poder amplificar o sinal e aumentar a relação sinal/ruido. 
O esquema de modulação comumente usado, pelo menos em nosso laboratório, é o de modulação de campo magnético. Neste es quema o campo magnético pode ser varrido, mas ao mesmo tempo seu valor oscila em torno de um valor médio instantâneo. A amplitude dessa modulação pode ser variada, sendo tiplcas amplitudes de 10 a 20 G (a largura total da linha de absorção pode ser de algumas centenas de gauss). Para conseguir a osc1lação do campo, duas boblnas de Helmholtz são colocadas sobre os polos do ímã. Modụ lando o campo magnético, o sinal obtido não è a linha de absorcão, mas a derıvada desta, o que pode ser esclarecido com auxíl1o da FIGURA 2.6. Se o campo magnētico è varrido lentamente, sụ

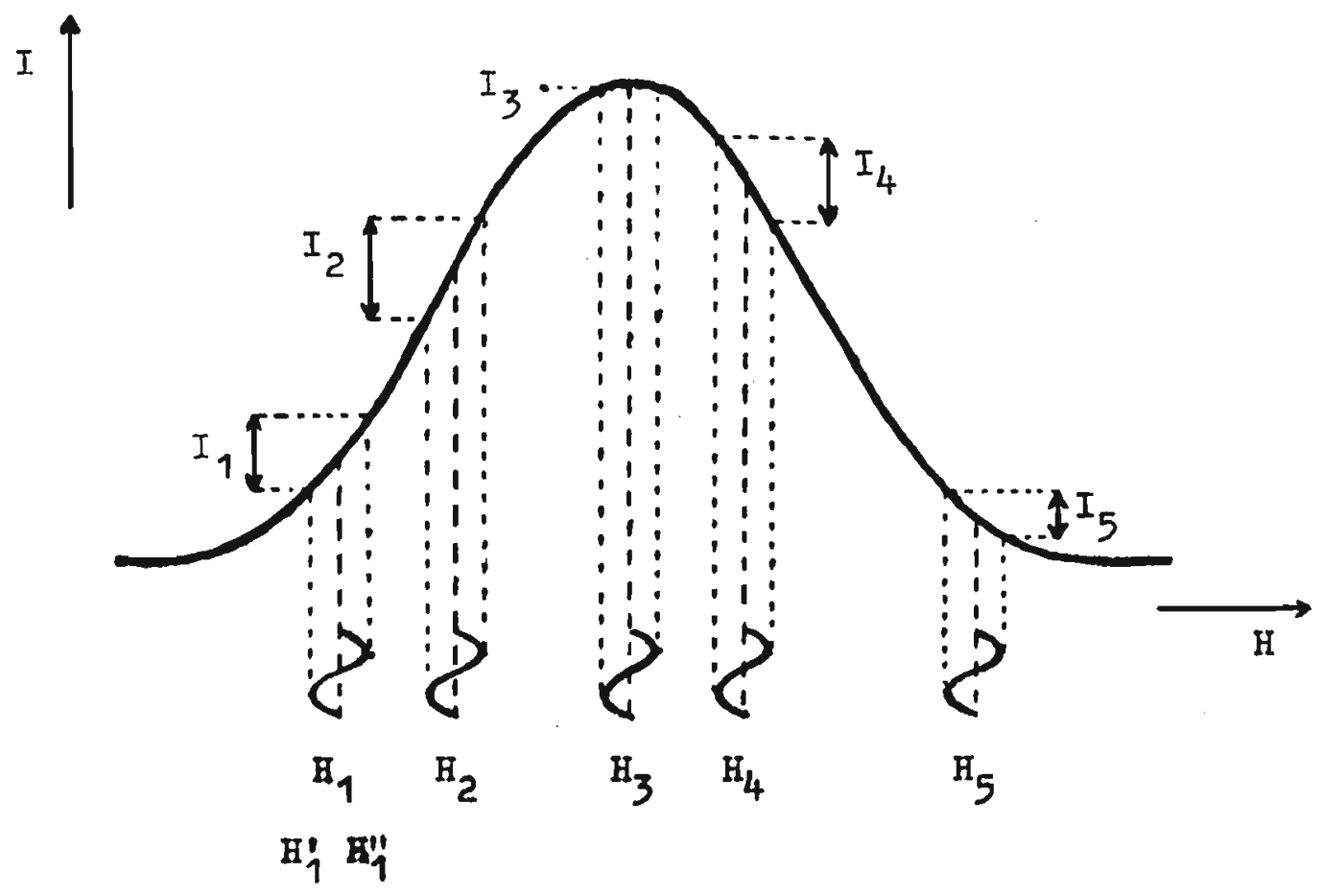

FIGURA 2.6. Modulação de campo magnético.

ponha-se que em dado instante tenha o valor $H_{1}$; na realidade ele estará oscilando entre $\mathrm{H}_{1}^{\prime}$ e $\mathrm{H}_{1}$ " e portanto o nível de rádio-fre quência do oscllador marginal, que depende da potência absorvida pelos íons, estará variandó entre dois extremos e o sinal re- 
tificado será proporcional à diferença entre os extremos, que é $I_{1}$. Vê-se que, quando o campo magnētico chegou em $\mathrm{H}_{2}$, 0 sinal aumentou continuamente de $\mathrm{I}_{1}$ a $\mathrm{I}_{2}$. Em $\mathrm{H}_{3} \circ$ sinal caĩu subitamen te para zero, e em $\mathrm{H}_{4}$ é novamente intenso, mas de polaridade oposta à anteriormente apresentada, pois em $\mathrm{H}_{4}$, a uma oscilação para campos maiores corf́esponde uma absorção menor, o contrário do que acontecia antes. Progressivamente a intensidade do sinal diminul em valor absoluto (vai de um valor negativo para zero). O que acabou de ser descrito corresponde à derivação da li nha de absorção.

Outro esquema é modulação da tensão de arraste na região fonte da cela, feita com ondas quadradas. Na parte do ciclo em que a tensão é baixa, os ions permanecem na região fonte; quando a tensão é alta, os ỉons são arrastados para a região ana lisadora. Logo, a absorção de potêncla é modulada pela varia ção do número de ions nesta região. Porēm, esse esquema de modụ lação não é mais usado, apesar de o aparelho possibilitā-lo,pois não permite um controle muito bom das condições na cela. Durante o tempo em que os Ions permanecem na região fonte a carga espacial aI aumenta, porque Ions continuam sendo produzidos; a car ga espacial faz com que os Ions "esguichem" para dentro da região analisadora, provocando oscilações periódicas no nível do oscilador marginal. 36

Este problema não existe com modulação da energia eletrônica, 36 onde o potencial no filamento (energia eletrônica) é mantido abaixo do potencial de ionização das moléculas presentes, não sendo produzidos Ions durante esse tempo; periodicamente o potencial é pulsado para um valor acima da energia de ioniza ção, havendo formação de Ions. Em geral usa-se modulação com on da quadrada. 
o melhor esquema de modulação è provavelmente o de feixe eletrônico, ${ }^{37}$ que requer um bloco de filamento especial, com uma grade (placa com furo) entre o filamento e a placa de aprisio namento. A grade é mantida num potencial mais negativo que o filamento, de modo a barrar a entrada do feixe de elétrons na cela. Perlodicamente o potencial'na grade è pulsado (onda quadrada) para um valor mais positivo que a energia eletrônica, podendo o fei xe eletrônico passar e ionizar molèculas do gás. Durante o tempo em que a entrada do feixe está bloqueada, a carga espacial devida ao mesmo è removida, havendo menos interferência no movimento dos ions. Este tipo de modulação tem grande importância na operação pulsada do espectrômetro de ressonância ciclotrônica de ions (seção 2.4.).

Os très ültimos esquemas de modulação fornecem direta mente linhas de absorção.

\subsubsection{Ressonância dupla}

A experiêncla de ressonâncla dupla ${ }^{38}$ é que torna a res sọância ciclotrônica de íons uma técnica muito poderosa na eluci dação de caminhos de reação.

Considere-se a reação

$\mathrm{A}^{+}+\mathrm{B}+\mathrm{C}^{+}+\mathrm{D}$

estando o espectrômetro sintonizado para observar $\mathrm{C}^{+}$, isto é, fre quência do oscilador marginal e campo magnētico são tais que $\omega_{1}=$ $\mathrm{qH}_{C} / \mathrm{m}_{C} c$, sendo $\mathrm{m}_{C}$ a massa do Ion $\mathrm{C}^{+}$. A constante de velocidade da maioria das reações varia com a energla translacional do ion rea gente (seção 3.2.1.). Logo, se o ỉon $\mathrm{A}^{+}$for acelerado por meio de um segundo campo de rädio-frequência (que tem que satisfazer a 
condição de ressonāncia de $\mathrm{A}^{+}$no campo $\mathrm{H}_{C^{\prime}}$ isto $\overrightarrow{\mathrm{e}} \boldsymbol{\omega}_{2}=\mathrm{qH}_{\mathrm{C}} / \mathrm{m}_{\mathrm{A}} \mathrm{c}$ ), poderá ocorrer uma variação no nümero de íons $\mathrm{C}^{+}$, o que se mani festarā por uma variação na intensidade do sinal de $\mathrm{C}^{+}$. Este segundo oscilador é ligado na placa superior da região analisadora.

A maneira usual de executar a experiência, é observar - sinal de $\mathrm{C}^{+}$e então desligar a modulação, qualquer que seja; co mo explicado na seção 2.1., o sinal não aparecerá mais. Em seguida irradia-se $A^{+}$na frequência $\omega_{2} / 2 \pi$ com um campo que è liga do e desligado periodicamente (modulado). A intensidade do sinal de $\mathrm{C}^{+}$variará periodicamente, obtendo-se diretamente um sinal propor cional ã variação do sinal de $\mathrm{C}^{+}$. Então, observando $\mathrm{C}^{+}$e varrendo a frequência do segundo oscilador, obtêm-se un espectro dos îons $\mathrm{A}_{1}{ }^{+}, \mathrm{A}_{2}{ }^{+}, \ldots$ precursores de $\mathrm{C}^{+}$, ou seja, è possivel identificar todas as reações que levam à formação de $c^{+} e$, estendendo a expe riêncla, observando outros produtos, ê possivel conhecer reagen tes e produtos iônicos de todas as reações que se dão no sistema. Irradiando $A^{+}$, o sinal de $\mathrm{C}^{+}$pode aumentar ou diminuir, obtendo-se, respectivamente, um sinal de ressonância dupla positıvo ou negatıvo, operando como descrito. No caso de reações sim ples, como as de transferência de pröton, um sinal positivo corresponde a uma reação endotérmica (o segundo oscilador fornece a energia para vencer a endotermicidade), e um sinal negativo, a uma reação exotērmica.

A ressonância dupla é uma ferramenta poderosa, mas é preciso tomar algumas precauçōes. ${ }^{39}$ E comum observar sinais devi dos a efeitos instrumentals, tendo quase sempre origem em correntes iônicas muito elevadas ou campos de rädio-frequência do oscilador de ressonância dupla muito intensos. Nestes casos è possível que o Ion $A^{+}$não esteja sendo apenas irradiado, mas acelerado a ponto de ser ejetado da cela, o que pode diminuir a carga espa- 
cial na cela, o que por sua vez altera as condições de ressonância para o ion que está sendo observado $\left(C^{+}\right)$, pondo-o fora de sintonia; dessa maneira seu sinal observado diminui, o que è equivalente a um sinal de ressonância dupla negativo. 0 próprio Ín $\mathrm{C}^{+}$pode ser ejetado quando sua oscilação natural no campo de apristonamento (veja a şeção 2.3.4.3. e a equação 2.18.) for aumentada pelo campo de rádio-frequência do oscilador de ressonância dupla (operando numa frequência apropriada), pelo fato de es se campo ter uma componente na direção $\underline{z}$, em virtude de o oscila dor ser ligado a apenas uma das placas de arraste. 40 Recomendase ${ }^{39}$ nas experiências de ressonância dupla registrar simultânea mente a corrente iônica total, medida na terceira região da cela; se esta corrente cair ao irradiar um ion, ions estão sendo removidos da cela e o resultado de ressonância dupla é suspeito. Pa ra fazer esta experiência simultânea, è preciso usar o segundo os cilador continuamente e lançar mão de algum outro esquema de modulação.

\subsubsection{Ejeção de Ions}

A ejeção de Ions, ocasionada por um nível de oscilação muito alto do oscilador de ressonância dupla, pode ser feita intencionalmente. Neste caso a rādio-frequência $\omega_{2}$ é ligada à região fonte e sua amplitude é ajustada de modo que o ion em questão seja removido inteiramente na região fonte. Esta amplitude minima para haver ejeção completa depende da tensão de arraste na fonte, pols quanto maior esta, menor o tempo disponivel para ejeção, tendo que ser, em consequência, maior a amplitude. . o Ion estarà removido, se atingir uma das placas de arraste, bastando pará isso que o raio de sua órbita seja igual à metade da 
altura da cela. Usando a equação 2.2. para o raio, com a velocí dade $\underline{v}$ dada pelas equações 2.9. e 2.10. (usadas no limite de baixa pressão, $\xi=0$, e substituindo $E_{1}$, o campo de rádio-frequên cia de observação, por $\mathrm{E}_{2}$, $\circ$ campo da rádio-frequência de ejeção) e, usando a equação 2.20. para o tempo que o ion leva para ir do filamento, onde è.formado, atē o fim da região fonte, onde já não deverá mais estar presente, sendo que nesta equação $\underline{E}$ ago ra é o campo de arraste na região fonte e 1 a distância do filamento atē o fim da região fonte, obtēm-se

$\mathrm{E}_{2}=\frac{2 \mathrm{rE}}{1}$

Quando $\underline{\underline{e}}$ é metade da distância ențre as placas de arraste, $\mathrm{E}_{2} \overline{\mathrm{e}}$ a amplitude mínima necessāria para que o Ion não chegue a sair da região fonte.

Esta técnica fornece informações anālogas às da ressonância dupla: se um Ion $A^{+}$for ejetado e isto causar uma diminui ção na intensidade do sinal de um ion $\mathrm{C}^{+}, \mathrm{A}^{+}$. e $\mathrm{C}^{+}$estão acopla dos através de uma reação quimica. Tambēm è possível obter in-' formações quantitativas; considerem-se as reações

$$
\begin{aligned}
& \dot{\mathrm{A}}_{1}^{+}+\mathrm{B} \rightarrow \mathrm{C}^{+}+\mathrm{D} \\
& \mathrm{A}_{2}^{+}+\mathrm{B} \rightarrow \mathrm{C}^{+}+\mathrm{E}
\end{aligned}
$$

Ejetando $\mathrm{A}_{1}^{+}$, a intensidade de $\mathrm{C}^{+}$diminui pela fração que $\mathrm{A}_{1}{ }^{+}$con tribui para essa intensidade, o mesmo valendo para $\mathrm{A}_{2}{ }^{+}$; isto per mite obter a contribuição relativa de diversos ions para a forma ção de dado produto. Obviamente a ténica só funciona para ions reagentes primārios, formados diretamente no felxe de elētrons,e sempre hả um pequeno erro envolvido, pols, mesmo que os ions rea gentes sejam totalmente removidos na região fonté, alguns já te- 
rão reagido. O erro é pequeno, pois geralmente a tensão de arraste na fonte é maior que na analisadora, de modo que os ions ficam mais tempo nesta Liltima região.

Outra possibilidade de ejeção vem do fato de os ions executarem um movimento oscilatório na direção paralela ao campo magnētico, ${ }^{31}$ cưja frequência, $\omega_{T} / 2 \pi$ è dada pela equação 2.18 . A amplitude desse movimento pode ser aumentada, aplicando um campo alternante de frequência $\omega_{\mathrm{T}} / 2 \pi$ atravës das placas de apri sionamento. A rádio-frequência pode ser ligada a uma das plą cas, formando a outra um "terra" para esse campo ou, a ambas as placas, com as fases invertidas. Os ĩons são removidos quando atingem as placas de aprisionamento. $\omega_{T}$ independe do campo magnético; logo, é possivel ejetar certo ion e verificar o efeito disso no espectro de ressonância simples. Também é possi vel operar como na experiência de ressonância dupla, modulando - campo de ejeção e observar a variação de intensidade que isto provoca em dado ion produto. o problema com esta técnica è que a resolução é muito baixa, ou seja, ao tentar ejetar certo Ion, os Ions de massas próximas tambēm são afetados.

\subsubsection{Constantes de velocidade de reação}

Em qualquer estudo de reações entre ĩons e molēculas è desejāvel ter tambēm as constantes de velocidade das reações. A equação 2.20. mostra que, variando a tensão de arraste na cela de ressonância ciclotrônica de ions, varia o tempo durante o qual os ions permanecem na cela e, portanto, o tempo que têm à disposição para reagir. Logo, è possivel em princípio obter informação cinética sobre um sistema, ou seja, obter as constantes de velocidade das reações que ocorrem. A grandeza medida em res 
sunânciar ciclotrônica de íons è um sinal de intensidade propon-cional a una potência absorvida, integrada sobre o tempo de observação dos ions. Esse sinal precisa ser relacionado com as correntes iônicas na cela e estas, por sua vez, com as constan tes de velocidade, através de uma análise cinética.

Não è possivel achar expressões analíticas para as constantes de velocidade, mesmo usando as expressões simplificadas de absorção de potência, isto é, as equações limite para alta ou baixa pressão; soluções exatas só podem ser obtidas por métodos iterativos.

Serão apresentados dois métodos de cálculo de constan tes de velocidade de reação: um, baseado na expressão para ab sorção de potência no limite de alta pressão (equação 2.12. com $\underline{\xi}$ muito grande) e outro, baseado nesta expressão no limite de baixa pressão (equação 2.12. $\operatorname{com} \xi=0$ ). Há diferenças interessantes entre os dois mëtodos por causa da forma particular com que as duas expressões se apresentam.

\subsubsection{1. o mētodo a pressão alta}

Este método foi apresentado por Beauchamp e colaboradores, ${ }^{41}$ que mediram as constantes de velocidade das reações em etileno.

Considere-se uma corrente de lons primários, $P(t)$, for necendo as correntes $s_{j}(t)$ de Ions secundārlos, atravēs de reação com molëculas neutras, sendo as constantes de velocidade desses processos indicados por $\mathrm{k}_{\mathrm{g}}$. As expressões cinéticas para essas reações são 
$\frac{d P(t)}{d t}=-n_{j}^{\sum_{j}} k_{j}(t)$

$\frac{d S_{j}(t)}{d t}=n k_{j} P(t)$

ficando as correntes lônicas,

$P(t)=P(0) e^{-n_{j}^{\Sigma_{j}} t}$

$s_{j}(t)=\frac{k_{j}}{\sum k_{j}} P(0)\left(1-e^{-n_{j}^{\Sigma_{k}} t}\right)$

$P(0)$ é a corrente de ions primários formados no feixe de elētrons; n é o número de moléculas neutras por unidade de volume; as constantes de velocidade das reações bimoleculares são geralmente dadas em $\mathrm{cm}^{3} \cdot$ molēcula $a^{-1} \cdot \mathrm{s}^{-1}$. Considera-se que os ĩons secundários sejam não reativos.

Se a corrente de ions de dada espécie è $c(t), c(t) d t$ íons estarão absorvendo a potência $\boldsymbol{A}(t)$ no instante $t$. A potēncia total absorvida, e com isso a intensidade do sinal, é

$\dot{I}=\int_{t_{i}}^{t_{i}^{\prime}} c(t) A(t) d t$

sendo $t_{i}$ e $t_{i}^{\prime}$ respectivamente os instantes em que os lons $\underline{i}$ entram e saem da região ahalisadora. As correntes $C(t)$ são $P(t)$ e $S_{j}(t)$ dadas acima e $A(t)$ é dada pela equação 2.12. que, no limi-

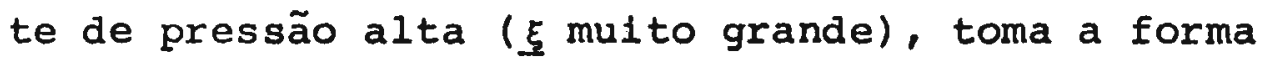

$A_{1}=\frac{q^{2} E_{1}^{2}}{4 m_{i} \xi_{i}}$

para o ion 1 . Substituindo 2.26. e separadamente 2.23. e 2.24. em 2.25 , resultam: 


$$
\begin{aligned}
& I_{p}=\frac{q^{2} E_{1}^{2} p(0)}{4 m_{p} \xi_{p} n_{j}^{\Sigma_{k}}}\left(e^{-n_{j}^{\Sigma_{j}} k_{j} t_{p}}-e^{-n_{j}^{\Sigma_{k}} k_{j} t_{p}^{\prime}}\right) \\
& I_{s j}=\frac{q^{2} E_{1}{ }^{2} p(0) k_{j}}{4 m_{s j} \xi_{s j} n\left({ }_{j}^{\Sigma_{k}}\right)^{2}}\left[n_{j}^{\Sigma_{k_{j}}}\left(t_{s j}^{\prime}-t_{s j}\right)-e^{-n_{j}^{\Sigma_{k j}} t_{s j}}+\right. \\
& \left.+e^{-n_{j}^{\Sigma_{k}} t^{\prime}}{ }_{s j}\right]
\end{aligned}
$$

Os indices $\mathrm{p}$ e $\underline{\mathbf{s}}$ referem-se, respectivamente, a Ions primārio

e secundário e o indice $j$, ao ion secundārio da espécie $j$. Des sas expressões não é possivel obter diretamente os $k_{j}$. Mas como em geral nkt $<<1$, as exponenciais podem ser expandidas numa série de McLaurin, desprezando os termos de ordem maior que 2 .

$I_{p}=\frac{q^{2} E_{1}^{2} p(0)\left(t_{p}^{\prime}-t_{p}\right)}{4 m_{p} \xi_{p}}\left(1-n_{j}^{\Sigma_{j}} \frac{t_{p}^{\prime}+t_{p}}{2}\right)$

$I_{s j}=\frac{q^{2} E_{1}{ }^{2} p(0)\left(t_{s j}^{\prime}-t_{s j}\right)}{4 m_{s j} E_{s j}}\left(n k_{j} \frac{t_{s j}^{\prime}+t_{s j}}{2}\right)$

Mas, usando as expressões 2.3. e 2.20. resulta, no caso de ser varrido o campo magnético e mantida fixa a frequêncla do oscilador marginal para a obtenção do espectro:

$$
t_{s j}=\frac{m_{s j}}{m_{p}} t_{p} \quad t_{s j}^{\prime}=\frac{m_{s j}}{m_{p}} t_{p}^{\prime}
$$

Substituindo isto na expressão de $I_{s j}$ :

$I_{s j}=\frac{q^{2} E_{1}^{2} p(0)\left(t_{p}^{\prime}-t_{p}\right)}{4 m_{p} s_{j j}}\left(n k_{j} \frac{m_{s j}}{m_{p}} \frac{t_{p}^{\prime}+t_{p}}{2}\right)$

Somando a equação 2.29. com as j equações 2.31. (um pouco rearran 
jadas), resulta:

$\xi_{p} I_{p}+\sum_{j} \frac{m_{p}}{m_{s j}} \xi_{s j} I_{s j}=\frac{q^{2} E_{1}{ }^{2} p(0)\left(t_{p}^{\prime}-t_{p}\right)}{4 m_{p}}$

- lado direito desta equação pode ser obtido tambēm a partir da equação 2.31.; fazendo isto, substituindo nesta ūltima equação e rearranjando, resulta:

$$
k_{j}=\frac{2 m_{p} \xi_{s j} I_{s j}}{n\left(t_{p}^{\prime}+t_{p}\right) m_{s j}\left(\xi_{p} I_{p}+\sum_{j} \frac{m_{p}}{m_{s j}} \xi_{s j} I_{s j}\right)}
$$

Usualmente ${ }^{41-44}$ esta equação è aplicada da seguinte for ma: $t_{p}$ e $t_{p}^{\prime}$ são calculados pela equação 2.20 ., sendo que o tempo em que o Ion entra na região analisadora depende do campo de. arraste na região fonte, $E_{f}$, e o tempo em que sal da região anali sadora depende do campo de arraste nesta região, $\mathbf{E}_{a}$. Logo,

$$
t_{p}=\frac{{ }^{H} I_{f}}{c E_{f}} \quad t_{p}^{\prime}=t_{p}+\frac{H l_{a}}{c E_{a}}
$$

$I_{f}$ e $l_{a}$ são, respectivamente, distância do filamento ao fim da re g̣ião fonte e, comprimento da região analisadora. $\underline{H}$ é o campo mag nētico adequado à observação do Ion primārio. Como geralmente fre quências de colisão de íons primârios e secundários num mesmo gās neutro são multo pröximas (veja a TABELA 4.4.), $\underline{\xi}$ é frequentemen te cancelado. Assim chega-se a uma expressão

$$
\frac{I_{s j}}{I_{p}+{ }_{j}^{\Sigma} \frac{m_{p}}{m_{s j}} I_{s j}}=\frac{{ }^{n} m_{s j{ }^{\omega}}\left(\frac{2 I_{f}}{a}+I_{a}\right)}{2 q} \cdot k_{j} \cdot E_{a}^{-1}
$$

cujo membro esquerdo, colocado num gráfico em função do inverso do campo de arraste na região analisadora, fornece uma reta cujo 
coeficiente angular contēm $k_{j}$ • Então, a experiência consiste em medir $T_{p}$ e os $I_{s j}$ ' variando a tensão de arraste na região analisa dora. (Também é preciso variar a tensão na região fonte propor cionalmente; a, na equação acima, è a relação entre as duas ten sões, $\left.a=V_{f} / V_{a}\right)$. As retas obtidas geralmente são satisfató rias dentro de certo intervaio de tensões de arraste. A tensões muito baixas impurezas na superfície das placas da cela alte ram os potenciais efetivamente sentidos pelos ions, o que causa um desvio na linearidade do gráfico. Quando a tensão é muito alta, ț è muito pequeno, ou seja, a extensão da reação é pequena e os $I_{s j}$ são pequenos, causando dificuldades na medição, o que leva a considerável espalhamento dos pontos experimentais.

o método descrito ê aproximado, por causa da expansão das exponencials numa sērie, mas pode ser tornado exato, se os $k_{j}$ assim calculados forem substituíos nas equações 2.27. e 2.28., calculando valores para $I_{p} e I_{s j}$ ' os quais são então comparados com os valores experimentais, tentando-se assim corrigir os $k_{j} i-$ niciais; as constantes corrigidas são novamente substituIdas em 2.27. e 2.28., até obter a convergência desejada. Isto, contudo, raramente é feito. 45

\subsubsection{O mētodo a pressão baixa}

Este método foi apresentado por Buttrill, 21 num traba Iho em que também fol deduzida a expressão de absorção de potên cia no limite de baixa pressão. Tambēm parte das equações 2.23., 2.24.e 2.25., só que a absorção de potência é dada pela équação 2.12. no limite de balxa pressão $(\xi+0)$. $A_{i}(t)=\frac{q^{2} E_{I}^{2}}{4 m_{i}} t$ 
Esta expressio difere fundamentalmente da 2.26. , pois agora a po tência instantânea absorvida depende do tempo e, num dado instan te, todos os ỉons não estarão absorvendo igual potência, mas aqueles que jā estão no campo de observação por mais tempo, absorverão mais. Disto se conclui que não é possível tratar todos os Ions secundārios da mesma forma, pois aqueles que foram produ zidos na região fonte entram na analisadora ao mesmo tempo e começam a absorver potência ao mesmo tempo; porém, os ỉons secundạ rios produzidos na região analisadora, o serão em diversos pontos da mesma e, portanto, estarão absorvendo potências dife rentes. Isto precisa ser levado em conta na integração e esta è a principal diferença com o método antertor, onde todos os Ions são tratados de maneira Idêntica.

Para deduzir a expressão da constante de velocidade de reação é conventente empregar uma escala de tempo que pode ser entendida com auxilio da FIGURA 2.7: ${ }^{19} t_{i}$ e $t_{i}^{\prime}$ são os instantes em que o Ion 1 (primārio ou secundārio j) entra e sai da região analisadora; $t$ ' e $t$ são dols Instantes qualsquer do periodo que' - Ion fica na região analisadora, tals que $t_{1} \leqslant t^{\prime}<t$ e $t_{1}<t \leqslant t_{1}^{\prime}$. Serão deduzidas separadamente expressões para a intensidade do sinal de ressonância simples de Ions primários, Ions secundários formados na fonte e ions secundários formados na ana lisadora.

Intensidade do sinal de ions primários. Num instante ț na região analisadora há lons primārios formados $\underline{t}$ unidades de tempo atrás no felxe de elétrons; a corrente $P(t)$ devida a esses Ions é dada pela equação 2.23.; esses ỉons permaneceram $t$ - $t_{p}$ unidades de tempo na região analisadora; logo, sua contribui ção para a potência absorvida é $A_{p}\left(t-t_{p}\right)$. Logo, a Intensidade do sinal è, usando a equação 2.25 .: 


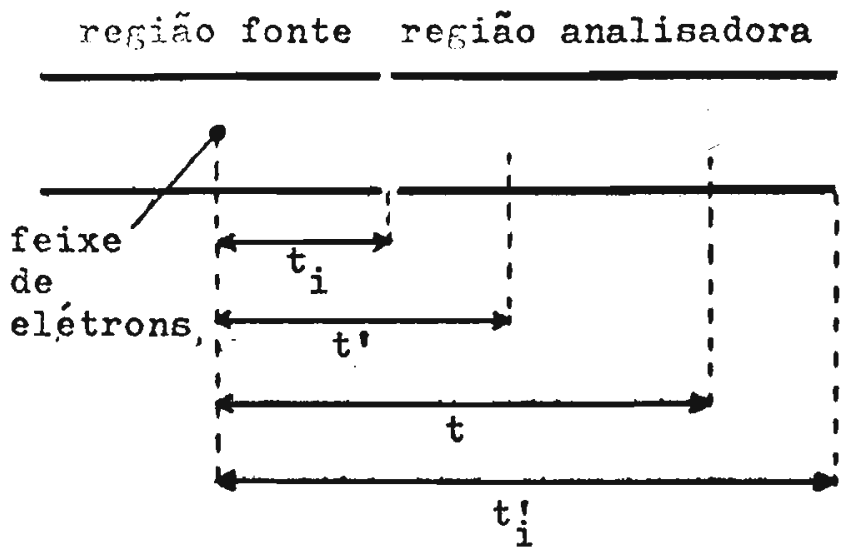

FIGURA 2.7. Escala de tempo na cela de ressonância ciclotrônica de lons.

$$
\begin{aligned}
I_{p} & =\int_{t_{p}}^{t^{\prime} p} P(t) A_{p}\left(t-t_{p}\right) d t \\
& =\frac{q^{2} E_{1}{ }^{2} p(0)}{4 m_{p}{ }^{2}\left(\Sigma_{j} k_{j}\right)^{2}}\left[e^{-n \sum_{j} k_{j} t_{p}}-e^{-n \sum_{j} k_{j} t_{p}^{\prime}-n_{j}^{\Sigma_{j}}\left(t_{p}^{\prime}-t_{p}\right)} x\right. \\
& \left.\times e^{-n \sum_{j} k_{j}^{\prime}}\right]
\end{aligned}
$$

Intensidade do sinal de ions secundários formados na fonte. Os ions secundários formados na fonte entram na analisadora no instante $t_{s j}$ e sua corrente, $s_{j}\left(t_{s j}\right)$, é dada pela equação 2.24. Como esses Ions são considerados não reativos, seu 
número permanece constante a partir da entrada na analisadora. No Instante $t$ estão absorvendo potência $A_{s j}\left(t-t_{s j}\right)$. Logo,

$$
\begin{aligned}
I_{s j}(\text { fonte) } & =\int_{t_{s j}}^{t^{\prime} s j} s_{j}\left(t_{s j}\right) A_{s j}\left(t-t_{s j}\right) d t \\
& =\frac{q^{2} E_{1}{ }^{2} p(0) k_{j}}{4 m_{s j} \sum_{j} k_{j}}\left(1-e^{\left.-n_{j} \sum_{j j} t_{s j}\right) \frac{\left(t_{s j}^{\prime}-t_{s j}\right)^{2}}{2}}\right.
\end{aligned}
$$

Intensidade do sinal de ions secundārios formados na

analisadora. O número de Ions formados entre os instantes $t^{\prime}$ e $t^{\prime}+d t^{\prime}$ pode ser obtido da equação 2.22 ., que, após substituir nela a equação 2.23 , flca

$\mathrm{ds}_{j}\left(t^{\prime}\right)=n k_{j} P(0) e^{-n_{j}^{\Sigma_{j}} t^{\prime}} d t^{\prime}$

o número de ions formados nesse intervalo permanece constante e, no instante $\underline{t}$, cada Ion terá permanecido pelo tempo $t-t$ ' na ana lisadora, de modo que estará absorvendo a potência $A_{s j}\left(t-t^{\prime}\right)$. E preciso somar sobre todos os instantes t' em que ions secundários podem ser formados na analisadora, 1sto ë, entre $t_{s j} e t$. Em seguida é preciso somar sobre todos os instantes em que os ions são observados, isto é, somar sobre $t$, de $t_{s j}$ a $t_{s j}^{\prime}$. Logo,

$$
\begin{aligned}
I_{s j}(\text { analisadora }) & =\int_{t_{s j}}^{t^{\prime} s j} d t \int_{t_{s j}}^{t} \frac{d s_{j}\left(t^{\prime}\right)}{d t^{\prime}} A_{s j}\left(t-t^{\prime}\right) d t^{\prime} \\
& =\frac{q^{2} E_{l}^{2} p(0) k_{j}}{4 m_{s j} n^{2}\left(\sum_{j} k_{j}\right)^{3}}\left[e^{-n_{j}^{\Sigma_{k}} t_{s j}-e^{-n_{j} k_{j} t_{s j}}-}\right.
\end{aligned}
$$




$$
\begin{aligned}
& -n_{j}^{i} k_{j}\left(t_{s j}^{\prime}-t_{s j}\right) e^{-n_{j}^{\sum} k_{j} t_{s j}}+ \\
& +n^{2}\left(\sum_{j} k_{j}\right)^{2}
\end{aligned}
$$

o sinal total devido aos íns secundārios é

$$
\begin{aligned}
& I_{s j}=I_{s j} \text { (fonte) }+I_{s j} \text { (analisadora) }
\end{aligned}
$$

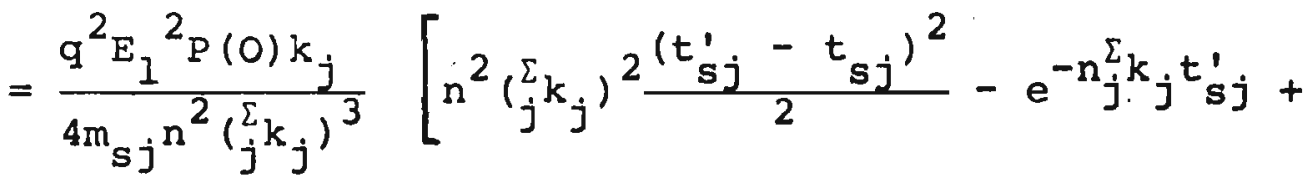

$$
\begin{aligned}
& \left.+e^{-n_{j}^{\Sigma} k_{j} t_{s j}}-n_{j}^{\Sigma_{j}}\left(t_{s j}^{\prime}-t_{s j}\right) e^{-n_{j}^{\Sigma} k_{j} t_{s j}}\right]
\end{aligned}
$$

Como no método anterior, as exponenciais em $I_{p}$ e $I_{s j}$ são expandi das numa série de McLaurin, mas desta vez até terceira ordem; em alguns produtos acabam sendo gerados termos de quarta ordem, que são desprezados. Na expressão de $I_{s j}$ também é feita a substitu1 ção indicada nas expressões 2.30. Obtēm-se:

$$
\begin{aligned}
& I_{p}=\frac{q^{2} E_{l}^{2} p(0)}{4 m_{p}}\left[\frac{\left(t_{p}-t_{p}^{\prime}\right)^{2}}{2}-n_{j}^{\Sigma_{k}}\left(\frac{t_{p}^{3}}{6}+\frac{t_{p}^{\prime 3}}{3}-\frac{t_{p} t_{p}^{\prime 2}}{2}\right)\right] \\
& I_{s j}=\frac{q^{2} E_{1}^{2} p(0) k_{j} m_{s j}^{2}}{4 m_{p}^{3}} n\left(\frac{t_{p}^{\prime 3}}{6}+\frac{t_{p}^{3}}{3}-\frac{t_{p}{ }^{2} t_{p}^{\prime}}{2}\right)
\end{aligned}
$$

Dividindo uma expressão pela outra e tirando da somatór ła dos $k_{j}$ - valor de $k_{j}$, chega-se ao resultado final,

$$
k_{j}=\frac{m_{p}^{2} I_{8 j}\left[3-n \sum_{\ell \neq j}^{\Sigma} k_{\ell}\left(t_{p}+2 t_{p}^{\prime}\right)\right]}{n I_{p} m_{s j}{ }^{2}\left(2 t_{p}+t^{\prime} p^{\prime}+n I_{s j} m_{p}^{2}\left(t_{p}+2 t_{p}^{\prime}\right)\right.}
$$


No caso partircular de o ion primário intervir só em uma reação, tem-se:

$$
k=\frac{3 m_{p}^{2} I_{s}}{n I_{p} m_{s}} \frac{{ }^{2}\left(2 t_{p}+t_{p}^{\prime}\right)+n I_{s} m_{p}^{2}\left(t_{p}+2 t_{p}^{\prime}\right)}{p_{p}}
$$

Esta fórmula foi usada extensivamente, principalmente para obter constantes de velocidade relativas. ${ }^{30}$ Ela é aproxima da, mas o método pode ser tornado exato, desde que por iteração se melhore sucessivamente o k calculado pela equação 2.37 , subs tituindo-o em 2.34. e 2.35. Buttrill, em seu trabalho original, 21 apresentou uma matrız com fatores de correção: calculando $\underline{k}$ por 2.37., obtém-se o $\underline{k}$ "exato", multiplicando o primeiro pelo fa tor da tabela. Os fatores foram dados em função da relação de massa dos ions primário. e secunaário e da relação de intensidades dos sinals dos lons primärio e secundärio; também só valem pá ra certa relação entre $t_{p} e t_{p}^{\prime}$ ' mas a dependêncla disto não ē grande. Os fatores de correção são próximos de 1,00 quando a $1 \underline{n}$ tensidade do sinal do Ion secundārio é pequena ou a massa do Ion secundário.è grande. O malor fator da tabela é 2,00. o empre go da fórmula 2.36. jā é complicado por si sō: para calcular uma constante de velocidade de reação é preciso conhecer as constan tes de velocidade de todas as reações paralelas.

\subsubsection{Métodos mais completos}

As equações 2.32. e 2.36. são obviamente muito limitadas, pois são aplicávels apenas no caso de um ion primárto produ zir Ions secundártos estáveis. Em sistemas de Ions positivos,co mo nos tratados nesta tese (capitulos 4, 5 e 6), a formação de Ions terciārlos è praticamente regra. 
Marshall e Buttrill 46 estenderam o mētodo da seção 2.3.j.2. para Ions secundārios reativos e Ions terciārios estạ veis. Os ions terciārios foram tratados de maneira análoga aos secundários no tratamento anterior. Não são obtıdas expressões explícitas para as constantes de velocidade, mas só para as intensidades dos sinais, mantendo as exponenciais; o método é iterativo. Foram calculadas as constantes de velocidade alas reações em fluoreto de metila e foi possível reproduzir por meio de cálculo as curvas experimentais de intensidades iônicas em função da pressão. Verificou-se que a teoria de baixa pressão é aplicāvel até a uma pressão de $5 \cdot 10^{-5}$ Torr. A teoria não leva em conta colisões não reativas. 47 Qualquer colisão de ions com moléculas reduz a intensidade do sinal de ressonância simples, pois a colisão interrompe a absorção de potência. Colisões reativas são mais eficientes nesse sentido, pois alteram a massa do Ion que está absorvendo, de modo que não absorva mais potência. Colisões não reativas apenas alteram a velocidade do Ion,que depois continua a absorver potência. Por causa disso a intensida de do sinal de Ions terciários é mais afetada la intensidade cal culada é malor que a experimental) que a de ions secundários e primários, pois os ions terciários são conslderados estáveis, de modo que todas suas colisões precisam ser não reativas.

Os cälculos de Comisarow ${ }^{19}$ levam em conta colisões não reativas, pois é usada a expressão geral de absorção de potên cia (equação 2.11.), onde $\circ \xi$ é justamente a frequência de colısão. Como $A(t)$ depende do tempo, o tratamento formal é semelhan te ao da seção 2.3.5.2., sendo porēm incluỉdos ỉons secundários reativos e ions terciărios estáveis. Deve-se notar que é empregada a equação 2.11., que vale em qualquer condição e não só na de ressonâncla; por isso as equações de Comisarow permitem calcu 
lar a forma da linha de absorção de ions reativos; para o cálculo de constantes de velocidade de reação bastam, no entanto, as intensidades dos sinais na condição de ressonância. Na publicação original ${ }^{19}$ esta teorla foi comparada com a da seção 2.3.5.2, verificando-se que as constantes de velocidade são de 15 a 208 maiores que as calculadas pela equação 2.37. Porēm, Bowers num estudo experimental 45 em que as três teorlas, a de Comisarow, a de pressão baixa e a de pressão alta, foram comparadas e todas $\underline{u}$ sadas na sua forma "exata" (ver seções 2.3.5.1. e 2.3.5.2.), verificou que em média a teoria de alta pressão fornece resultados 11,28 menores que a de Comisarow, e a de baixa pressão, 1,88. O tratamento da referência 46 fol estendido 48 no sentido de permitir calcular a forma das linhas de absorção; tambēm fol incluía uma discussão pormenorizada de colisões entre íns e moléculas em geral.

Todos os mētodos mencionados nesta seção requerem solu ções iterativas. Por 1sso usam-se frequentemente mētodos mais simples para obter uma primeira aproximação para as constantes de velocidade de reação. Porēm como será visto a seguir, hā vărios problemas experimeritais que afetam a medição de constantes de ve locidade de reação e que tornam inútil a aplicação de teorias mui to sofisticadas, bastando então os métodos ma1s simples.

\subsubsection{Medicão experimental do tempo de residência}

Nas fórmulas 2.32. e 2.36., bem como nas apresentadas nas deduções mais elaboradas, aparecem $t_{p} e t_{p}^{\prime}$ os tempos em que os ions entram na região analisadora e saem da mesma, sendo o tempo zero, o instante de formação de Ions primários no feixe de elétrons. Vê-se que é necessārio conhecer o tempo que os ions 
levam para atravessar a cela, que tipicamente é de 1 a $5 \mathrm{~ms}$. Como explicado em 2.3.5.1., este tempo é calculado pela equação 2.20., em função das tensões de arraste na cela. Todavia, como mostrado em 2.3.3., existe o campo de aprisionamento, que tem uma componente na direção do campo de arraste. Além disso os campos elétricos na cela não são perfeitamente homogêneos. Tudo isto faz com que os tempos de residência calculados não correspondam muito à realidade, principalmente quando a tensão de arraste é baixa (ver seção 4.5. ).

Porém, é possỉvel medir experimentalmente o tempo de permanência dos ions na cela sob dadas condições de operação e a maneira de fazer isso fol sugerida por Beauchamp 49 e Futrell. 50

E preciso empregar uma cela com placas de aprisionamen to separadas entre as regiōes fonte e analisadora (veja a FIGURA 2.5.) e fazer uso da terceira região, o coletor de ỉons; também é necessārio poder usar modulação de feixe eletrônico (seção 2.3.4.1.). A experiência é realizada da seguinte maneira: A gra de do canhão de elétrons é mantida num potencial mais negativo que o filamento, de modo a barrar a entrada dos elétrons; um pul so positivo de 50 a $200 \mu \mathrm{s}$ è aplicado à grade, de modo a permi tir a passagem do feixe e a formação de um conjunto de ions; esses Ions são arrastados através da cela e vão para o coletor de Ions, onde se registra uma corrente devida aos ions. Após o pul so de lonização, è aplicado a uma das placas de aprisionamento na região analisadora um pulso negativo (para Ions positivos); se o atraso do segundo pulso for tal que os ions ainda estejam na fon te ou já tenham saỉdo da analisadora, esse pulso não terá efeito algum; porēm, se os Ions alnda estiverem na região analisadora , serão removidos da cela e a corrente iônica registrada será zero. Desta maneira, registrando corrente de ions em função de atraso 
do pulso, na placa de aprisionamento em relação ao pulso de forma ção dos lons, obtēm-se um grăfico, onde incialmente se tem a cor rente iônica total, constante (íons ainda na região fonte), que depois cai abruptamente para zero (Ions na região analisadora,sen do removidos pelo pulso), subindo depois novamente para o valor inicial (ĩons jā no coletor). A queda e a subida de corrente dão respectivamente os instantes nos quais os Ions entram na analisa dora e saem da mesma. Obviamente queda e subida não são muito bruscas, principalmente por causa de um espalhamento dos íons atravēs da cela, resultante da repulsão entre os Ions (carga espa cial). Por isso o erro nas medidas dos tempos é considerado como 5\%, 45 mas esta experiêncla representa considerävel avanço em relação às em que os tempos são calculados pelas tensões de arraste.

Futrell estudou ${ }^{50}$ a reação entre $\mathrm{H}_{2}{ }^{+}$e $\mathrm{CO}_{2}$ e apli cou para a anālise dos dados simplesmente a equação $\ln \left[\mathrm{I}_{0}\left(\mathrm{H}_{2}{ }^{+}\right) /\right.$ $\left.\mathrm{I}\left(\mathrm{H}_{2}{ }^{+}\right)\right]=\mathrm{kt}\left[\mathrm{CO}_{2}\right]$, onde $\mathrm{I}\left(\mathrm{H}_{2}{ }^{+}\right)$é a intensidade do sinal de $\mathrm{H}_{2}{ }^{+}$ no espectro de ressonâncla simples, $\mathrm{I}_{\mathrm{o}}\left(\mathrm{H}_{2}{ }^{+}\right)$è esta intensidade quando a pressão de $\mathrm{CO}_{2}$, expressa como $\left[\mathrm{CO}_{2}\right]$, è zero: $\underline{t}$ é medido experimentalmente. E claro que este mētodo só é aplicável nestas condiçōes particulares, de ions provenientes de dado gās rea girem com moléculas de outro gãs, mas ilustra a possibilidade de obter em casos especlais constantes de velocidade de reação de manelra direta, sem ser necessárlo preocupar-se com absorção de potência e outras características de ressonância ciclotrônicas de Ions.

Os estudos de ressonâncla clclotrônica de Ions são geralmente realizados na faixa de $10^{-6}$ a $10^{-4}$ Torr. Neste interva lo dificilmente conseguem-se medidas de pressão muito melhores que 108 e este é o principal fator limitante da precisão 
constantes de velocidade de reação. Esta é a razão pela qual os mētodos aproximados são plenamente satisfatórios, de nada adiantando os mëtodos "exatos" para melhorar os resultados. Bowers 45 desenvolveu um procedimento parecido com o da seção 2.3.5.2. (pressão baixa), só que as exponenciais que aparecem nas equações cinēticas são expandidas até terceira ordem antes de integrar sobre o tempo de observação dos İons. Chegam-se a expres sões que indicam que um grāfico de uma relação de intensidades de sinais em função de pressão è uma reta, cujo coeficiente angu lar contēm k. Comparado com o método de Comisarow, este aqui le va a constantes de velocidade que são em média 5,98 menores, mas sua grande simplicidade justifica inteiramente seu uso; no entanto, só foram dadas equações para o caso de ions secundārios estáveis, não sendo considerados ions terciários.

Resumindo pode ser dito que é possivel obter constantes de velocidade de reação, por ressonância clclotrônica de Ions, usando a cela de três regiões, com erro da ordem de 10z, sen do os fatores limitantes o tempo de permanência dos Ions na cela e a pressão. A anālise de sistemas complexos, isto è, nos quais ocorrem multas reações paralelas e consecutivas, com formação de ions terciārios, è dificil e, frequentemente os sistemas são estudados em condições em que algumas das reações são desprezí veis. Por tudo 1sso não compensa aplicar teorlas muito sofisticadas.

\subsection{Operação pulsada}

o problema da determinação do tempo de permanência dos Ions na cela foi atacado de um outro lado, usando uma cela de de senho diferente. 51 E adotado o seguinte esquema experimental: 
Ions sãq formados por um pulso de um feixe de elétrons e depois aprisionados por um longo período de tempo na cela especial. En quanto os íons reagem com as molēculas do gás, a mistura de reação pode ser analisada em qualquer instante durante o curso da reação, para determinar a concentração de um ion de qualquer mas sa. E, portanto, possîyel seguir a concentração de um ỉon de da da massa em função do tempo de reação. Esta tẻćnica especial, de nominada espectroscopła de ressonância ciclotrônica de ions pulsada, fol desenvolvida por McIver na Untversidade de stanford (USA). 5I-53

\subsubsection{A cela de aprisionamento}

A cela usada nesta técnica difere daquela descrita na seção 2.3.3., pelo fato de os Ions não atravessarem simplẹsmen te a cela em virtude de uma tensão de arraste, mas sim, ficarem efetivamente aprisionados na mesma. E constituÍda de apenas uma região, de modo que os íons são formados e detectados no mesmo espaço; a carga espacial do feixe de elētrons, porēm, não interfere na deteç̧ão, pois produção de ions e detecção estão separa das no tempo.

A cela é constituída đe seis placas metálicas formando uma caixa retangular. Para íons positivos, as placas de apri sionamento são mantidas num potencial positivo, as placas de arraste são ambas negativas $e, o$ que è novidade, existem placas ter minals que fecham a cela, negativas. Para lons negativos os potenciais são invertidos. Esta configuração de potencials permite manter os ions por algumas centenas de milissegundos na cela. Os ions executam um movimento ciclotrônico ao redor das linhas de força do campo magnētico e um movimento harmônico simples na direção dessas linhas de força, por causa do campo de aprisiona- 


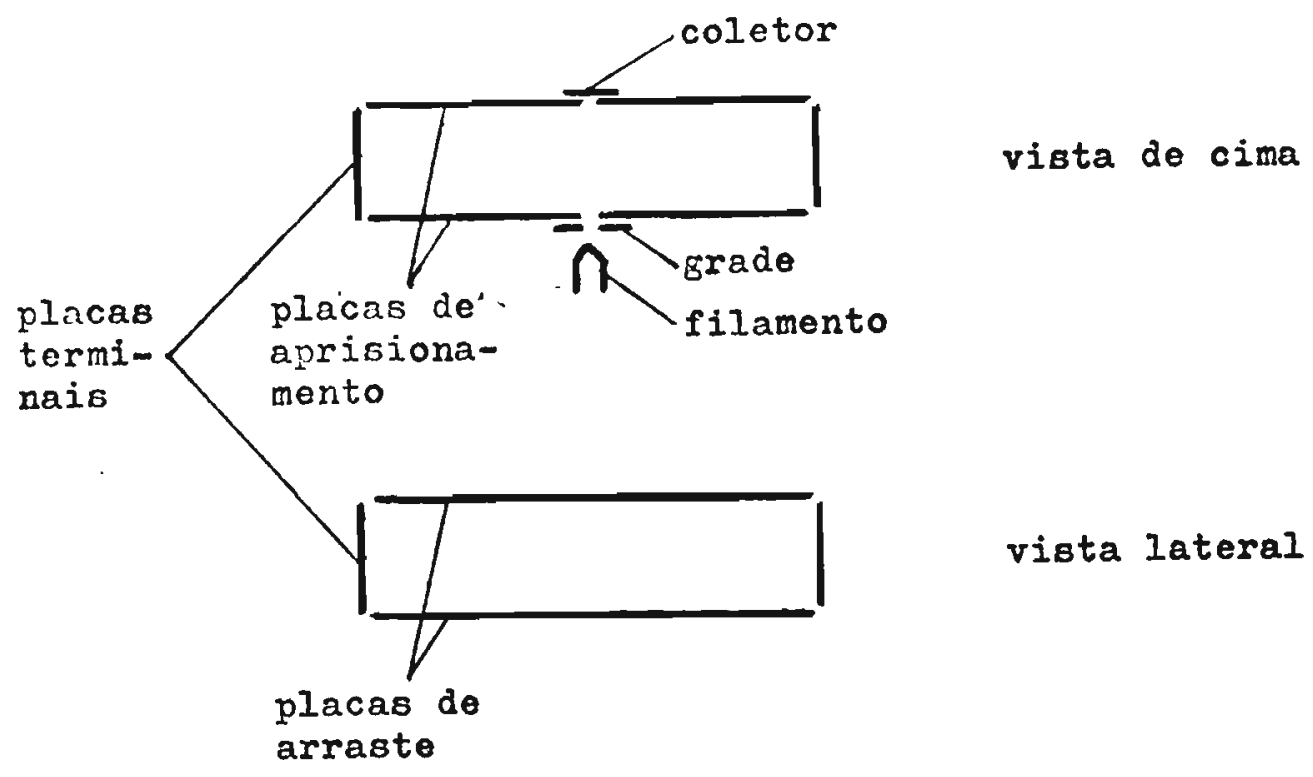

FIGURA 2.8. Cela de aprisionamento.

mento. O resultado è que o ion se desloca sobre uma superfí cie cilíndrica orlentada na direção do campo magnētico. Isto tam bẹem acontece na cela de arraste (seção 2.3.3.). Na cela de aprị sionamento esse cilindro ainda se move ao redor de uma linha semelhante a uma elipse, mas mantendo seu eixo ná direção do campo magnético. 54 Este ültimo movimento tem uma frequência de alguns hertz, enquanto que os dois primeiros estão na região de rạ dio-frequência.

Na cela existe ainda o coletor de elëtrons e, na frente do filamento, a grade, que è simplesmente uma peça metálica com um furo. A grade normalmente è mantida num potencial mais negativo que o fllamento, de modo que os elétrons não possam entrar na cela; quandó desejado, é aplicado um pulso na grade, 
tornando-a alguns volts mais positiva que o filamento, permitindo a pissagem do feixe de elētrons. Entre coletor e placa de aprisionamento e entre grade e placa de aprisionamento são colocadas grades (telas de arame) no mesmo potencial das placas de aprisionamento, para atenuar a penetração dos potenciais do cole tor e da grade de.controle na cela, o que afetaria seriamente a capacidade de aprisionamento. As placas finais tambēm são geral mente feltas de tela para evitar gradientes de pressão dentro e fora da cela. A placa de arraste inferiox è ligada ao oscila dor marginal.

\subsubsection{Sequência de pulsos}

A experiência com a cela de aprisionamento é realizada da seguinte maneira: o campo magnético e a frequência do oscí lador marginal são ajustados de modo que o ion a ser estudado es teja fora de ressonâncla; ou melhor, a frequência è um pouco mais baixa que a necessāria para haver ressonância. Um pulso na grạ de em frente ao filamento faz com que o feixe de elétrons penetre na cela e produza alguns ions. A duração do pulso é bem conhecida e è tipicamente de 1 a $5 \mathrm{~ms}$. Em segulda os ions reagem livremente e como estão fora de ressonância, não são acelera dos pelo oscllador marginal, nem absorvem potência. o tempo de reação pode ser estendido em casos favorāveis atẽ $500 \mathrm{~ms}$. Após um tempo de reação qualquer é ativado o pulso de deteç̧ão para determinar a concentração do ion em questão. Este pulso é aplicado nas placas de aprisionamento e é positivo para ions positi vos. De acordo com a equação 2.17. a frequêncla clclotrônica nạ tural $\omega_{c} / 2 \pi$ de um ion num campo magnético $\underline{H}$ é deslocada para uma frequêncià efetiva, $\omega_{\text {ef }} / 2 \pi$, em virtude da tensão de aprisionamen 
to $V_{T}$. O pulso faz com que $V_{T}$ aumente, ou seja, $\omega_{\text {ef }}$ diminua e coincicia com $w_{1}$, a frequência do oscillador marginal. Desta manei ra os ions que entraram em ressonāncia começam a absorver potên cia do campo de rādio-frequência. A potência instantânea absorvi da em ressonância é dada pela equação $2.12 .$, mas quando o tempo de observação é muito cụrto, pode ser aproximada pela equação 2.33. Logo, observa-se um sinal crescendo linearmente a partir do instante em que o pulso de deteç̧ão é acionado, caindo abrupta mente para zero no instante em que o pulso termina. Se o tempo de observação for mais longo, nota-se que a subida no final não é mais linear, havendo tendência para um nivelamento, o que estā de acordo com a equação 2.12. A duração do pulso de deteç̧ão é tipicamente de 3 a $10 \mathrm{~ms}$. Finalmente todos os ions, independente mente de massa, são rapidamente neutralizados nas paredes da cela por um pulso de destruição: a cela deixa de aprisionar ions ao in verter temporarlamente a polaridade do potencial da placa de arraste superior. o pulso de destruição pãra a reação e impede que Ions de uma sequência de pulsos alnda estejam presentes na próxị ma sequêncla; tem duração típica de 1 a $5 \mathrm{~ms}$. o ciclo todo é repetido automaticamente logo em seguida.

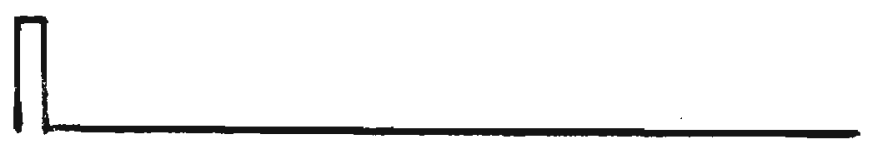

pulso de formação

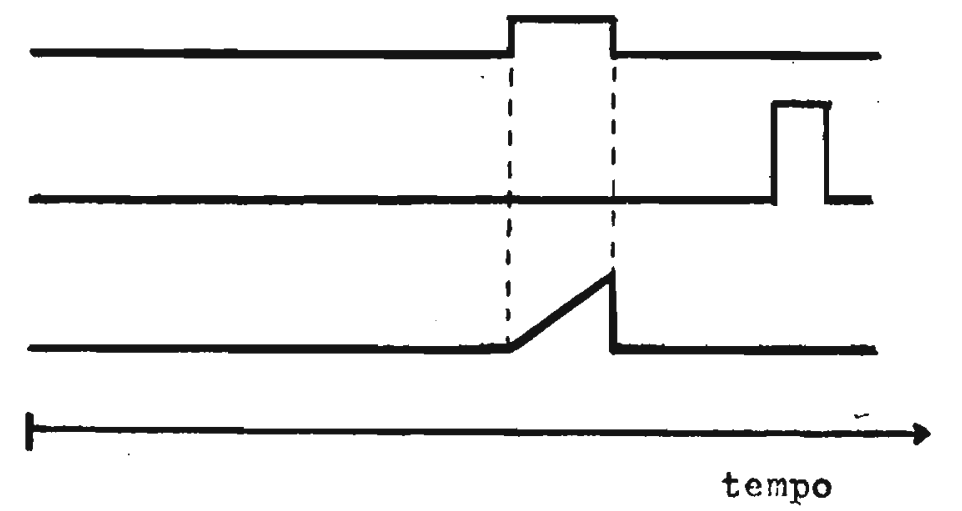

pulso de deteç̧ão

pulso de destruição

sinal

FIGURA 2.9. A Bequênoia de pulsob o sinal detectado. 
Existem outras formas de aplicar o pulso de detecção.A maneira óbvia é a de pulsar o campo magnético para o valor corre to de ressonância. Isto foi feito, ${ }^{51}$ mas não é muito conveniente. outra maneira requer um oscilador marginal pulsado: ${ }^{55}$ os ions em princípio estão em ressonância, mas o oscilador marginal é desli gado; só è ligado durante o perỉodo de deteç̧ão. Este deve ser o melhor método, mas ainda não está suficientemente desenvolvido.

A intensidade do sinal, dada pela equação $2.33 .$, é obviamente diretamente proporcional ao número de ions em ressonância. Vejamos como esse sinal è processado. Usar um detetor de fase, como era feito em conjunto com a cela de arraste, não funciona, pois no presente caso o ciclo ütil é muito reduzido, ou seja, a relação entre o tempo em que se tem um sinal e o tempo total è muito pequena. Explicando melhor: A sequência de pulsos tem por exemplo uma duração total de $100 \mathrm{~ms}$ e o pulso de detec ção, uma duração de $3 \mathrm{~ms}$; portanto, de um total de $100 \mathrm{~ms}$, só a parece um sinal por $3 \mathrm{~ms}$. Um detetor de fase não pode retificar um sinal assim, que na maior parte do tempo è zero. o que se faz é usar um integrador, ${ }^{56,57}$ um circuito desenvolvido para aumentar a relação sinal/ruido no caso de sinals repetitivos, quan do hã muito "tempo morto". O integrador tem uma janela que só abre durante o tempo em que chega o sinal de interesse, o qual é então armazenado num condensador até a janela abrir novamente e chegar um outro sinal. E possivel analisar uma forma de onda repetitiva, fazendo o integrador abrir sucessivamente em diferen tes pontos da curva; o condensador armazena os sinais correspondentes aos diversos pontos da curva e um registro da carga do condensador em função dos instantes em que é feita a amostragem, representa a curva. Na experiência de ressonância ciclotrônica pulsada a amostragem colncide com o pulso de detecção; durante o 
resto do tempo só é produzido ruído, que entretanto não è admiti do pelo integrador, não degradando o sinal.

\subsubsection{Curvas cinēticas}

o pulso de detecção pode ser ajustado arbitrariamente em relação ao de formação dos ions. A separação entre os dois pulsos pode ser medida bastante bem com um osciloscópio ou, melhor ainda, com um contador de frequências, que geralmente permi te fazer tal mediảa. Varrendo o campo magnëtico, obtēm-se um es pectro de ressonância simples comum, onde no entanto todos os ions reagiram durante tempos iguais, bem conhecidos. Alèm de espectros de massa com essas características, è possível realizar uma experiência mais interessante, na qual o atraso do pulso de detecção em relação ao de formação de ions è variado continuamen te, de modo que o sistema seja testado em diferentes instantes no decorrer da reação. O resultado è uma curva de intensidade do sinal de certo Ion em função do tempo de reação, ou seja, uma curva cinētica. Conhecidas as reações nas quais o ion intervém, a curva pode ser analisada diretamente com auxilio das equações cinēticas. Por exemplo, se um lon primärio reage sem ser formado por algum outro processo, um gráfico do logaritmo da inténsidade do sinal, medida diretamente na curva registrada, em função do tempo de reação, isto è, do atraso do pulso de deteç̧ão em re lação ao de formação, dá uma reta cujo coeficiente angular è Igual ao produto da constante de velocidade de desaparecimento do Ion primário pela pressão de molēculas neutras na cela. Então constantes de velocidade de reação podem ser calculadas sem as equações que descrevem o movimento dos Ions na cela, se bem que a equação 2.33. seja usada implicitamente. 
A cela de aprisionamento, operada de forma pulsada, re solve o problema do tempo de reação. As ünicas aproximações fei tas são devidas à duração finita dos pulsos de formação e detecção, isto é, os íons não são formados e detectados instantaneamente. Isto pode no entanto ser levado em conta, mas de qualquer maneira os erros não são sērios, pois os pulsos são tipicamente de 1 e $3 \mathrm{~ms}$, o que è desprezível, comparado com um tempo de reação de $100 \mathrm{~ms}$.

Foram medidas constantes de velocidade de uma sērie de reações, tanto de ions positivos, como de negativos, $3,52,53$ e nos casos em que comparações são possiveis, hã concoraâncla muito boa com outras técnicas. Geralmente é possivel testar se os resultados são consistentes. Por exemplo, se um Ion primārio dá um ion secundārio, seguindo o decaimento do ion primārio e a for mação do secundārio, as constantes obtidas a partir das duas cur vas têm que ser iguais. Ultimamente esta técnica despertou intẹ resse no estudo de equilibrios, -o que permite a obtenção de gran dezas termodinâmicas (vide capitulo 5).58-62 Neste tipo de expé riência faz-se na realidade apenas uso da capacidade de aprisionamento da cela por tempos muito longos, de modo que, apesar de a pressão ser muito balxa, condições de equilíbrio sejam alcança das. Quando as intensidades dos sinais dos Ions em questão se tornam constantes com o tempo, elas são medidas e, em conjunto com as pressões das moléculas neutras, fornecem diretamente cons tantes de equilibrio.

A ressonância ciclotrônica de lons pulsada é menos sen sível que a contínua, o que è inerente à técnica, pois o sinal só aparece durante um período muito curto do ciclo total. Com o mesmo empenho na tentativa de aumentar a relação sinal/ruido, a operação pulsada sempre ficará perdendo para a continua. Por-1sso 
é desejāivel poder operar o espectrômetro das duas maneiras. Primeiro estuda-se o sistema com a cela de três regiões, para identificar todos os reagentes e produtos; depois fazem-se as medidas quantitativas com a cela de aprisionamento. Isto é o ideal, mas requer a troca frequente das celas, para o que è necessá rio quebrar o vācuo. Beauchamp ${ }^{63}$ consegulu construir uma cela que pode ser operada das duas formas; trata-se de uma cela de três regiões, na qual os Ions são formados e aprisionados na região fonte por meio de potenclais convenientes nas diversas placas da cela; depois de os ions terem reagido livremente por al gum tempo, todos os potenciais são pulsados de maneira que a cela funcione como uma cela de arraște normal, sendo a deteç̧ão feí ta na região analisadora. A conveniência deste método de trabatho alnda não estã assegurada.

Para concluir, pode-se dizer que a cela de áprisionamen to é út1l para medidas quantitativas, não o sendo tanto para estú dos qualitativos, devido à dificuldade de detectar sinais fracos. Obviamente não resolve o problema da pressão. 


\section{REAÇÕES ENTRE IONS E MOLECULAS}

Nas seções 2.3.5. e 2.4.3. foram discutidas as maneiras de obter constantes de velocidade de reação por espectroscopia de ressonância ciclotrônicá de ions. Apesar da escala em que as experiências são realizadas, as constantes de velocidade obtidas são na realidade grandezas macroscópicas. Para alcançar uma compre ensão mais profunda dos fenômenos que ocorrem nas reações entre ions e moléculas em fase gasosa, seria interessante poder reprodụ zir essas constantes de velocidade de reação através de cálculos baseados em principios físicos bem estabelecidos. E então necessārio descrever a reação ao nivel microscópico. Para isso é precịso conhecer inicialmente as forças que atuam entre as partícu las reagentes (forças entre lons e moléculas), com o que é possî vel calcular a energia potencial do sistema em função da distância entre as particulas. As equações de movimento apropriadas podem então ser resolvidas para dada energia (translacionàl e intér na) dos reagentes. A reação pode ser definida em termos de traje tórlas das partículas e assim uma seção de choque de colisão pode ser deduzida. Se for calculada uma seção de choque média para par tículas com certa distribuição de energia, efetua-se desta maneira a conexão entre as descrições microscóplca e macroscópica do processo. 64

Serão apresentados neste capĩtulo os modelos teōricos mais importantes para a descrição de reações entre Ions e moléculas em fase gasosa. Os resultados da seção 3.2 .1 . serão utilizados na seção 4.5. para comparar resultados experimentais e teöricos. A discussão da seção 3.2.2.1. permitiră sugerir um modelo cinētico na seção $4 \cdot 6 \cdot 3$. 


\subsection{Reações em fase gasosa}

o processo conhecido industrialmente como alquilação, no qual se aprovelta a fração $C_{4}$ proveniente das operações de craqueamento do petróleo, consiste em adicionar butenos e isobutano em presença de ácido sulfúrico concentrado, para sintetizar ọc tanos altamente ramificados. Um ion de carbônio terciobutilico é formado a partir do buteno e se adiciona a outra molécula de bute no, fornecendo um dimero iôntco, o qual abstrai hidreto de isobutano, regenerando o Ion de carbônio terciobutillico, ${ }^{65}$ sendo assim obtido 2,2,4-trimetilpentano. Os intermediários iônicos presentes nessa reação, cujo interesse prático é grande, não são nor malmente observados, pois sua existência è muito breve, uma vez que rapidamente colidem com molèculas neutras, reagindo, devido à densidade do sistema. Fol possivel preparar fons de vida longa em sistemas altamente ácidos (e, portanto de baixa nucleofilicida de) e consequentemente sua estrutura pôde ser estabelecida por métodos espectroscópicos. 66 Um outro método de estudar ions é fazê-1o em fase gasosa, a pressões baixas, onde a velocidade de reação dos Ions è menor, justamente devido à pressão balxa. Os parâmetros reacionals obtidos permitem uma explicação da quimica dessas espēcles em sistemas complexos. 67

Ions são intermediārios bastante comuns e reações entre ions e moléculas precisam ser consideradas em qualquer sistema em que Ions são formados, pols as constantes de velocidade dessas reações são multo grandes, devıdo à forte interação carga - dipolo Induzido, que aproxima Ion e molécula. Porēm, em solução as reações são mais lentas, pois são l1mitadas por difusão. Por exemplo, comparando uma reação de transferêncla de próton em solü ção aquosa, ${ }^{68}$ representada de maneira simplificada por 
$\mathrm{H}^{+}+\mathrm{NH}_{3} \rightarrow \mathrm{NH}_{4}^{+} \quad \mathrm{k}=4,3 \cdot 10^{10} 1 \cdot \mathrm{mol}^{-1} \cdot \mathrm{s}^{-1}$

com uma reução típlca em fase gasosa, 69

$\mathrm{CH}_{4}{ }^{+}+\mathrm{CH}_{4}+\mathrm{CH}_{5}^{+}+\mathrm{CH}_{3} \quad \mathrm{k}=7,2 \cdot 10^{11} 1 . \mathrm{mol}^{-1} \cdot \mathrm{s}^{-1}$

ou, expressando o $\underline{k}$ nas unidades comumente usadas neste caso,

$$
k=1,2 \cdot 10^{-9} \mathrm{~cm}^{3} \cdot \text { molécula } a^{-1} \cdot \mathrm{s}^{-1}
$$

verifica-se que a constante de velocidade da segunda é uma ordem de grandeza maior que a da primeira.

A existência de Ions gasosos é conhecida desde o fim do século XIX por causa da condutividade elétrica de chamas e de gases submetidos a descargas elétricas ou radiação de alta energia. Em 1905 Langevin estudou do ponto de vista teórico a interação de uma partícula pontual carregada com uma particula neutra polarizável, em fase gasosa, e deduziu expressões que dão as trajetórias dos reagentes em certas reações de íns com moléculas. Em 1925 Hogness e Lunn explicaram o Ion de razão massa/ carga 1gual a 3 (observado por Thomson em 1912 ao introduzir h1 drogênio em seu aparelho de raios catódicos) como devido a reação

$\mathrm{H}_{2}^{+}+\mathrm{H}_{2} \rightarrow \mathrm{H}_{3}^{+}+\mathrm{H}$

Eyring, Hirshfelder e Taylor calcularam em 1936 uma constante de velocidade para essa reação por uma aproximação essencialmente clássica da teoria da velocidade absoluta das reaçōes. Porém, estudos experimentals sistemāticos, tendo como objetivo princi pal a investigação de reações entre Ions e moléculas, só começaram em 1952 com Tal'rose. 70,71

o Interesse por reações entre lons e moléculas vem do fato de ser essenclal um conhecimento das mesmas para a compreen 
são de fenômenos tais como quỉmica da radiação, física da alta aţ mosfera, chamas, espectroscopia de massa. Estas reações tambëm têm grande interesse físico-químico, na elucidação de problemas de cinética quimica, pois podem ser estudadas ao nível molecu lar, jã que se tem uma idéia do potenclal de interação dos reagentes.

Quando espécies iônicas reagem em solução, trata-se em geral de espécies solvatadas, o que não acontece na fase gasosa. Por 1sso reações e propriedades de compostos em solução diferem frequentemente até qualitativamente das correspondentes em fase gasosa. Um exemplo disso è a basicidade de aminas. Para a série de compostos $\mathrm{NH}_{3}, \mathrm{CH}_{3} \mathrm{NH}_{2},\left(\mathrm{CH}_{3}\right)_{2} \mathrm{NH},\left(\mathrm{CH}_{3}\right)_{3} \mathrm{~N}$, raclocinando em termos de efelto Indutivo, aumentando o número de substituintes met 1 la, deve aumentar a basicldade da amina. Porém, em solução aquo sa a ordem de basicidade observada é

$$
\left(\mathrm{CH}_{3}\right)_{2} \mathrm{NH}>\mathrm{CH}_{3} \mathrm{NH}_{2}>\left(\mathrm{CH}_{3}\right)_{3} \mathrm{~N}>\mathrm{NH}_{3}
$$

enquanto que em condlções de ausêncla de solvente, a ordem é

$$
\left(\mathrm{CH}_{3}\right)_{3} \mathrm{~N}>\left(\mathrm{CH}_{3}\right)_{2} \mathrm{NH}>\mathrm{CH}_{3} \mathrm{NH}_{2}>\mathrm{NH}_{3}
$$

concordando com a teoria. Portanto, para distinguir propriedades moleculares intrinsecas de efeltos de solvatação, experiên clas em fase gasosa são necessārias.67,72 A etapa seguinte é o estudo da reatividade de Ions solvatados por apenas uma ou algu mas poucas moléculas neutras na fase gasosa, ${ }^{73-75}$ chegando-se des sa maneira gradativamente a compreender o que ocorre nas fases condens adas .

3.2. Modelos para reações entre ions e molēculas em fase gasosa

A teorla formal de reações entre Ions e molēculas pode ser desenvolvida diretamente atravēs da mecânica quântica, mas 
sua aplicaçäo a processos específicos requer a introdução de aproximações arāsticas. ${ }^{76}$ Na realidade são usados sempre modelos clássicos ou semi-clássicos.

São descritos a seguir alguns modelos com diferentes graus de sofisticação para reações entre lons e moléculas. Esses modelos não são nécessáriamente alternativas para dada reação,mas em certos casos, complementares, pois alguns modelos dão mais ên fase à aproximação Inicial das partículas carregada e neutra, en quanto que outros consideram essencialmente a decomposição de um eventual complexo de col1são. As vezes a mesma reação é melhor descrita por um modelo a balxas energias translacionais dos rea gentes, e por outro, a altas energias.

\subsubsection{Modelo de polarização}

O modelo de polarização fol desenvolvido por Gioumousis e stevenson, 77 que deduziram uma expressão teórıca para a cons tante de velocldade de reações b1nārias, baseando-se no modelo de Langevin de Interação de uma carga pontual com uma particula neutra, polarizável, em repouso.

o momento dipolar Induzido numa particula de polarizabilidade $\underline{\alpha}$ por um campo elētrico $\underline{E}$ é

$\mu_{D}=\alpha E$

A energla de indução do momento dipolar é

$v_{1}=\frac{1}{2} \alpha E^{2}$

e a energia de interação do dipolo induzido com o campo elétrico è

$v_{2}=-\alpha E^{2}$ 
de modo que a energia potencial total é $V=v_{1}+v_{2}=-\frac{1}{2} \alpha E^{2}$

Se o campo elétrico è produzido por uma carga pontual, tem-se $V=-\frac{1}{2} \alpha \frac{e^{2}}{r}$

sendo e a carga e $\underline{r}$ a distância da carga ao dipolo.

As trajetōrias clássicas de espalhamento de un ion por uma molécula num potenclal desse tipo são determinadas por dois parâmetros: a velocidade inicial $v_{1}$ do ion incidente de mas sa $m_{1}$ e o parâmetro de impacto $\underline{b}$. Quando $\underline{b}$ è grande, o lon é pouco desviado de sua trajetōrla infcial; existe um valor criti $c o b_{c}$ que faz o Ion entrar numa órbita de raio $r_{c}$ ao redor da mo lécula; quando o parâmetro de impacto é menor que $b_{c}$, o Ion apro xima-se da molēcula atē que forças repulsivas entre as camadas eletrônicas das particulas façam com que se afaste novamente ou, no caso de ocorrer uma reação quimica,haja separação dos produtos.

E conveniente descrever a col1são em termos de coordenadas do centro de massa. ${ }^{78}$ Consıdere-se a col1são entre um ion de massa $m_{1}$ e velocidade $v_{1}$ com uma molécula de massa $m_{2}$ em repouso, no sistema de coordenadas do laboratōx1o. Por conservação de quantidade de movimento, tem-se que o centro de massa se desloca na mesma direção que o lon, com velocldade $v_{c}=\frac{m_{1}}{m_{1}+m_{2}} v_{1}$

No sistema de coordenadas do centro de massa o Ion tem velocidade $v_{1}-v_{c} e$ a molécula neutra, velocidade $v_{c} \cdot A$ energía cinêtica no sistema de coordenadas do laboratórto é $E_{1}=\frac{1}{2} m_{1} v_{1}^{2}$ 


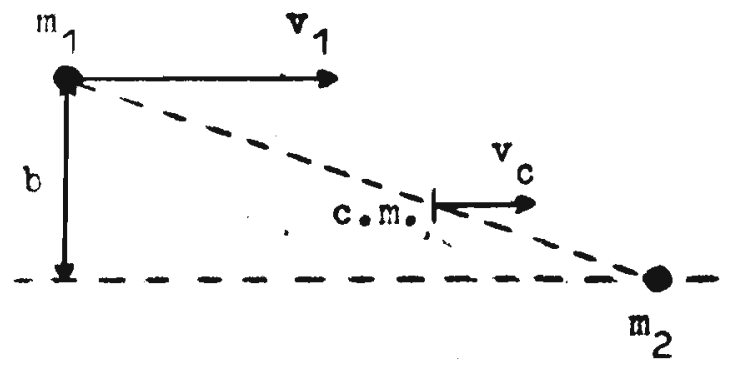

FIGURA 3.1. Colisão de duas partículas nos sistemas de coordenadas do

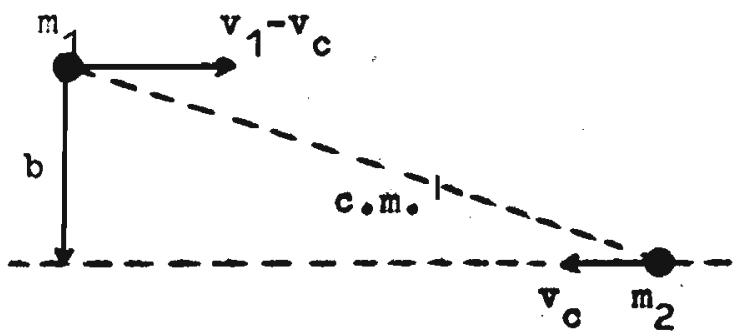
laboratório do centro de massa.

se $\mathrm{m}_{2}$ está em repouso. No sistema de coordenadas do centro de massa:

$E_{r}=E_{1} \frac{m_{2}}{m_{1}+\dot{m_{2}}}=\frac{1}{2} \mu v_{1}^{2}$

sendo $\mu$ a massa reduzida do sistema. $E_{r}$ é a energia total do sistema, e è conservada; frequentemente è chamada de energia cinētlca relativa do sistema a separação Infinita.

Durante a colisão as duas particulas são aceleradas devido à energia potencial $\underline{V}$, dada pela equação 3.1 . A soma das energias potenctal e cinëtica é constante durante a colisão: $E_{r}=V+E_{\text {cin }}$

Quando $\underline{r}$ é grande, $E_{r}=E_{c i n}$. O vetor velocldade pode ser decomposto numa componente na direção do centro de massa (componen te translacional) e numa componente perpendicular a essa dire- 
çäo (componente rotacional). Logo, pode-se escrever:

$E_{r}=V+E_{\text {rot }}+E_{\text {trans }}$

A energia rotacional no sistema de coordenadas do centro de massa $\overline{\mathrm{e}}$

$E_{\text {rot }}=\frac{L^{2}}{2 \mu r^{2}}$

onde $L$ é o momento angular.

$L=\mu v_{1} b$

Substituindo 3.2. e 3.5. em 3.4.:

$E_{\text {rot }}=E_{r} \cdot \frac{b^{2}}{r^{2}}$

Substituindo 3.1. e 3.6. em 3.3.:

$E_{r}=-\frac{a e^{2}}{2 r^{4}}+E_{r} \cdot \frac{b^{2}}{r^{2}}+E_{t r a n s}$

A soma das energlas potencial e rotacional è chamada "potenclal e fetivo".

$E_{e f}=-\frac{a e^{2}}{2 r^{4}}+E_{r} \cdot \frac{b^{2}}{r^{2}}$

Então

$\dot{E}_{r}=E_{\text {ef }}+E_{\text {trans }}$

O gräfico de $E_{\text {ef }}$ em função de I mostra um mãximo que representa uma barreira de potencial. A distância critica $r_{c}$ na qual $E_{e f} e ́$ máximo e o valor de $E_{\text {ef }}$ māximo, Eef,c' são obtidos da equação 3.7. fazendo $d E_{e f} / d r=0$.

$r_{c}=\frac{e}{b}\left(\frac{a}{E_{r}}\right)^{\frac{1}{2}}$

$E_{e f, c}=\frac{b^{4} E_{r}^{2}}{2 a e^{2}}$ 
As particulas podem vencer a barreira se tiverem energia maior que $E_{e f, c}$

Se $E_{r}=E_{e f, c}$ quando $r=r_{c^{\prime}} E_{\text {trans }}=0$ (equação 3.8.), ou seja, a componente da velocidade na direção do centro de massa é zero e o ion entra em órbita de raio $r_{c}$ ao redor da molécula. Lo go, a partir de 3.10.:

$b_{c}^{2}=e\left(\frac{2 a}{E_{r}}\right)^{\frac{1}{2}}$

sendo $b_{c} \circ$ parâmetro de impacto crítico que faz com que o ion entre em örbita, e que se relaciona com o raio crítico através de

$r_{c}=\frac{b_{c}}{\sqrt{2}}$

- que se obtēm, substituindo 3.11 . em 3.9 .

A seção de choque para eventos que ponham o lon em örbita ao redor da molécula ou o façam colidir com a mesma é

$$
\begin{aligned}
0 & =\pi b_{c}^{2} \\
& =\pi e\left(\frac{2 \alpha}{E_{r}}\right)^{\frac{1}{2}} \\
& =\frac{2 \pi e}{v_{1}}\left(\frac{a}{\mu}\right)^{\frac{1}{2}}
\end{aligned}
$$

Se ocorrer uma reação química sempre que ion e molécula se apro ximarem até uma distâncla lgual: a, ou menor do que, $r_{c}$ a seção de choque de reação será dada por 3.13 . e a constante de vé locidade de reação será

$k=\alpha v_{1}=2 \pi e\left(\frac{\alpha}{\mu}\right)^{\frac{1}{2}}$

independente da energla translacional do ion. 
Este formalismo desenvolvido por Gioumousis e Steven son não implica na formação de complexos (entidades que persis tem por tempo longo comparado com os movimentos rotacional e vibracional); considera apenas trajetórlas de Ions que vencem a barreira do potencial efetivo e que portanto atingem a parede re pulsiva. ${ }^{69}$ Se a reflexão nesta parede repulsiva for completamente elāstica, as partículas voltam por sobre a barrelra, resul tando estas colisões em espalhamento elástico. Se a refle xão for inelāstica, havendo conversão de energia cinética em energia interna, os reagentes que se separam podem ter energia translacional insuficiente para atravessar a barreira, sendo então mantidos temporariamente no poço do potencial radial, formando um complexo; eventualmente suficiente energia interna è convertida novamente em energia cinētica, podendo as particulas atravessar a barreira; tais colisōes resultam em espalhamento 1nelāstı́co.

Em seu trabalho original 77 Gioumousis e Stevenson com pararam as constantes de velocidade experimentais de uma série de reaçōes com as calculadas pela equação 3.14 . tendo encon trado concordância bastante boa em muitos casos. Na referência 67 há uma lista de constantes de velocidade, na qual se observa uma concordância excepcional de valores experimentais com teōri cos. As espécles reagentes são no entanto muito simples; os Ions são, por exemplo, $\mathrm{Ar}^{+}, \mathrm{H}_{2}{ }^{+}, \mathrm{N}_{2}{ }^{+}$, etc. Porém, quando, espécles mais complexas reagem, é frequentemente necessár1o multi plicar o membro direito da equação 3.14. por um fator de probab1 lidade, pelo mottvo de não ocorrer uma reação química em cada co lisão dos reagentes. Além disso são possiveis reaçōes competití vas; os modelos estatisticos (seção 3.2.2.) tratam das probabili dades relativas de fragmentação de um complexo. Quando o reagen 
te é diatômico ou poliatômico, sua polarizabilidade não è um escalar, mas uma grandeza tensorial, o que causa anisotropia no po tencial 3.1; em geral, usando uma polarizabilidade média na equa Ção, ela fornece resultados bons. 71 Verificou-se experimentalmente que em principio a teoria só é aplicável a reações que ocorrem a energias térmicas. 76

Se o reagente neutro possui um momento dipolar permanente, a interação entre o ion e o dipolo faz com que a seção de choque de colisão se torne maior que a dada pela equação 3.12 . o potencial de interação Ion - dipolo pode ser acrescentado à expressão 3.1. :

$V=-\frac{\alpha e^{2}}{2 r^{4}}-\frac{\mu_{D} e \cos \theta}{r^{2}}$

sendo $\mu_{D} \circ$ momento dipolar da molécula neutra e $\underline{\theta}$ o ângulo entre - dipolo e a linha que une os centros de colisão. Em primeira aproximação pode-se supor que o dipolo esteja orientado na posi ção de energía mintma, 1 sto $e \dot{e}$, alinhado na direção do ion. 79 En tão, $\theta=0$. o potencial efetivo, equação 3.7., fica:

$E_{e f}=-\frac{a e^{2}}{2 r^{4}}-\frac{\mu_{D} e}{r^{2}}+E_{r} \cdot \frac{b^{2}}{r^{2}}$

Para o ralo crítico, o potencial efetivo critico e o parâmetro de impacto critico, tem-se:

$$
\begin{aligned}
& r_{c}^{2}=\frac{\alpha e^{2}}{E_{r} b^{2}-\mu_{D} e} \\
& E_{e f, c}=\frac{\left(E_{r} b^{2}-\mu_{D} e\right)^{2}}{2 \alpha e^{2}} \\
& b_{c}^{2}=\frac{\mu_{D}}{E_{r}}+\left(\frac{2 \alpha e^{2}}{E_{r}}\right)^{\frac{1}{2}}
\end{aligned}
$$


A seção rlo choque é

$\sigma=\pi e\left[\frac{{ }^{\prime} D}{E_{r}}+\left(\frac{2 \alpha}{E_{r}}\right)^{\frac{1}{2}}\right]$

Esta expressão dā geralmente resultados muito maiores que os encontrados experiméntalmente, pois um alinhamento total do dipolo na direção do ỉon não ocorre, devido à energia rotacional térmica das molēculas. Foram feitos cālculos quânticos e numéricos de trajetórias, levando em conta o movimento rotacional da molēcu la dipolar, perturbado pelo campo elétrico do ion. ${ }^{79} \mathrm{Em}$ outra teoria $^{80}$ parte-se da equaçāo 3.15 . e calcula-se um ângulo de orientação médio, $\bar{\theta}$, entre o dipolo e a linha dos centros de colisão, dependente de $\underline{r}$, a distância entre ion e dipolo.

$\vec{\theta}=\frac{\int \theta P(\theta) d \theta}{\int P(\theta) d \theta}$

$P(\theta)$ è a probabilidade de 0 dipolo estar numa orientação $\underline{\theta}$, inversamente proporcional ã velocidade angular do dipolo no plano de colisăo e diretamente proporcional ao nümero de orientaçöes equivalentes do dipolo. Esta teoria foi parametrizada, 81 quando se verificou que na equaçäo 3.16. o momento dipolar pode ser multiplicado por uma constante, que varia entre 0 e 1 , e que corrige a seção de choque pela extensão do alinhamento do dipolo na direção do Ion; o valor dessa constante, como pode ser deduzido, 81 de pende só da relação entre o momento dipolar e a raỉz quadrada da polarizabilidade da molēcula; na referência 81 é dado um gráfico da constante em funçäo de $\mu_{\mathrm{D}} / \alpha^{1 / 2}$ e dessa maneira a teoria é tão fácil de aplicar como a equaçāo 3.16 .

O modelo de Gioumousis e stevenson fornece uma constante de velocidade de reaçäo independente da energia translacional 
do Ion reagente. Levando em conta o momento dipolar da molécula, chega-se a uma constante de velocidade de reação que è função de energia translacional. Na experiência de ressonância ciclotrônica de ions dupla (seção 2.3.4.2.) aproveita-se essa dependência de energia translacional das constantes de velocidade de reação.

\subsubsection{Modelos estatisticos}

o principal nesses modelos é a separação da colisão em dois estágios: a formação e o subsequente decaimento de um inter mediário. A velocidade da reação é então o produto da velocidade de formação do Intermediārio e a probabilidade da transi ção entre o intermediário e os estados finais. A probabilidade de transição pode ser calculada pela teoria das reações unimoleculares ou por argumentos de espaço de fase.

A principal utilidade dos modelos não é no cálculo de constantes de velocidade absolutas; sua força reside no cálculo de relações entre constantes de velocidade de reações paralelas.

\subsubsection{Teoria do quase-equilibrio}

O tratamento de reações entre Ions e moléculas em ter mos do potencial Ion-dipolo induzido não dã nenhuma informa ção sobre a probabilidade relativa de diferentes caminhos de rea ção ou sobre a natureza de um eventual complexo de reação. Entretanto, se o complexo de reação existir pelo menos por vários períodos vibraclonais, as velocidades das vārias dissociações poṣ siveis podem ser calculadas da mesma maneira como nos espectros de massa. De fato, há semelhança entre o espectro dos produtos 
iônicos obtidos por exemplo na reação entre $\mathrm{C}_{2} \mathrm{H}_{4}{ }^{+}$e $\mathrm{C}_{2} \mathrm{H}_{4}$ e os es ${ }^{-}$ pectros de massa de diversos butenos isomérlcos produzidos por im pacto eletrôntco. Tais observações levaram a sugerir que interme diárlos semelhantes devam ser formados nos dois sistemas. 0 sucesso da teoria do quase-equilíbrio para explicar espectros de massa comuns levoù à aṕlicação dessa teoria à fragmentação do intermediărio equivalente, produzido por reação.

A formação de um espectro de massa envolve a ruptura de ligações químicas no ion molecular e às vezes a criação de novas Iigações. Logo, os processos de fragmentação podem ser vistos como anālogos a reações quimicas comuns. Este fato levou à formulação da teoria do quase-equilíbrio, usada para descrever as caracteristicas gerais de espectros de massa.

As caracteristicas principais do modelo teórico são: ${ }^{82}$

1. Moléculas complexas podem ser representadas por uma coleção de osciladores harmônicos e rotores rígidos acoplados.

2. o processo de ionização inicial por impacto de elétrons obedece ao princípio de Franck-Condon. Consequentemente só transições verticais são permitıdas, delxando geralmente o ion molecular num estado excitado.

3. O Ion molecular excitado não sofre decomposição ime diata. Conversão interna na molécula faz com que o excesso de energia fique distribuido ao acaso em todos os graus de liberdade internos acessivels da molécula.

4. O espectro de massa é formado por uma série de dẹ composições unimoleculares competitivas e consecutıvas do ion molecular excitado.

5. A constante de velocidade para cada uma dessas reações espontâneas pode ser calculada por melo de uma forma apropria 
da da teoria da velocidade absoluta das reações.

A teoria do quase-equilỉbrio é anāloga à teoria da decomposição unimolecular, à qual estão ligados os nomes de Lindemann, Hinshelwood, e Rice, Ramsperger, Kassel e Marcus e que também é conhecida por teoria RRKM.

Do ponto de vista cinético a sequência de eventos no es pectrômetro de massa pode ser descrita nos seguintes termos. ${ }^{83}$ Um conjunto de molēculas que não interagem è lonizado e excitado por impacto de elétrons (ou de fótons ou Ions). Todos os estados quânticos acessivels dos Ions excitados ficam populados. Entretanto, hã uma diferença importante entre decomposições unimolecu lares que ocorrem no espectrômetro de massa e aquelas tratadas em cinētica química comum. Neste ültimo caso condições de equílí brio prevalecem por causa do elevado número de colisões entre moléculas, de modo que o sistema pode ser caracterizado por uma tem peratura e a distribuição de energia num conjunto de molēculas po de ser descrita em termos da distribuição de Maxwell-Boltzmann.Por outro lado, no espectrômetro de massa a pressão è muito baixa e o número de colı̣sões é insigniflcante;cada Ion é formado com certa guantidade de energla interna,sendo que esta é conservada indepen dentemente para cada ion, que se comporta como um sistema ișolado. 84 Certa fraçäo dos estados quânticos corresponde a assim chamados complexos ativados. o postulado de equilibrio permite admitir que a fração de Ions que são complexos atıvados è sempre igual à fração de estados quânticos que representam estados de complexo atıvado. A velocidade de decomposição dos lons é então dada pela concentração (ou fração) de complexos ativados, multiplica da pela velocidade média com a qual os complexos ativados atravessam a barreira de potencial. Conhecida esta velocidade de decomposição, a extensão da fragmentação è determinada pelo tempo 
de permanência do ion na fonte; tipicamente esse tempo è da ordem de 1 rs.

o comportamento do sistema isolado (íon molecular) è descrito em termos de um ensemble microcanônico. O sistema tem certo número de estados quânticos no intervalo de energia $\mathrm{E}$ e $E+d E$ e uma fração desses estados se refere ao complexo ativado. Este é definido como uma espécie molecular com um de seus graus de liberdade internos convertido numa translação interna ao longo da coordenada de reação. Esta tem uma barreira de energia potencial, correspondente à energia de ativação, E。 Conside ra-se que num grande número de sistemas, no intervalo de energia dado, a distribuição de estados quânticos seja a mesma, pelo fato de transições internas entre todos os estados quânticos serem rápidas, de modo que as reações de decomposição não perturbem apreciavelmente a distribuição. ${ }^{85}$ A fração de sistemas em estados ativados é tomada simplesmente como a razão entre o nümero de tais estados e o número total de estados.

Num sistema com grande nümero de graus de liberdade 0 nümero de estados com energia entre $E$ e $E+d E$ é grande e sua dis tribuição pode ser representada por uma função de densidade $\rho(E) d E$, que tem dimensões de nümero de estados por unidade de energia. Os estados correspondentes ao complexo ativado podem ser defini dos como aqueles com energia total entre $E$ e E + dE, com energia potencial $E_{0^{\prime}}$ e com energla cinética $E_{t}$ localizada na coordenada de reação. A distribuição de estados de complexo ativado pode ser representada por uma função de densidade total $\rho_{\text {tot }}^{\ddagger}$ (E, E。' $\left.E_{t}\right) d E$, mas é melhor escrever uma função de densidade separada, $D_{t}\left(E_{t}\right) d E_{t}$, para os estados com energia cinētica entre $E_{t} e E_{t}+d E_{t}$ na coordenada de reação. Então a função de densidade total para - complexo ativado é $\rho^{\ddagger}\left(E, E_{o}, E_{t}{ }^{i} \rho_{t}\left(E_{t}\right) d E d E_{t}\right.$. A fração de siste 
mas em estados ativados é dada pela razão das duas funções de densidade.

$N\left(E_{t}\right)=\frac{\rho^{+}\left(E, E_{O}, E_{t}\right) \rho_{t}\left(E_{t}\right) d E d E_{t}}{\rho(E) d E}$

A constante de velocidade, $k\left(E_{t}\right) d E_{t}$, de decomposição de comple xos ativados com energia cinética entre $E_{t}$ e $E_{t}+d E_{t}$ na coordena da de reação é dada pelo produto da fração de íons moleculares ativados e a frequência, $r\left(E_{t}\right)$, com a qual tals complexos ativa dos atravessam a barreira de potencial.

$k\left(E_{t}\right) d E_{t}=N\left(E_{t}\right) r\left(E_{t}\right)$

Esta frequência de cruzamento da barreira è

$r\left(E_{t}\right)=\frac{v_{t}}{2 l}$

onde $v_{t}$ é a velocldade ao longo da coordenada de reação,

$v_{t}=\left(\frac{2 E_{t}}{\mu}\right)^{\frac{1}{2}}$

( $\mu$ é a massa reduzida do sistema) e $\ell \underline{e}$ o comprimento do topo da barreira, considerado como uma caixa unidimensional: ${ }^{1} \underline{\ell}$ não precisa ser especificado, pois é cancelado. o fator $1 / 2$ vem do fato de sō metade dos complexos ativados passarem a barreira na direção correspondente a reação. A energia de uma partícula numa caixa unidimensional de comprimento $\underline{\ell}$ è

$E_{t}=\frac{n^{2} h^{2}}{8 \mu \ell^{2}}$

Logo, 82

$\rho_{t}\left(E_{t}\right)=\frac{d n}{d E_{t}}$

$$
=\frac{\ell}{h}\left(\frac{2 \mu}{E_{t}}\right)^{\frac{1}{2}}
$$


Um sistema com energia total E pode ter qualquer energia translacional $E_{t}$, desde zero até o valor máximo disponível no complexo ativado, $E-E_{0}$. Substituindo $3.17 ., 3.19 .3 .20$ e e 3.21. em 3.18. e integrando sobre todos os valores possiveis da energia translacional, obtēm-se a constante de velocidade total.

$$
k=\frac{1}{h} \int_{0}^{E-E_{0}} \frac{\rho^{+}\left(E, E_{0}, E_{t}\right)}{\rho(E)} d E_{t}
$$

Esta expressão é geral e expressões específicas para as duas funções de densidade precisam ser desenvolvidas. Como muito pouco é conhecido a respeito de funçōes de densidade de es tados eletrônicos de ions, è necessārio supor que estas funções de dado íon e dado complexo ativado formado cancelem na equação integrada e apenas osciladores harmônicos fracamente aco plados são considerados ao escrever as funções de densidade de estado. 85 Entretanto, em vez de deduzir expressōes para essas funções é mais fácil na prática fazê-lo para W(E), o número total de estados de um sistema com energia menor do que, ou igual a, E. A função de densidade de estados é então

$\rho(E)=\frac{d W(E)}{d E}$

e a constante de velocidade de reação, 82,86

$k=\frac{1}{h}\left[\frac{W^{\dagger}\left(E, E_{O}\right)}{d W(E) / d E}\right]$

onde $\mathrm{W}^{\ddagger}\left(E, E_{O}\right)$ é o número de estados do complexo ativado com ener gia não excedendo $E-E_{0} \cdot$ Para $\underline{M}$ ou menos quanta em Nㅡ oscilado res idênticos a solução exata para o nümero de estados com enex gia que não exceda $\underline{E}$ è 
$W(E)=\frac{(N+M) !}{N ! M !}$

É impraticāvel generalizar essa expressão para $\mathbf{N}$ osciladores arbitrários. Em geral, os osciladores de frequências menores tenderão a ser multiplamente excitados, 87 por causa do maior número de estados possiveis, enquanto que os de frequências maiores ten derão a ser não excitados. Assim pode-se obter : 87

$W(E)=\sum_{\mathrm{P}=0}^{\mathrm{M}}\left({ }_{\mathrm{P}}^{N}\right) \frac{1}{\mathrm{P} !}\left[\frac{\sigma_{\mathrm{P}} E}{h \tilde{v}}-\frac{\mathrm{P}-1}{2}\right]^{\mathrm{P}}$

onde $\underline{P}$ é o número de osciladores excitados; $\underline{N}, 0$ número tota 1 de osciladores; $\tilde{v}$ é a média geométrica das frequênclas $v_{1}$ dos osciladores e $\sigma_{P}$ é a média aritmética de termos $\tilde{v} / v_{1}$ elevada a $1 / P$; a sērie termina $\operatorname{com} M=N$ ou com o ültimo termo positivo, dependendo do que acontecer antes.

As frequências vibracionais do ion molecular e do complexo ativado não são conhecidas e precisam ser estimadas a partir de dados de moléculas neutras. Muitas vezes estas frequên clas foram empregadas como parâmetros ajustáveis, tornando uma concordància com resultados experimentais pouco significativa.

Não é făcil obter a energia total E de un Ion molecu lar; por isso prefere-se calcular constantes de velocidade em função de $\underline{E}$.

A energia de ativação $E_{0}$ pode ser obtida de potenciais de ionização e de aparecimento. o potencial de aparecimento de $\mathrm{A}^{+}$a partir da molécula $\mathrm{AB}$ pode ser tomado como a energia da rea ção

$\mathrm{AB}+\mathrm{e}^{-} \rightarrow \mathrm{A}^{+}+\mathrm{B}+2 \mathrm{e}^{-}$

e o potencial de ionização de $A B$ pode ser tomado como o calor da 
reação

$\mathrm{AB}+\mathrm{e} \rightarrow \mathrm{AB}^{+}+2 \mathrm{e}^{-}$

A diferença entre essas duas quantidades é a energia de ativação para a reação de interesse:

$\mathrm{AB}+\mathrm{A}^{+}+\mathrm{B}$

Este mētodo porēm não é exato, pois potenciais de aparecimento não são bem conhecidos, devido ao "deslocamento cinétíco" (è necessário fornecer um excesso de energia para a reação 3.23. para haver fragmentação ainda na fonte $e \circ$ ion $A^{+}$ser detectado). 88

Para obter concordância com resultados experimentais, frequentemente o número de graus de liberdade vibracionais usado nos cálculos foi menor que $3 \mathrm{~N}-6$ (N, número de átomos no íon). Foi verificado que a falha na teoria é devida a uma aproximação matemática, 83 a saber, a substituição de uma somatóría por uma integral, na dedução da expressão 3.22. O erro é tal que equiva le a uma redução no número efetivo de osciladores.

No caso de fragmentações consecutivas, supōe-se que a teoria do quase-equilíbrio também seja aplicável aos intermediārios. Conhecendo todas as constantes de velocidade de decom posição e o tempo de permanência dos Ions na fonte do espectrôme tro de massa, obtëm-se a extensão da fragmentação, ou seja, o es pectro de massa. o problema que surge é o de determinar a energía dos fragmentos iônicos excitados que ainda sofrem decomposi ção posterior. Intcialmente supôs-se que na decomposição de um Ion toda a energia interna do mesmo, a menos de uma quantidạ de Igual à energia de atıvação do processo, fosse distribuỉa en tre o fragmento ionico e o fragmento neutro; portanto, a ener gia seria distribuída na razão do nümero de graus de liberdade internos dos dols fragmentos. Mas veriflcou-se que, quando um 
ion dissocia, a fraçāo de energia que o fragmento iônico recebe não é única, mas mostra uma distribuição. Isto é chamado de efeito de flutuação e é devido à estatística de números pequenos. Isto leva a uma incerteza no potencial de aparecimento do fragmento. 71

A ocorrência de reações entre ions e moléculas pode ser descrita em termos da teoria do quase-equilibrio como segue: 86 Um ion $A^{+}$e um neutro $B$ aproximam-se até que a distância que os separa seja menor que uma distância crîtica, onde forças químicas tornam-se dominantes, resultando na formação de um comple xo de reação $\mathrm{C}^{+}$. A interação de $\mathrm{A}^{+} \operatorname{com} \mathrm{B}$ não precisa ser obrigatoriamente descrita por algum potencial do tipo Ion-dipolo induzido; isto é irrelevante; a teoria trata somente do comporta mento do complexo de reação $\mathrm{C}^{+}$, independentemente de sua formação. O complexo de reação não é formado no seu estado fundamen tal, mas contēm uma quantidade de energia interna

$E=\Delta H_{f}\left(A^{+}\right)+\Delta H_{f}(B)-\Delta H_{f}\left(C^{+}\right)+\frac{1}{2} \mu v^{2}+E_{i n t}$ onde $\Delta H_{f}(X)$ é o calor de formação da espécie $\underline{X} ; \underline{\mu}$ e $\underline{v}$ são massa reduzida e velocidade relativa de $A^{+}$e $B ;$ e $E_{i n t}$ é a energia de excitação interna, se houver, de $A^{+}$ou $B$. A reação se dá pela formação de uma configuração de complexo atıvado, $\left[c^{+}\right]^{\dagger}$, a par tir do complexo de reação. A energia de atıvação para a decompo sição de $\mathrm{c}^{+}$é $E_{o}=\Delta H_{f}\left(\left[C^{+}\right]^{\ddagger}\right)-\Delta H_{f}\left(C^{+}\right)$

o complexo ativado decompõe então em produtos ou volta à configu ração de complexo de reação.

Se os fragmentos iônicos não sofrem decomposição postẹ rior, as quantidades relativas dos mesmos são proporcionals às 
velocidades de formação, independentemente da escala de tempo da experiência.

o cálculo de distribuições de produtos de reações entre ions e moléculas é fácil, mas requer quantidade substancial de informação sobre os reagentes, os produtos e o complexo de reação: 1. uma estrutura, que precisa ser postulada, para o com plexo de reação; 2. os calores de formação dos reagentes iônico e neutro, dos produtos iônicos e neutros, e do complexo de reação: 3. as frequências vibracionais para o complexo de reação e cada uma das configurações do complexo ativado. E razoāvel admitir que o complexo de reação seja a estrutura iônica mais estável com a fórmula correta. Os calores de formação das várias espécies envolvidas numa reação são em geral acessíveis. 89 Frequências vibracionais de ions são praticamente desconhecidas, de modo que as frequências vibracionals das moléculas neutras correspondentes precisam ser usadas. Esta aproximação resulta em erros nas velocidades de decomposição calculadas, mas aparentemente esses erros são cancelados ao tomar as razões das velocidades para obter distribuições relativas de produtos.

Para se ter realmente um teste da hipótese de equili brio, é necessārlo que os cálculos possam prever a distribuição de produtos para diferentes valores de $\underline{E}$. Experimentalmente a distribuição de produtos de reação precisa ser medida em função da energia dos ions reagentes, ou, precisa-se achar um siste ma em que um mesmo complexo de reação seja produzido a partir de diversos reagentes, de modo que possa ser obtido com energias internas diferentes. Este mëtodo fol usado 86 para estudar as reações em misturas de acetileno e etileno, sendo o complexo de reação, $\mathrm{C}_{4} \mathrm{H}_{6}^{+}$, tomado como butadieno-1,3. 


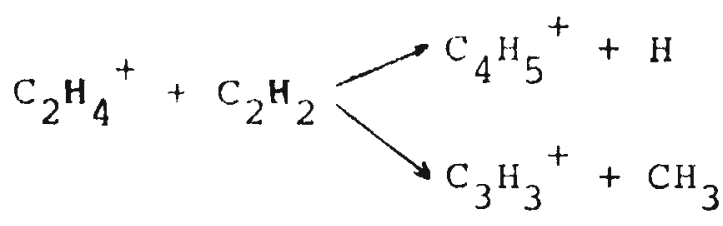

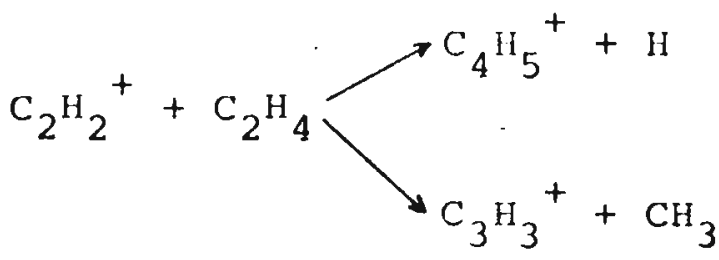

A concordância entre as distribuições de produtos experimental e calculada é excelente, constituinäo o trabalho ${ }^{86}$ um teste bastan te rigoroso da teoria do quase equilíbrio, uma vez que não foram usados parâmetros ajustáveis.

Deve-se esperar que para descrever reações de ions com. molēculas a teoria do quase-equilíbrio tenha o mesmo sucesso que para a descrição de espectros de massa. O problema é que a teoria requer muita informação a respeito dos intermediārios forma dos, e em muitas reações, como nas relatadas nesta tese, não exis tem moléculas neutras comparāveis que possam ser usadas como ponto de partịda para obter as frequênclas vibracionals dos complexos de reação. Por isso sempre se procurou aplicar a teoria a casos em que são formados intermediārios com estruturas bem semelhantes às de molēculas neutras. 90

\subsubsection{Teoria do espaco de fase}

Na teoria do espaço de fase calcula-se a seção de choque total de formação de um complexo de colisão, a qual é então dividida estatisticamente entre os vários produtos nos quais o complexo pode dissociar. 
Dífere a teoria de várias maneiras da do quase-ecuilíbrio. Em primeiro lugar, descreve a reação em termos de uma tran sição do sistema de um estado inicial para um estado final, bem definidos, enquanto que na teoria do quase-equilibrio o comporta mento os reagentes não é considerado. Em segundo lugar, na teo ria do espaço de fase é preciso fazer suposições apenas a respei to das condições que levam à formação de um complexo de colisão, mas não sobre sua vida ou configuração; por outro lado, na teoria do quase-equilíbrio o complexo de transição precisa ser tratado formalmente como molécula bem definida, tendo certa configu ração de equilíbrio não observãvel, e estados vibracionais conhe cidos, mas não observáveis. Ambas as teorias são na realidade a presentadas como hipóteses, mas a do espaço de fase pode ser mais facilmente testada por comparação com a experiência, pois na teoria do quase-equilíbrio poàe, em princípio, sempre ser usa do um estado de transição que dê concordância com a experiência.

A teoria do espaço de fase fol desenvolvida por Light ${ }^{91}$ para reações de troca bimolecular envolvendo somente três átomos.

$A+B C+A B+C$

A teoria é, porēm, mals geral, sendo apenas limitada pela comple xidade dos cálculos. E aplicāvel tanto a reações entre espécies neutras, como a reações entre ĩons e moléculas, variando apenas o potencial de interação dos reagentes.

Na teoria do espaço de fase define-se um complexo de "acoplamento forte" como uma entidade que, uma vez formada, não tem mals nenhuma relação com a maneira pela qual foi formada. Pa ra reações que se dão sem energia de ativação, postula-se: ${ }^{91}$ A probabilidade de formação de certo produto numa colisão de "acoplamento forte" è proporctonal à razão do espaço de fase disponi 
vel a esse produto e o espaço de fase total disponível, com conservação de energia e momento angular.

Chamando os estados possiveis do sistema de q, q', q",.. (por exemplo, $q \bar{e} A B+C$ ) com estados vibracionals $1_{q}{ }^{\prime}$ a suposição fundamental pode ser escrita:

$p\left(q^{\prime}, i_{q^{\prime}} \mid E, J\right)=\Gamma_{q^{\prime}}^{\prime}\left(E, J, i_{q^{\prime}}\right) / \sum_{x=q} \Sigma_{q^{\prime}, \ldots} \sum_{i_{x}} \Gamma_{x}\left(E, J, i_{x}\right)$ onde $P\left(q^{\prime}, i_{q^{\prime}} \mid E, J\right)$ é a probabilidade de formação do produto $q^{\prime}$ no estado $i_{q}{ }^{\prime}$, condicionado à formação de um complexo de energia E e momento angular J. $\Gamma_{x}\left(E, J, 1_{x}\right)$ è o espaço de fase diponi vel ao produto $\underline{\mathbf{x}}$ no estado vibracional $1_{\mathbf{x}}$, dados $\underline{\mathrm{E}} \mathbf{e} \underline{\mathbf{J}}, \mathbf{e} \Gamma_{\mathbf{X}}^{\prime}(E$, $J, i_{x}$ ) é a porção de $\Gamma_{x}$ correspondente a produto estável $\underline{x}$ (por exemplo, $\Gamma_{\mathbf{x}}^{\prime}$ exclui regiões de $\Gamma_{\mathbf{x}}$ nas quais o produto é instávei devido ao momento angular elevado). Se a seção de choque de formação do complexo de dado $\underline{E}$ e $\underline{J}$ a partir dos reagentes $q, i_{q}$ é $\sigma_{q}\left(E, J, 1_{q}\right)$, a seção de choque para a reação $q, 1_{q} \rightarrow q^{\prime}, 1_{q}{ }^{\prime}$ é $\sigma=\int \sigma_{q}\left(E, J, i_{q}\right) P\left(q^{\prime}, i_{q}, \mid E, J\right) d E d J$

A teoria na sua formulação original 91 não era interna mente consistente: a expressão deduzida para a seção de choque de reação não satisfazia o teorema de balanceamento detalhado. 92 Num trabalho publicado logo a seguir, 93 isto fol incluido, verifican do-se que o teorema impõe certas restrições ao espaço de fase dis ponivel aos produtos.

Define-se canal como uma região de espaço de configura ção no qual as partículas envolvidas numa reação estão em estados internos definidos, separados por distâncias grandes, de modo que sua interação seja desprezivel. 76 os números quânticos dos estados internos das particulas e o momento angular orbital de mo vimento relativo especificam um canal. 
Sejarn $q, q^{\prime}, q^{\prime \prime}, \ldots$ os canais possíveis da reaçăo 3.24 . No canal $q$ as partículas têm números quânticos dos estados internos dados por $\mathrm{s}_{\mathrm{q}}$; o número quântico do momento angular interno è $L_{q}$; o número quântico do momento angular orbital do movimento relativo é $\underline{L}$; a energia translacional relativa è $E_{q}$; e a massa redú zida è $\mu_{\mathrm{q}}$.

Intcialmente duas considerações devem ser feltas sobre um "complexo de acoplamento forte", sendo a primeira absolutamente necessāria, fundamental na teoria, e a segunda não simplifi cando, ou de fato possibilitando, porém, os cálculos. 94

(a) O modo de decomposição de um "complexo de acoplamen to forte" não tem correlação com o modo de formação, exceto latravês de leis de conservação de energia, momento linear e momento. angular total è sua projeção sobre um eixo.

(b) A probabilidade de formação de um "complexo de acoplamento forte" num canal q è ou unitärla ou nula, dependendo dos valores de $\mathbf{s}_{q^{\prime}} L_{q^{\prime}}$ I e $E_{q^{\prime}}$

$P_{\text {form }}= \begin{cases}I & L<L_{\max }\left(s_{q^{\prime}} L_{q^{\prime}} E_{q}{ }^{\prime}\right. \\ 0 & L>L_{\max }\left(s_{q^{\prime}}, L_{q^{\prime}} E_{q}\right)\end{cases}$

Is to vem do fato de que, falando classicamente, o sistema deve pas sar sobre a barreira de momento angular no potenclal efetivo, para àada energla; hã, portanto, um momento angular orbital māximo que alnda provoca espalhamento. O valor desse $I_{\max }$ é geralmente tomado como o apropriado ao modelo de Gioumousis e stevenson (seção 3.2.1.). A supos1ção (b) è uma aproximação, pols sempre hã certa probabilidade de tunelamento através de uma barreira de potenclal finita e certa probabilidade de reflexão de particulas com energia 
suflciente para passar sobre a barreira. Porëm, para partículas pesadas, tais como ātomos, a aproximação è numerlcamente satısfa tōria.

A seção de choque de espalhamento inelástico, em que - projētll é absorvido pelo alvo, havendo formação de um comple xo de colisão, è 76

$$
\sigma=\frac{\pi \hbar^{2}}{2 \mu E} \quad \sum_{L=0}^{\infty}(2 L+I)
$$

Pela suposição (b) colisōes com L> $L_{\max }$ não precisam ser conside radas e a seção de choque total para formação de um "complexo de acoplamento forte" numa colisão especificada por $q^{\prime} s_{q}{ }^{\prime} L_{q} E_{q} e ́$

$$
\begin{aligned}
\sigma & =\frac{\pi \hbar^{2}}{2 \mu_{q} E_{q}} \quad \sum_{L=0}^{L_{\max }}(2 L+1) \\
& =\frac{\pi \hbar^{2}}{2 \mu_{q} E_{q}}\left(L_{\max }+1\right)^{2}
\end{aligned}
$$

Para $L_{\max }$ grande essa seção de choque colnclde com a clássica:

$$
\sigma=\frac{\pi \hbar^{2} L_{\text {max }}{ }^{2}}{2 \mu_{q}{ }^{E} q}=\pi b_{c}^{2}
$$

onde $b_{c}$ é o parâmetro de impacto critico da teoria de Gioumousis e Stevenson (seção 3.2.1.).

As suposições (a) e (b), juntamente com o principlo de balanceamento detalhado, determinam de maneira única as probabilidades de decomposição do complexo nos diversos estados finais. Balanceamento detalhado requer que 92

$$
\left(2 L_{q}+1\right) \mu_{q^{\prime}} E_{q} \sigma\left(q-q^{\prime}\right)=\left(2 L_{q^{\prime}}+1\right) \mu_{q^{\prime}} E_{q^{\prime}} \cdot \sigma\left(q^{\prime}-q\right)
$$


onde $\mathcal{g}$ indica agora o conjunto de nūmeros quânticos 's $q{ }^{\prime} L_{q}$ ' $E_{q} e$ o (q-q') è a seção de choque de reação.

A suposição (a) permite escrever a seção de choque de reação como produto da seção de choque de formação do complexo e a probabilidade de decomposição do complexo. ${ }^{94}$ Assim, para da da energia total

$a\left(q-q^{\prime}\right)=\sum_{J} \sigma(q-J) P\left(J-q^{\prime}\right)$

onde $\underline{\text { I }}$ é o número quântico do momento angular total do complexo, formado pelo acoplamento do momento angular interno (número quântico $L_{q}$ ) e do momento angular orbital de movimento relativo (núme ro quântico L).

A seção de choque de formação de um complexo de dado $\underline{I}$ è, pela equação 3.25 .:

$$
\begin{aligned}
\sigma(q-J) & =\frac{\pi \hbar^{2}}{2 \mu_{q} E_{q}} \quad \stackrel{\Sigma}{L(q, J)}(2 L+1)\left[\frac{2 J+1}{(2 L+1)\left(2 L_{q}+1\right)}\right] \\
& =\frac{\pi \hbar^{2}}{\left.2 \mu_{q}{ }^{E}{ }_{q}^{(2 L} L_{q}+1\right)}(2 J+1) \quad \sum_{L(q, J)} 1
\end{aligned}
$$

o termo entre colchetes é a fração de colisões descritas pelos números quânticos $\mathrm{L}$ e $\mathrm{L}_{\mathrm{q}^{\prime}}$ que acoplam para dar dado $\mathrm{J}$. A somatória sobre $\underline{L}$ termina obedecendo às condições $\left|L-L_{q}\right| \leqslant J \leqslant I+L_{q}$ e $L$ $\leqslant L_{\text {max }}$ e é Igual ao número de seus termos, que è o número de esta dos no canal $q$ que pode formar (ou ser formado de) um complexo de momento angular $\underline{J}$ e energia $\mathrm{E}_{\mathrm{q}^{*}}$

$\sum_{L(\mathrm{q}, \mathrm{J})} 1=\mathrm{n}(\mathrm{q}, \mathrm{J})$

Subst1tuindo 3.29 . em 3.28 , o resultado em 3.27 . e, novamente em 3.26., resulta; 
$\sum_{J}(2 J+1) n(q, J) P\left(J-q^{\prime}\right)=\sum_{J}(2 J+1) n\left(q^{\prime}, J\right) P(J-q)$

Por indução, começando com $J=0$, vê-se que a solução desta equa ção è

$\frac{p\left(J-q^{\prime}\right)}{n\left(q^{\prime}, J\right)}=\frac{p(J-q)}{n(q, J)}=C$

A constante $\underline{c}$ é obtida pela condição de a soma das probabilida des de decomposição do complexo ser 1 .

$\frac{p(J-q)}{n(q, J)}=\frac{1}{x=q, q^{\prime}, \ldots n(x, J)}$

onde a somatōria é o número total de estados que podem ser forma dos pelo complexo. Substituindo 3.29. em 3.28 . e o resultado e 3.30: em 3.27., obtẻm-se a seção de choque total para o processo:

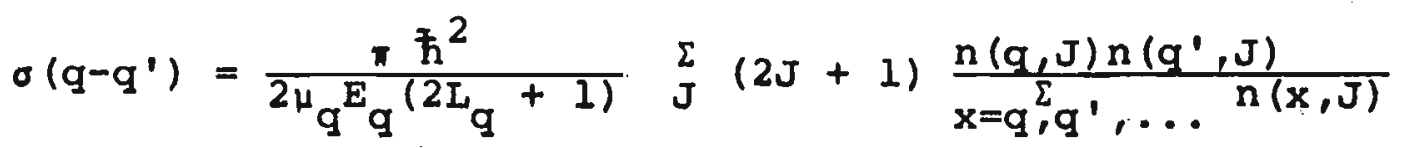

Esta equação é pelo menos qualitativamente correta ao sugerir que a seção de choque para dada reação diminui rapidamen te quando mais canals se abrem, mas os valores numéricos calcula dos são frequentemente um pouco menores que os experimentais. De vido à complexidade dos cálculos, a teoria só fol aplicada a rea ções envolvendo trêse quatro ãtomos, enquanto que justamente os sistemas pollatômicos seriam os mais sucetiveis a uma descrição pela teorla do espaço de fase. ${ }^{69}$ A concordândia entre teoria e experiência não é boa no caso de reações de transferên cia de carga por processos de ressonância, pols então a seção de choque total è maior que a seção de choque de Gloumousis e Stevenson, que é necessárla para calcular $I_{\max }$ Os resultados tam- 
bëm não:são bons no caso de reações que requerem uma energia de ativação para formar o complexo. 71 Uma das vantagens mais importantes da teoria do espaço de fase è de não ser altamente parametrizada, requerendo apenas um conhecimento das proprieda des iniclais e finais do sistema e, ao contrārio da teoria do quase-equilíbrio, não se preocupa com o complexo de transição.

\subsubsection{Modelos diretos}

Se uma reação se dá atravēs da formação de um complexo que existe por mais de um periodo rotacional (mais de $10^{-12} \mathrm{~s}$ ), - complexo "esquece" a direção da qual os reagentes vieram e qualquer decomposição do mesmo é isotróplca no sistema de coorde . nadas do centro de massa. Por outro lado, se a reação se dā por um mecanismo direto, os produtos iônicos mantẻm a informação direcional dos ions reagentes e a distribuição de produtos é assimëtrica em torno de uma linha que passa pelo centro de massa e è perpendicular à direção do ion reagente.

Medirido.a distribulção de velocidadesdos produtos iôni cos, Henglein mostrou que a energias translacionais elevadas (40 eV) a reação 78

$\mathrm{Ar}^{+}+\mathrm{H}_{2} \rightarrow \mathrm{ArH}^{+}+\mathrm{H}$

ocorre por um mecanismo que é um caso limite do modelo direto e que fol denominado de "spectator stripping" em ingles.

No mecanismo de "spectator stripping" a reação

$\mathrm{A}^{+}+\mathrm{BC}+\mathrm{AB}^{+}+\mathrm{C}$

se dá de modo que nehuma quantidade de movimento seja transferi- 
da do i̊n reagente $\mathrm{A}^{+}$para o átomo $\mathrm{C}$, que, portanto, não particí pa da reação a não ser sob a forma de um espectador passivo.

Por este mecanismo não são feitas previsões quantitatí vas quanto à seção de choque de reação, mas efeitos isotópicos em reações podem ser calculados.

Existem espectrômetros ${ }^{78}$ que possibilitam selecionar os Ions quanto à sua velocidade e obter um espectro de velocidade.Co mo o modelo de "spectator stripping" só é aplicado a energias translacionais elevadas, numa reação como a 3.31., a molécula neu tra pode ser considerada em repouso, pois sua velocidade térmica è menor que a velocidade do ion incidente; o movimento tërmico da molécula não desloca a posição da banda do produto iônico no espectro de velocidade, pois seu movimento é Igualmente provável em todas as direções, provocando apenas um alargamento da linha.

Na dedução abaixo ${ }^{78}$ será usada a seguinte notação, representando $\mathrm{v}$ uma velocidade no sistema de coordenadas do laboratōrio e $\underline{u}$, uma velocidade no sistema de coordenadas do centro de massa:

$$
\text { Espēcie }
$$

íon primārio

reagente neutro

produto iônico

produto neutro

centro de massa
Massa

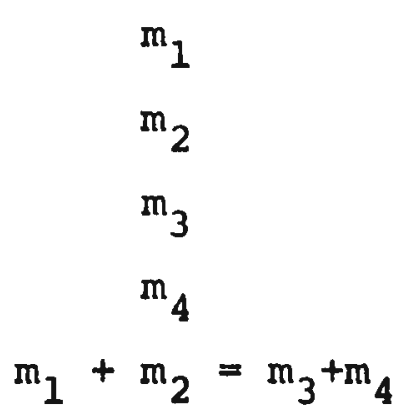

Veloctdade
lab. c.m.

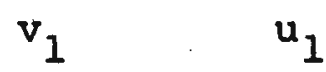

0

$u_{2}$

$v_{3} \quad u_{3}$

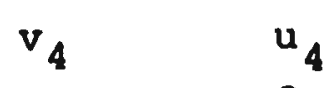

c

0

No sistema de coordenadas do laboratório o centro de massa tem velocidade $v_{c} e$, por conservação de quantidade de movi mento (seção 3.2 .1$. ): 
$v_{c}=\frac{m_{1}}{m_{1}+m_{2}} v_{1}$

o centro de massa aproxima-se de $m_{2}$ com velocidade $v_{c} e$, portanto, no sistema de coordenadas do centro de massa é $\mathrm{m}_{2}$ que tem velocidade $v_{c}$, ou seja, $u_{2}=v_{c} ; \operatorname{logo}, u_{1}=v_{1}-v_{c}$. Mas

$m_{1} u_{1}=m_{2} u_{2}$

o que se demonstra substituindo $u_{1}$ por $v_{1}-v_{c}$ e $u_{2}$ por $v_{c}$. De 3.33.:

$\mathrm{u}_{1}=\frac{\mathrm{m}_{2}}{\mathrm{~m}_{1}} \mathrm{v}_{\mathrm{c}}$

No caso de formação de um complexo, este terá a velocí dade do centro de massa e o produto lônico salrá do mesmo em qualquer direção, ou seja, em média $m_{3}$ terá a velocidade do complexo.

$v_{3}=v_{c}$

Como o Ion terà essa velocidade em mēdia, a linha corresponden te $\mathrm{a}_{3}$ no espectro de velocidade será larga. $u_{3}$ e. $u_{4}$ não são calculāveis, pois dependem do calor de reação, já que parte do calor de reação pode aparecer como energla clnética dos produtos. No caso de um processo de "spectator stripping", um àtomo é capturado pelo Ion incidente sem transferência de quantidade de movimento ao outro átomo, o espectador. Isto significa que no sistema de coordenadas do centro de massa o átomo especta dor continua com a velocidade da molécula reagente, $u_{4}=u_{2}$, que é igual a $v_{c}$; o produto lônico tem velocidade $u_{3}$, que, portanto, $\overline{\mathrm{e}} \mathrm{v}_{3}-\mathrm{v}_{\mathrm{c}}$. 
$v_{3}=v_{c}+u_{3}$

Então, analogamente a 3.34.:

$u_{3}=\frac{m_{4}}{m_{3}} v_{c}$

Substituindo 3.36. e 3.32. em 3.35. e lembrando que $m_{1}+m_{2}=m_{3}$ $+m_{4}$, obtēm-se:

$v_{3}=\frac{m_{1}}{m_{3}} v_{1}$

Repetindo as expressões da velocidade do produto iônico em função da velocidade do ion reagente, para os modelos de complexo e "spectator strıpping" para comparação:

complexo

$$
v_{3}=\frac{m_{1}}{m_{1}+m_{2}} v_{1} \quad \text { (banda larga) }
$$

"spectator stripping" $\quad v_{3}=\frac{m_{1}}{m_{3}} v_{1} \quad$ (banda estreita)

Por meio destas equações é possivel distinguir, por exemplo, se a reação de Ions argônio com hidrogênio ocorre por um mecanismo de complexo ou de "spectator stripping". Usando HD como gãs alvo na câmara de colisão, os produtos iôntcoś da reação

$$
\mathrm{Ar}^{+}+\mathrm{HD} \sum_{\mathrm{ArD}^{+}+\mathrm{H}}^{\mathrm{ArH}^{+}+\mathrm{D}}
$$

são esperados na mesma posição no espectro de velocidade, se forem produzidos de um complexo intermediărto $\mathrm{ArHD}^{+}$. Mas no caso de "spectator stripping", devem produzir duas bandas separadas, tendo as mesmas posıções que $\mathrm{ArH}^{+}$da reação $\mathrm{Ar}^{+}+\mathrm{H}_{2}$ e $\mathrm{ArD}^{+}$da 
reação $A r^{+}+D_{2}$, respectivamente. O espectro de velocidade mostra duas bandas, de acordo com o modelo "spectator stripping".

o modelo "spectator stripping" é apenas um caso limite de um modelo de colisão. Todos os tipos de situações interme diárias entre esse modelo e o de complexo são concebíveis. Mesmo para dada reação e dada energia cinética nem todas as colisões reativas obedecem ao modelo "spectator stripping",pois sempre são possĩveis colisões centrais, isto è, colisões com parâme tros de impacto pequenos, que resultam em espalhamento para trás no sistema de coordenadas do centro de massa.

Tanto a altas como a baixas energias translacionais do Ion reagente ocorrem desvios do modelo "spectator stripping" e foram desenvolvidos modelos de "stripping" modificados. A ener gias altas o ātomo espectador não é totalmente passivo, mas rece be certa quantidade de movimento, retrocedendo. A energias ba xas não è mais desprezível uma força atrativa que os reagentes experimentam ao se aproximarem e que acelera um na direção do oụ tro, de modo que sua velocidade relativa seja maior quando alcan Çam a distância de aproximação mäxima do que à distância Inifinita; a transferência de átomo se dá de maneira direta e os produtos se afastam um do outro, sendo um pouco decelerados pelo potencial atrativo existente entre eles; resulta geralmente um aumento na velocidade do Ion em relação ao esperado pelo modelo "spectator stripping". Para este caso värlos modelos foram desenvolvidos.95,96 o formalismo geral dos modelos de referência 95 será apresentado a seguir.

\section{Considere-se a reação de transferência}

$X+Y Z+X Y+Z$

No primeiro estãglo da reação (reagentes em separação Infinita), 
os reagentes se aproximam com velocidade inicial relativa $v_{l}$ e parâmetro de impacto $\underline{b}$. A energia cinética relativa é

$T_{1}=\frac{1}{2} \frac{m_{X}\left(m_{Y}+m_{Z}\right)}{m_{X}+m_{Y}+m_{Z}} v_{1}^{2}=\frac{1}{2} u v_{1}{ }^{2}$

(A notação difere da usada antes: Indices numēricos indicam agora estágios da reação e não espēcies químicas). Quando os reagentes alcançam a distância de aproximação máxima $r_{c^{\prime}} 0$. potencial atrativo (potencial íon-dipolo induzido no caso de reações entre ions e moléculas) acelerou-os de modo a terem energia cinē tica

$\mathrm{T}_{2}=\mathrm{T}_{1}+\mathrm{P}$

onde $\underline{p}$ è a energia cinëtica ganha entre infinito e $r_{c}$

A velocidade relativa $v_{2}$, na distância $\mathbf{r}_{c}$, pode ser desdobrada numa componente paralela $\left(v_{2} \|\right)$ e numa perpendicular $\left(v_{2 \perp}\right)$ à superfícte de reaçäo. Esta partição é determinada pelo parâmetro de impacto $\underline{b}$ e a velocidade relativa inicial v ${ }_{1}$, atrávēs de conservação de momento angular:

$\mu \mathrm{bv} v_{1}=\mu \mathrm{r} \mathrm{c}_{2} \|$

Definindo energias cinēticas correspondentes às componentes de velocidade paralela e perpendicular,

$\mathrm{T}_{2 \|}=\frac{1}{2} \mu \mathrm{v}_{2 \|}{ }^{2} \quad \mathrm{~T}_{2 \perp}=\frac{1}{2} \mu \mathrm{v}_{2 \perp}{ }^{2}$

tem-se, substitulndo 3.38 e e 3.40 . em $3.41 .:$

$T_{2 \|}=\left(\frac{b}{r_{C}}\right)^{2} T_{1}$

e, empregando 3.39. e 3.42.: 


$$
\begin{aligned}
\mathrm{T}_{2 \perp} & =\mathrm{T}_{2}-\mathrm{T}_{2 \|} \\
& =P+\left[1-\left(\frac{\mathrm{b}}{\mathrm{r}_{\mathrm{C}}}\right)^{2}\right] \mathrm{T}_{1}
\end{aligned}
$$

Transferência de $\underline{Y}$ a $\underline{X}$ ocorre agora. No estāglo 3 os produtos, numa distância de aproximação mãxima $r_{c}$, começam a separar-se. A energia cinética relativa inicial é $\mathrm{T}_{3}=\frac{1}{2} \frac{\mathrm{m}_{\mathrm{Z}}\left(\mathrm{m}_{\mathrm{X}}+\mathrm{m}_{\mathrm{Y}}\right)}{\mathrm{m}_{\mathrm{X}}+\mathrm{m}_{\mathrm{Y}}+\mathrm{m}_{\mathrm{Z}}} \mathrm{v}_{3}{ }^{2}=\frac{1}{2} \mu^{\prime} \mathrm{v}_{3}{ }^{2}$

Para governar a partição de $v_{3}$ em componentes paralela e perpendicular à superfície de reação, são feitas as seguintes suposi ções :

Suposição A: A componente paralela da velocidade da particula liberada $\underline{z}$ é igual à que a partícula tinha enquanto es tava combinada no reagente.

$v_{2 \| Y Z}=v_{3 \| Z}$

A energia cinética de YZ (antes da transferência) e a de $\mathrm{z}$ (logo após a transferência), são:

$\mathrm{T}_{2 \| \mathrm{YZ}}=\frac{1}{2}\left(\mathrm{~m}_{\mathrm{Y}}+\mathrm{m}_{\mathrm{Z}}\right) \mathrm{v}_{2} \| \mathrm{YZ}^{2}$

$\mathrm{T}_{3 \| \mathrm{z}}=\frac{1}{2} \mathrm{~m}_{\mathrm{z}} \mathrm{v}_{3 \| \mathrm{z}^{2}}$

Logo:

$T_{3 \| z}=\frac{m_{z}}{m_{Y}+m_{z}} T_{2 \| Y Z}$

Suposição B: A energla cinëtica dos produtos, $T_{3} \perp^{\text {, cor }}$ respondente à componente perpendlcular de sua velocidade relativa, está relaclonada com a quantidade semelhante $T_{2 \perp}$ por algum mült1plo a. 


$$
\begin{aligned}
\mathrm{T}_{3 \perp} & =a \mathrm{~T}_{2 \perp} \\
& =a P+a\left[1-\left(\frac{b}{\mathrm{r}_{C}}\right)^{2}\right] \mathrm{T}_{1}
\end{aligned}
$$

Os produtos $\mathrm{XY}$ e $\mathrm{Z}$ são agora decelerados pelo potencial atrativo entre eles, de modo que no quarto estägio da reação (pro dutos em separação infinita) sua energia cinética é

$$
\begin{aligned}
\mathrm{T}_{4} & =\mathrm{T}_{3}-\mathrm{P}^{\prime} \\
& =\mathrm{T}_{311}+\mathrm{T}_{3 \perp}-\mathrm{P}^{\prime}
\end{aligned}
$$

onde $\mathrm{P}^{\prime}$ é a energia cinética perdida entre $r_{c}{ }^{\prime}$ e infinito.

Por conservação de quantidade de movimento:

$$
\begin{aligned}
& \left(m_{X}+m_{Y}\right) v_{3}\left\|X Y=m_{Z} v_{3}\right\| z \\
& m_{X} v_{2}\left\|x=\left(m_{Y}+m_{Z}\right) v_{2}\right\| Y Z
\end{aligned}
$$

Estas igualdades levam, respectivamente, a

$$
\begin{aligned}
& T_{3 \|}=\frac{m_{X}+m_{\dot{Y}}+m_{z}}{m_{X}+m_{Y}} T_{3 \| z} \\
& T_{2 \|}=\frac{m_{X}+m_{Y}+m_{z}}{m_{X}} T_{2 \| y z}
\end{aligned}
$$

Substituindo $3.46,3.43 ., 3.47,3.42$ e 3.44 . em 3.45 :

$T_{4}=\left(a P-P^{\prime}\right)+\left\{\left(\frac{b}{r_{c}}\right)^{2}\left[\frac{m_{X} m_{Z}}{\left(m_{X}+m_{Y}\right)\left(m_{Y}+m_{Z}\right)}-a\right]+a\right\} T_{I}$

A grandeza que se mede experimentalmente è

$$
v_{4}=\left[\frac{2\left(m_{x}+m_{Y}+m_{z}\right)}{m_{z}\left(m_{x}+m_{Y}\right)} T_{4}\right]^{\frac{1}{2}}
$$


No modelo "spectator stripping" forças intermoleculares são desprezadas, de modo que $\mathrm{P}=\mathrm{P}^{\prime}=0$; além disso, as trajetō rias retilineas resultantes implicam em $r_{c}=b$. Logo, substituin do a expressão de $\mathrm{T}_{4}$ assim simplificada na de $\mathrm{v}_{4}$ ' obtëm-se:

$v_{4}=\frac{m_{x}}{m_{X}+m_{y}} v_{1}$

que é o resultado obtido anterformente (equação 3.37. ).

A suposição $A$, de que a componente da velocidade da par tỉcula $\underline{\text { Z }}$, paralela à superfỉcie de reação, permaneça constante, ē fislcamente razoāvel para qualquer modelo de reação de transferên cia, pois as forças envolvidas são radials e não tangenciais. E mais dificil conceber uma situação na qual a componente perpendicular permaneça inalterada em módulo, a menos que a ligação Y-Z fosse enfraquecida antes da transferência de $\underline{Y}$ a $\underline{x}$, de modo que as particulas estivessem essencialmente viajando independentemente. $\underline{Z}$ poderia então ser espalhada elasticamente de $X Y$, sua velocidade permanecendo inalterada. Entretanto $\underline{\mathrm{Y}}$ e $\underline{\mathrm{Z}}$ precisam permanecer fortemente acopladas durante a fase de aceleração, pois de outra forma, à menos que sejam particulas Idênticas, não teriam a mesma velocidade.

No caso de reações entre ions e moléculas os termos $P$ e $P^{\prime}$ são

$P=\frac{\alpha_{Y Z} e^{2}}{2 r_{c}^{4}} \quad P^{\prime}=\frac{\alpha_{z} e^{2}}{2 r_{C}{ }^{4}}$

Como a polarizabilidade de $\mathrm{YZ}\left(\alpha_{\mathrm{YZ}}\right)$ é geralmente malor que a de Z sozinha $\left(\alpha_{Z}\right)$, a aceleração seguida de uma deceleração mais fraca faz com que os produtos iônicos tenham velocidades maiores que as calculadas pelo modelo "spectator stripping". A energias cranslā:ionais relativas elevadas $\underline{\underline{p}}$ é desprezível em relação a $\mathrm{T}_{1}$ 
(ver eçilação 3.39.) e tem-se o modelo "spectator stripping" como caso limite.

Para aplicar o modelo, ajustam-se os parâmctros $r_{C}$ e $r_{c}$ ' de molo que as velocidades calculadas coincidam com as experimentais à menor energia cinética possível. o parâmetro b è calcula do por

$b=\frac{b}{\sqrt{2}}$

sendo

$b_{c}^{2}=\epsilon\left(\frac{2 \alpha}{T_{1}}\right)^{\frac{1}{2}}$

(ver equação 3.11.). O modelo é então testado, verificando se as distâncias de reação são razoāveis e, usando os mesmos parāmetros, tenta-se predizer os resultados a energias maiores. 95

Nestes modelos diretos o que se calcula são velocida des de ions, que são grandezas que podem ser medidas em experiências de feixes $97,98 \mathrm{Em}$ espectroscopia de ressonância ciclotrōnica de Ions è medida apenas a concentração de ions, se bem que os ions reagentes possam ser acelerados a velocidades conhecidas; fol possível usar a técnica para distinguir um mecanismo de"stripping" de um de formação de complexo. ${ }^{42}$

3.2.4. Outros modelos

Diagramas de correlação de orbitais moleculares podem ser aplicados a reações entre ions e molēculas. 99 Quando ocorre uma reação bimolecular, os orbitais moleculares dos reagentes interagem e formam os orbitais do complexo de colisão e depois os dos produtos. Consequentemente é possivel fazer um diagrama de 
currelaçăo que mostra a conexão entre os orbitais de reagentes e produtos.

Esses diagramas explicam por exemplo porque a reação en dotérmica

$\mathrm{H}_{2}^{+}+\mathrm{He}+\mathrm{HeH}^{+}+\mathrm{H}$

ocorre, enquanto que o processo exotérmico

$\mathrm{He}^{+}+\mathrm{H}_{2} \rightarrow \mathrm{HeH}^{+}+\mathrm{H}$

não ocorre. Entrando no diagrama de correlação para o sistema $(\text { HeHH })^{+}$com a configuração dos reagentes $\mathrm{H}_{2}^{+}\left(\sigma_{g}\right)^{l}+\mathrm{He}(1 s)^{2}$, vêse que esses reagentes passam para $\mathrm{HeH}^{+}(1 \sigma)^{2}+\mathrm{H}(1 s)^{1}$, o que está de acordo com a reação 3.48 ., endotérmica, mas que tem uma seção de choque apreciável para energias cinéticas acima do limiar de reação. Porém, entrando com a configuração para $\mathrm{He}^{+}(1 \mathrm{~s})^{1}+\mathrm{H}_{2}$ $\left(\sigma_{g}\right)^{2}$, obtēm-se do lado dos produtos $\mathrm{HeH}^{+}(1 \sigma)^{1}(2 \sigma)^{1}+\mathrm{H}(1 \mathrm{~s})^{1} ; 0$ orbital $2 \sigma$ é antiligante e portanto esse $\mathrm{HeH}^{+}$não estaria ligado e dissoclaria em $\mathrm{He}^{+}$e H; a não ocorrência desta reação estã de acordo com a experiência.

Tambēm è possivel explicar por melo dos diagramas de correlação porque a reação

$\mathrm{CO}^{+}+\mathrm{H}_{2} \rightarrow \mathrm{HCO}^{+}+\mathrm{H}$

se dā por um mecanismo direto e não de complexo, apesar da grande estabilidade do possivel intermediārio $\mathrm{H}_{2} \mathrm{CO}^{+}$. o diagrama de correlação e potenciais de aparecimento mostram que hã uma barrei ra de 4,5 eV entre $\mathrm{CO}^{+}+\mathrm{H}_{2}$ e o estado fundamental de $\mathrm{H}_{2} \mathrm{CO}^{+}$na configuração de formaldeído $\left(C_{2 v}\right)$. Logo, o poço de potencial cor respondente a $\mathrm{H}_{2} \mathrm{CO}^{+}$não é acessivel em colisões de baixa energia 
entre $\mathrm{CO}^{+}$e $\mathrm{H}_{2}$. O diagrama de correlação para colisões colineares $\left(\mathrm{H}_{2} \mathrm{CO}^{+}\right.$linear) mostra que não há barreiras altas, nem poços profundos entre reagentes e produtos para essa configuração. A reação deve então ocorrer por um mecanismo direto a todas as ener gias, como observado experimentalmente.

A passagem de reagentes para produtos numa colisão en volvendo reação química pode ser descrita em termos de um movi mento sobre uma superficie de energia potencial. Muitas reações são não adiabāticas e envolvem o cruzamento de superficies de energia potencial. A probabilidade desse cruzamento é considerada como determinante da seção de choque total de reação. 69

Os modelos para reações entre ions e moléculas descritos não constituem na realidade alternativas para o tratimento teórłco de dada reação, mas abordam aspectos diferentes das reações. Assim, o modelo de polarização permite calcular uma seção de choque total de reação, enquanto que os modelos estatísticos possibilitam o cálculo de distribuições de produtos no caso de reações paralelas. por outro lado, em se tratando de mecanismós diretos, calcula-se a distribuição de velocidades dos produtos iônicos. Esses modelos podem ser obtidos a partir de um tratamento de mecânica quântica rigoroso, introduzindo posteriormente as simplificações apropriadas. 76 


\section{REAÇÕES DE ACETILAÇÃO}

Quando foram iniciados os estudos descritos neste capi tulo, tinha-se na realidade por objetivo testar a validade das equações que descrevem o movimento dos ions numa cela de ressó nância ciclotrônica de ions e que foram apresentadas no capítulo 2. Foi escolhido o sistema da acetona para realizar os testes, uma vez que poucas espécies iônicas diferentes são formadas e as reações desses ions com molêculas neutras de acetona não pareciam muito complexas. Uma das reações nesse sistema é a auto-acetilação da acetona.

$\mathrm{CH}_{3} \mathrm{COCH}_{3}^{+}+\mathrm{CH}_{3} \mathrm{COCH}_{3} \rightarrow \mathrm{CH}_{3} \mathrm{CO}^{+}\left(\mathrm{CH}_{3} \mathrm{COCH}_{3}\right)+\cdot \mathrm{CH}_{3}$

Esta reação jā havia sido observada na acetona, 100 mas seu meca nismo não era bem conhecido. O conhecimento deste só se tornou possível, quando cetonas alifáticas superiores foram examinadas, tendo-se notado que a reação de acilação é geral nas cé' tonas. Grãfiços, em função de pressão, das correntes iônicas ṛelativas das espécles presentes em cada sistema, a sistematiza ção dos fatores que governam a estabilidade dos produtos iônicos dessa reação e, principalmente, a observação do interme diārio provável da reação 4.1. nos espectros de ressonâncla ciclotrônfca de lons no caso das cetonas superiores a préssões mais altas, permitiram a elucidação do mecanismo de acilação.

Os resultados dessa pesquisa foram comunicados em nota preliminar na XXIV Reunião Anual da Sociedade Brasileira para o Progresso da Ciêncial ${ }^{101} \mathrm{e}$, em forma final, no Journal of the American Chemical Society. 102 
Neste capítulo será disqutida inicialmente a espectros copia de massa usual das cetonas. ${ }^{103}$ Em seguida será apresentado o que anteriormente havia sido publicado a respeito das reações entre ions e molēculas de cetonas; também serão mencionados alguns estudos relacionados com os de acilação, apesar de não se referirem a cètonas alifáticas simples. Como este é o primeiro capitulo desta tese, no qual uma parte experimental è desenvolvida, o espectrômetro utilizado será descrito com algum detalhe; nos próximos capítulos, nos quais outras experiências serão relatadas, far-se-á referência a esta descrição, mencionan do-se apenas o que é particular às experiências em questão; no capitulo 2 o funcionamento do espectrômetro foi abordado de maneira superficial, apenas para tornar compreensivel a dedução das equações necessárias à interpretação dos espectros de ressonância ciclotrônica de ions. Após a relação dos reagentes empre gados neste estudo, os testes de validade das equações, menciona dos acima, serão discutidos. Finalmente, tratar-se-ã da parte química, isto é, do mecanismo das reações de acilação e da es-, trutura dos compostos formados.

\subsection{Espectros de massa de cetonas}

A acetona tem três potencials de ionização, 1039,8 , 10,6 e $11,5 \mathrm{eV}$. O processo de Ionização de menor energia corres ponde à remoção de um dos elétrọns $\underline{\mathrm{n}}$ do oxigênio, enquanto que $10,6 \mathrm{eV}$ è a energia necessária para a remoção de um elétron $\underline{\pi}$ da ligação $C=0, e 11,5 \mathrm{eV}$ é a energia que precisa ser fornecida para arrancar um elêtron ó da ligação $\mathrm{C}=0$. Com as energias eletrônicas geralmente usadas para obter espectros de massa de com postos orgânicos, todos esses processos acontecem. Porẻm, os 
processọs de fragmentação característicos de compostos de carbonila podem ser vistos mais facilmente, considerando a decomposição da espécie iônica de menor energia, que é a que apresenta a deficiência eletrônica no orbital $\underline{n}$.

O processo principal de fragmentação das cetonas envol ve a ruptura da ligação entre o grupo carbonila e o carbono $\underline{\alpha}$, sendo que a carga fica no fragmento que contém o oxigênio.

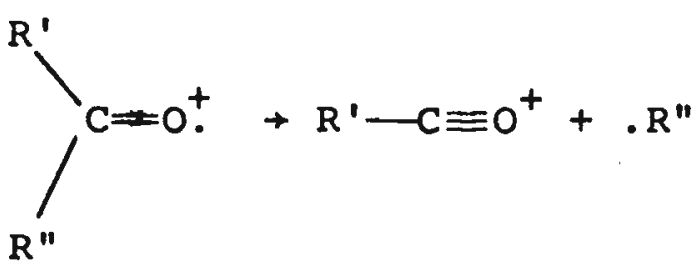

Num grande número de metilcetonas o pico mais intenso do espec tro è o de $\mathrm{CH}_{3} \mathrm{CO}^{+}$. Nos espectros de $70 \mathrm{eV}$ de energia eletrônica,. - pico oriundo de perda do grupo alquila maior é mais intenso que o associado com a perda do grupo menor. Porém, não se pode concluir que eliminação do grupo alquila maior é o processo mais favorável, pols a $70 \mathrm{eV}$ de energia eletrônica, os Ions actla resultantes decompõem, perdendo $\mathrm{Co}$.

$\mathrm{R}-\mathrm{C} \equiv \mathrm{O}^{+} \rightarrow \mathrm{R}^{+}+\mathrm{CO}$

Portanto, as abundâncias relativas dos ions acila não refletem ne cessariamente a proporção na qual os grupos alquila são elimi nados da cetona. De fato, trabalhando a energias eletrônicas baí xas $(\sim 10 \mathrm{eV})$, de modo que os ions acila não decomponham e não apareçam os fragmentos $\mathrm{R}^{+}$, observa-se justamente o conträrio: 0 processo no qual o grupo alquila menor è eliminado, è o preferido.

Cetonas ionizadas que possuem hidrogênios $Y$ fragmentam, transferindo o hidrogênio $Y$ através de um estado de transição $c \underline{I}$ clico (um anel de seis membros), havendo eliminação de olefina e formação de um enol tônico. 


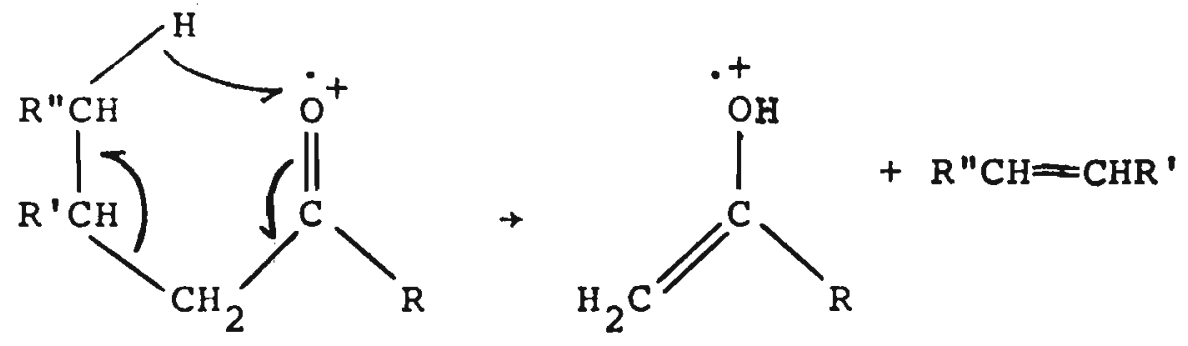

Esse processo é conhecido como rearranjo de McLafferty. Quando ambos os grupos alquila da cetona são constituidos por cadeias de três ou mais ātomos de carbono, um segundo rearranjo de McLafferty se torna possivel, pois o produto enólico formado no primeiro rearranjo pode novamente fragmentar.<smiles>[R]C1CC[C@H](CC(=C)[OH2+])C1</smiles><smiles>C=C([CH2+])[OH2+]</smiles>

Estes rearranjos são específicos para transferência de hidrogê -

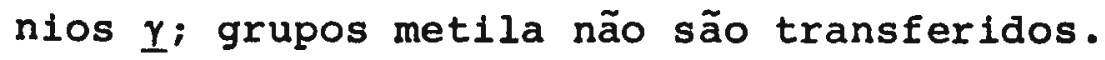

Estes são os principais tipos de. fragmentação observados em cetonas. Na referêncla 104 estão tabelados os espectros de massa de mals de 40 cetonas.

\subsection{Reações entre Ions e moléculas de cetonas}

Já em 1961 haviam sido descobertos, 105 em espectros de massa de compostos oxigenados, picos de lons $(M+R)^{+}$, onde $\underline{M}$ é a fórmula do ion molecular $\mathrm{e} \underline{\mathrm{R}}$, a do Ion que fornece o pico mais intenso no espectro. Estas experiências foram realizadas num espectrômetro de massa dotado de fonte de alta pressão e o Ion $(M+R)^{+}$nada mais é do que a acetona acetilada da reação 4.1. 
quando a substância examinada é a acetona. Outros estudos de ce tonas seguiram, usando-se espectrômetros semelhantes, isto é, es pectrômetros de massa modificados para poder operar a fonte a pressões elevadas. Munson ${ }^{106}$ examinou uma série de compostos oxigenados quanto às reações de protonação ou, como também as chamou, reações de solvatação do próton. Concluíu que o agregado mais estável de moléculas ligadas a um próton é formado, quan do cada hidrogênio ligado a um oxigênio na molécula protonada é ligado a outra molēcula. Assim, nos agregados $(M)_{n} H^{+}, n=4$ se $M$ é $\mathrm{H}_{2} \mathrm{O}, \mathrm{n}=3$ se $\mathrm{M}$ é $\mathrm{CH}_{3} \mathrm{OH}, \mathrm{n}=2$ se $\mathrm{M}$ é $\mathrm{CH}_{3} \mathrm{OCH}_{3}$.

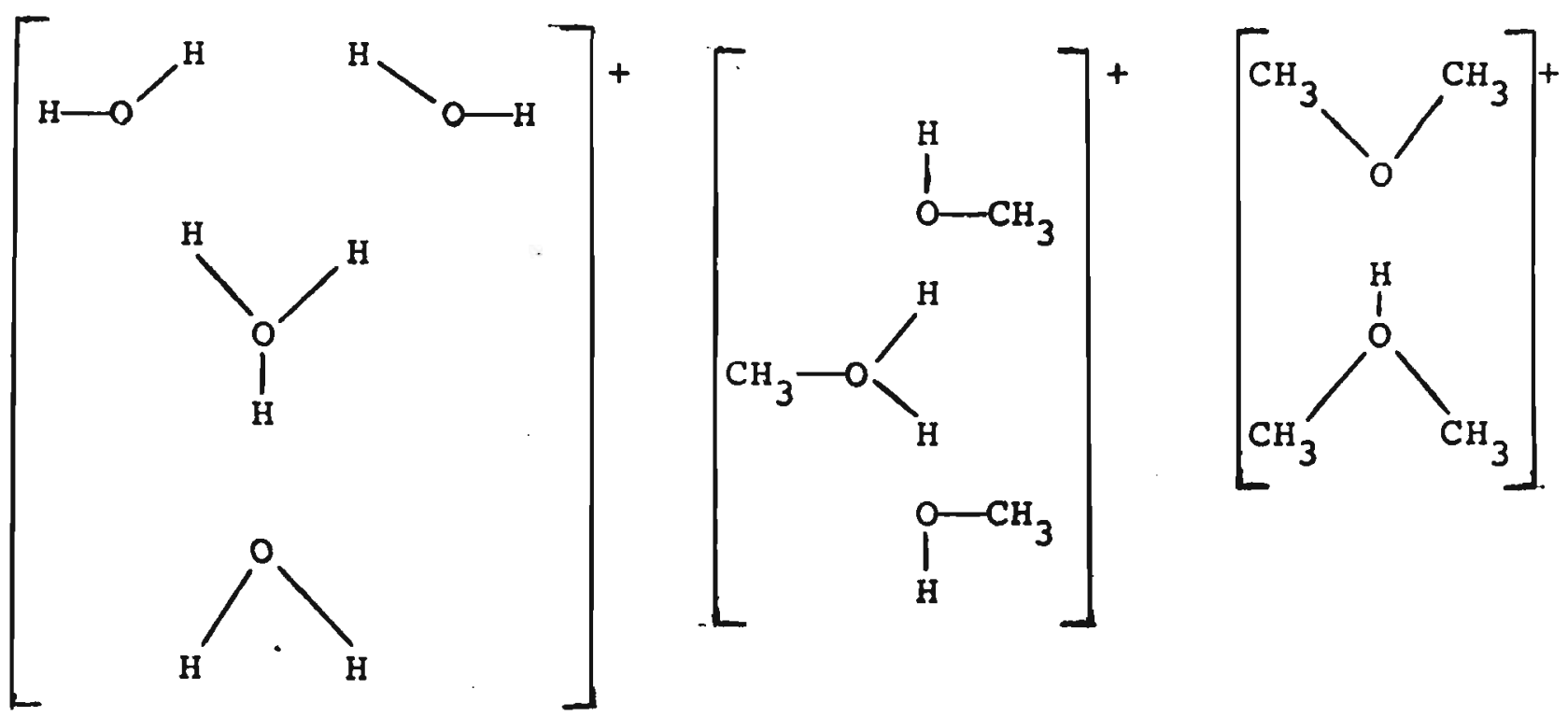

Concordando com isso, verificou que o próton di-solvatado é o agregado mais estável no caso da acetona, não tendo encontrado o próton tri-solvatado. Também observou um ion de $\mathrm{m} / \mathrm{e}=99$, proveniente de eliminação de água do dímero protonado da acetona; atri buiu a esse ion a estrutura do óxido de mesitila. Além disso observou ions correspondentes a acetona acetilada e acetona metilada, a origem dos quais, porēm, não descobriu. Num outro estudo de cetonas 107 apenas as moléculas protonadas foram observadas, ten do-se verificado que são formadas por transferência de próton do Ion molecular para a molēcula neutra, e não, por abstração de 
hidrogênio pelo íon molecular. As constantes de velocidade de protonação de algumas cetonas foram medidas e os valores encon tram-se na TABELA 4.1., mas provavelmente são grandes demais.

\section{TABELA 4.1 .}

Constantes de vélocidade de protonação de cetonas. 107

\begin{tabular}{lc}
\multicolumn{1}{c}{ cetona } & $\mathrm{k}\left(\mathrm{x} 10^{8} \mathrm{~cm}^{3} \cdot\right.$ molécula $\mathrm{s}^{-1} \cdot \mathrm{s}^{-1}$ \\
\hline acetona & 0,5 \\
butanona & 0,9 \\
pentanona-2 & 1,6 \\
pentanona-3 & 0,9 \\
3,3-dimetilbutanona & 2,4
\end{tabular}

Um estudo exaustivo das reações entre íons e moléculas no sistema da acetona foi realizado por Futrell. 108 Para tanto, fez uso de duas técnicas: espectrometria de ressonância ciclotrộ nica de ions e espectrometria de massa com uma fonte capaz de ser operada até 0,6 Torr. Com o espectrômetro de alta pressão foram observados os seguintes ions primärios: $\mathrm{CH}_{3}{ }^{+}, \mathrm{CH}_{3} \mathrm{CO}^{+}$e $\mathrm{CH}_{3} \mathrm{COCH}_{3}{ }^{+}$, alēm de íons de m/e 14, 26, 27, 29, 39, 41 e 42, de intensidade muito menor. Dentre os produtos encontram-se Ions de förmula geral $\left(\mathrm{CH}_{3} \mathrm{COCH}_{3}\right)_{\mathrm{n}^{\mathrm{H}}}{ }^{+}, \operatorname{com} \mathrm{n}=1,2,3$ e 4 . Munson 106 não havia encontrado essa espécie $\operatorname{com} n>2$ e, de acordo com sua teoria, a espēcie $\operatorname{com} n=2$ seria a mais estāvel; mas é realmente este $\circ$ ion que fornece o pico mais intenso nos espectros de Futrel1. 108 Se bem que com intensidades uma ordem de grandeza menores que as dos ions protonados, foram encontrados picos de Ions $\left(\mathrm{CH}_{3} \mathrm{COCH}_{3}\right)_{n} \mathrm{CH}_{3}^{+} \operatorname{com~} \mathrm{n}=1,2,3$ e 4. Também agregados com o cátion acila, $\left(\mathrm{CH}_{3} \mathrm{COCH}_{3}\right)_{n} \mathrm{CH}_{3} \mathrm{CO}^{+}$, foram encontrados, mas neste 
caso só com $n=1,2$ e 3. Ions de m/e 99 e 157, correspondantes, respectivamente, a dimero e trimero protonados, dos quais āgua foi eliminada, também estiveram presentes, o espectrômetro de ressonância ciclotrônica de ions foi usado nesse estudo para a medição das constantes de velocidade das reações. Como não è possîvel operar esse, instrumento a pressões tão elevadas como o outro, os agregados que contēm vārias molēculas de acetona não são estabilizados e consequentemente nem todas as constantes de velo cidade de reação puderam ser medidas. Nāo foi mencionada a ener gia de ionização empregada no espectrômetro de ressonância c1clotrônica de íons (500 eV no de alta pressão), mas presume-se que seja relativamente elevada, devido à presença de Ions $\mathrm{CH}_{3}{ }^{+}$. Na TABELA 4.2. estão as constantes de velocidade medidas por Futrell, que tambēm calculou alguns valores através da teoria de Gioumousis e Stevenson (equação 3.14.). Somando as constan tes de velocldade das três reações que levam à formação de $\left(\mathrm{CH}_{3} \mathrm{COCH}_{3}\right) \mathrm{H}^{+}$, obtëm-se $1 ; 0 \cdot 10^{-9} \mathrm{~cm}^{3} \cdot$ molëcula ${ }^{-1} \cdot \mathrm{s}^{-1}$, que pode ser comparado com o valor de $5 \cdot 10^{-9} \mathrm{~cm}^{3} \cdot \operatorname{molécula}{ }^{-1} \cdot \mathrm{s}^{-1}$ da TABELA 4.1 .

No contexto das reações de acetilação estão também os trabalhos de Bursey, 109,110 nos quais se mostrou que a butanodio na é capaz de transferir um grupo acetila para certas outras moléculas, inclusıve para a própria butanodiona e que o produto desta última reação è, por sua vez capaz de acetilar outros compostos. 109

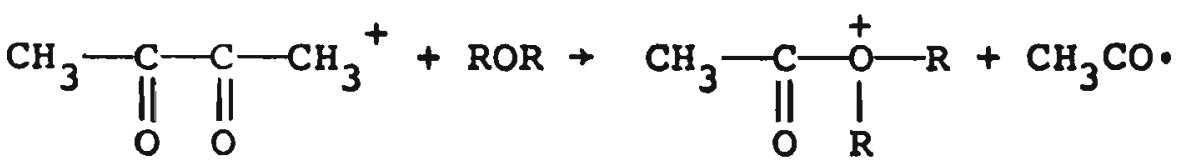<smiles>CC(=O)OC(C)=O</smiles>

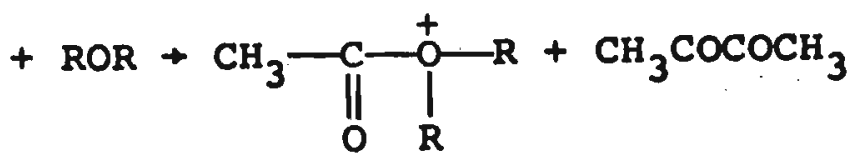


TABELA 4.2 .

Constantes de velocidade de reações no sistema da acetona ${ }^{108}$

\begin{tabular}{|c|c|c|c|}
\hline reagente iônico & produto iônico & $\mathrm{k}\left(\mathrm{x} \quad 10^{9} \mathrm{cn}\right.$ & $\left.1 a^{-1} \cdot s^{-1}\right)$ \\
\hline & & experim. & teōrico ${ }^{a}$ \\
\hline $\mathrm{CH}_{3}^{+}$ & $\mathrm{b}$ & 2,0 & 1,68 \\
\hline $\mathrm{CH}_{3}^{+}$ & $\mathrm{CH}_{3} \mathrm{CO}^{+}$ & 0,92 & \\
\hline $\mathrm{CH}_{3}^{+}$ & $\mathrm{CH}_{3} \mathrm{COCH}_{3}^{+}$ & 0,20 & \\
\hline $\mathrm{CH}_{3}^{+}$ & $\left(\mathrm{CH}_{3} \mathrm{COCH}_{3}\right) \mathrm{H}^{+}$ & 0,2 & \\
\hline $\mathrm{CH}_{3} \mathrm{CO}^{+}$ & $\mathrm{b}$ & 0,43 & 1,18 \\
\hline $\mathrm{CH}_{3} \mathrm{CO}^{+}$ & $\mathrm{CH}_{3} \mathrm{COCH}_{3}^{+}$ & 0,04 & \\
\hline $\mathrm{CH}_{3} \mathrm{CO}^{+}$ & $\left(\mathrm{CH}_{3} \mathrm{COCH}_{3}\right) \mathrm{H}^{+}$ & 0,39 & \\
\hline $\mathrm{CH}_{3} \mathrm{COCH}_{3}^{+}$ & $\mathrm{b}$ & 0,54 & $.1,09$ \\
\hline $\mathrm{CH}_{3} \mathrm{COCH}_{3}^{+}$ & $\left(\mathrm{CH}_{3} \mathrm{COCH}_{3}\right) \mathrm{H}^{+}$ & 0,38 & \\
\hline $\mathrm{CH}_{3} \mathrm{COCH}_{3}^{+}$ & $\left(\mathrm{CH}_{3} \mathrm{COCH}_{3}\right) \mathrm{CH}_{3} \mathrm{CO}^{+}$ & 0,19 & \\
\hline$\left(\mathrm{CH}_{3} \mathrm{COCH}_{3}\right) \mathrm{H}^{+}$ & $\mathrm{b}$ & 0,43 & 1,08 \\
\hline$\left(\mathrm{CH}_{3} \mathrm{COCH}_{3}\right) \mathrm{CH}_{3} \mathrm{CO}^{+}$ & $\mathrm{b}$ & $<0,54$ & 0,97 \\
\hline
\end{tabular}

a) Equação 3.14 .

b) Foi medida apenas a velocidade de desaparecimento do Ion reagente.

Misturas de butanodiona e butanodiona-d 6 mostraram que 0 grupo acetila adictonado à molécula de butanodiona è o que é transfer do quando este complexo acetila alguma outra molécula. o próprio grupo $\mathrm{CH}_{3} \mathrm{CO}^{+}$não é agente acetilante. Os compostos que 
podem rosceber o grupo $\mathrm{CH}_{3} \mathrm{CO}^{+}$são: ${ }^{10}$ älcoois, éteres, aminas, al deidos, cetonas, ácı́dos, ésteres, cloreto de acetila, nitrilas, nitroalcanos; com os haletos de alquila a reação é muito lenta e nos alcanos nem ocorre. A reação foi sugerida como meio de ionização quimica, ${ }^{110}$ foi usada para distınguir os epímeros exoe endo-norborneol, achando-se que o exo-norborneol reage mais ra pidamente, ${ }^{111} \mathrm{e}$, atravēs de acetilação com butanodiona, encon traram-se efeitos estéricos em reações entre Ions e molēculas em fase gasosa: ${ }^{112}$ enquanto que os orto-derivados do fenol, $\mathrm{C}_{6} \mathrm{H}_{3} \mathrm{R}_{2} \mathrm{OH}$, com $\mathrm{R}=\mathrm{H}, \mathrm{CH}_{3}$ e $\mathrm{C}_{2} \mathrm{H}_{5}$, são acetilados, os $\operatorname{com} \mathrm{R}=\mathrm{CH}\left(\mathrm{CH}_{3}\right)_{2}$ $\mathrm{C}\left(\mathrm{CH}_{3}\right)_{3}$, não o são; porēm, se os substituintes estão nas posi ções meta, todos esses derivados reagem. A butanodiona tambēm Intervēm em reações de condensação, sem fragmentar. 113

Para finalizar, deve ser mencionada ainda a importān cia das reações entre íons e molēculas em cetonas na elucidação das estruturas dos produtos dos rearranjos de Mclafferty • Na seção 4.1. estas estruturas foram apresentadas (reações 4.2. e 4.3.), mas na realidade existe: ainda muita discussão em torno das mesmas. O. problem é: 0 que acontece com o enol formado no primeiro rearranjo de McLafferty (reação 4.2.)? Em reaçōes posteriores essa espécle reage na forma enólica ou volta a uma forma cetônica? Neste segundo caso, qual a escala de tempo em que - processo ocorre? Se o produto do primeiro rearranjo de . McLafferty voltar a uma forma cetōnica, o produto do segundo rearranjo de McLafferty obviamente não poderá ter a estrutura indicada na reação 4.3. O problema foi atacado por meio de ressonân cia clclotrônica de ions ${ }^{100,114-117}$ e espectrometria de massa convencional. $118-120$ os resultados são frequentemente contraditörios, justamente por causa das escalas de tempo diferentes nas diversas tëcnicas. Uma Indicação clara disto fol obtida por 
ressonância ciclotrônica de ions $i^{117}$ quando o ion molecular da 2-propilciclopentanona sofre um rearranjo de McLafferty, o produ to dá reações tỉpicas de enol quando o tempo de permanência dos ỉons na cela não é muito longo, mas dā reaçōes típlcas de ceto nas a tempos de residência maiores. Isto indica que a forma enólica tem um tempo de. vida entre 1 e 5 ms, mas 1sto só vale pa ra o caso especifico desta ciclopentanona.

\subsection{O espectrômetro de ressonância ciclotrônica de ions}

o espectrômetro usado na realização das experiências relatadas nesta tese foi fabricado comercialmente pela Varian Associates (Palo Alto, California, USA), sob a designação de Syrotron ICR - 9, modelo V - 5902. O instrumento consiste de vā rlas unidades que serão descritas a seguir. Essa descrição serā talvez demasiadamente extensa, pois tambēm detalhes de operação do espectrômetro serão mencionados, mas eventualmente ela possa ser ütil, uma vez que na versão atual, após a introdução de uma série de modificações no espectrômetro, ele pouco corresponde ao catālogo.

o imã pode talvez ser considerado a peça central do conjunto, pelo menos devido ao seu peso $(810 \mathrm{~kg})$. Trata-se de um eletro-Imã (modelo V - 3400), cujos polos têm um diâmetro de $22,8 \mathrm{~cm}$ ( 9 polegadas), sendo, porém, de $19,5 \mathrm{~cm}$ o diâmetro efeti vo, devido às peças polares que reduzem a distância entre os polos para $5 \mathrm{~cm}$. O Imã tem duas bobinas de baixa impedância(1/8 8 ) ligadas em sérle e refrigeradas por água proveniente de um troca dor de calor. Este tem um circuito fechado de água destilada, que circula pelas bobınas do Imã e pela fonte do mesmo; esta água é, por sua vez, refrlgerada por água da canalização do préd1o. Dols 
interruptores termo-sensiveis despligam a corrente do ímã, se a temperatura das bobinas subir acima de $70^{\circ} \mathrm{C}$ por falta de refrige ração. Para uma proteção adicional foi instalado posteriormente um controlador de pressão (Danfoss, Dinamarca), que não permi te que o Imã seja ligado se não houver pressão suficiente $(\sim \mathrm{kg} /$ $\mathrm{cm}^{2}$ ) na linha de água externa ou a bomba do trocador de calor não estiver ligada. A máxima corrente por bobina é de 168 A, a qual vem de uma fonte regulada de $7 \mathrm{~kW}$ (modelo $\mathrm{V}-2503$ ). Variando a corrente nas bobinas, è possível controlar o campo magnético pro duzido pelo Imã entre 0 e 14300 G (acima disto, ele desliga auto maticamente). Este controle é feito numa unidade separada, registrada pela Varian sob o nome de Fieldial (modelo Mark I) e que faz parte do painel do instrumento. Nesta unidade existe um controle grosso que permite ajustar o campo magnético continuamente entre 0 e $14300 \mathrm{G}$, sendo de 5 G a menor divisão da esca la correspondente. Um controle fino permite ajustar o campo mag nético entre o que indica a escala do controle grosso e 99,9 G acima deste valor (menor divisão nesta escala: 0,1 G). No interior do Fieldial há dois potenciômetros para calibrar as escalas do campo magnético; para fazer isso è necessārio observar um s1nal numa experiência de ressonâncla ciclotrôntca de ions. Existe tambēm uma chave (externa) que permite selecionar um interva10 de varredura, por exemplo, $10 \mathrm{kG}$ (o intervalo mais usado, mas existem intervalos desde $250 \mathrm{mg}$ até $40 \mathrm{kG}$ ). Associado a esta chạ ve existe um potenciômetro que possibilita varrer o campo magnético entre -508 e +508 do que indica o seletor de intervalo de varredura e ao redor do que indicam os controles grosso e fino de campo magnético. Exemplificando: Se o campo magnético è ajustạ do em $6000 \mathrm{G}$ (controle grosso) e o seletor de intervalo de varre dura estä em $10 \mathrm{kG}$, com o potenciômetro de varredura o campo 
magnëtioo pode ser variado desde 1000 G (50\% de 10 kG substraí dos de $6000 \mathrm{G})$ até $11000 \mathrm{G}(50$ z de $10 \mathrm{~kg}$ somados a $6000 \mathrm{G})$. Esta varredura pode ser feita automaticamente, pois o potenciómetro po de ser acionado mecanicamente por um relógio; pode-se varrer no sentido de campos magnéticos mals altos, como no de campos mais baixos. Um aspecto importante nesse eletro-imã da Varian è que não è a corrente das bobinas a grandeza controlada, mas sim, o próprio campo magnētico. Quando a corrente é controlada, o campo magnético real depende de se o ímã acabou de ser ligado, ou a corrente foi aumentada ou diminuida, por causa da histerese do Imã. A Varian emprega o efeito Hall para regular o campo magnético. Um cristal semicondutor de Hall é colocado num dos polos do ỉmã e uma corrente passa através do cristal numa dada direção; o campo magnético tem que ser perpendicular a essa direção e então aparece uma diferença de potencial perpendicular à corrente e ao campo magnētico. Essa diferença de potencial, proporcional ao campo magnétıco, è medida e usada para gerar um sinal de erro, que por sua vez reajusta a corrente através das bo binas, para que o campo magnëtico seja o indicado pelos contro les externos. Finalmente, hã uma chave para poder inverter o campo magnético.

Para realizar uma experiência, a cela de ressonância ciclotrônica de Ions precisa obviamente estar entre os polos do Imã, mas todo o sistema de vācuo está montado sobre uma articu lação que permite girar a cela para fora dos polos do Imã, o que facilita qualquer trabalho nela ou no sistema de vácuo. A cela foi descrita na seção 2.3.3. A FIGURA 2.5. apresenta a cela com uma seção retangular $(1,27 \mathrm{~cm} \times 2,54 \mathrm{~cm})$, que foi a nor malmente usada. A Varlan também forneceu uma cela de seção quadrada $(2,54 \mathrm{~cm} \times 2,54 \mathrm{~cm})$, usada em algumas experiênclas. Estas 
peças são construídas de placas de cobre prateada, fixas a postes de cerâmica por meio de grampos.

A FIGURA 4.1. mostra o sistema de vācuo do espectrômetro. O desenho è esquemático, pois não está em escala, não são mostradas as flanges e os cotovelos não correspondem à realidade. O sistema é todo construído de aço inoxidável. As flanges são do tipo "conflat". com guarnições de cobre; algumas flanges são rotatörias.

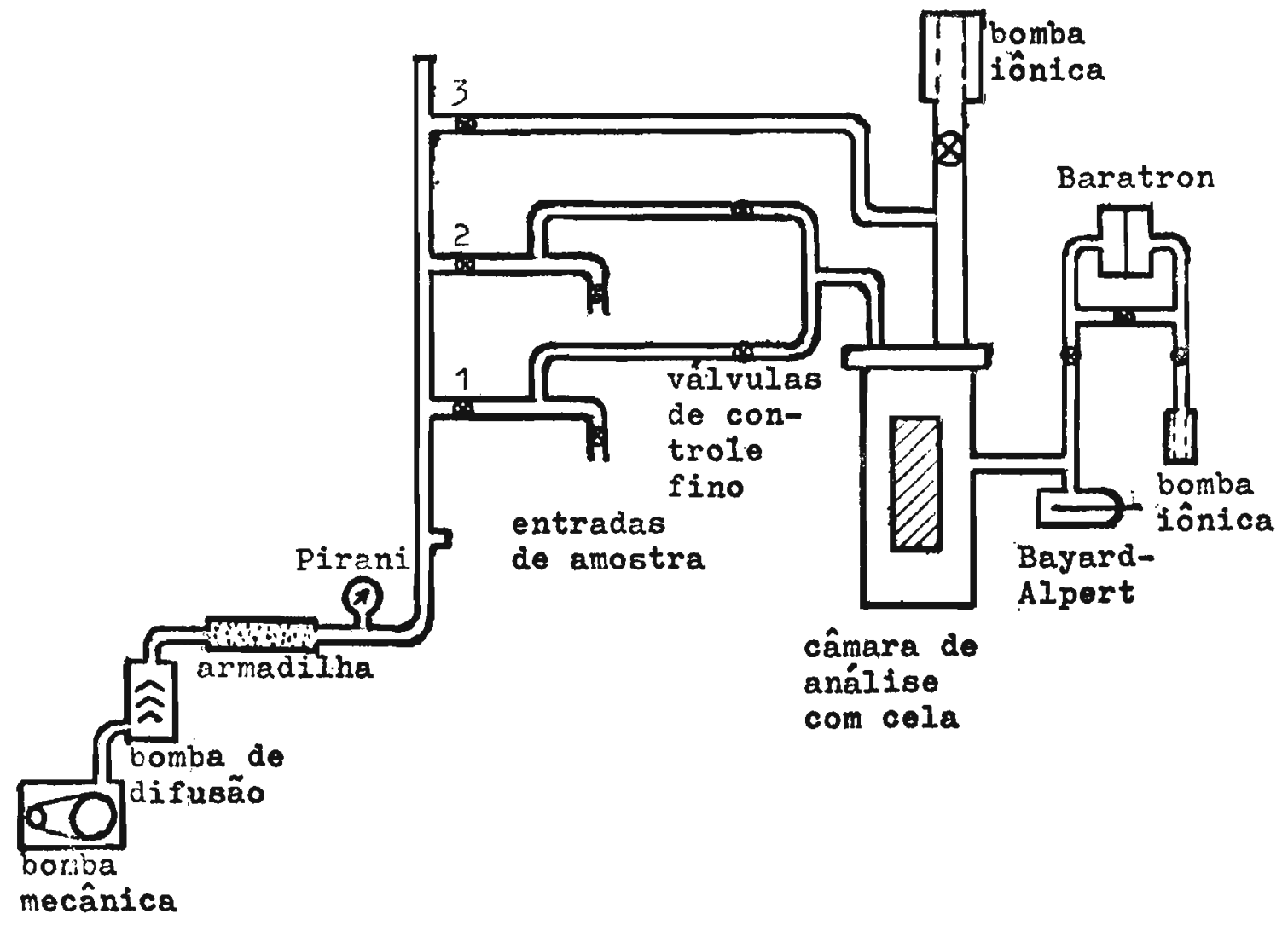

FIGURA 4.1. Sistema de vácuo do espectrômetro de ressonância ciclotrônica de íons.

A cela fica numa câmara, na qual ela entra quase sem nenhuma folga na direção paralela ao campo magnētico; nas outras direçōes existe espaço livre. A câmara pode ser retirada, soltando-se uma flange, de modo a expor completamente a cela, o que 
é necessārio para substitui-la ou trocar um filamento. Os fios que conectam as placas da cela com as diversas fontes de rádiofrequência e corrente continua, entram pela base da flange atravēs de dois conectores de olto pinos e de dois conectores blinda dos (TNC) (oscilador marginal e eletrômetro; vide seção 2.3.3.). A câmara de análise está ligada a uma bomba tônica (Varian VacIon, $8 \mathrm{l} / \mathrm{s})^{121}$ por um tubo de $3,0 \mathrm{~cm}$ de diâmetro interno (os outros tubos do sistema têm $1,1 \mathrm{~cm}$ de diâmetro). A parte de alto vácuo está isolada da parte de baixo văcuo pelas válvulas de con trole fino e a vālvula 3 (FIGURA 4.1.). Só quando a cela foi ex posta à pressão atmosférica é que se abre a válvula 3, para baixar a pressão na câmara de anālise até $10^{-5}$ Torr e poder ligar a bomba iônica. A parte de baixo vácuo forma uma antecâmara, eva cuada por uma bomba mecânica e uma bomba de difusão de óleo refrigerada por água (estajinintalada posteriormente). Uma armadilha de peneira molecular completa o sistema de bombeamento, ca paz de evacuar a antecâmara até aproximadamente $10^{-5}$ Torr. Um medidor de Pirani 1ndica essa pressão, sendo a leitura feita no painel do espectrômetro.

Há duas entradas de amostras, que terminam em juntas 14/35 de aço inoxidável (macho). Para introduzir uma substância liquida (na temperatura e na pressão ambientes), procede-se da seguinte maneira: Coloca-se a substância num tubo com junta 14/35 (fêmea) e liga-se o tubo à entrada do espectrómetro, untan do a junta com graxa (Apiezon $N$ ). Congela-se a substância (geralmente com nitrogênto 1iquido, no qual o tubo è mergulhado)e abrem se a vâlvula da entrada de amostras e a vâlvula 1 lou a 2, se for - caso, FIGURA 4.1.), de modo a bombear todo o ar do tubo. Em segulda fecha-se a vălvula da entrada de amostras, deixa-se descongelar a substâncla e repete-se o processo (congelamento, bom- 
beamento, descongelamentol, atē desgassificar totalmente a substância. Se a amostra é gasosa, ela é geralmente armazenada num balão de vidro de $250 \mathrm{ml}$, provido de torneira de alto vácuo e junta fêmea $14 / 35$ (FIGURA 4.2.); neste caso só é prec1so bombear

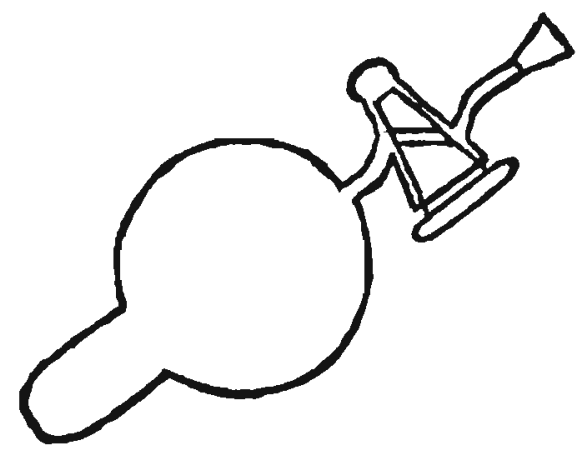

FIGURA 4.2. Balão para amostras gasosas.

- ar que fica entre a torneira do balão e a vālvula da entrada do espectrômetro, não havendo necessidade de congelar a amostra. Feito 1sso, fecha-se a válvula 1 (ou a 2), abre-se a de amostras (no caso de usar o balão da FIGURA 4.2., abre-se a torneira do mesmo) e abre-se lentamente a vālvula' de controle finó.Es ta vălvula è constituỉa por um selo de cobre (anel) no qual encosta a face polida de uma safira, impedindo a passagem do gás; a safira é levantada por uma alavanca, que por sua vez è acionada por um eixo com rosca. Assim é possivel controlar bas tante bem o fluxo de gás que entra na câmara de análise; o gás é bombeado continuamente pela bomba iônica. Com 1sto a cela é sempre banhada por quantidades novas de gás, evitando-se o acúmulo de eventuais produtos de pirólıse devidos ao fllamento quen te.

A própria bomba iôntca permite conhecer a pressão na câmara de anālise, uma vez que a corrente através da bomba se 
relaciona com a pressão; esta corrente é medida e pode ser lida no painel do espectrômetro, num instrumento de escala linear de 1 a 10 (divisões de 0,2); um multiplicador permite selecionar 0 intervalo de pressão: $10^{-8}, 10^{-7}, 10^{-6}$ e $10^{-5}$ Torr. Com o multiplicador em qualquer uma dessas posições, a bomba desliga auto maticamente acima de $10^{-4}$ Torr; existe uma posição, designada START, para ligar a bomba; para fazer isto tem que se ter certeza de que a pressão está abaixo de $10^{-4}$ Torr, pois nesta posi ção a bomba não está protegida, não desligando automaticamente.A medição de pressão baseia-se no princỉpio do medidor Penning 122 e, como neste, existem problemas de reprodutibilidade. No entanto, a maior parte das experiências relatadas nesta tese foi realizada, usando, como única indicação de pressão, a corrente da bomba iônica, como descrito. Posteriormente foi adicionado ao espectrômetro um sistema de medição de pressão de malor confiabilidade. Existe na parte lateral da câmara de análise, na dire ção perpendicular ao campo magnético, uma flange $(1,5 \mathrm{~cm}$, diâmetro do orificio), à qual foi ligado um tubo que faz a união com dois medidores de pressão: um medidor de ionização do tipo Bayard-Alpert ${ }^{123}$ e um medidor de diafragma ${ }^{124}$ (FIGURA 4.1.). De vido à sensibilidade do medidor de ionização ao campo magnētico, existem $55 \mathrm{~cm}$ de tubo entre a câmara de anālise e o medi dor. Isto faz com que o sistema demore para entrar em equili brio, mas torna o medidor praticamente insensível a campos magnẹ ticos menores que $9 \mathrm{~kg}$. Uma välvula permite isolar todo esse sistema de medição de pressão. o medidor de Ionização fol inicialmente usado para calibrar o medidor assoclado à bomba iônica do espectrômetro; não se trata propriamente de uma calibração, pois as le1turas no controle da bomba lônica não são reprodutị veis num intervalo de tempo de algumas horas. o que se queria 
verificar, era a linearidade desse medidor. O gráfico da FIGURA 4.3. , de leituras no controle da bomba iônica em função de leitú ras no medidor de ionização, mostra que a resposta do primeiro

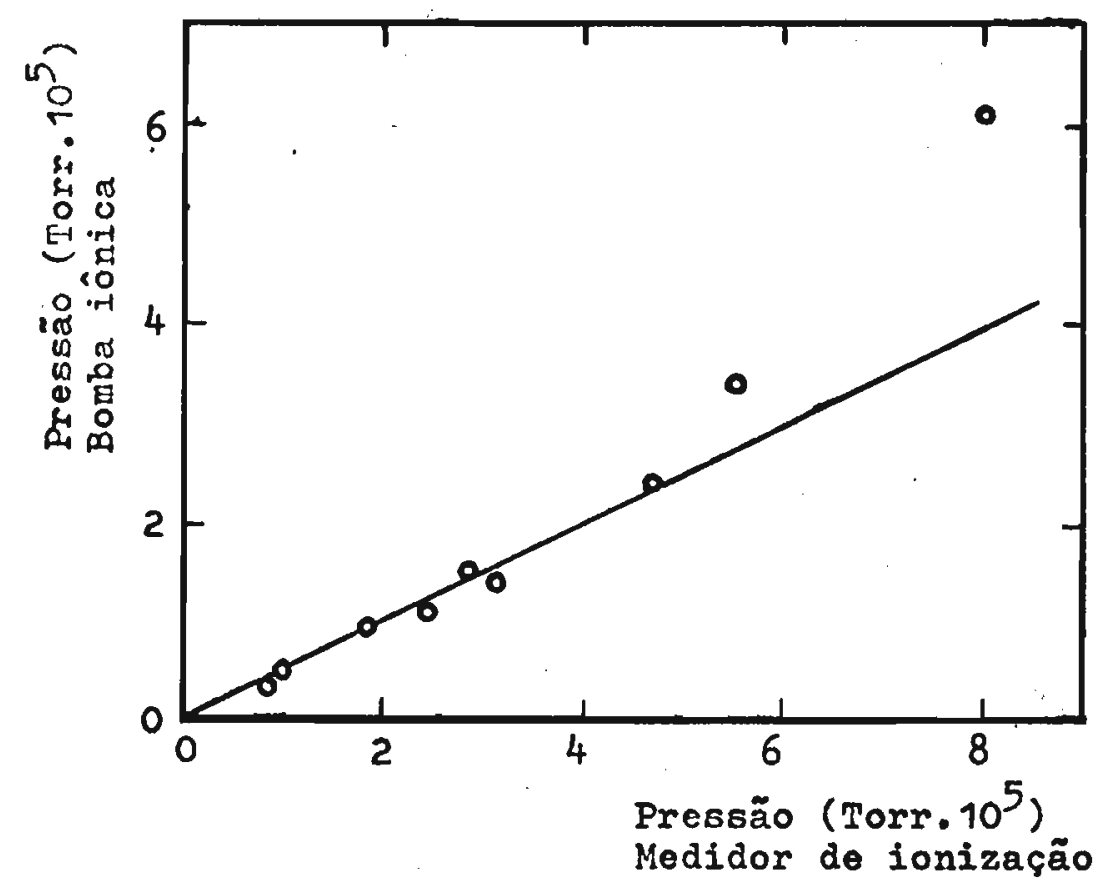

FIGURA 4.3. Verificação da linearidade do medidor de pressão associado à bomba iônica, com o medidor de ionização.

medidor è linear até $5 \cdot 10^{-5}$ Torr. Devido ao seu principio de funcionamento, a pressão indicada por um medidor de ionização depende da natureza do gãs. Logo, è necessārio calibrá-lo com um outro instrumento, que não tenha essa limitação. Perguntar se-ia certamente por que não usar diretamente esse segundo dispositivo? o problema è que não existe nenhum indicador de pres são desse tipo que opere na faixa de interesse em ressonância cí cloțrônica de ions, isto é, de $10^{-8}$ a $10^{-3}$ Torr. 0 medidor de ionização funciona nesse intervalo de pressão e por isso é usado durante a experiência, sendo depois calibrado numa faixa de pressão adequada para o medidor de comparação $\left(10^{-4}\right.$ a $10^{-3}$ Torr $)$, fazendo-se a suposição de que a curva de calibração continue 
linear até pressões mais baixas. Para a caliḅração é usado um medidor de diafragma, que na realidade mede pressões relativas. Consta de duas câmaras separadas por um diafragma que se deforma, se a pressão nas duas câmaras è diferente, e que constitui uma placa de um condensador, o qual faz parte de uma ponte de rädiofrequência. No nosso laboratório uma das câmaras é constantemen te mantida numa pressão da ordem de $10^{-8}$ Torr por meio de uma pe quena bomba iônica (2 1/s, Varian VacIon, FIGURA 4.1.); esta pres são é considerada zero quando comparada com $10^{-4}$ Torr; assim o medidor indica diretamente a pressão no sistema, podendo ser usa do desde 1 Torr até $3 \cdot 10^{-4}$ Torr (fundo de escala, sendo $1.10^{-5}$ Torr a menor divisão da escala). Realizando experiências de ressonância ciclotrônica de ions nessas pressões mais elevadas es se medidor poderia ser usado diretamente; no entanto, isto é difícil, pois o instrumento é pouco estável por longos períodos de tempo, sendo extremamente sensĩvel a variações de temperatura (o sensor foi colocado dentro de uma caixa de espuma de plástico,mas mesmo assim, ainda é afetado por correntes de ar). Ambos os medidores, o de ionização (Veeco) e o de diafragma (MKS Baratron), possuem saldas para um registrador. Para fazer a calibração, es tas duas saídas são ligadas num registrador XY (Varian F - 80A). Em seguida, operando uma das vālvulas de controle fino: (FIGURA 4.1.), a amostra é introduzida na câmara de análise, registrạ do-se a leitura do medidor de Ionização em função da leitura do medidor de diafragma. A FIGURA 4.4. mostra um registro obtido para o caso da acetona; o instrumento da Veeco foi ligado ao eixo $\underline{X}$ do registrador e o Baratron ao $\underline{Y}$ (notar que a saída do me didor da Veeco é negativa). A introdução do gás no sistema tem que ser lenta, pois o equilỉbrio de pressão demora um pouco até ser alcançado; se o gãs entra muito rapidamente não se obtém uma reta no gráfico de calibração. 


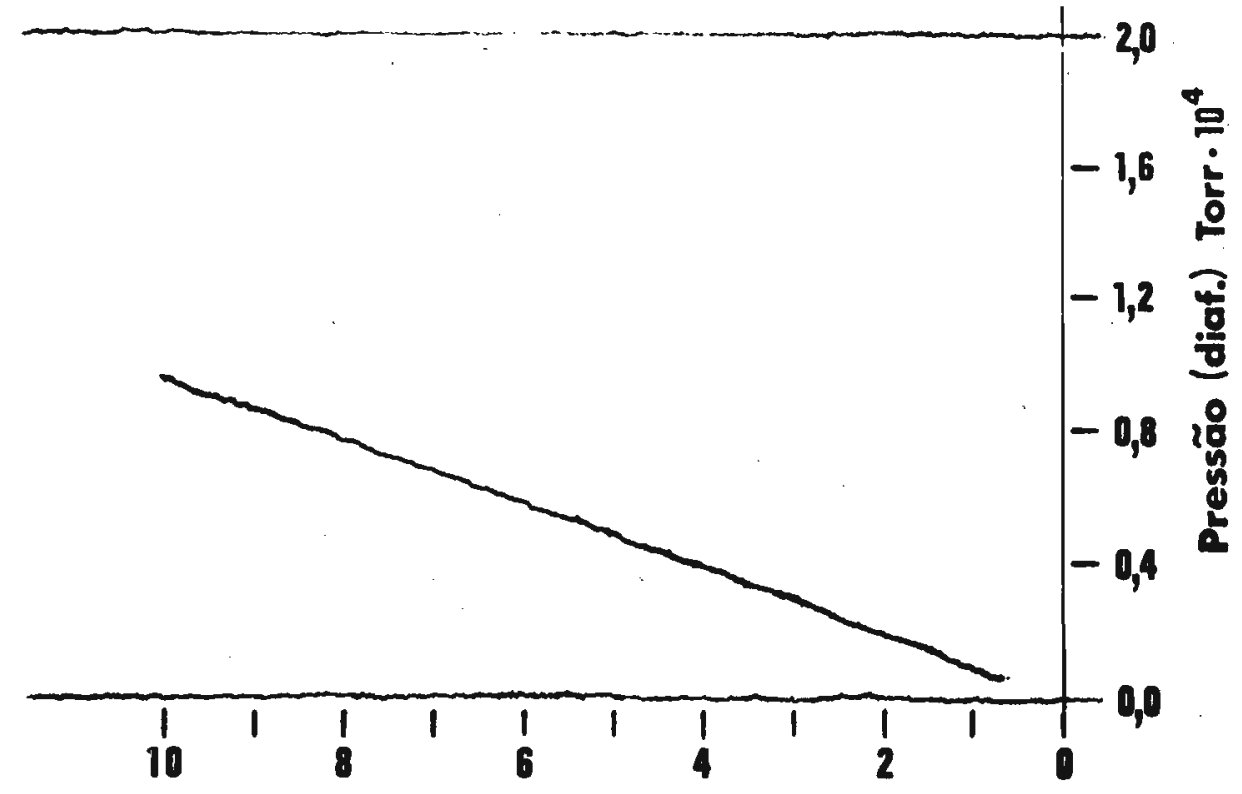

Pressão (ioniz.) Torr $\cdot 10^{5}$

FIGURA 4.4. Calibração do medidor de ionização com o de diafragma. Da inclinação da reta obtém-se que as leituras do medidor de ionização devem ser multiplicadas por 0,96 , para obter a pressão corriglda.

o sistema de vácuo do instrumento pode ser aquecido a pós a realização de uma experiência, para fins de limpeza. Ele fica praticamente todo dentro de um forno, podendo ser aquecido até $150^{\circ} \mathrm{C}$. A câmara de análise tem aquecedores separados,po dendo a temperatura da câmara ser elevada até $250^{\circ} \mathrm{C}$. O aquecimento desliga automaticamente após um tempo pré-selecionado (ge ralmente $8 \mathrm{~h}$ ). O sistema de medição de pressão adicionado posteriormente ao espectrômetro teve seus tubos envolvidos com fita de aquecimento. 
Fixado à armação do sistema de vãcuo e próximo à câmara de análise, para manter curta a ligação à cela, está o oscila dor marginal (FIGURA 2.1.). Trata-se de um circuito a válvulas, capaz de operar a $767,85 \mathrm{kHz}, 307,14 \mathrm{kHz}$ e, continuamente variāvel entre 153,57 e $76,78 \mathrm{kHz}$. A mudança de frequência é conse guida, encaixando no oscilador diferentes unidades, que consis tem essencialmente de uma bobina que faz parte do circuito LC; aunidade de frequência variāvel tem tambēm um condensador variāvel. As frequências relacionadas acima correspondem, respectiva mente, às seguintes relações entre campo magnētıco e razão massa/carga (em unidades atômicas): 500, 200, 100 e 50 G/u.m.a. (ve ja a equação 2.3.). No oscilador marginal existe uma saida para medir a frequência, o que é feito com um contador Hewlett-Packard 5216A (Hewlett-Packard, Palo Alto, Califörnia, USA), e, um poten ciômetro para ajustar o nível de oscilação, indicado num micrô amperímetro (é só uma lettura proporcional à amplitude de oscila ção) .

Na mesa do espectrômetro estão, além da unidade de coṇ trole do campo magnético, mencionada acima, um detetor de fase, uma unidade de controle dos diversos potenciais da cela, o oscilador de ressonância dupla, o controle dos aquecedores do sistema de vācuo, o controle da bomba iôntca e uma unidade de modulação da energia eletrônica.

Alēm dos controles usuais de um detetor de fase, existem no palnel do mesmo alguns controles especificos do espectrômetro de ressonância clclotrônica de ions. Assim, tem-se o eletrômetro (ligado à região coletora de ions da cela) com escala de 1 a 10 (divisões de 0,2) e um multiplicador de 13 posições, de $10^{-10}$ a $10^{-14}$ A. Há tambēm uma chave inversora de polaridade, que trabalha junto com os potenciometros para os diversos poten- 
ciais da cela (isto será descrito mais abaixo). Alēm disso, há uma chave para selecionar o tipo de modulaçäo (vide seção 2.3.4.1.): modulação de campo magnētico, modulação de tensão de arraste na região fonte da cela e, nenhuma modulação. Esta últí ma posição da chave è usada quando se deseja empregar algum outro tipo de modulação, por exemplo, de energia eletrônica. Hã ainda uma chave para ajustar a amplitude de modulação do campo magnético, entre 0,025 e $20 \mathrm{G}$, sendo geralmente usadas amplitudes de 10 ou $20 \mathrm{G}$. O detetor de fase tem um controle de fase (fase entre a onda de referência e o sinal, vide seção 2.1.), um controle de sensibilidade, um controle de tempo de resposta (cons tante de tempo), e um mostrador, no qual é lida a amplitude do sinal. Esse detetor de fase opera na frequência de modulação de $27 \mathrm{~Hz}$, fixa. O sinal detectado pelo oscilador marginal entra num osciloscópio (Hewlett-Packard 130C) e tambëm no detetor de fase, onde è processado, Indo depois ao eixo $\underline{Y}$ de um registrador XY (Varian F-80A), cujo eixo X está ligado com o potenciômetro de varredura do campo magnētico. No painel posterior do detetor de fase há um conetor no qual a frequêncla de modulação de $27 \mathrm{~Hz}$ está disponível, podendo ser usada para algum outro tipo de modulação (por exemplo, de energia eletrônica). Por um oụ tro conetor pode tambëm ser introduzida uma frequência de modula ção qualquer, se uma chave ao lado do conetor for colocada na po sição apropriada para essa operação. Isto è muito útil, pois permite utilizar um outro detetor de fase, sem a necessidade de fazer muitas ligações: basta introduzir no conetor mencịonado a frequência de modulação gerada pelo segundo detetor de fase e In troduzir nele o sinal do oscilador marginal. Isto foi felto fre quentemente, tendo sido usado o detetor de fase da PAR (Prince ton Applied Research, Princeton, N. J., USA, modelo 121), que 
tem a vantagem de ser mais sensivel $(10 \mu \mathrm{V})$, de poder operar entre $1,5 \mathrm{~Hz}$ e $150 \mathrm{kHz}$, e de ter um supressor de zero (conveniente para observar uma pequena variação na intensidade de um sinal).

Outra unidade da mesa do espectrômetro é a que reúne os controles de corrente de emissão, de energia eletrônica e dos potenciais das plácas da cela. A corrente de emissão (corrente de elétrons emitidos pelo filamentol pode ser variada, varian do a corrente atravēs do filamento, que geralmente não ultrapas sa 4 A e que pode ser lida no voltimetro de energia eletrônica (ver abaixo), ligando este em paralelo a uma resistência de precisão, pela qual passa a corrente a ser medida; para fazer esta ligação, basta pressionar um botão. A corrente de emissão é lida num microamperimetro ligado entre o coletor de elétrons da cela e "terra". Como a menor divisão da escala deste instrumen to é de $0,2 \mu \mathrm{A}$, e como se deseja trabalhar frequentemente a cor

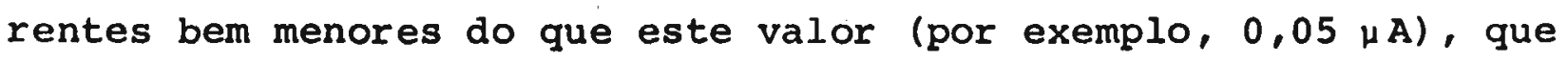
não podem ser lidas com precisão, o microamperimetro foi substituido por um instrumento da RCA (Harrison, N. J., USA, modelo WV - 511A), cọ uma sensibilidade de até 1 pA. Tanto o amperime tro orlginal da Varian, como o da RCA, fazem parte de um circu1 to de realimentação que controla a corrente de emissão; se essa corrente varia, o circuito faz com que a corrente de filamento au mente ou diminua, conforme o caso, para manter constante a corrente de emissão. Isto è em principlo importante, pois varrendo o campo magnético no sentido de campos maiores, o felxe de elëtronsque sai do filamento é progressivamente mais bem focaliza do, de modo que mals elétrons entram na cela; 1sto precisa ser compensado, reduzindo a corrente de emissão. Porém, usando uma fonte externa (Hewlett-Packard, 6281A, 0 a $7,5 \mathrm{~V}$ e 0 a 5 A), para alimentar o filamento, de modo que a corrente de emissão pas- 
sasse a não ser mais regulada, notou-se que o efeito do campo magnético sobre a corrente de emissão só é perceptivel a campos menores que 1 kG, ou seja, só se observa uma variação na corren te de emissão ao varrer o campo magnētico entre 0 e 1 kG; daí a té os $14 \mathrm{kG}$ a corrente permanece constante. Resolveu-se então usar definitivamente a fonte HP 6281A, pois dificilmente se trabalha a menos de $1 \mathrm{kG}$. A fonte da Varian também não fornece a corrente necessária para trabalhar com o filamento de seção retangular, que requer uma corrente maior que o de seção circular para a mesma corrente de emissão, tendo, porém, a vantagem de ser de maior durabilidade. A fonte HP 6281A fornece até 5 A de corrente regulada e tem um controle fino, permitindo ajustar melhor a emissão.

A energia eletrônica (potencial do filamento em rela ção à "terra") è ajustada por meio de um potenciômetro, entre 0 e $100 \mathrm{~V}$ e lida num voltimetro (pode ser lida também num voltí metro externo, para o que há um ponto de prova). Existe uma chave que, colocada na posição adequada, permite varrex a energia eletrônica entre o que è ajustado com o potenciômetro e ?0 $\mathrm{V}$ acima desse valor. A varredura é feita com o mesmo potenciômetro que varre o campo magnético, localizado no controle do campo magnético (ver acima).

Cinco potenciômetros de dez voltas são usados para ajustar os potenciais nas placas da cela: arraste inferior e su perior da região fonte, arraste infertor e superior da região analisadora e aprisionamento (vide FIGURA 2.5.). Todas essas tensões podem ser medidas em pontos de prova apropriados, poden do ser varladas entre 0 e $3 \mathrm{~V}$ (valores em mödulo, pois, depen dendo da placa da cela, o potencial é positivo ou negativo). o potencial no coletor de elétrons precisa ser regulado com chave 
de fenda e pode ser medido num ponto de prova; geralmente não se altera esse potencial (qualquer valor entre 4 e $20 \mathrm{~V}$ é adequado). Todas essas tensões, chegam à cela pelos conetores de of to pinos da base da câmara de análise, exceto a da placa inferior da região analisadora, que entra junto com a rádio-frequência do osci lador marginal. Examinando ions positivos, são positivos os potenclais nas placas de aprisionamento e nas placas superiores de arraste; nas placas inferiores de arraste os potenciais são nega tivos. Para examinar ions negativos, bastaria tornar negati vas as placas de aprisionamento, o que neutralizaria os ions positivos, retendo os negativos na cela. Entretanto, para poder es tudar Ions negativos e preservar a configuração do campo elētrico no interlor da cela, todos os potenciais são invertidos simultaneamente por melo de uma só chave (localizada no painel do detetor de fase). Mas, invertendo o campo elétrico de arraste, os ions passam a deslocar-se no sentido errado na cela, isto é, não vão do fillamento em direção à região de añálise (equação 2.16.); para resolver este problema, o campo magnético tambëm precisa ser invertido.

O oscilador de ressonância dupla opera até $1 \mathrm{MHz}$, sendo a frequência ajustāvel num potenciômetro de dez voltas e podendo ser medida com um contador (Hewlett-Packard 5216A) 1igado a um conetor no painel posterior da unidade. A amplitude da rādio-frequência é selecionada com uma chave (não pode ser varia da de forma continua) entre 0,0012 e $1 \mathrm{~V}$ (valor eficaz). Uma chave de três posições permite aplicar a rädio-frequêncla de for ma continua na cela, de forma intermitente, sendo Iguals os períodos em que está ligada e desligada (onda quadrada de $27 \mathrm{~Hz}$ sobreposta à rảdlo-frequência) e, de forma pulsada, podendo a largura dos pulsos de rádio-frequência ser variada com uma cha- 
ve, mas'não podendo ser variada a frequência de pulsação, que per manece constante em $27 \mathrm{~Hz}$ (é a frequência de modulação produzida pelo detetor de fase). Colocando uma chave na posição adequada e escolhendo com outra um intervalo de varredura ( $1 \mathrm{kHz}, \ldots, 1$ MHz), a frequência de rádio pode ser varrida com o potenciômetro da varredura de cámpo magnētico. A experiência de ressonância dụ pla è realizada da seguinte maneira (veja tambëm a seção 2.3.4.2.): Ajustam-se campo magnético e frequência do oscilador marginal para ter o mãximo de absorção de algum produto iônico (é preciso es tar realmente no pico da absorção o que, no caso de estar usando modulação de campo magnético, corresponde a ter o campo magnético em que a derivada da linha de absorção cruza a linha base); desliga-se a modulação e liga-se o oscilador de ressonância du pla, modulado em $27 \mathrm{~Hz}$; varre-se a frequência do oscilador numa região na qual se suspeita que estejam os ỉons precursores do prọ duto; às vezes, para obter um sinal mais intenso, é preciso rea justar a fase do detetor de fase. o oscilador de ressonância dujla pode ser ligado tanto à região analisadora da cela (placa superior, seção 2.3.4.2.), como à região fonte (placa inferior, seçäo 2.3.4.3.) para experiências de ejeção de ions. Para selecio nar a região à qual o oscilador é ligado, basta mover uma chave. Dois cabos saem de trās da unidade, Indo cada um para a região apropriáa. Na realidade eles entram primeiro num circuito const tuído por condensadores e bobinas (filtros), que têm a finalidade de fazer com que a rädio-frequência vá realmente para a placa apropriada da cela e não para a fonte da tensão estática aplicada nessa mesma placa. Existem quatro filtros nesse circuito, para os casos em que uma tensão alternada e uma tensão continua têm que chegar à mesma placa da cela: um filtro para a placa infe rior $\dot{a}=$ fonte, na qual tambèm è aplicada a rădio-frequência de 
ejeção de íons; um filtro para a placa superior da região analisadora, na qual também è ligado o oscilador de ressonância dupla; um filtro para a placa inferior da região analisadora, na qual tambēm é ligado o oscilador marginal e um filtro para a pla ca superior da fonte, na qual chega também a onda quadrada para modulação da tensão de arraste na fonte. (Na ligação da ten são de aprisionamento tambēm existe uma bobina).

A próxima unidade da mesa do espectrômetro é a do controle de temperatura do forno, onde está o sistema de vácuo, e da câmara de análise. As temperaturas de forno e câmara são medị das por termopares no interior dos mesmos e lidas num mostrador. E possivel regular a temperatura (do forno até $150^{\circ} \mathrm{C}$, da câmara até $250^{\circ} \mathrm{C}$ ) de modo que, alcançado o valor pré-fixado, este se mantenha. O aquecimento pode ser ligado ininterruptamente ou pode ser ligado para desligar automaticamente após certo núme ro de horas; geralmente aquece-se o aparelho por $8 \mathrm{~h}$ após um dia de uso

Ao lado desta unidade fica a de controle da bomba iôni ca, (com o mostrador e a chave que a liga), que tambēm contēm o Indicador de pressão do medidor de Pirani.

A última unidade è a de modulação de energia eletrōnica (vide seção 2.3.4.1.). Quando essa unidade é ligada, os controles de energia eletrônica mencionados acima ficam inoperantes (a energia ainda pode ser lida no voltímetro). Há um primeiro potenciômetro, de dez voltas, para selecionar a energia eletrôni ca, entre 0 e $100 \mathrm{~V}$. Querendo pulsar a energia eletrōnica, é preciso entrar nessa unidade com a frequência de modulação do de tetor de fase. Essa onda, senoldal, chega à base de um transistor e è amplificada; o transistor trabalha saturado, de modo que 
a senóide é cortada, obtendo-se uma onda quadrada. A amplitude desta acertada com um potenciómetro. Em geral a energia eletrônica é pulsada entre um valor ligeiramente menor que o potencial de ionização da substância em estudo e um valor acima deste potencial. Com o primeiro potenciômetro ajusta-se o limi te inferior da energia eletrônica e, com o outro, a altura do pulso.

\subsection{Compostos usados}

Foram usados os seguintes compostos nas experiências de acetilação, sendo indicada entre parênteses a origem dos mes mos: acetona (Fisher), acetona-d 6 (Merck), butanona (Fisher),pen tanona-2 (Eastman), pentanona-3 (Eastman), hexanona-2 (Light), heptanona-3 (Eastman), 3,3-dimetilbutanona (Eastman), acetofeno na $(\mathrm{BDH})$, etanol (Merck), benzaldeído (BDH).

o composto $2,2,4,4$-tetrametilpentanona-3 (diterciobutilcetona, hexametilacetona, ou pivalona) foi sintetizado a par tir de cloreto de pivaloila e do composto de Grignard do cloreto de terciobutila! $125-127$

$\left(\mathrm{CH}_{3}\right)_{3} \mathrm{CMgCl}+\left(\mathrm{CH}_{3}\right)_{3} \mathrm{CCOCl}+\left(\mathrm{CH}_{3}\right)_{3} \mathrm{CCOC}\left(\mathrm{CH}_{3}\right)_{3}+\mathrm{MgCl}_{2}$

o composto organometálico não reage com o cloreto do ácido a temperaturas baixas $\left(-78^{\circ} \mathrm{C}\right)$, mesmo em presença de cloreto cuproso como catalisador. ${ }^{125}$ A temperaturas mais elevadas $\left(-5^{\circ} \mathrm{C}\right)$, a reação de radicais torna-se importante e não se obtém bom ren dimento em cetona. A maneira mais satisfatória de realizar a condensação parece ser a de juntar os reagentes a $-78^{\circ} \mathrm{C}$ e deixar a mistura de reação atingir a temperatura ambiente gradativamen te. A formação da cetona dá-se lentamente no decorrer da eleva 
ção da temperatura e não ocorrem reações de radicais. ${ }^{125}$ Para a preparação da $2,2,4,4$-tetrametilpentanona-3 for am usados cloreto de terciobutila (Aldrich, destilado inicialmente; ponto de ebuli Ção $46,5-47,5^{\circ} \mathrm{C} / 200$ Torr), cloreto de pivaloila (Merck), éter (purificado da maneira usual para sinteses de Grignard: secagem com cloreto de cálcio, destilação, tratamento com ácido sulfúrí co concentrado, destilação e tratamento com fita de sódio), clore to cuproso (Baker) e magnésio. o composto de Grignard foi preparado da maneira usual: ${ }^{128}$ Num balão de três bocas, $200 \mathrm{ml}$, provi do de agitador com selo de mercúrio, condensador e funil de separação, foram colocados $6,1 \mathrm{~g}$ de magnésio, $22 \mathrm{ml}$ de éter, um cristal de iodo e 1,5 ml de cloreto de terciobutila. O sistema foi aquecido em banho de ar para iniciar a reação e apōs 20 minutos fó ram adicionados $23,5 \mathrm{ml}$ de cloreto de terciobutila em $61,5 \mathrm{ml}$ de èter; essa adição prolongou-se por 40 minutos, durante os quais houve forte refluxo no sistema. Depois de 5 minutos o balão foi aquecido por 1 hora. A seguir passou-se à sintese da cetona propriamente: 0 balão foi resfriado a $-78^{\circ} \mathrm{C}$ com mistura de gelo seco e isopropanol. Foram juntados $11,4 \mathrm{~g}$ de cloreto cuproso e 13,9 ml de clóreto de pivaloila em $15 \mathrm{ml}$ de éter,previamente resfriado a $-78^{\circ} \mathrm{C}$. Agltando continuamente, deixou-se o sistema atin gir a temperatura ambiente, o que levou 1 hora, aproximadamente; continou-se com a agitação por mais 1 hora. O conteúdo do balão foi despejado sobre $150 \mathrm{~g}$ de gelo, filtrado, e o resĩduo sō lido lavado com ēter; foram separadas as fases aquosa e etērica e a fase aquosa tratada mais quatro vezes com éter; os extratos foram reunidos, lavados com soluçāo de bicarbonato de sódio a 58 e āgua. A solução foi secada com sulfato de magnésio, filtrada e o éter destilado. o resíduo fol destilado duas vezes com coluna de fracionamento; na primeira destilação fol recolhido o liquido que 
destilov entre 147 e $153^{\circ} \mathrm{C}$; na segunda, o liquido que destilou en tre 149 e $152^{\circ} \mathrm{C}(\sim 700$ Torr $)$. Ponto de ebulição indicado na litera tura: ${ }^{129} 152-154^{\circ} \mathrm{C}$. Obtiveram-se $3,7 \mathrm{~g}$ de cetona, ou seja, um rendimento de 22\%. Na TABELA 4.3. é apresentada a relação entre - número de mols dos compostos envolvidos na sintese da 2,2,4,4tetrametilpentanona-3 e o número de mols de cloreto de pivaloila empregados. O espectro de ressonância magnética nuclear da cetona (sem solvente e sem referência) apresentou apenas um pico intenso (alguns picos menores perfazem menos de 18 do pico princi pal). Um espectro de ressonāncia ciclotrônica de íons encontrase na FIGURA 4.13 .

TABELA 4.3 .

Proporções molares na sintese da 2,2,4,4 -tetrametilpentanona-3

$\mathrm{Mg} \quad\left(\mathrm{CH}_{3}\right)_{3} \mathrm{CCl} \quad \mathrm{CuCl} \quad\left(\mathrm{CH}_{3}\right)_{3} \mathrm{CCOCl} \quad\left(\begin{array}{lll}\left.\left(\mathrm{CH}_{3}\right)_{2} \mathrm{C}\right) \\ 2\end{array}\right.$

\begin{tabular}{|c|c|}
\hline$\frac{\mathrm{n}}{\mathrm{n}}$ & 2,1 \\
\hline
\end{tabular}

4.5. Frequências de colisão elāstica

Havendo interesse em extrair do espectro de ressonân cia ciclotrônica de Ions não apenas informação quanto às intensi dades dos picos, mas também quanto à forma e à largura dos mesmos, è mais conveniente registrar diretamente a linha de absorção e não, a sua derivada. Consegue-se 1sso, usando modula ção de energia eletrônica em lugar de modulação de campo magnéti co (que è o tipo de modulação normalmente usado). Na maioria 
das experiências a energia eletrônica foi pulsada entre 9 e 15 ev, ou seja, a energia eletrônica foi ajustada em 9 ev (o que é insuficiente para ionizar a acetona; seção 4.1.) e foram aplica dos pulsos de $6 \mathrm{eV}$. (Estes valores são nominais; foram lidos nas escalas dos potenciômetros.)

Para obter a Erequência de colisão entre um íon e molẹ culas neutras, è preciso fazer uso das equações que representam a forma do pico de um ion no espectro, como será visto a seguir. Estas equações foram deduzidas no capítulo 2 e, para testá- las foi registrado o pico de um ion, tentando-se reproduzi-10 por meio da equação apropriada. A equação que melhor se presta para um teste è a equação 2.14., por não possuir nenhum parâmetro ajustável; ela é aplicāvel no limite de pressão baixa. As equaçōes 2.15. (vãlida no limite de pressão alta) e 2.13. (equação ge ral) contēm $\underline{\xi}$, a frequência de colisão reduzida do ion, que é justamente a quantidade que se quer determinar. Na equação 2.14. ț foi substituido pela equação 2.20 ; a vartável independente é ${ }^{\omega_{1}}$, a frequêncla do oscilador marginal (multiplicada por $2 \pi$ ), mas como usualmente è esta a grandeza mantida fixa, varrendo-se o Çampo magnético, $\omega_{1}$ fol substituỉdo por $\mathrm{H}_{1}$, através da equação 2.3.; $\omega_{C} / 2 \pi$ é então a frequência do oscilador marginal, náqual hā ressonância. A amplitude da rádio-frequência de observação, $E_{1}$, foi de $40 \mathrm{mV} / \mathrm{cm}$. Foi registrado o pico do ion $\mathrm{CH}_{3} \mathrm{CO}^{+}(\mathrm{m} / \mathrm{e}$ 43) da acetona, a uma pressão de 7,5 $10^{-7}$ Torr, com o oscila dor marginal operando a $308,2 \mathrm{kHz}$; foram varridos $50 \mathrm{G}$ em torno de um campo magnético de $8630 \mathrm{G}$, onde deve haver o máximo de absorção de potência pelo ion; o campo elétrico de arraste na região analisadora da cela foi de $0,24 \mathrm{~V} / \mathrm{cm}$ (esse valor é necessário na equação 2.20.). A linha base fol registrada, varrendo o campo magnético em torno de 8300 G (FIGURA 4.5.). Depols fol 


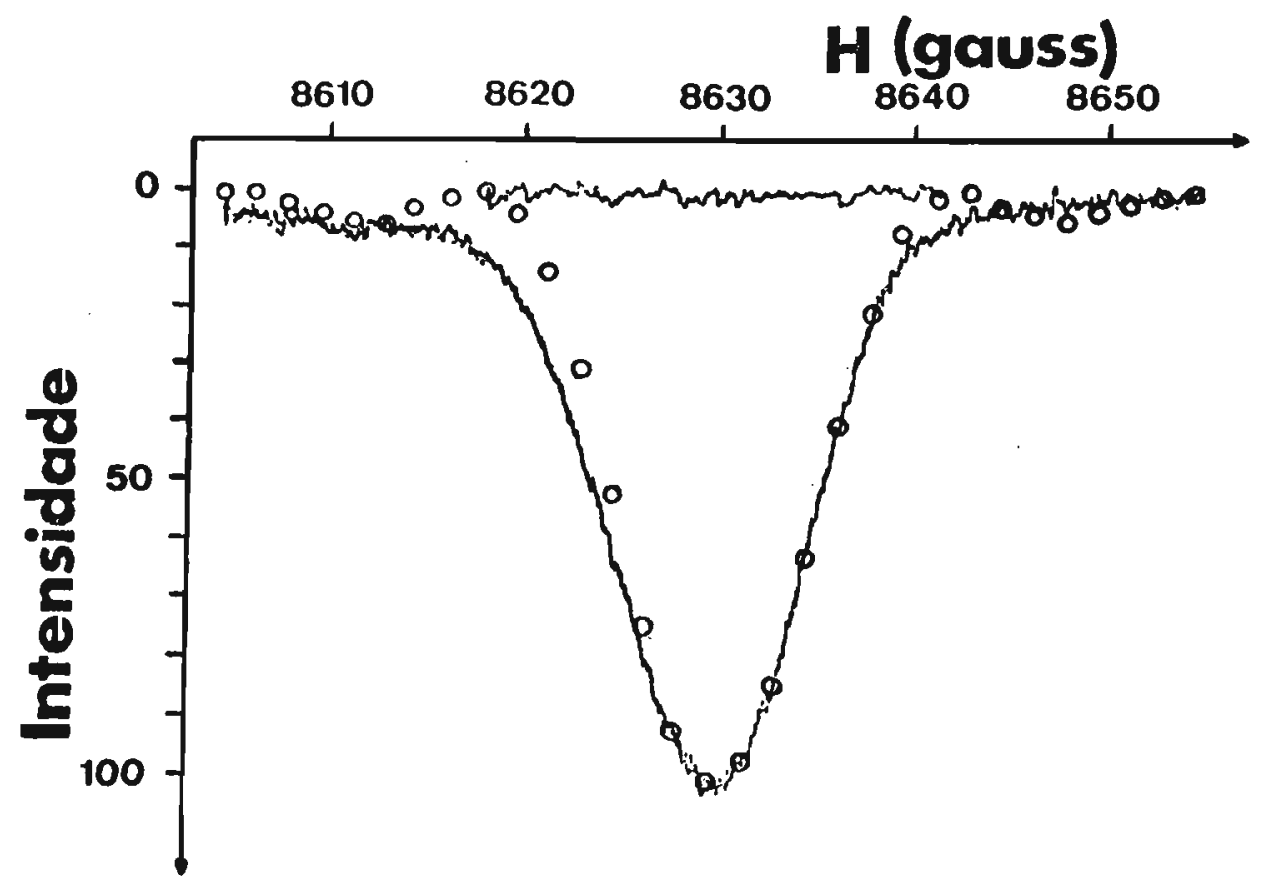

FIGURA 4.5. Iinhas de absorção de $\mathrm{CH}_{3} \mathrm{CO}^{+}$da acetona. Registrada: energia eletrônica : $15 \mathrm{eV}$ (base: $9 \mathrm{eV}$, pulso: $6 \mathrm{eV}$ ); pres são $7,5 \cdot 10^{-7}$ Torr; oscilador margí nal: $308,2 \mathrm{kHz}$; campo de arraste na re gião analisadora: $0,24 \mathrm{~V} / \mathrm{cm}$. Calculada: equação 2.14 .

calculada a absorção de potência pelo Ion de $\mathrm{m} / \mathrm{e} 43$ na condição de ressonância (absorção māxima), pela equação 2.14 ., obtendose $1,6 \cdot 10^{-8} \mathrm{erg} \cdot \mathbf{s}^{-1}$. Em seguida a potência absorvida foi calculada para uma série de campos magnéticos (ao redor de 8630 G) e os valores foram expressos como porcentagem do valor máximo, obtido anteriormente. Após a devida normalização no máximo de absorção, os pontos assim calculados foram superpostos ao espectro registrado (FIGURA 4.5.). Verifica-se que do lado de 
campos magnéticos maiores a superposição é excelente, não o sendo porám do lado de campos magnéticos menores, onde a linha calculada è mais estreita que a experimental. Em outras palavras,o plco é assimétrico. Aparentemente isto se deve a problemas com - sistema de modulação de energia eletrônica. Nota-se que em am bos os lados da curva calculada aparecem dois plcos menores; isto reflete o termo do cosseno da equação 2.14.; do lado de campos magnēticos menores hā uma ligeira tendência em seguir essa linha; frequentemente hā uma definição melhor nessa ondulação, que não deve ser confundida com o pico de outro Ion. o pico do Ion $\mathrm{CH}_{3} \mathrm{CO}^{+}$foi registrado também a pressōes maiores, mantidas to das as outras condições. A $1,0 \cdot 10^{-6}$ Torr o pico calculado já è sensivelmente mais estreito que o experimental, mas è justamen te o alargamento dos picos com o aumento de pressão que permite calcular frequências de colisão entre ions e molēculas. A pressões mais elevadas a absorção de potência é limitada pelas colisões que o Ion sofre e não mais pelo tempo que permanece no campo de rádio-frequência de observação (seção 2.2.), de modo que a equação 2.14. não é mais aplicável.

Frequências de colisão entre ions e moléculas foram dẹ terminadas por meio da espectroscopia de ressonância ciclotrônica de Ions, usando diversas técnicas. 13, 17, 20, 21, 130-133 Duas delas 17,20 são em princípio superiores à usada nos demais casos e tambēm aqui, por envolverem a potência instantânea absorvida pelos Ions (vide seção 2.2.), o que permite uma definição melhor da energla translacional dos ions, mas requerem substancials modi ficações na aparelhagem. A maneira mals simples de proceder, è medir a largura dos picos em função da pressão. Isto será explí cado em contınuação.

A potência média absorvida por um Ion é dada pelas expressões 2.14. e 2.15., nos limites de balxa e alta pressão, res 
pectivamente. Em princípio poderia ser usada a expressão geral, 2.13., nesse tratamento, mas isto levaria a expressões finais mais complexas, o que difultaria a compreensão dos fenômenos físicos que ocorrem (a divisão em limites de alta e baixa pressão é bastante útil) e não melhoraria substancialmente os resultados. Na situação de ressonância as expressões 2.14. e 2.15. se simplificam, fornecendo, respectivamente:

$A\left(\omega_{1}=\omega_{c}\right)=\frac{q^{2} E_{1}{ }^{2} t}{8 m}$

$A\left(\omega_{1}=\omega_{c}\right)=\frac{q^{2} E_{1}^{2}}{4 m \xi}$

A potência absorvida na metade da altura do pico é obviamente

$A=\frac{A\left(\omega_{1}=\omega_{C}\right)}{2}$

o que é necessário calcular é o valor de $\omega_{1}$, ou melhor, de quanto $\omega_{1}$ difere de $\omega_{C}$ (situação de ressonância) quando se estā nạ metade da altura do pico. Obtēm-se isto, resolvendo a equação 4.6. para os pares de equações 2.14 e $4.4 .$, e 2.15 e 4.5. Oḅ tëm-se, respectivamente:

$$
\begin{aligned}
& \left|\omega_{1}-\omega_{c}\right|=\frac{2,783}{t} \\
& \left|\omega_{1}-\omega_{c}\right|=\xi
\end{aligned}
$$

Estas são semi-larguras de picos na metade da altura; as largu ras totais são:

$\Delta \omega=\frac{5,566}{t}$ 
A equaçao 4.7. refere-se ao limite de pressão baixa; portanto,nes tas condições, a largura dos picos e com isso a resolução do instrumento, são limitadas pelo tempo $t$ que o ion permanece na região analisadora, ou seja, sob a ação do campo da rádio-frequên cia de observação. ${ }^{134}$ se o ion for irradiado por mais tempo pelo oscllador marginal, a resolução serã maior. Quando a pressão aumentar, aumentará a frequência de colisão do ĩon, o que farà com que também a frequência de colisão reduzida, $\underline{\text { g }}$ aumente (equação 2.6.), provocando o alargamento do pico (equação 4.8.). Logo, a largura total do pico é dada pela soma das expressões 4.7. e 4.8.

As expressões 4.7. e 4.8. podem então ser combinadas,mas é mais conveniente espressar a largura dos picos em termos de cam po magnético e não de frequência, pois é usualmente a primeira a grandeza varrida. Somando 4.7. e 4.8. e recorrendo a 2.3. e 2.20., obtëm-se: 21

$\Delta H=\frac{5,566 C E}{\omega_{1} \ell}+\frac{2 m c \xi}{q}$

$\Delta H$ é a largura total do pico na metade da altura quando se usa varredura de oampo magnētico; $c$ é a velocidade da luz; E é o campo elētrico de arraste na região analisadora da cela, cujo comprimento é $\ell$; ${ }^{\omega_{l} / 2 \pi}$ è a frequência do oscilador marginal; $\underline{\mathrm{m}}$ è a massa do ion cujo pico foi registrado; g é a sua carga; e $\underline{\xi}$ è a frequência de colisão reduzida do ín.

Esta última grandeza relaciona-se com a frequência de colisão entre Ions e molēculas, $\underline{\nu}$, atravēs da equação 2.6 , repetida aqui:

$\xi=\frac{M}{m+M} v$

onde $\underline{m}$ é a massa do Ion e $\underline{M}$ a da molēcula neutra. Esta equação pode ser interpretada da seguinte maneira: Se dois Ions diferentes, 
dentro do mesmo gás neutro, apresentarem a mesma frequência de colisăo $\_$com as moléculas neutras, o ion de massa menor relaxa rá em cada colisão uma fração maior da sua quantidade de movimen to do que o outro ion; para o ion de massa menor $\underline{\xi}$ è maior e é justamente a velocidade de relaxação da quantidade de movimento do ion a grandeza representada por $\underline{\xi}$. Geralmente a frequêncla de colisão $\underline{\nu}$, dada em $\mathrm{s}^{-1}$, é escrita como produto entre a densidade numērica de moléculas neutras $\underline{n}$, dada em molēculas . $\mathrm{cm}^{-3}$, e uma constante de velocidade de colisão $\underline{\mathbf{k}}$, dada em $\mathrm{cm}^{3}$. molécula ${ }^{-1} \cdot s^{-1}$. Efetuando esta substituição em 2.6., usando a equação dos gases ideais para substituir $\underline{n}$, e representando por 上 a massa reduzida do sistema de ion e molēcula, a equação 4.9. toma a forma

$\Delta \mathrm{H}=\frac{5,566 c}{\omega_{1} \ell} \mathrm{E}+\frac{2 \mu c k}{q R T} \mathrm{P}$

sendo $\underline{R}$ a constante dos gases, $\underline{T}$, a temperatura $\mathrm{e} P$, a pressão.

Esta equação sugere a realização de dois estudos: medí ção da largura do pico de um ion em função: 1) do campo elétrico de arraste na região analisadora da cela (E) e, 2) em função da pressão (P), sempre mantendo constante a outra quantidade.

A FIGURA 4.6. mostra um gräfico de $\Delta H$ em função de $\underline{E}$ para o Ion $\mathrm{CH}_{3} \mathrm{CO}^{+} \mathrm{da}$ acetona. A experiência foi realizada da se guinte maneira: 0 pico do lon $\mathrm{CH}_{3} \mathrm{CO}^{+}$fol registrado, varrendo 50 G em 2,5 minutos em torno de $8630 \mathrm{G}$; a energia eletrônica foi pulsada entre 9,0 e $15,0 \mathrm{eV}$, a corrente de emissão fol de $0,05 \mu \mathrm{A}$, a frequência do oscilador marginal foi de $308,2 \mathrm{kHz}$ e a constante de tempo do detetor de fase foi de 0,3 s. A tensão de arraste na região fonte foi de $0,53 \mathrm{~V}$ e a tensão de apristonamento, de $0,20 \mathrm{~V}$. A pressão fol mantida constante em $1,0 \cdot 10^{-5}$ Torr e a 


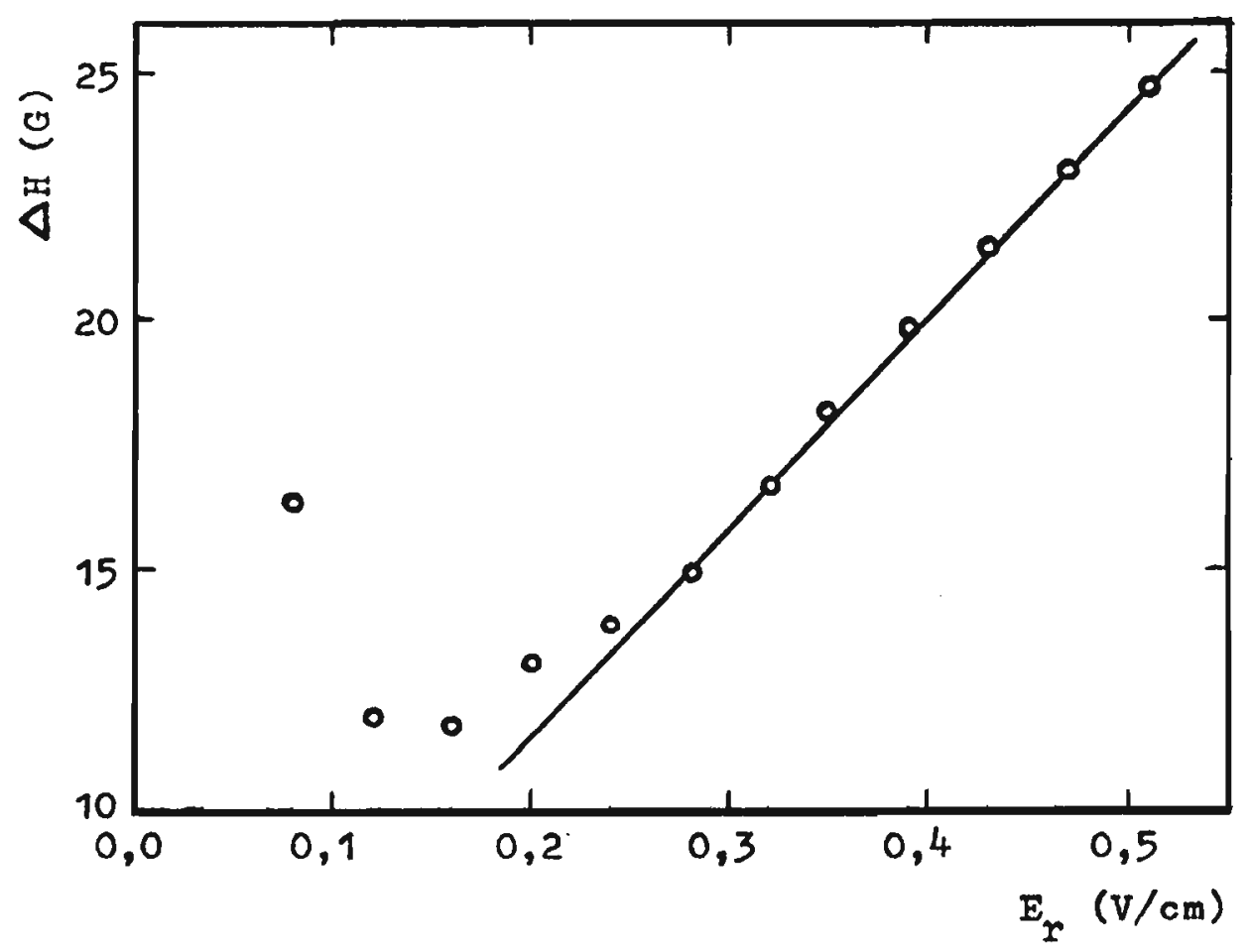

FIGURA 4.6. Largura do pico $(\Delta \mathrm{H})$ de $\mathrm{CH}_{3} \mathrm{CO}^{+}$da acetona em função do campo de arraste $\left(E_{r}\right)$ na região analisadora. Pressão: 1,0.10-5 Torr; oscilador marginal: 308,2 $\mathrm{kHz}$.

tensão de arraste na região analisadora foi variada sucessivamen te por meio do potenciômetro que controla o potencial na placa superior da região analisadora; a tensão foi medida com um voltí metro Sanwa (Sanwa Electric Instrument Co., Japão); como a separação das placas de arraste é de $1,27 \mathrm{~cm}$, pode-se calcular o cam po elétrico a partir da tensão medida. A largura dos plcos foi medida com régua e depois transformada em gauss. Vārios comentários podem ser feitos em relação ao grāfico da FI GURA 4.6. Em primeiro lugar nota-se que o gräficoé linear para campos elétricos málores que $0,25 \mathrm{~V} / \mathrm{cm}$; 0 coeficiente angular da reta è $1,3 \cdot 10^{4}$ e o coeficiente I1near, 3,1 G. O coeflciente angular pode ser calculado, dada a frequên 
cia do oscilador marginal e o comprimento da região analisadora: $1,36 \cdot 10^{4}$. A média dos coeficientes angulares obtidos em dezes seis experiências, realizadas a diversas pressões e para os vārios ions da acetona (o coeficiente angular independe desses fatores), foi de $1,4 \cdot 10^{4}$. Experiências realizadas com o oscilador marginal em 153,6 kHz forneceram, como esperado, coeficientes angulares ao redor de $2,7 \cdot 10^{4}$. Do coeficiente IInear pode rla em principio ser obtida a constante de velocidade de colisão k, mas como o coeficlente linear è de menor conflabilidade que o coeficiente angular, è melhor obter $\underline{k}$ dos grāficos de $\Delta H$ em função de $\underline{\text { P. }}$ Quando o campo elétrico de arraste se torna menor, o gráfico deixa de ser linear (FIGURA 4.6.) e a largura dos picos chega a aumentar, provavelmente por não ser mais dado o campo elétrico pelo potencial aplicado, mas por potenciais erran tes, que impedem que o Ion permaneça por muito tempo na região anal1sadora: isto causa alargamento do pico (equação 4.7.).

A FIGURA 4.7. mostra o grä́fico de $\Delta H$ em função de $\underline{P}$ para o Ion $\mathrm{CH}_{3} \mathrm{CO}^{+}$da acetona. A experiêncla fol realizada de maneira semelhante à anterior. A tensão de arraste na regão fon fonte foi de $0,51 \mathrm{~V}$, a de aprisionamento, de $0,16 \mathrm{~V}$ e a de arras te na região analisadora, de $0,56 \mathrm{~V}$, o que corresponde a um campo de $0,44 \mathrm{~V} / \mathrm{cm}$. O gráfico é linear a partir de 1,5 $10^{-5}$ Torx, fornecendo um coeficiente angular de 2,6 $10^{5} \mathrm{G} / \mathrm{Torr}$ e um coefí ciente linear de $18 \mathrm{G}$ (calculado: $20 \mathrm{G}$ ). A pressões aba1xo de $1,5 \cdot 10^{-5}$ Torr há uma tendência de a largura dos picos ficar constante, limitada pelo tempo que o Ion permanece sob a ação do campo de rádlo-frequência; essa largura limite pode ser calcụ lada, obtendo-se $20 \mathrm{G}$; isto é dado pelo campo elétrico de arraste de $0,44 \mathrm{~V} / \mathrm{cm}$. O coeficiente angular permite obter a constante de velocidade de colisão: $k=1,6 \cdot 10^{-9} \mathrm{~cm}^{3} \cdot \operatorname{molëcula} a^{-1} \cdot \mathrm{s}^{-1}$. 


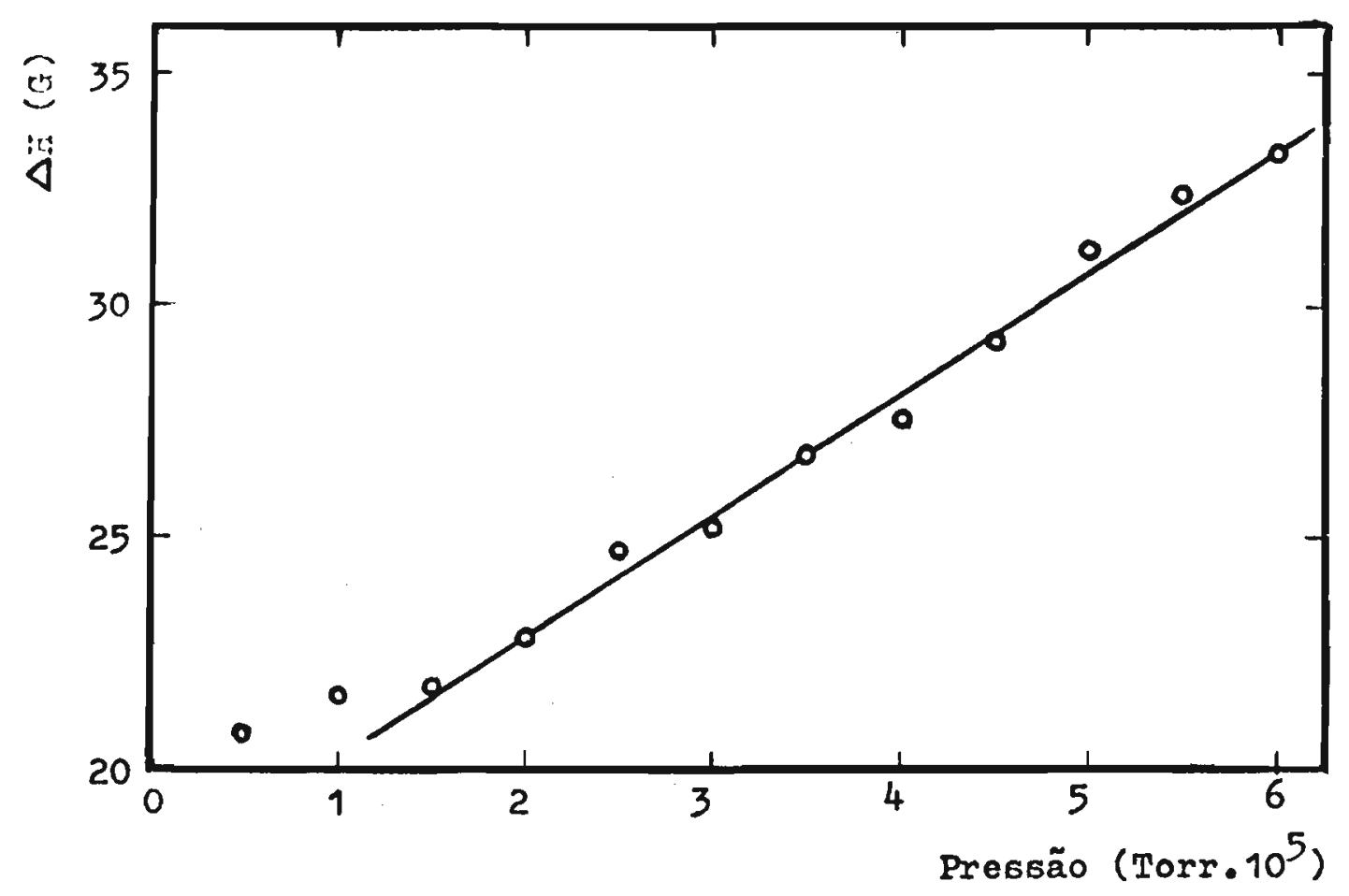

FIGURA 4.7. Largura do pico $(\Delta \mathrm{H})$ de $\mathrm{CH}_{3} \mathrm{CO}^{+}$da acetona em função da pressão. Campo de arraste na região analíbadora: $0,44 \mathrm{~V} / \mathrm{cm}$; oscilador marginal: $308,2 \mathrm{kHz}$.

Curvas desse tipo foram obtidas para todos os Ions da acetona, ob servados por ressonância ciclotrônica de ions (vide seção 4.6.), mas antes de apresentar os resultados finais, é preciso ver um pouco mais de teoria.

A equação 3.16. dã a seção de choque de colisão entre ions e moléculas de acordo com a teoria de polarização (seção 2.2.1.), supondo que a molécula possua um momento dipolar, que se orienta na direção do íon. A frequência de colisão reduzida se relaciona com essa seção de choque de acordo com a equação 4.11. 131

$\frac{\xi}{n}=\sigma v_{1}\left(\frac{M}{m+M}\right)$ 
Esta é na realidade apenas uma outra forma de escrever a equa Ção 2.6. $v_{1}$ è a velocidade relativa entre Ion e molécula.Subst1tuindo as equações 3.16. e 3.2. na equação 4.11., obtém-se

$\frac{\xi}{n}=\frac{2 \pi e(\alpha \mu)^{\frac{1}{2}}}{m}+\frac{M \pi e \mu_{D}}{m+M}\left(\frac{2}{\mu E_{r}}\right)^{\frac{1}{2}}$

Quando um ion se aproxima de uma espécie neutra, sem realmente colidir com a mesma, sendo apenas desviado, hã uma variação na quantidade de movimento do ion. A equação 3.16. dã somente a se ção de choque de eventos que efetivamente resultam numa coli são. Na expressão de $\underline{\xi}$ devem no entanto ser levados em conta todos os eventos que ocasionam uma relaxação da quantıdade de mo vimento do ion. Desta maneira obtém-se 131,132

$\frac{\xi}{n}=\frac{2,21 \pi e(\alpha \mu)^{\frac{l}{2}}}{m}+\frac{M \pi e_{\mu_{D}}}{m+M}\left(\frac{2}{\mu E_{r}}\right)^{\frac{1}{2}}$

Esta expressão se torna mais tratável, se a frequêncla de coll são reduzida $\underline{\xi}$ for substituida pela constante de velocidade de colisão k (equação 2.6.).

$k=\pi e\left[2,21 \alpha^{\frac{1}{2}}+\mu_{D}\left(\frac{2}{E_{r}}\right)^{\frac{1}{2}}\right] \mu^{-\frac{1}{2}}$

Portanto, $\underline{k}$ è dado em função de polarizabilidade $\underline{\alpha}$ e momento dipolar ${ }_{D}$ da molécula neutra, e de energia relativa $E_{r}$ e massa re duzida $\mu$ do sistema formado por ion e molécula.

Na TABELA 4.4. encontram-se as constantes de velocidade de colisão, determinadas para os ions da acetona. Como na li teratura se encontram frequentemente tabelados os valores de $\xi / n$, estes tambēm foram incluídos na tabela. Os inversos das ralzes quadradas das massas reduzidas dos sistemas de ion e molécula são necessārios na equação 4.12. A FIGURA 4.8. mostra o grāfico de ḳ 
TABELA 4.4 .

Constantes de velocidade de colisão elástica entre ions e molécú las da acetona.

\begin{tabular}{lccccc}
\multicolumn{9}{c}{ ion } & $(\mathrm{m} / \mathrm{e})$ \\
43 & 58 & 59 & 101 & 117 & unidades
\end{tabular}

\begin{tabular}{lllllll}
$\xi / \mathrm{n}$ & 8,2 & 6,6 & 8,0 & 4,8 & 3,0 & $\mathrm{~cm}^{3} \cdot \mathrm{s}^{-1} \cdot 10^{10}$ \\
$\mathrm{k}$ & 1,4 & 1,3 & 1,6 & 1,3 & 0,9 & $\mathrm{~cm}^{3} \cdot \mathrm{s}^{-1} \cdot 10^{9}$ \\
$\mu^{-1 / 2}$ & 1,56 & 1,44 & 1,43 & 1,28 & 1,25 & $\mathrm{~g}^{-1 / 2} \cdot 10^{-11}$ \\
\hline
\end{tabular}

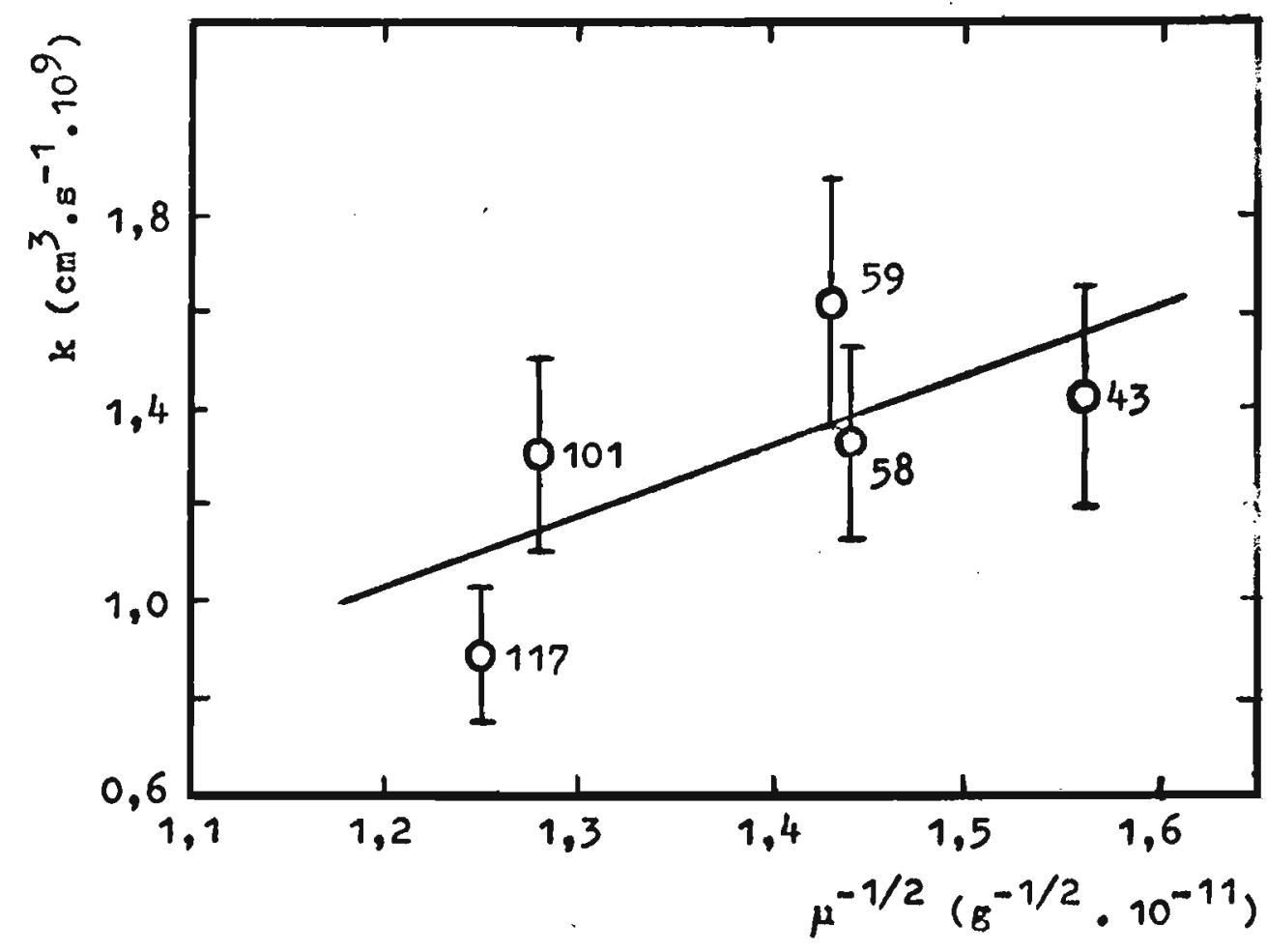

FIGURA 4.8. Constantes de velocidade de colisão elástica dos ions da acetona em acetona, em função dos inversos das raízes quadradas das massas reduzidas dos sistemas de ín - molécula. Os números ao lado dos pontos experimentais referem-se à relação $\mathrm{m} / \mathrm{e}$ dos respectivos lons. 
em função dej-1/2, correspondentes à TABELA 4.4. Esses dados re ferem-se a uma experiência na qual a pressão fol medida com o me didor de ionização, o qual foi em seguida calibrado com o medi dor de diafragma (seção 4.3.). A experiência foi realizada vārias vezes com a pressão medida atravēs do controle da bomba iônica; por isso esses resultados não são em princípio tão bons co mo o outro, mas o desvio padrão foi calculado a partir de oito desses resultados; as barras de erro colocadas na FIGURA 4.8.cor respondem a dois desvios padrão. A dispersão dos pontos no gräfico pode ser atribuida a erros experimentais ao acaso, mas também as experiência realizadas sem o controle adequado de pressão forneceram na média um quadro semelhante lapenas o ponto do íon de m/e 58 fica mais próximo do ponto do ion de m/e 59). Um cálculo de minimos quadrados para os pontos da FIGURA 4.8. resulta numa reta de coeficiente angular $1,4 \cdot 10^{-20} \mathrm{~cm}^{3} \cdot \mathrm{g}^{1 / 2} \cdot \mathrm{s}^{-1}$ (a reta não intercepta a origem do sistema de coordenadas, como - deveria pela equação 4.12., mas apresenta um coeficiente 1inear de $-0,7 \cdot 10^{-9} \mathrm{~cm}^{3} \cdot \mathrm{s}^{-1}$ ). Introduzindo na equação $4.12 .0 \mathrm{~s}$ valores da polarizabilidade $e^{135}$ e do momento dipolar ${ }^{136}$ da aceto $\mathrm{na}, \alpha=6,42 \cdot 10^{-24} \mathrm{~cm}^{3} \mathrm{e} \mu_{D}=2,88 \cdot 10^{-18} \mathrm{stc} \cdot \mathrm{cm}$, chega-se a $k=\pi e\left(5,60 \cdot 10^{-12}+4,07 \cdot 10^{-18} \cdot E_{r}^{-1 / 2}\right) \mu^{-1 / 2}$

Para energias tērmicas $\left(E_{r}=\frac{3}{2} \mathrm{kT}\right)$ o segundo termo entre parênte ses é $1,64 \cdot 10^{-11}$, sendo portanto mator que o primeiro, o que mostra que a constante de velocidade de collsão depende consideravelmente da energia do ion. Na realidade esse segundo termo, que envolve o momento dipolar da molécula, não deve ser tão gran de assim, pois a equação foi deduzida, supondo que durante a interação do Ion com a molēcula, o dipolo desta se orienta na direção do İon, o que não ocorrẹ, devido à energla tērmica das molē- 
culas (seção 3.2.1.). Em todos os casos, para o modelo adotado e para energias tērmicas, o fator que multiplica $\mu^{-1 / 2}$ na equa ção 4.12. e $3,32 \cdot 10^{-20} \mathrm{~cm}^{3} \cdot \mathrm{g}^{1 / 2} \cdot \mathrm{s}^{-1}$; este valor pode ser comparado com o coeficiente angular da reta da FIGURA 4.8; o coeficiente angular calculado è 2,3 vezes maior que o experimental,o que pode ser simplesmente devido à aproximação feita no modelo (dipolo orientado na direção do íon), mas tambēm é possível argumentar da seguinte maneira. o que diminui a inclinação da reta da FIGURA 4.8 é principalmente o ponto correspondente ao Ion de m/e 43 (achou-se em outras experiências que o ponto do íon de $\mathrm{m} / \mathrm{e} 58$ fica mais próximo ao do ion de $\mathrm{m} / \mathrm{e} 59$ ). Se a constante de velocí dade de colisão realmente depender em grande extensão da energia do ion, diminuindo com aumento da mesma, isto pode ser facilmente explicado. Quanđo uma espēcie neutra é ionizada (no casó da acetona forma-se o ion de $\mathrm{m} / \mathrm{e} 58$ ), o Ion resultante pode estar num estado excitado (eletrônico, vibracional ou rotacional), mas o elētron não the comunica uma quantidade de movimento apreciável, de modo que o Ion continua com energia translacional tērmica; porém, quando o Ion excitado fragmenta, o produto iônico (m/e 43, no caso) pode adquirir parte da energia de excitação em forma de energia translacional. No caso de ions formados em rea ções entre ions e moléculas, sua energia translacional depende da exotermicidade da reação (esta, porëm, não aparece obrigatoriamen te como energia translacional do íon). Além disso, devido à maneira de como é feita a detecção dos ions em espectroscopia de ressonância clclotrônica de ions, a potência absorvida do oscilador marginal é inversamente proporcional à massa do Ion (equa ção 2.33.); 10go, ỉons de massa menor adquirem energla cinética maior. 18,41,137 portanto, há dois fatores responsãvels por uma energia translacional maior do ion de $\mathrm{m} / \mathrm{e} 43$, que, de acordo com 
a equação 4.12., deve então apresentar uma constante de velocidade de colisão menor. Admite-se constituir tudo isto apenas uma tentativa de explicação, aplicável no contexto do modelo de polarização acrescida de dipolo orientado na direção do íon, e que a dispersão dos pontos no grāfico de $k=f\left(u^{-1 / 2}\right)$ possa ser devida apenas a erros experimentais, mas em todos os casos a dificuldade de controle da energia dos ions em ressonância ciclo trônica de ions, quando se trata de efeitos pequenos, merece ser lembrada, pois este è um aspecto frequentemente negligenciado, se bem que esse controle seja mais dificil ainda em multas outras técnicas.

\subsection{Reações de acilação}

Os espectros de ressonância ciclotrônica de ions de cetonas mostraram que as reações que conduzem à formação das espécies protonadas $\mathrm{RR}^{\prime} \mathrm{COH}^{+}$constituem em geral os processos predominantes. Experiências de ressonância dupla revelaram que es sas espécies são formadas pelos fragmentos $\mathrm{RCO}^{+}, \mathrm{R}^{\prime} \mathrm{CO}^{+}$e pelo Ion molecular $\mathrm{RCOR}^{\prime+}$. Esta ūltima reação sö foi detectada na mistura de acetona e acetona- $d_{6}$, pois em geral não é possivel reali zar uma expertência de ressonância dupla na qual se observa o Ion $(M+1)^{+}$e se irradia o ion $M^{+}$, isto $\dot{e}$, Ions que diferem de apenas uma unidade de massa atômica, pois então as frequências dos osciladores marginal e de ressonância dupla estão muito prōximas, causando interferência. Por exemplo, no caso da acetona, se $\circ$ Ion $\left(\mathrm{CH}_{3}\right)_{2} \mathrm{COH}^{+}$, de $\mathrm{m} / \mathrm{e} 59$, for observado a $153,6 \mathrm{kHz}$, $\mathrm{CH}_{3} \mathrm{COCH}_{3}{ }^{+}$, de $\mathrm{m} / \mathrm{e} 58$, terā que ser Irradiado a $156,2 \mathrm{kHz}$. Mas a reação 
$\left(\mathrm{CH}_{3}\right)_{2} \mathrm{CO}^{+}+\left(\mathrm{CD}_{3}\right)_{2} \mathrm{CO} \rightarrow\left(\mathrm{CD}_{3}\right)_{2} \mathrm{COH}^{+}+\mathrm{CH}_{2} \mathrm{CO}+. \mathrm{CH}_{3}$

$\mathrm{m} / \mathrm{e} 58 \mathrm{~m} / \mathrm{e} 65$

pode ser detectada, pois então as frequências são $153,6 \mathrm{kHz}$ para observar o ion de m/e 65 e $172,0 \mathrm{kHz}$, para irradiar o de m/e 58 .

Os Ions moleculares protonados reagem com outra molécula de cetona e produzem um dỉmero protonado, um ion terciário.<smiles></smiles>

Provavelmente esse dimero protonado precisa colidir com outra molécula neutra, para relaxar o excesso de energla e estabilizar-se.

A FIGURA 4.9. mostra um espectro da acetona, com todos os Ions que aparecem nas condições relnantes numa cela de resso-

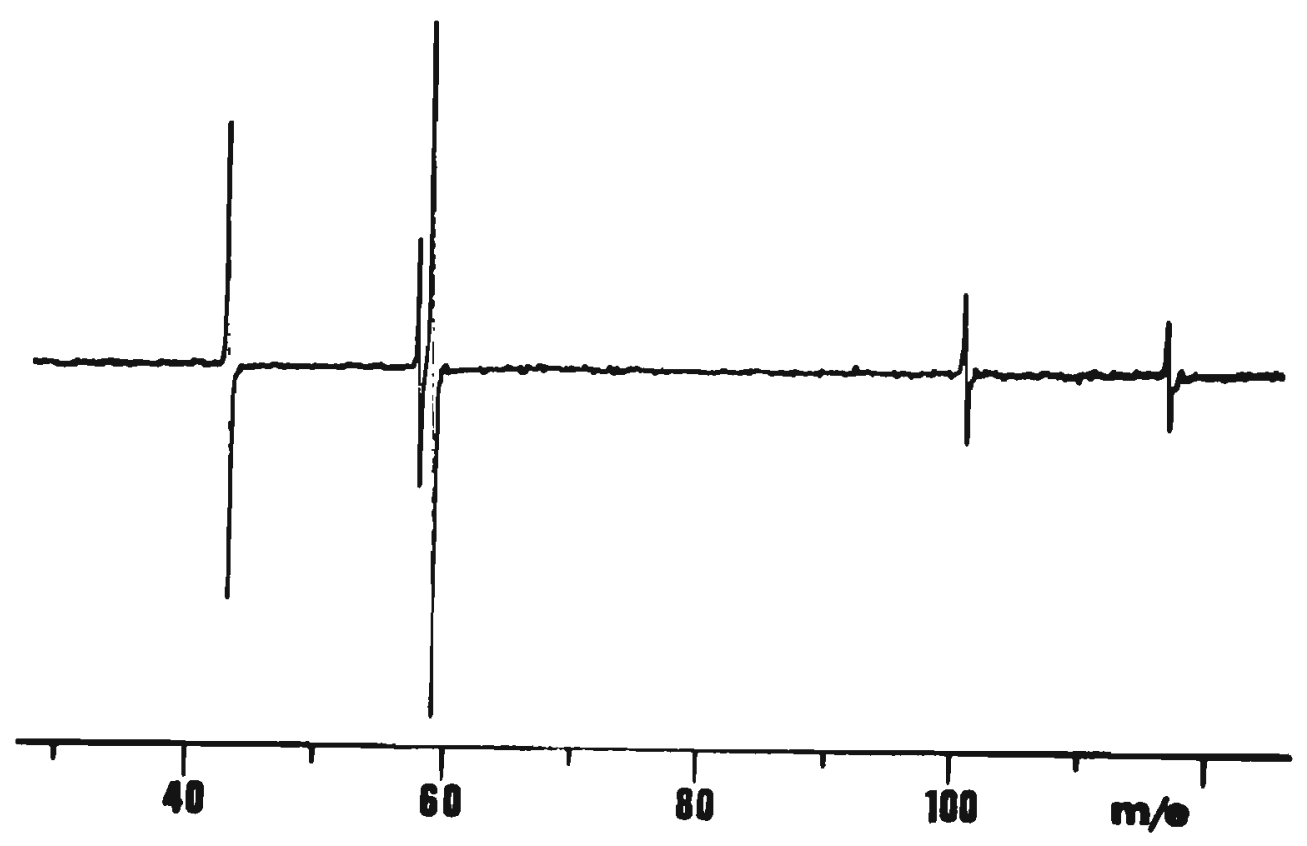

EIGURA 4.9. Espectro de massa da acetona. Energia eletrônica: $20 \mathrm{eV}$; pressão: $2,0 \cdot 10^{-5}$ Torr; oscilador marginal: $153,6 \mathrm{kHz}$; modulação de campo magnētico. 
nância ciclotrônica de íons, quanḍo a energia de ionização é bậ xa, e a FIGURA 4.10., a variação das correntes desses ions em função da pressão na cela. Esse gráfico fol obtido, registran do o espectro da acetona a várias pressões, usando modulação de

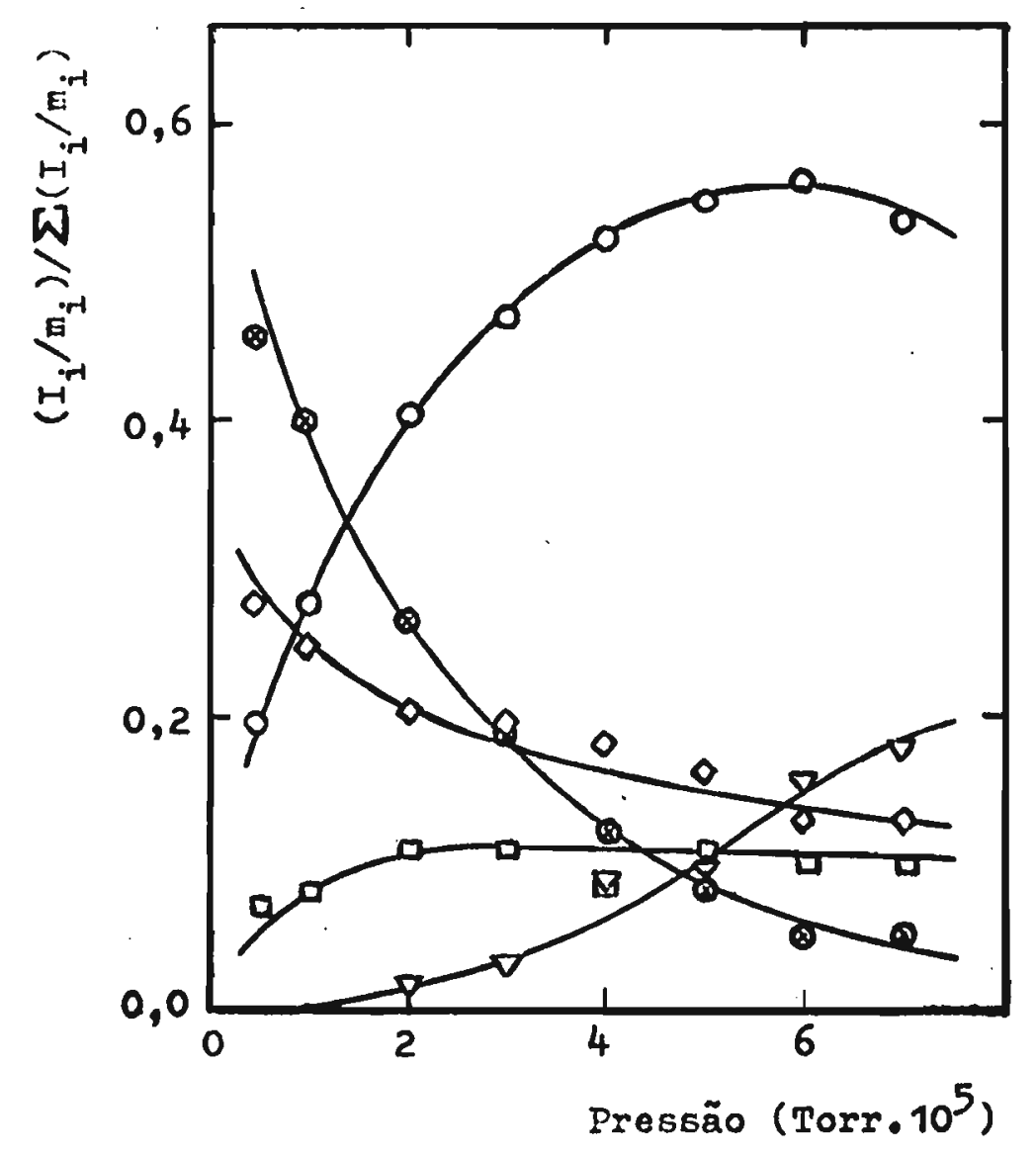

FIGURA 4.10. Correntes iônicas relativas dos

Íons da acetona em função de pressão:

(O) $\mathrm{CH}_{3} \mathrm{CO}^{+}$, (Q) $\mathrm{CH}_{3} \mathrm{COCH}_{3}^{+}$, (O) $\left(\mathrm{CH}_{3} \mathrm{COCH}_{3}\right) \mathrm{H}^{+}$,

(a) $\mathrm{CH}_{3} \mathrm{CO}^{+}\left(\mathrm{CH}_{3} \mathrm{COCH}_{3}\right),(\nabla)\left(\mathrm{CH}_{3} \mathrm{COCH}_{3}\right)_{2} \mathrm{H}^{+}$.

energia eletrônica; em seguida as intensidades dos picos dos diversos ions foram medidas e, para transformar essas intensidades em correntes iônicas, foram divididas pela massa do Ion correspondente (vide equação 2.21.); a seguir os dados foram normalizados, de modo que em cada pressão a soma das corren 
tes de todos os ions fosse unitárịa. Nota-se que a corrente dos jons $\mathrm{CH}_{3} \mathrm{CO}^{+}(\mathrm{m} / \mathrm{e} 43)$ e $\mathrm{CH}_{3} \mathrm{COCH}_{3}{ }^{+}$(58) decresce exponencialmente com aumento da pressão; trata-se de ions primários que reagem, produzindo ambos o ion $\left(\mathrm{CH}_{3}\right)_{2} \mathrm{COH}^{+}(59) ; \mathrm{CH}_{3} \mathrm{COCH}_{3}{ }^{+}$também produz - íon de m/e 101 (seção 4.6.1.). A curva do íon de m/e 59 cresce a partir de corrente iônica zero, passa por um máximo e decresce novamente, o que indica outra reação; trata-se da forma ção do dimero protonado $\left[\left(\mathrm{CH}_{3}\right)_{2} \mathrm{CO}\right]_{2} \mathrm{H}^{+}(117)$, cuja corrente aumenta continuamente no intervalo de pressão examinado. A corren te do ion de m/e 101 varia de maneira peculiar com pressão e a elaboração de um mecanismo de reação para explicar esse comporta mento constitui o objetivo principal desse capítulo (vide seção 4.6.3.). A formação de Ions análogos ao de m/e 101 na acetona é geral nas cetonas, mas dependendo da estrutura desse composto cạ bonilico, outras reações podem ocorrer; mals especificamente, ē nas cetonas que possuem hidrogênios $\underline{y}$ que ocorrem reações não oḅ servadas nas cetonas que não possuem hidrogênios $\underline{\gamma}$. Por isso as cetonas serão classificadas quanto a esse aspecto na discussão que seque.

\subsubsection{Cetonas sem hidrogênios $x$}

o ion de m/e 101 da acetona, formado a partir do Ion de $\mathrm{m} / \mathrm{e} 58$, corresponde a acetona acetilada; esse processo è geral e foram observadas as seguintes reações de auto-acllação em cetonas :

$$
\begin{gathered}
\mathrm{CH}_{3} \mathrm{COCH}_{3}^{+}+\mathrm{CH}_{3} \mathrm{COCH}_{3} \rightarrow \mathrm{CH}_{3} \mathrm{CO}^{+}\left(\mathrm{CH}_{3} \mathrm{COCH}_{3}\right)+. \mathrm{CH}_{3} \\
\mathrm{~m} / \mathrm{e} 101
\end{gathered}
$$

$\mathrm{CH}_{3} \mathrm{COC}_{2} \mathrm{H}_{5}^{+}+\mathrm{CH}_{3} \mathrm{COC}_{2} \mathrm{H}_{5} \rightarrow \mathrm{CH}_{3} \mathrm{CO}^{+}\left(\mathrm{CH}_{3} \mathrm{COC}_{2} \mathrm{H}_{5}\right)+. \mathrm{C}_{2} \mathrm{H}_{5}$ 


$$
\begin{gathered}
\mathrm{C}_{2} \mathrm{H}_{5} \mathrm{COC}_{2} \mathrm{H}_{5}^{+}+\mathrm{C}_{2} \mathrm{H}_{5} \mathrm{COC}_{2} \mathrm{H}_{5} \rightarrow \mathrm{C}_{2} \mathrm{H}_{5} \mathrm{CO}^{+}\left(\mathrm{C}_{2} \mathrm{H}_{5} \mathrm{COC}_{2} \mathrm{H}_{5}\right)+. \mathrm{C}_{2} \mathrm{H}_{5} \\
\text { m/e } i 43
\end{gathered}
$$

$$
\begin{gathered}
\mathrm{CH}_{3} \mathrm{COC}\left(\mathrm{CH}_{3}\right)_{3}^{+}+\mathrm{CH}_{3} \mathrm{COC}\left(\mathrm{CH}_{3}\right)_{3}+\mathrm{CH}_{3} \mathrm{CO}^{+}\left[\mathrm{CH}_{3} \mathrm{COC}\left(\mathrm{CH}_{3}\right)_{3}\right]+. \mathrm{C}\left(\mathrm{CH}_{3}\right)_{3} \\
\mathrm{~m} / \mathrm{e} 143
\end{gathered}
$$

$$
\begin{gathered}
\left(\mathrm{CH}_{3}\right)_{3} \mathrm{CCOC}\left(\mathrm{CH}_{3}\right)_{3}++\left(\mathrm{CH}_{3}\right)_{3} \mathrm{CCOC}\left(\mathrm{CH}_{3}\right)_{3}+ \\
+\left(\mathrm{CH}_{3}\right)_{3} \mathrm{CCO}^{+}\left[\left(\mathrm{CH}_{3}\right)_{3} \mathrm{CCOC}\left(\mathrm{CH}_{3}\right)_{3}\right]+. \mathrm{C}\left(\mathrm{CH}_{3}\right)_{3} \\
\mathrm{~m} / \mathrm{e} 227
\end{gathered}
$$

$$
\begin{gathered}
\mathrm{C}_{6} \mathrm{H}_{5} \mathrm{COCH}_{3}^{+}+\mathrm{C}_{6} \mathrm{H}_{5} \mathrm{COCH}_{3} \rightarrow \mathrm{C}_{6} \mathrm{H}_{5} \mathrm{CO}^{+}\left(\mathrm{C}_{6} \mathrm{H}_{5} \mathrm{COCH}_{3}\right)+. \mathrm{CH}_{3} \\
\mathrm{~m} / \mathrm{e}^{225}
\end{gathered}
$$

Nas FIGURAS $4.9,4.11 ., 4.12$ e 4.13 . estão os espectros de acetona, butanona, pentanona-3 e 2,2,4,4-tetrametilpentanona-3 (diterciobutilcetona), respectivamente, sendo os picos dos ions de m/e 101, 115, 143 e 227 razoavelmente intensos. Nos espectros da butanona da FIGURA 4.11. não aparece o pico do dimero protonado(m/e 145), pois os espectros foram obtidos a balxa pressão $\left(1,0 \ldots 10^{-6}\right.$ Torr), onde esse produto não è estabilizado. No espectro da pentanona-3 da FIGURA 4.12. nota-se que picos de Ions que diferem àe uma unidade de massa atômica são assimétricos;isto é devido a problemas de resolução, pois, para poder observar um ion de $\mathrm{m} / \mathrm{e}$ 173 (dimero protonado), foi preciso baixar a frequêncla do oscila dor marginal para 122,2 kHz; de acordo com a equação 4.9., quanto menor essa frequência $\left(\omega_{1} / 2 \pi\right)$, tanto maior a largura do pico $(\Delta H)$ e tanto menor a resolução. No espectro da 2,2,4,4-tetrametilpentanona-3 da FIGURA 4.13. os picos dos fragmentos $\left(\mathrm{CH}_{3}\right)_{3} \mathrm{C}^{+}$(m/e 57) e $\left(\mathrm{CH}_{3}\right)_{3} \mathrm{CCO}^{+}$(85) são pouco intensos devido à pressão relativamente 

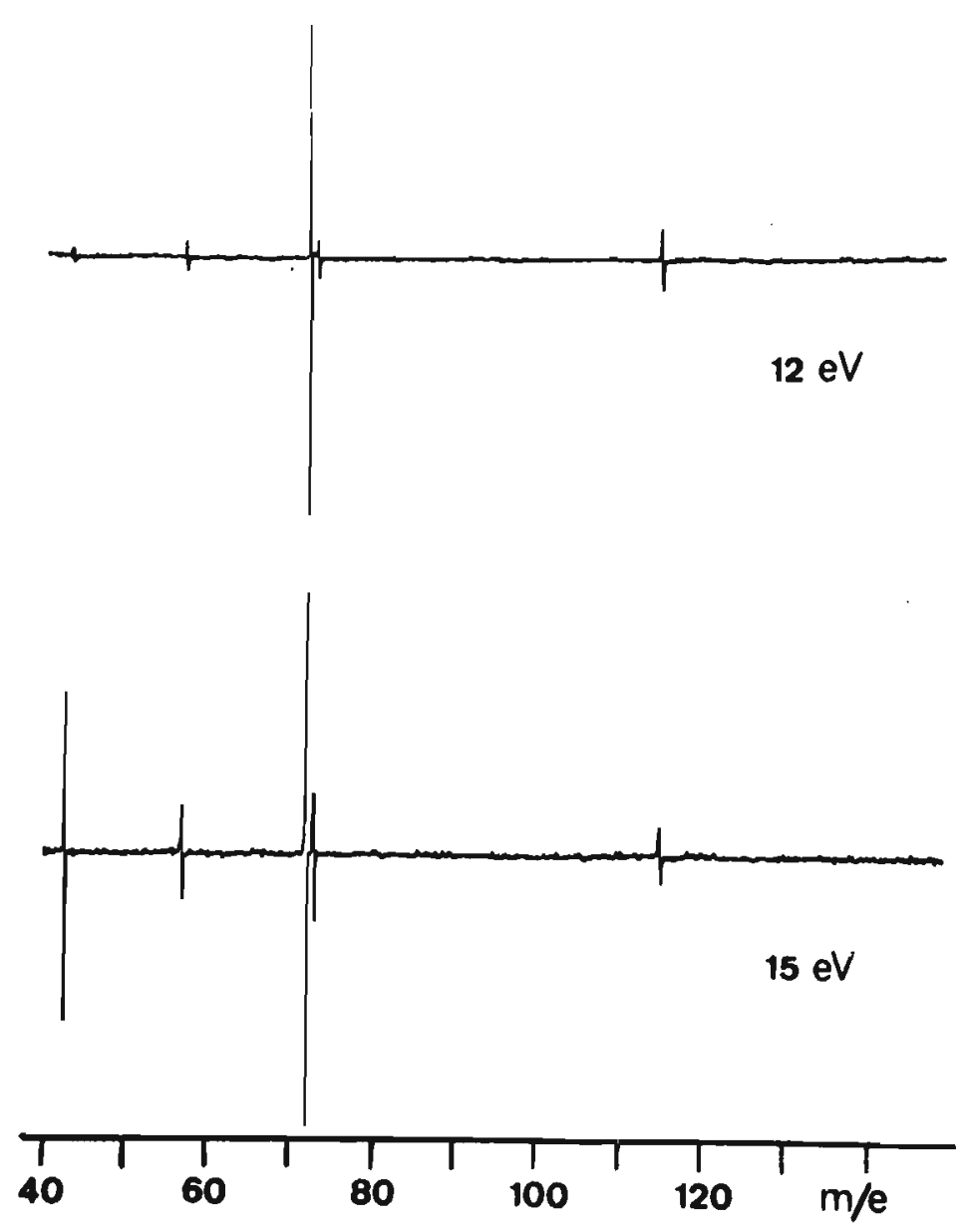

FIGURA 4.11. Espectros de massa da butanona. Ener gia eletrônica: 12 e $15 \mathrm{eV}$; pressão: $1,0 \cdot 10^{-6}$ Torr; oscilador marginal: $138,3 \mathrm{kHz}$.

alta $\left(3,5 \cdot 10^{-5}\right.$ Torr); o pico do ion molecular (m/e 142) praticamente não está resolvido do pico do Ion molecular protonado, pois a frequência do oscllador marginal teve que ser ainda mais baixa que no caso anterior $(75,0 \mathrm{kHz})$; a pressões mats balxas es ses picos são resolvidos, o que è compreensível através da equação 4.10.; a origem do pico bastante intenso do Ion de $\mathrm{m} / \mathrm{e} 173$, bem como a dos picos de ions de m/e 102 e 159, não fol Investigada; a possibilidade de se tratar de impurezas não pode ser afasta da: o İon de m/e 285 é o dímero protonado. 


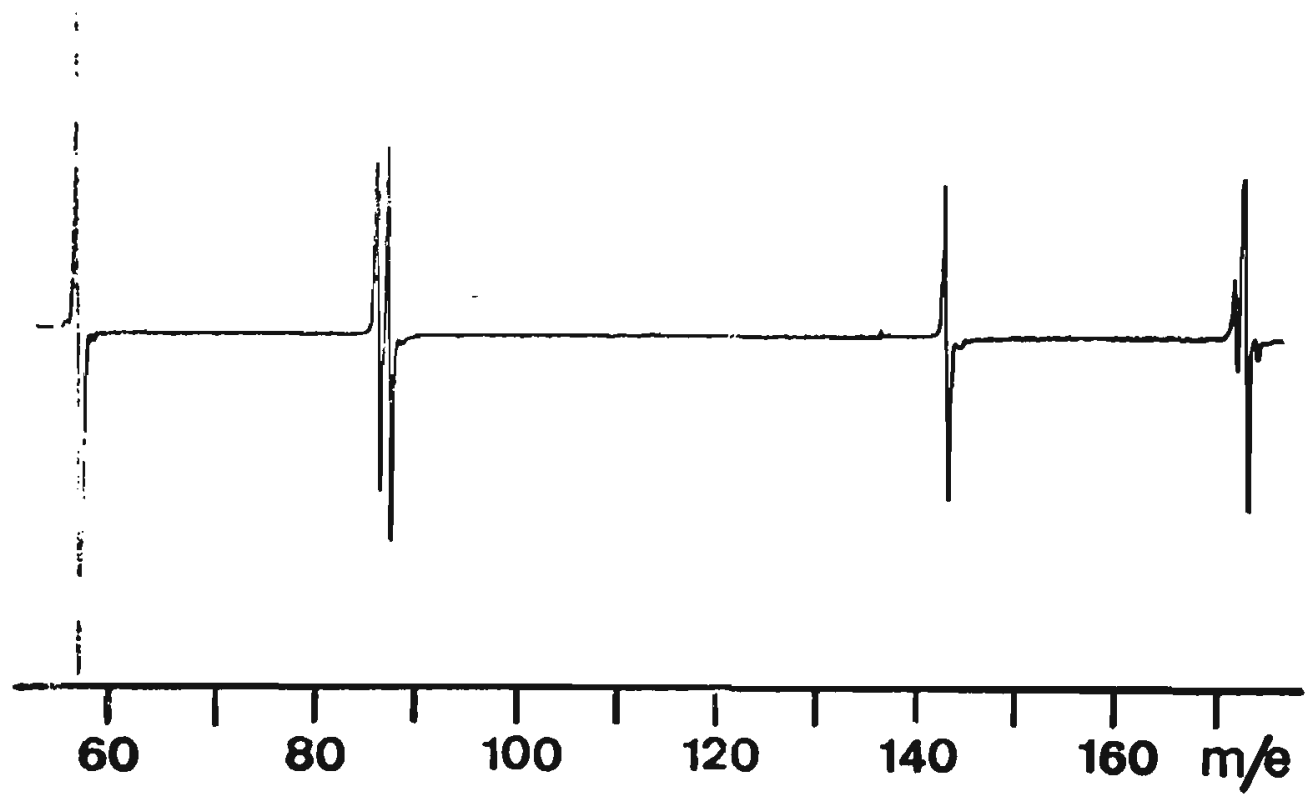

FIGURA 4.12. Espectro de massa da pentanona-3. Energia eletrônica: $15 \mathrm{eV}$; pressão: $3,0.10^{-5}$ Torr; oscilador marginal: $122,2 \mathrm{kHz}$.

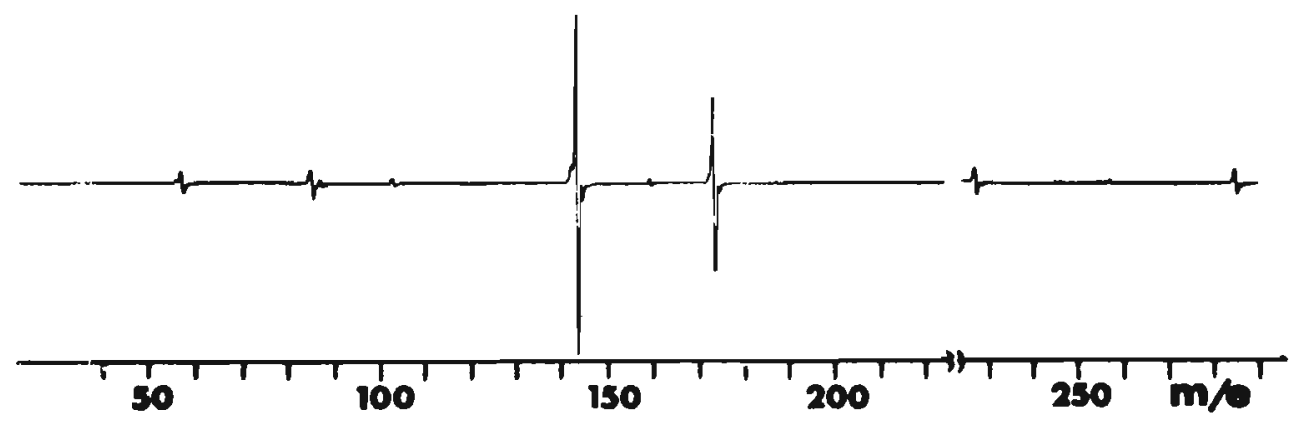

FIGURA 4.13. Espectro de massa da 2,2,4,4-tetramet11pentanona-3. Energia eletrônica: $15 \mathrm{ev;}$ pressão: $3,5 \cdot 10^{-5}$ Torr; oscilador marginal: $75,0 \mathrm{kHz}$. A escala de massa fol interrompida para facilidade de registro do espectro. 
Reações análogas às escritas acima são observadas em aldeidos. Assim, etanol forma $\mathrm{CH}_{3} \mathrm{CO}^{+}\left(\mathrm{CH}_{3} \mathrm{CHO}\right)(\mathrm{m} / \mathrm{e} \mathrm{87})$. Tambēm forma o dimero protonado ( $\mathrm{m} / \mathrm{e} 89$ ), mas ambos os Ions são menos abundantes do que em qualquer uma das cetonas estudadas. Benzal deỉo forma 0 ion $\mathrm{C}_{6} \mathrm{H}_{5} \mathrm{CO}^{+}\left(\mathrm{C}_{6} \mathrm{H}_{5} \mathrm{CHO}\right)$ (m/e 2ll), muito pouco intenso. ( Neste caso o pico do dỉmero protonado, m/e 213, è mais intenso.) Deve-se mencionar que no caso da acetofenona a reação que conduz à formação do ion $\mathrm{C}_{6} \mathrm{H}_{5} \mathrm{CO}^{+}\left(\mathrm{C}_{6} \mathrm{H}_{5} \mathrm{COCH}_{3}\right)$ (m/e 225) è muito mais lenta que nas outras cetonas. Os aldeidos fragmentam em maior extensão que as cetonas e no benzaldeỉdo, por exemplo, são formados os fragmentos $\mathrm{C}_{6} \mathrm{H}_{5}{ }^{+}$e $\mathrm{C}_{6} \mathrm{H}_{6}{ }^{+}$sendo que $\mathrm{C}_{6} \mathrm{H}_{5}{ }^{+}$reage, dando origem a um ion de $\mathrm{m} / \mathrm{e}$ 155; o produto neutro dessa reação pro vavelmente é co.

Nas reações de acetilação escritas acima, surge a ques tão da procedência do radical R., o produto neutro dessas reações. Este problema 100 foi resolvido com a mistura de acetona e acetona perdeuterada, um espectro da qual está na FIGURA 4.14.; este foi obtido com modulação de energia eletrônica a uma pressão total de 4,0 $10^{-5}$ Torr, sendo aproximadamente iguais as pressões parciais das duas cetonas. Aparecem todos os Ions acet1lados possiveis, a saber, de m/e 101, 104, 107 e 110, 1sto é , $\mathrm{CH}_{3} \mathrm{CO}^{+}\left(\mathrm{CH}_{3} \mathrm{COCH}_{3}\right), \mathrm{CD}_{3} \mathrm{CO}^{+}\left(\mathrm{CH}_{3} \mathrm{COCH}_{3}\right), \mathrm{CH}_{3} \mathrm{CO}^{+}\left(\mathrm{CD}_{3} \mathrm{COCD}_{3}\right)$ e $\mathrm{CD}_{3} \mathrm{CO}^{+}\left(\mathrm{CD}_{3} \mathrm{COCD}_{3}\right)$. Tambēm aparecem os seis dimeros protonados possĩveis. Na FIGURA 4.15. estão quatro espectros de ressonân cia dupla, obtidos com modulação do oscilador de ressonância dupla, nos quais foram observados respectivamente os lons de $\mathrm{m} / \mathrm{e}$ 101, 104, 107 e 110 e a frequência do segundo oscllador foi varrida numa região tal que os ions de m/e $58\left(\mathrm{CH}_{3} \mathrm{COCH}_{3}{ }^{+}\right)$e 64 $\left(\mathrm{CD}_{3} \operatorname{COCD}_{3}{ }^{+}\right)$fossem acelerados; esses são os ūntcos possiveis pre cursores dos quatro lons acetilados. O primeiro espectro mostra 


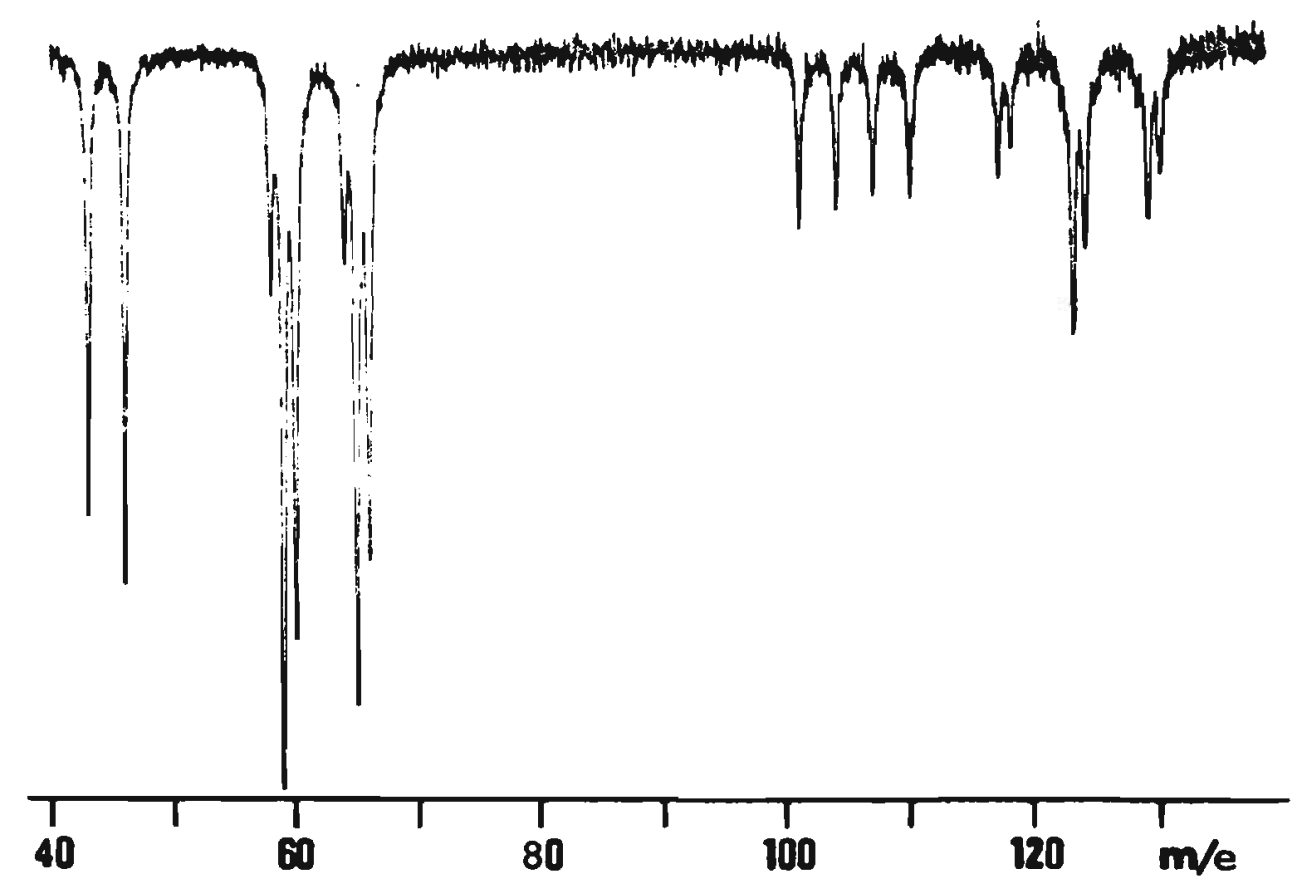

FIGURA 4.14. Espectro de massa da mistura de aceto na e acetona-d 6 . Energia eletrônica: $18 \mathrm{eV}$; pressão total: 4,0 $\cdot 10^{-5}$ Torr (pressões parciais das duas ceto nas: $2,0 \cdot 10^{-5}$ Torr); oscilador marginal: $153,6 \mathrm{kHz}$; modulação de energia eletrônica (base: $9 \mathrm{~V}$, pulso: $9 \mathrm{~V}$ ).

que o íon de m/e 101 é formado apenas pelo íon de m/e 58 e nem podê-lo-ia ser pelo de $\mathrm{m} / \mathrm{e} 64$, que só contém deutério, enquanto que o produto só contēm hidrogênio. Por outro lado o lon de m/e 104 tem como precursores tanto o ion de m/e 58, como o de m/e 64, sendo que a contribuição deste último è malor. Isto indica que a reação preferencial é

$\mathrm{CD}_{3} \mathrm{COCD}_{3}^{+}+\mathrm{CH}_{3} \mathrm{COCH}_{3}+\mathrm{CD}_{3} \mathrm{CO}^{+}\left(\mathrm{CH}_{3} \mathrm{COCH}_{3}\right)+. \mathrm{CD}_{3}$

m/e 64

m/e 104

e não

$\mathrm{CH}_{3} \mathrm{COCH}_{3}^{+}+\mathrm{CD}_{3} \mathrm{COCD}_{3} \rightarrow \mathrm{CD}_{3} \mathrm{CO}^{+}\left(\mathrm{CH}_{3} \mathrm{COCH}_{3}\right)+. \mathrm{CD}_{3}$

me 58

m/e 104 


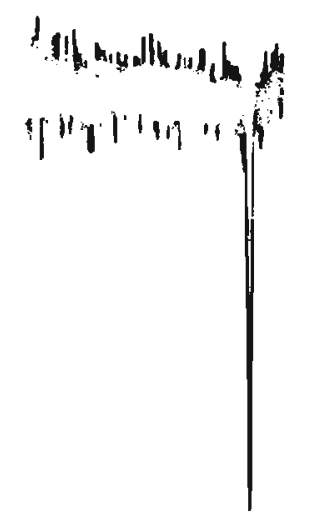

a

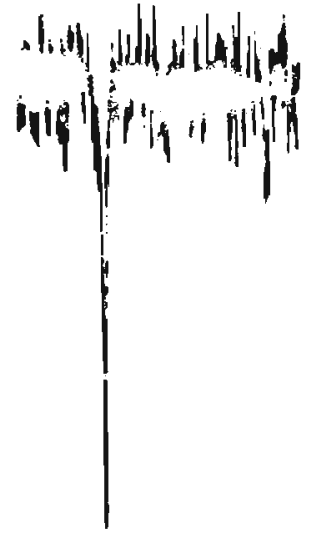

FIGURA 4.15. Espectros de ressonân

b cia dupla da mistura de acetona $e$ acetona$\mathrm{d}_{6}$. Energia eletrônica: $20 \mathrm{eV;}$ pressão total:7,7 $10^{-6}$ Torr (pressōes parciais iguais); oscilador mar ginal: $153,6 \mathrm{kHz}$; amplitude de oscilação

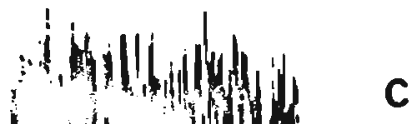
do oscilador de resso nância dupla: pulsada entre 0 e $10 \mathrm{mV}$. São observados respectiva mente os ions de m/e: a) 101, b) 104, c) 107 e d) 110 .

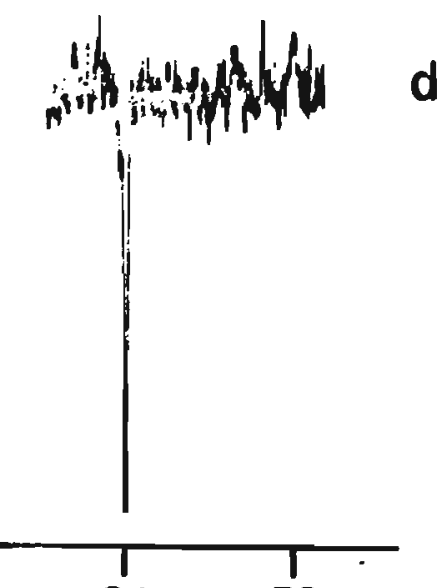

$6458 \mathrm{~m} / \mathrm{e}$ 
A situação é anāloga no caso do ion de m/e 107, formado preferen cialmente pelo ion de m/e 58. Como esperado, o ion de m/e 110 provēm apenas do ion de $\mathrm{m} / \mathrm{e} 64$. As reações que têm como produto os ions de m/e 104 e 107 evidenciam que é um dos grupos metila do ion reagente, e não da molécula neutra, a espécie preferencial mente eliminada na reação. Várias experiências de ressonância dụ pla desse tipo, realizadas com misturas de acetona e acetona- $d_{6}$ em vārias proporções, mostraram que a probabilidade de o radical metila provir do ion é aproximadamente o dobro da probabilidade de provir da molécula neutra. E possível que na realidade o mecanismo seja um só (vide seção 4.6.3.), isto é, que o radical metila tenha sua origem sempre no ion, podendo o Ion, que fi nalmente fragmenta, ser formado durante a colisão dos reagentes, através de uma reação de transferência de carga rápida. Rẹ sultados idênticos foram obtidos com misturas de acetona e penta nona-3, $\mathrm{CH}_{3} \mathrm{COCH}_{3}$ e $\mathrm{C}_{2} \mathrm{H}_{5} \mathrm{COC}_{2} \mathrm{H}_{5}$, onde foram observados os lons aci lados de m/e 101, 115, 129 e 143 .

Duas estruturas foram propostas para os Ions acila dos nas cetonas, após ter-se verificado que o radical alquila provém do ion. No caso da acetona, foram propostos os mecanis mos :<smiles>C[O+]=C(C)[O+]=C(C)C(C)(C)OC(C)(C)[O+]=C(C)COC(C)C</smiles>

(A)

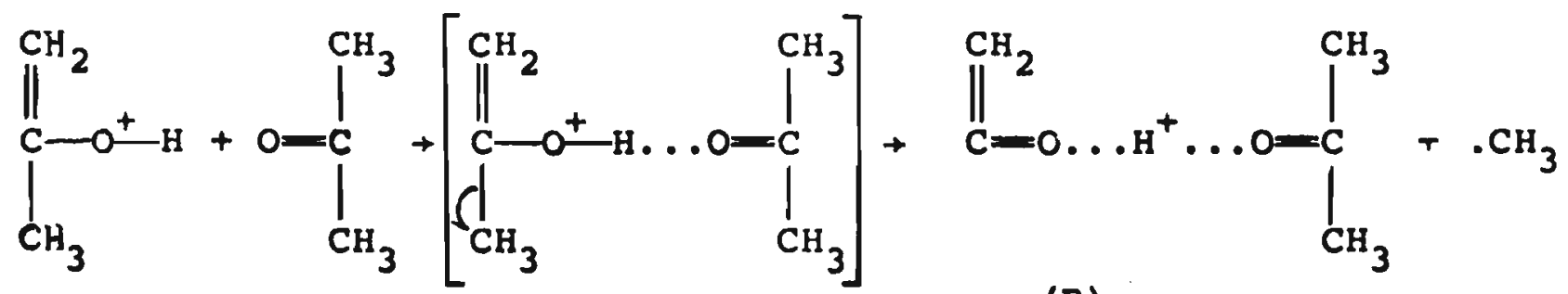


A estrutura $\underline{B}$ corresponde à cetona ligada por ponte de hidrogênio à acetona. Cetena é um produto de processos de fragmenta ção em espectroscopia de massa bastante favorável ${ }^{138}$ e essas estruturas com pontes de hidrogênio são comuns como produtos de reações entre ions e molēculas. 139 porēm, a experiência com a 2,2,4,4-tetrametilpentanona-3 (m/e 227, FIGURA 4.13.) excluỉu a possibilidade da existência da estrutura $\underline{B}$, pois, em princípio, para que esta estrutura fosse possivel, a cetona teria que admi tir uma forma enólica, o que não se dã com a 2,2,4,4-tetrametilpentanona-3. O mecanismo de reação deve ser o mesmo em todas as cetonas, pois as reações ocorrem a velocidades comparáveis.

Interessante é ver o que acontece em cetonas de radicais alquila diferentes. Por exemplo, na butanona observa-se apenas o produto de m/e 115 e não o de m/e 129, a pressōes menores que $9 \cdot 10^{-5}$ Torr, nas condições de ressonância ciclotrônica de íons.

$\mathrm{CH}_{3} \mathrm{COC}_{2} \mathrm{H}_{5}^{+}+\mathrm{CH}_{3} \mathrm{COC}_{2} \mathrm{H}_{5} \rightarrow \mathrm{CH}_{3} \mathrm{CO}^{+}\left(\mathrm{CH}_{3} \mathrm{COC}_{2} \mathrm{H}_{5}\right)+. \mathrm{C}_{2} \mathrm{H}_{5}$

$\mathrm{CH}_{3} \mathrm{COC}_{2} \mathrm{H}_{5}^{+}+\mathrm{CH}_{3} \mathrm{COC}_{2} \mathrm{H}_{5} \nrightarrow \mathrm{C}_{2} \mathrm{H}_{5} \mathrm{CO}^{+}\left(\mathrm{CH}_{3} \mathrm{COC}_{2} \mathrm{H}_{5}\right)+. \mathrm{CH}_{3}$

Porēm, o ion de m/e 129 ser obtido em misturas de butanona e pen tanona -3 :

$\mathrm{C}_{2} \mathrm{H}_{5} \mathrm{COC}_{2} \mathrm{H}_{5}^{+}+\mathrm{CH}_{3} \mathrm{COC}_{2} \mathrm{H}_{5} \rightarrow \mathrm{C}_{2} \mathrm{H}_{5} \mathrm{CO}^{+}\left(\mathrm{CH}_{3} \mathrm{COC}_{2} \mathrm{H}_{5}\right)+. \mathrm{C}_{2} \mathrm{H}_{5}$

A situação è anāloga na 3,3-dimetilbutanona onde apenas $\mathrm{CH}_{3} \mathrm{CO}^{+}\left[\mathrm{CH}_{3} \mathrm{COC}\left(\mathrm{CH}_{3}\right)_{3}\right]$ (m/e 143) è formado e não $\left(\mathrm{CH}_{3}{ }_{3} \mathrm{CCO}^{+}\left[\mathrm{CH}_{3} \mathrm{COC}\left(\mathrm{CH}_{3}\right)_{3}\right]\right.$ (m/e 185). Na acetofenona, se bem que neste caso a reação é mais lenta, só se observa $\mathrm{C}_{6} \mathrm{H}_{5} \mathrm{CO}^{+}\left(\mathrm{C}_{6} \mathrm{H}_{5} \mathrm{COCH}_{3}\right)$ (m/e 225) e não $\mathrm{CH}_{3} \mathrm{CO}^{+}\left(\mathrm{C}_{6} \mathrm{H}_{5} \mathrm{COCH}_{3}\right)(\mathrm{m} / \mathrm{e}$ 163). O aparecimento de ape nas um dos possíveis íons, sendo, porēm, possível obter o outro íon através de misturas de cetonas, sugere que fatores dinâmicos desempenhem um papel preponderante na reação. 
Apesar do número limitado de casos examinados, é possí vel perceber uma analogia entre a formação de produtos iônicos a cilados em cetonas e a fragmentação desses compostos em espeç troscopia de massa convencional: ${ }^{104}$ No produto acilado encontrase sempre o grupo $\mathrm{RCO}^{+}$que predomina no espectro de massa de alta energia eletrônica (vide seção 4.1.). Assim, na FIGURA 4.11. (butanona), observa-se que o pico do Ion $\mathrm{C}_{2} \mathrm{H}_{5} \mathrm{CO}^{+}(\mathrm{m} / \mathrm{e} 57$ ) è mais intenso que o do íon $\mathrm{CH}_{3} \mathrm{CO}^{+}(43)$ a $12,0 \mathrm{eV}$, ocorrendo o contrário já a $15,0 \mathrm{eV}$. O Íon acilado da butanona è o que contém o grupo $\mathrm{CH}_{3} \mathrm{CO}^{+}$. A situação é a mesma na 3,3-dimetilbutanona, onde $\left(\mathrm{CH}_{3}\right)_{3} \mathrm{CCO}^{+}$tem o potencial de aparecimento menor, sendo que, a e nergias eletrônicas bem acima do potencial de ionização da molécula, $\mathrm{CH}_{3} \mathrm{CO}^{+}$predomine; este é o grupo que se liga à cetona na reação entre o ion molecular da cetona e a molécula neutra. Na acetofenona o principal fragmento no espectro de massa é $\mathrm{C}_{6} \mathrm{H}_{5} \mathrm{Co}^{+}$ observando-se $\mathrm{C}_{6} \mathrm{H}_{5} \mathrm{CO}^{+}\left(\mathrm{C}_{6} \mathrm{H}_{5} \mathrm{COCH}_{3}\right)$ e não $\mathrm{CH}_{3} \mathrm{CO}^{+}\left(\mathrm{C}_{6} \mathrm{H}_{5} \mathrm{COCH}_{3}\right)$. Semelhanças entre produtos de reaçōes entre Ions e moléculas e proces sosde fragmentação em espectroscopia de massa podem ser esperadas no caso,pois a reação corresponde a um fragmentação do Ion molecu彑 lar, induzida pela molécula neutra.

Misturas de cetonas duas a duas revelaram aspectos inte ressantes da estabilidade relativa dos ions em estudo. Por exem plo, na mistura de acetona e butanona apareceram $\mathrm{CH}_{3} \mathrm{CO}^{+}\left(\mathrm{CH}_{3} \mathrm{COCH}_{3}\right)$ e $\mathrm{CH}_{3} \mathrm{CO}^{+}\left(\mathrm{CH}_{3} \mathrm{COC}_{2} \mathrm{H}_{5}\right)$. Este último íon, além de ser produzido diretamente a partir dos ions moleculares de acetona e butanona, 0 è também através da reação

$\mathrm{CH}_{3} \mathrm{CO}^{+}\left(\mathrm{CH}_{3} \mathrm{COCH}_{3}\right)+\mathrm{CH}_{3} \mathrm{COC}_{2} \mathrm{H}_{5} \rightarrow \mathrm{CH}_{3} \mathrm{CO}^{+}\left(\mathrm{CH}_{3} \mathrm{COC}_{2} \mathrm{H}_{5}\right)+\mathrm{CH}_{3} \mathrm{COCH}_{3}$ o que foi mostrado por ressonância dupla. A reação no sentido o posto não foi detectada. Portanto, houve a transferência do grupo $\mathrm{CH}_{3} \mathrm{CO}^{+}$da molécula da acetona para a molécula da butanona e, da maneira como è definida a afinidade protônica (seção 5.1.), 
137 pode ser definida uma afinidade acỉlica, dizendo-se então que butanona tem afinidade acilica maior que acetona. A afinidade acilica relativa, determinada em misturas de acetona, butanona e pentanona-3, aumenta na ordem $\mathrm{CH}_{3} \mathrm{COCH}_{3}<\mathrm{CH}_{3} \mathrm{COC}_{2} \mathrm{H}_{5}<\mathrm{C}_{2} \mathrm{H}_{5} \mathrm{COC}_{2} \mathrm{H}_{5}$. Is to é anālogo à ordem de afinidades protônicas (vide a sequèn cia 5.9.).

Nos espectros de butanona, pentanona-3, 3,3-dimetilbuta nona e 2,2,4,4-tetrametilpentanona-3 há picos correspondentes a verdadeiros dímeros dessas cetonas (alëm dos dímeros protonados). Esse dímero não foi detectado na acetona a pressōes menores que $9 \cdot 10^{-5}$ Torr; nas outras cetonas aparecem ao redor de $2 \cdot 10^{-5}$ Torr. E esse o Ion chave na elucidação do mecanismo da forma ção dos íons acilados, como será visto na seção 4.6.3.

As FIGURAS $4.10 ., 4.16 ., 4.17$. e 4.18. referem-se respectivamente a acetona, butanona, pentanona-3 e 3,3-dimetilbutano na. Representam a variação das correntes iônicas das espécies oḅ servadas em ressonância ciclotrônica de Ions com a pressão. No caso da acetona foram incluidos todos os íns; nos outros casos foram incluidas apenas as curvas de produtos iônicos e não as de Ions reagentes. Não foram considerados os picos dos íns que con tém carbono-13. Observa-se nestas figuras que nas diversas ceto nas o comportamento dos Ions correspondentes è semelhante.

\subsubsection{Cetonas com hidrogênios $\gamma$}

As cetonas desse tipo examinadas foram pentanona-2, hexanona-2 e heptanona-3. Seus espectros são um puco ma1s compl1cados que os das outras cetonas. Em primeiro lugar, o fon molecu lar sofre um rearranjo de McLafferty (reação 4.2.), dando origem a lons de $\mathrm{m} / \mathrm{e} 58,58$ e 72 , respectivamente, nas cetonas 


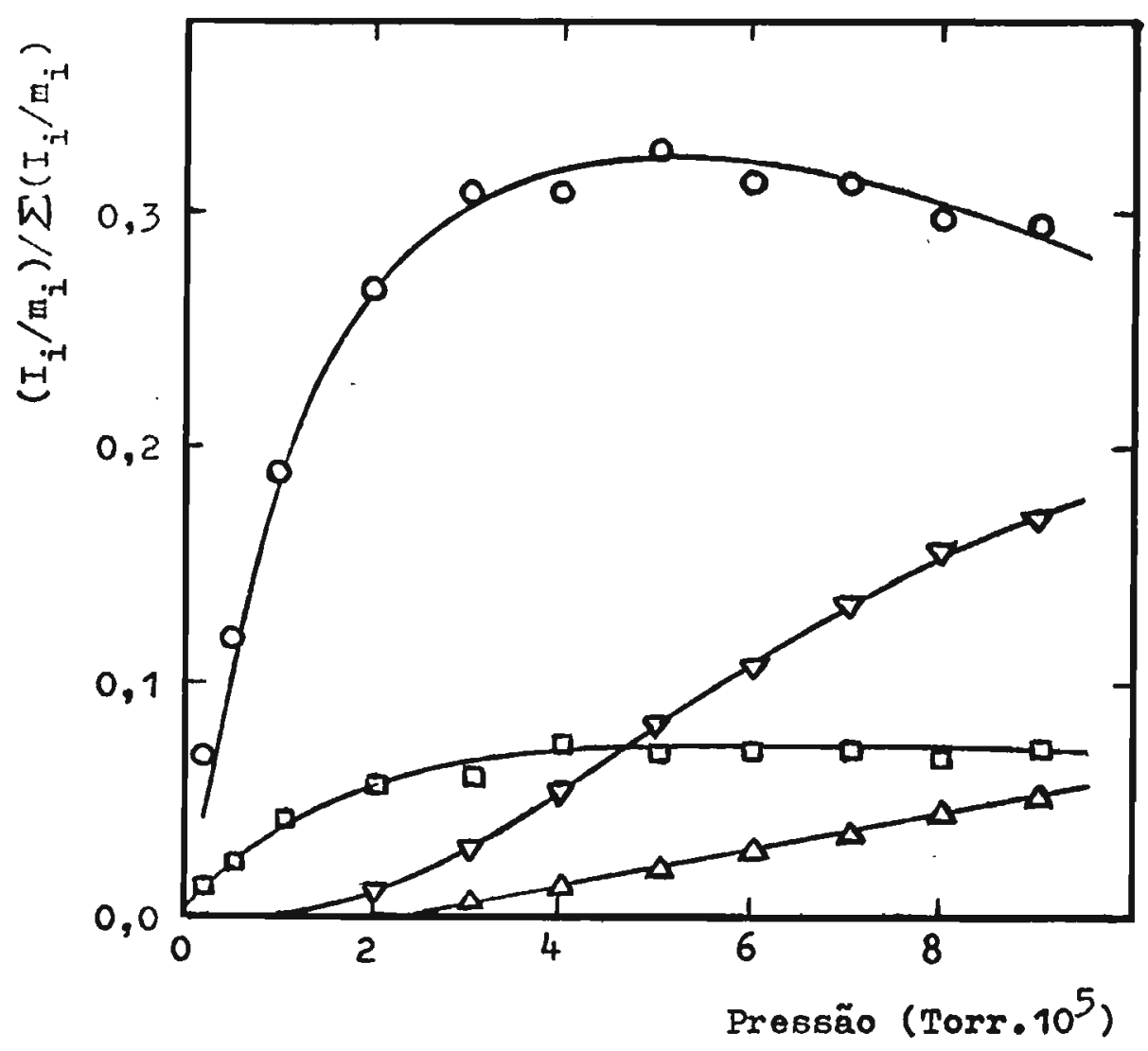

FIGURA 4.16. Correntes iônicas relativas dos produtos iônicos em butanona em função de pressão:

(O) $\left(\mathrm{CH}_{3} \mathrm{COC}_{2} \mathrm{H}_{5}\right) \mathrm{H}^{+}$, (a) $\mathrm{CH}_{3} \mathrm{CO}^{+}\left(\mathrm{CH}_{3} \mathrm{COC}_{2} \mathrm{H}_{5}\right)$,

(A) $\left(\mathrm{CH}_{3} \mathrm{COC}_{2} \mathrm{H}_{5}\right)_{2}^{+},(\nabla)\left(\mathrm{CH}_{3} \mathrm{COC}_{2} \mathrm{H}_{5}\right)_{2} \mathrm{H}^{+}$.

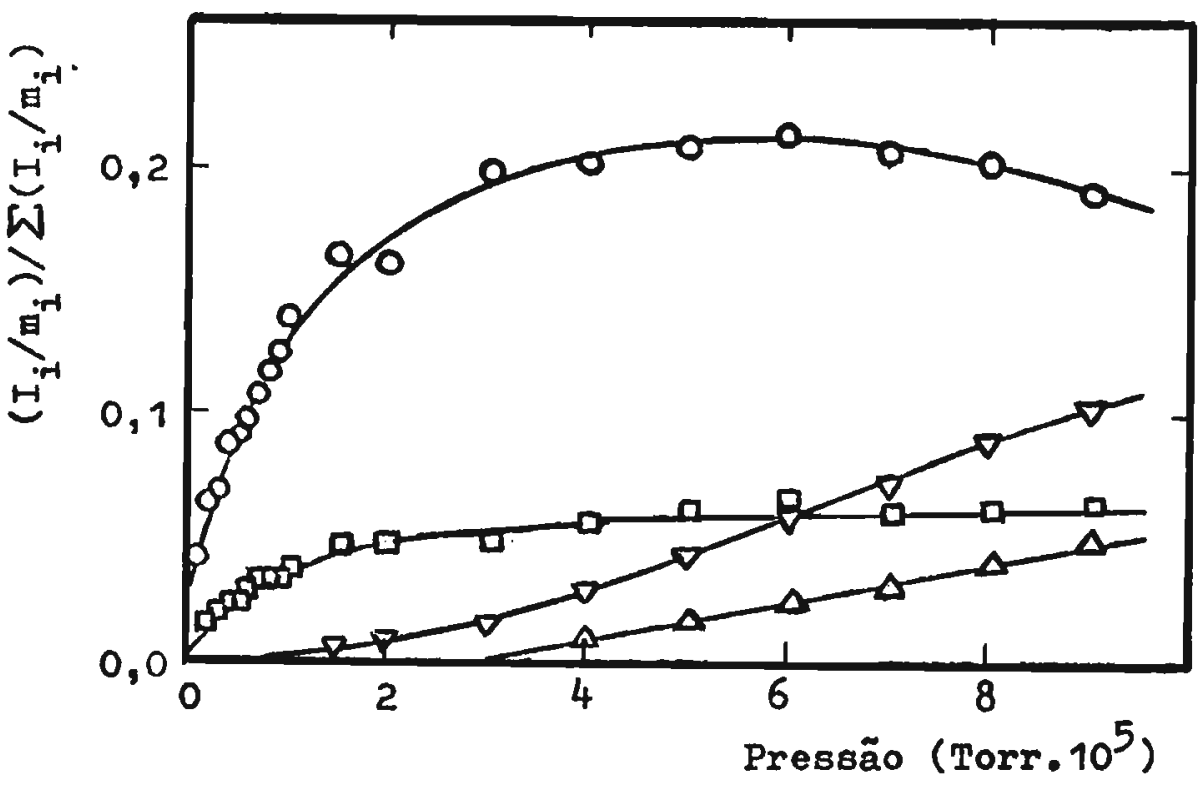

FIGURA 4.17. Correntes iônicas relativas dos produtos iônicos em pentanona-3 em função de pressão:
(O) $\left(\mathrm{C}_{2} \mathrm{H}_{5} \mathrm{COC}_{2} \mathrm{H}_{5}\right) \mathrm{H}^{+}$,
(a) $\mathrm{C}_{2} \mathrm{H}_{5} \mathrm{CO}^{+}\left(\mathrm{C}_{2} \mathrm{H}_{5} \mathrm{COC}_{2} \mathrm{H}_{5}\right)$,

(A) $\left(\mathrm{C}_{2} \mathrm{H}_{5} \mathrm{COC}_{2} \mathrm{H}_{5}\right)_{2}^{+}$,

(D) $\left(\mathrm{C}_{2} \mathrm{H}_{5} \mathrm{COC}_{2} \mathrm{H}_{5}\right)_{2} \mathrm{H}^{+}$. 


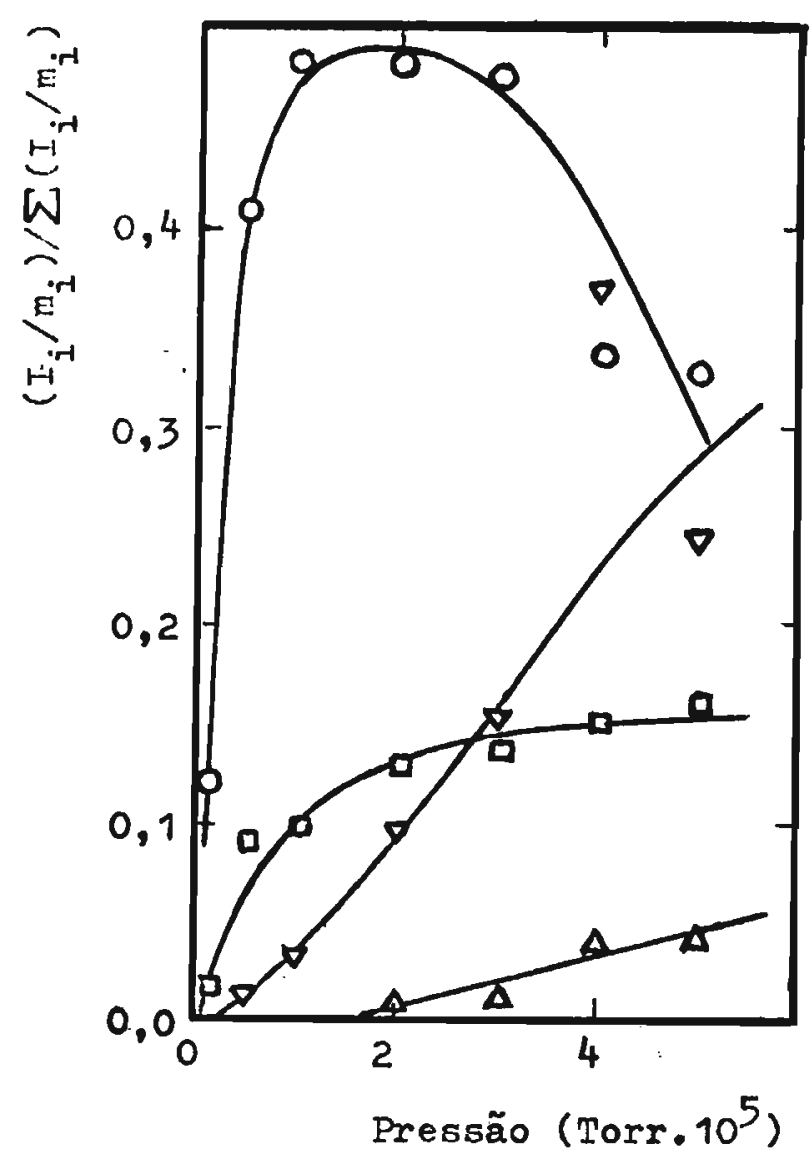

FIGURA 4.18. Correntes iônicas relativas dos produtos iônicos em 3,3-dimetilbutanona, em função de pressão: (O) $\left(\mathrm{CH}_{3} \mathrm{COC}\left(\mathrm{CH}_{3}\right)_{3}\right) \mathrm{H}^{+}$, (D) $\mathrm{CH}_{3} \mathrm{CO}^{+}\left(\mathrm{CH}_{3} \mathrm{COC}\left(\mathrm{CH}_{3}\right)_{3}\right),(\Delta)\left(\mathrm{CH}_{3} \mathrm{COC}\left(\mathrm{CH}_{3}\right)_{3}\right)_{2}^{+}$, (v) $\left(\mathrm{CH}_{3} \mathrm{COC}\left(\mathrm{CH}_{3}\right)_{3}\right)_{2} \mathrm{H}^{+}$.

relacionadas acima. O interessante é que o principal produto de condensação nessas cetonas corresponde à adição do produto do rearranjo de McLafferty à cetona neutra, se bem que o produto do rearranjo não reaja diretamente, mas sim, o Ion molecular. Assim, na pentanona-2 ocorre a reação:

$$
\begin{aligned}
& \mathrm{CH}_{3} \mathrm{COC}_{3} \mathrm{H}_{7}^{+}+\mathrm{CH}_{3} \mathrm{COC}_{3} \mathrm{H}_{7} \rightarrow \mathrm{C}_{3} \mathrm{H}_{6} \mathrm{O}^{+}\left(\mathrm{CH}_{3} \mathrm{COC}_{3} \mathrm{H}_{7}\right)+\mathrm{C}_{2} \mathrm{H}_{4} \\
& \mathrm{~m} / \mathrm{e} 144
\end{aligned}
$$

$\mathrm{Na}$ hexanona-2 è formado o Ion de $\mathrm{m} / \mathrm{e} 158$ e na heptanona-3, o de 
m/e $186 ;$ em reações análogas.

Na FIGURA 4.19. tem-se um espectro da pentanona-2, obtido a $2,0 \cdot 10^{-5}$ Torr, onde aparecem os ions $\mathrm{CH}_{3} \mathrm{CO}^{+}(\mathrm{m} / \mathrm{e} 43)$,

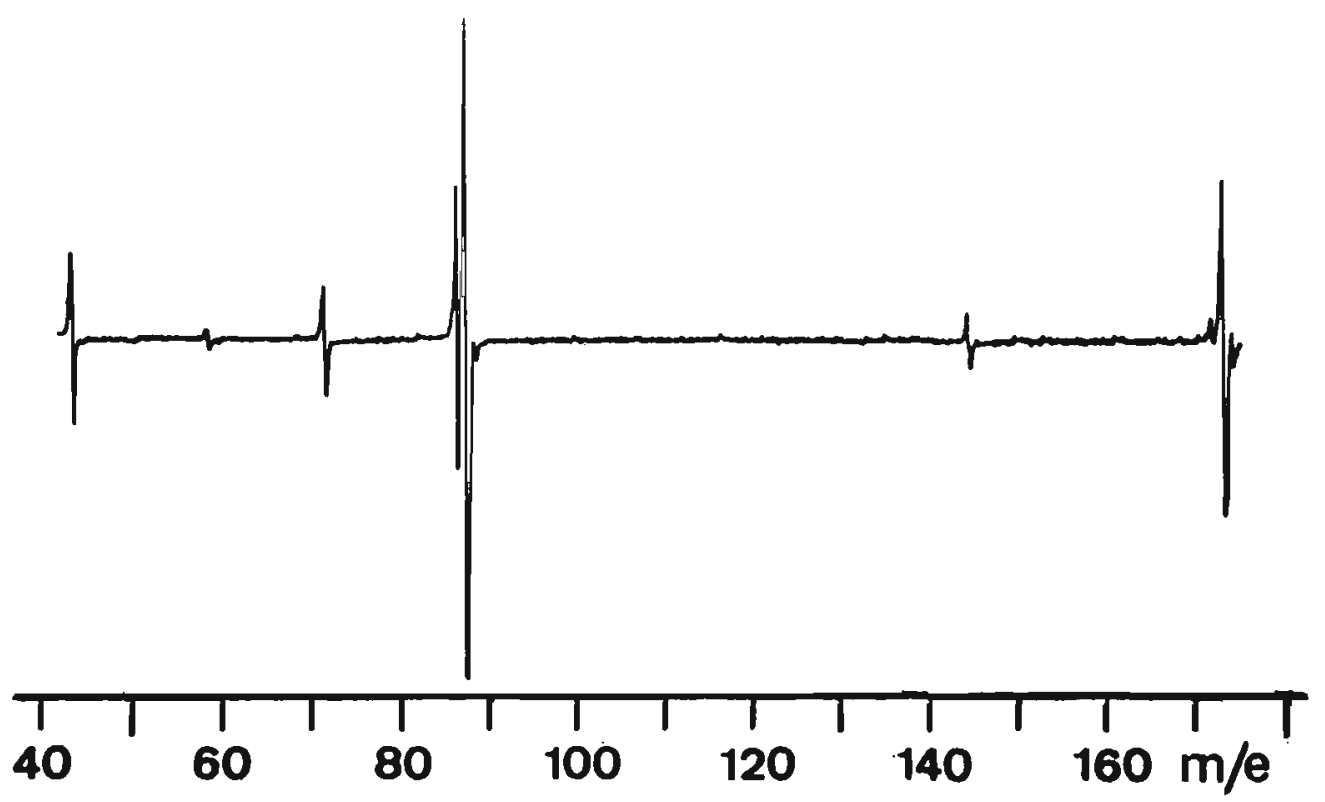

FIGURA 4.19. Espectro de massa da pentanona-2. Energia eletrônica: 15 ev; pressão: $2,0 \cdot 10^{-5}$ Torr; oscilador marginal, $114,1 \mathrm{kHz}$.

$\mathrm{CH}_{3} \mathrm{COHCH}_{2}{ }^{+}$(58, proveniente do rearranjo de McLafferty), $\mathrm{C}_{3} \mathrm{H}_{7} \mathrm{CO}^{+}$ (71), $\mathrm{CH}_{3} \mathrm{COC}_{3} \mathrm{H}_{7}^{+}(86),\left(\mathrm{CH}_{3} \mathrm{COC}_{3} \mathrm{H}_{7}\right) \mathrm{H}^{+}(87)$, o ion de $\mathrm{m} / \mathrm{e} \quad 144$, mencionado acima, o dimero (172) e o dímero protonado (173). A pressões maiores que $6 \cdot 10^{-5}$ Torr aparece 0 fon de $\mathrm{m} / \mathrm{e} 157$, $\mathrm{C}_{3} \mathrm{H}_{7} \mathrm{CO}^{+}\left(\mathrm{CH}_{3} \mathrm{COC}_{3} \mathrm{H}_{7}\right)$, um produto de acilação, anālogo aos observa dos nas cetonas sem hidrogênios $x$. Na FIGURA 4.20 . tem-se a variação da corrente iônica dos produtos formados em reações en tre Ions e moléculas da pentanona-2 em função da pressão. A abundâncla do produto de condensação envolvendo rearranjo de McLafferty (m/e 144) passa por um mäximo e o seu desaparec1 - 


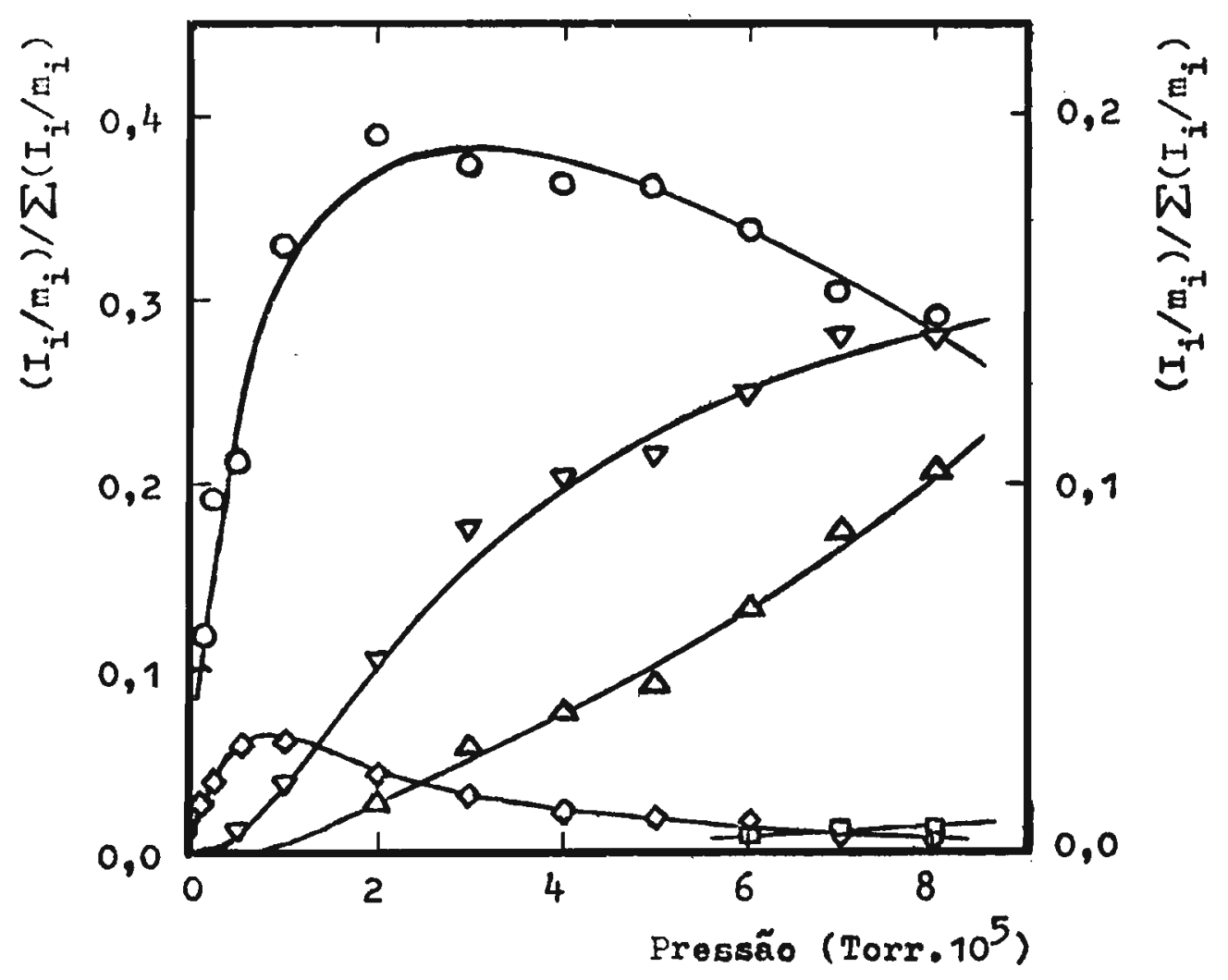

FIGURA 4.20. Correntes iônicas relativas dos produtos iônicos em pentanona-2, em função de pressão:

(O) $\left(\mathrm{CH}_{3} \mathrm{COCH}_{2} \mathrm{CH}_{2} \mathrm{CH}_{3}\right) \mathrm{H}^{+}(\mathrm{m} / \mathrm{e} 87)$,

(O) $\mathrm{C}_{3} \mathrm{H}_{6} \mathrm{O}^{+}\left(\mathrm{CH}_{3} \mathrm{COCH}_{2} \mathrm{CH}_{2} \mathrm{CH}_{3}\right)(\mathrm{m} / \mathrm{e} \mathrm{144)}$,

(D) $\mathrm{CH}_{3} \mathrm{CH}_{2} \mathrm{CH}_{2} \mathrm{CO}^{+}\left(\mathrm{CH}_{3} \mathrm{COCH}_{2} \mathrm{CH}_{2} \mathrm{CH}_{3}\right)(\mathrm{m} / \mathrm{e}$ 157),

(A) $\left(\mathrm{CH}_{3} \mathrm{COCH}_{2} \mathrm{CH}_{2} \mathrm{CH}_{3}\right)_{2}{ }^{+}(\mathrm{m} / \mathrm{\theta} 172)$,

(จ) $\left(\mathrm{CH}_{3} \mathrm{COCH}_{2} \mathrm{CH}_{2} \mathrm{CH}_{3}\right)_{2} \mathrm{H}^{+}(\mathrm{m} / \mathrm{e}$ 173)

As escalas dos f́ns de $\mathrm{m} / \mathrm{e} 87$ - 173 são as da esquerda.

mento esta aparentemente relacionado com o aparecimento do Ion acilado (m/e 157).

A situação da pentanona-2 não difere da de hexanona-2 e heptanona-3. E interessante relacionar os produtos de acila ção dessas três cetonas, que, porêm, sỏ estão presentes a pressões mais elevadas que nas cetonas sem hidrogênios $\Upsilon$. Esses produtos são respectivamente: $\mathrm{C}_{3} \mathrm{H}_{7} \mathrm{CO}^{+}\left(\mathrm{CH}_{3} \mathrm{COC}_{3} \mathrm{H}_{7}\right), \mathrm{C}_{4} \mathrm{H}_{9} \mathrm{CO}^{+}\left(\mathrm{CH}_{3} \mathrm{COC}_{4} \mathrm{H}_{9}\right)$ e $\mathrm{C}_{4} \mathrm{H}_{9} \mathrm{CO}^{+}\left(\mathrm{C}_{2} \mathrm{H}_{5} \mathrm{COC}_{4} \mathrm{H}_{9}\right)$, nas condições experimenta1s empregadas 
não foram encontrados os produtos envolvendo o outro grupo $\mathrm{RCO}^{+}$ das respectivas cetonas. Portanto, se a analogia entre a forma ção desses ions e a fragmentação em espectroscopia de massa usual for vălida, ocorre aqui justamente o conträrio do que nas cetonas sem hidrogênios $\underline{Y}$ : na formação de $\operatorname{RCO}^{+}\left(R C O R^{\prime}\right)$ è adiciona do à cetona o grupo $\mathrm{RCO}^{+}$que constitui o Ion menos abundante no espectro de massa de energia eletrônica bem acima do potencial de ionização do composto. Na heptanona-3 não se forma $\mathrm{C}_{2} \mathrm{H}_{5} \mathrm{CO}^{+}\left(\mathrm{C}_{2} \mathrm{H}_{5} \mathrm{COC}_{4} \mathrm{H}_{9}\right)$, mas esse ion pode ser obtido, misturando es sa cetona com a pentanona-3. Isto é anālogo ao caso das cetonas sem hidrogêniogy: o produto de acilação não observado diretą mente numa cetona com radicais alquila diferentes pode ser obt 1 do na mistura de duas cetonas apropriadas.

\subsubsection{Mecanismo das reações de acilação}

A dependência de pressão das reações de acilação em cẹ tonas sem hidrogênios $y$ mostra que a abundância dos íns acilados aumenta na região de $10^{-6}$ Torr e se torna constante a partir de aproximadamente $2 \cdot 10^{-5}$ Torr. Ao mesmo tempo, um dimero, que porēm não é estabilizado na acetona, aparece acima de $2 \cdot 10^{-5}$ Torr e aumenta continuamente com pressão (FIGURAS 4.16 a 4.18.). Tal comportamento sugere que essas reações procedem atravēs de um dímero excitado que, a baixas pressões, dissocia unimolecula mente, de maneira anāloga a ions moleculares excitados e, a altas pressões é estabilizado ao colidir com outra molécula neutra.

Estas considerações permitem propor uma sequência de reações nas cetonas sem hidrogênios $\underline{y}$, dada abaixo. A fim de facllitar a representação, foram adotados os seguintes simbolos: $\underline{M}$ indica a molécula neutra da cetona e $\mathrm{M}^{+}$, O Ion molecular corres- 
pondente; $\mathrm{F}^{+}$e $\mathrm{F}^{+}$são fragmentos do tipo $\mathrm{RCO}^{+} ; \mathrm{MH}^{+}$é a molêcula protonada $\mathrm{e}_{2} \mathrm{H}^{+}$, o dímero protonado; $\mathrm{M}_{2}{ }^{+}$é o dimero, que, quando excitado, é representado por $\left(\mathrm{M}_{2}{ }^{+}\right)^{*} ; \mathrm{A}^{+}$é o Ion acilado do tipo $\mathrm{RCO}^{+}\left(\mathrm{RCOR}^{\prime}\right)$. Os produtos neutros geralmente não estão especificados.

$$
\begin{aligned}
& M^{+}+M \frac{\mathrm{k}_{1}}{\mathrm{k}_{-1}}\left(\mathrm{M}_{2}{ }^{+}\right)^{*} \\
& \left(\mathrm{M}_{2}{ }^{+}\right)^{\star} \stackrel{\mathrm{k}_{2}}{\longrightarrow} A^{+}+\mathrm{N}
\end{aligned}
$$$$
\left(\mathrm{M}_{2}^{+}\right)^{*} \stackrel{\mathrm{k}_{3}}{\longrightarrow} \mathrm{MH}^{+}+\mathrm{O}
$$$$
\left(\mathrm{M}_{2}^{+}\right)^{*}+\mathrm{M} \stackrel{\mathrm{k}_{4}}{\longrightarrow} \mathrm{M}_{2}^{+}+\mathrm{M}^{*}
$$$$
\mathrm{M}^{+}+\mathrm{M} \stackrel{\mathrm{K}_{5}}{\longrightarrow} \mathrm{MH}^{+}+\mathrm{P}
$$$$
\mathrm{F}^{+}+\mathrm{M} \stackrel{\mathrm{k}_{6}}{\longrightarrow} \mathrm{MH}^{+}+\mathrm{Q}
$$$$
\mathrm{F}^{+}+\mathrm{M} \stackrel{\mathrm{k}}{\longrightarrow} \mathrm{MH}^{+}+\mathrm{R}
$$$$
\mathrm{MH}^{+}+\mathrm{M} \stackrel{\mathrm{k}_{8}}{\longrightarrow} \mathrm{M}_{2} \mathrm{H}^{+}
$$

Segundo esse esquema, è formado um dỉmero excitado, que pode decompor, fornecendo novamente os reagentes, ou, o ion acilado; eventualmente pode tambēm ser responsável pela formação da molécu la protonada (terceira reação), mas este ion tambēm pode ser for mado diretamente a partir do Ion molecular (quinta reação). A quarta reação representa a establlização do dimero excitado. Nệ 
tc esquema cinëtico supõe-se que valham condições de estado estą cionário para o dimero excitado, isto é,

$\frac{d\left(M_{2}{ }^{+}\right)^{\star}}{d t}=0$

Logo,

$$
\left(\mathrm{M}_{2}{ }^{+}\right)^{\star}=\frac{\mathrm{k}_{1}(\mathrm{M})\left(\mathrm{M}^{+}\right)}{\mathrm{k}_{-1}+\mathrm{k}_{2}+\mathrm{k}_{3}+\mathrm{k}_{4}(\mathrm{M})}
$$

Nestas equações (M) representa a concentração da cetona (moléculas $\cdot \mathrm{cm}^{-3}$ ) e as outras quantidades entre parênteses repre sentam as respectivas correntes iônicas (ions $\mathbf{s}^{-1}$ ). As equaçōes cinēticas de formação do Ion acilado e do dímero são, respectivamente:

$\frac{d\left(A^{+}\right)}{d t}=k_{2}\left(M_{2}{ }^{+}\right)^{*}$

$\frac{\mathrm{d}\left(\mathrm{M}_{2}{ }^{+}\right)}{\mathrm{dt}}=\mathrm{k}_{4}(\mathrm{M})\left(\mathrm{M}_{2}{ }^{+}\right)^{*}$

Logo ,

$$
\begin{aligned}
\left(A^{+}\right) & =\frac{\frac{k_{1} k_{2}\left(M^{+}\right)_{0}}{k_{-1}+k_{2}+k_{3}+k_{4}(M)}}{k_{1}+k_{5}-\frac{k_{1} k_{-1}}{k_{-1}+k_{2}+k_{3}+k_{4}(M)}}\left\{1-e^{-\left(k_{1}+k_{5}-\frac{k_{1} k_{-1}}{k_{-1}+k_{2}+k_{3}+k_{4}(M)}\right)(M) t}\right\} \\
\left(M_{2}{ }^{+}\right)= & \frac{\frac{k_{1} k_{4}^{(M)(M)^{+}}{ }^{(M)}}{k_{-1}+k_{2}+k_{3}+k_{4}(M)}}{k_{1}+k_{5}-\frac{k_{1} k_{-1}}{k_{-1}+k_{2}+k_{3}+k_{4}(M)}}\left\{1-e^{-\left(k_{1}+k_{5}-\frac{k_{1} k_{-1}}{k_{-1}+k_{2}+k_{3}+k_{4}(M)}\right)(M) t}\right\}
\end{aligned}
$$


$\left(\mathrm{M}^{+}\right)_{\mathrm{O}} \overline{\mathrm{e}}$ a velocidade de formação (ions. $\mathrm{s}^{-1}$ ) de ions moleculares no filamento $(t=0)$. Estas expressões são anālogas à 2.24, mas válidas para um esquema cinētico especifico (é fácll perceber a que equivalem no presente caso $k_{j}$ e $\sum_{j} k_{j}$ da equação 2.24.). Substituindo estas expressões por $c(t)$ na equação 2.25., efetuando as integrações aI indicadas e a expansão das exponenciais, obtēm-se expressões anālogas à equação 2.31.(rearranjadas agora):

$I_{A}+=\frac{q^{2} E_{1}^{2}\left(M^{+}\right)_{O}(M) m_{A}+k_{1} k_{2}\left(t^{\prime} M^{+}{ }^{2}-t_{M^{+}}{ }^{2}\right)}{8 m_{M^{+}}{ }^{2} \xi_{A}+\left(k_{-1}+k_{2}+k_{3}+k_{4}(M)\right) !}$

$I_{M_{2}}+=\frac{q^{2} E_{1}{ }^{2}\left(M^{+}\right)(M)^{2} m_{M_{2}}+k_{1} k_{4}\left(t^{\prime} M^{+2}-t_{M}{ }^{2}\right)}{8 m_{M^{+}}{ }^{2} \xi_{M_{2}+}+\left(k_{-1}+k_{2}+k_{3}+k_{4}(M)\right)}$

Estas expressões dão as intensidades dos picos do ion acilado e do dímero nos espectros de ressonância ciclotrônica de Ions de cetonas. Para comparar estas intensidades com as curvas das FIGURAS 4.16. e 4.17., é preciso dividi-las pela massa dos res pectivos ions e pela soma das expressões correspondentes de todos os ions da cetona em questão, para obter correntes iônicas relativas.

E Interessante verificar o que se dā com $\mathrm{I}_{\mathrm{A}}+$ e $\mathrm{I}_{\mathrm{M}_{2}}+$ nos limites de baixa e alta pressão. A pressão è dada pelo fator (M) . Quando é baixa, pode-se supor que no denominador das equaçöes 4.13. e 4.14. $k_{-1}+k_{2}+k_{3} \gg k_{4}(M)$; então $I_{A}+$ depende linearmen te da pressão e $\mathrm{I}_{\mathrm{M}_{2}}{ }^{+}$, quadraticamente. No limite de pressões 
muito altas, pode-se considerar $k_{-1}+k_{2}+k_{3} \ll k_{4}(M)$; então $I_{A}+$ se torna independente da pressão pois (M) è cancelado, e $\mathrm{I}_{\mathrm{M}_{2}}{ }^{+}$ passa a variar linearmente com a pressão. As FIGURAS 4.10. e 4.16. a 4.18. mostram que as curvas em função de pressão dos Ions acilados de acetona (m/e 101), butanona (m/e 115), pentanona-3 (m/e 143) e 3,3-dimetilbutanona (m/e 143) realmente são paralelas ao eixo de pressão a pressões maiores que $4 \cdot 10^{-5}$ Torr. No caso de butanona, pentanona-3 e 3,3-dimetilbutanona a corrente iônica relativa dos dỉmeros (m/e 144, 172 e 200, respectivamente) aumenta linearmente com a pressão a pressões maio res que $4 \cdot 10^{-5}$ Torr (no caso da acetona o dímero não é esta bilizado). Estes resultados estão em excelente concordância com o que foi deduzido acima para o limite de pressão alta e, portanto, os resultados dos estudos em função de pressão em cetonas estão de acordo com o esquema cinētico proposto, ou seja,com a idéia de um dỉmero intermediārio nas reações de acilação.

o tempo de vida do dímero intermediário excitado pode ser estimado, tomando a razão entre a corrente iônica relativa do ion acilado a uma pressão baixa e o valor limite dessà correntè, usando a equação 4.13 .

$\frac{I_{A}+(\text { pressão baixa })}{I_{A}+(\text { pressão alta })}=\frac{k_{4}(M)}{k_{-1}+k_{2}+k_{3}}$

A quantidade (M) refere-se à concentração (moléculas $\cdot \mathrm{cm}^{-3}$ ) da cetona à pressão baixa considerada. Pelo esquema cinētico prọ posto, $k_{4}$ é a constante de velocidade de colisăo de dímeros excitados com moléculas da cetona. A TABELA 4.4. mostra que essas constantes estão todas ao redor de $1 \cdot 10^{-9} \mathrm{~cm}^{3}$. molécu$1 \mathrm{a}^{-1} \cdot \mathrm{s}^{-1}$, no caso dos Ions da acetona. Como as larguras dos picos dos Ions de butanona, pentanona-3 e 3,3-dimetilbutanona 
são comparáveis às da acetona e como de qualquer maneira só intẹ ressa a ordem de grandeza do tempo de vida do dimero, uma vez que não se têm dados de pressão multo bons (trata-se de experiên cias realizadas com a pressão lida no controle da bomba iônica), $\mathrm{k}_{4}$ pode ser considerado igual a $1 \cdot 10^{-9} \mathrm{~cm}^{3} \cdot \operatorname{molécula}{ }^{-1} \cdot \mathrm{s}^{-1}$ em todos os casos. $k_{-l}, k_{2}$ e $k_{3}$ referem-se a decomposições unimoleculares do dimero excitado e, portanto, o inverso da soma dessas constantes, $1 /\left(k_{-1}+k_{2}+k_{3}\right)$, è o tempo de vida desse dimero. Tomando valores de $\mathrm{I}_{\mathrm{A}}+$ (pressão baixa) no intervalo de pres são de 0,10 a $1,0 \cdot 10^{-5}$ Torr nos casos de acetona, butanona, pen tanona-3 e 3,3-dimetilbutanona, obtēm-se sempre um tempo de vida do intermediārio excitado ao redor de $2 \mathrm{~ms}$. Este valor parece um pouco alto demals, pois constitui fração apreciāvel do tempo de permanência de ions em geral na cela de ressonância ciclotrônica de ions ( 3 a $5 \mathrm{~ms}$ ). Portanto, esses intermediários se rlam detectados pelo oscilador marginal e, Indistinguiveis dos dimeros estabilizados. Mesmo que as reações ocorressem da manei ra proposta no esquema cinëtico, os resultados de ressonância cli clotrônica de Ions seriam outros, pois os fenômenos ocorrertam nu彑 ma escala de tempo inadequada a essa tëcnica. Como os resultados säo qualitativamente compativeis com 0 esquema cinêtico sugerido, mas não quantitativamente, è provãvel que o valor dema siadamente elevado do tempo de vida do intermediārio tenha sido obtido por causa de um erro um tanto grande no valor absoluto da pressāo.

Os estudos relatados nesse capitulo mostram que a auto-acilação lônica de cetonas em fase gasosa ocorre pela reação do Ion molecular e' se dá atravēs de um complexo intermediārio iô nico. A dependência de pressão dessas reações no intervalo de $10^{-6}$ a $10^{-4}$ Torr mostra que esse intermediărio, um dimero, pode 
ser estabillzado a pressões superiores a $10^{-5}$ Torr num espectrômetro de ressonância ciclotrônica de Ions. Acetona é o único ca so em que o dỉmero não é detectado nas pressões mais elevadas. A decomposição do complexo intermediārio segue, em geral, o camil nho de fragmentação predominante de cetonas em espectroscopia de massa. Essa analogia e o tempo de vida aparentemente longo do intermediário sugerem gue a teoria do quase-equilíbrio de espectros de massa (seção 3.2.2.1.) seja aplicável à distribuição de produtos dessas reações. A decomposição do intermediārio excita do em produto acilado e radical neutro aparentemente se dá antes de a carga se deslocar no intermediário, pois é o íon molecular que fragmenta preferencialmente na reação de acilação. Na seção 4.6.1. fol mencionado brevemente que aldeỉdos tambēm sofrem a reação de auto-acilação; será mencionado no capitulo 6 que alguns ācidos e ésteres tambēm reagem dessa maneira. Assim, parece que a reação de acilação è um processo bastante geral. 


\section{BASICIDADE DE ACIDOS, ALCOOIS E ESTERES SIMPLES}

Durante o estudo de reações de esterificação e transes terificação (a serem relatadas no capitulo 6), surgiu a necessidade de conhecer as basicidades dos reagentes envolvidos. Como esses dados não se encontravam na literatura, partiu-se para a obtenção dos mesmos. Disso resultou publicação no Journal of The Chemical Society de Londres. 140 se bem que não relaciona das com as reações de esterifıcação, tambēm foram ıncluías nas experlências concernentes à basicidade algumas das cetonas menclonadas no capitulo 4, a fim de mostrar algumas generalidades quanto à basicldade de compostos carbonilicos. Tals informa -ções constituem uma etapa essencial na compreensão dos princíplos que governam a química dos Ions desses compostos em fase gạ sosa e dos fatores que contribuem para a estabilização de um pró ton em compostos carbonilicos. Tambëm é possivel obter grande zas termodinâmicas, por exemplo, o calor de formação de certas espécies iônicas, o que por sua vez permite calcular os calores de reação de processos em que esses ions intervém. Como foi vis to na seção 3.1., os efeitos de estrutura molecular e eletrônica sobre a basicidade só podem ser analisados corretamente, se dados de fase gasosa estiverem à disposição, pols nas fases condensadas efeitos de solvatação muitas vezes mascaram as propriedades intrinsecas dos compostos.

Por 1 sso os presentes estudos atravēs de ressonân cla clclotrônica de Ions são de relevância bastante grande e, realmente, tem-se notado uma concentração de esforços de outros pesquisadores na medição de basicidades em fase gasosa, usando 
vários instrumentos, tais como espectrômetros de massa com fonte de alta pressão,"14-143 a técnica de "flowing afterglow", 144146 além de ressonância ciclotrônica de Ions. 2,72,147-150

5.1. Afinidade protônica

Define-se afinidade protônica de um composto A como a variação de entalpia, com o sinal trocado, da reação
$\mathrm{A}+\mathrm{H}^{+} \rightarrow \mathrm{AH}^{+}$
$\Delta \mathrm{H}=-\mathrm{AP}(\mathrm{A})$

A variação de energia livre correspondente é a basicidade de A.

Como reações de transferêncla de próton em fase gasosa se dão com energia de ativação desprezivel, 151 a observação de um processo como
$\mathrm{AH}^{+}+\mathrm{B} \rightarrow \mathrm{BH}^{+}+\mathrm{A}$
$\Delta H=A P(A)-A P(B)$

é interpretado como uma indicação de que a afinidade protônica de $B$ é maior do que a de $A$ (ou 1gual); $A P(B) \geqslant A P(A)$. Isto permi te determinar ordens de basicldade relativa: comparando os com postos A e B, conclui-se, por exemplo, que a afinidade protôni Ca de $B$ é maior que a de $A$; em seguida, comparando B com um outro composto $C$, obtēm-se, por exemplo, que a afinidade protôní ca de $\mathrm{C}$ é malor que a de $\mathrm{B}$. Isto permite escrever a ordem decrescente de basicidades: $C>B>A$. Se as afinidades protôn cas de A e C forem conhecidas, obtidas atravēs de algum outro método, è possivel chegar a um valor numérico para a afinidade protônica de B, dentro de certos limites, que dependem da dife rença de afinidades protônicas de $C$ e $A$.

Os valores numéricos que essa tẻcnica fornece têm um erro de $\pm_{2}$ a $\pm_{5} \mathrm{kcal} / \mathrm{mol}$, dependendo dos compostos usados na com 
paração. 143 Obter experimentalmente valores absolutos de afinidades protônicas é muito difícil, 152,153 mas fol desenvolvida uma

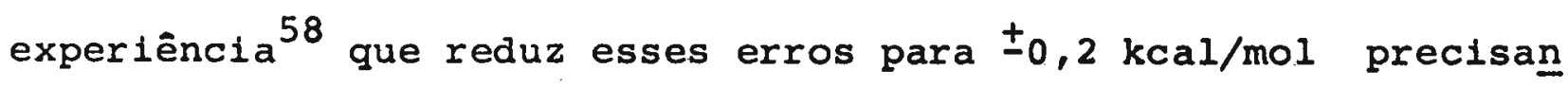
do-se, porém, ainda de um composto de referência. Trata-se de estudar a reação 5.2., escolhendo as moléculas neutras adequadamente, de maneira que a variação de energia livre ( $\Delta G$ ) do processo seja pequena e assim uma situação de equilíbrio seja alcançada nas condições reinantes numà'cela de ressonância ciclo trônica de ions; en outras palavras, procura-se fazer com que, no processo 5.2., a reação indlcada e a reação no sentido inverso ocorram ambas com a mesma velocidade nas pressões balxas e com os tempos de reação curtos típicos em espectroscopia de ressonância ciclotrônica de íons. Experimentalmente procede-se da seguinte maneira: A pressão total da mistura das substâncias A e B é elevada progressivamente, até que as intensidades relativas dos sinais de $\mathrm{AH}^{+} \mathrm{e} \mathrm{BH}^{+}$permaneçam constantes. Medem-se as intensidades desses sinais, $\left(\mathrm{AH}^{+}\right)$e $\left(\mathrm{BH}^{+}\right)$, e calcula-se a constante de equilibrio;

$$
K=\frac{\left(\mathrm{BH}^{+}\right)}{\left(\mathrm{AH}^{+}\right)} \frac{(\mathrm{A} \cdot)}{(\mathrm{B})}
$$

' onde (A) e (B) são as pressões parcials das substâncias A e B. A variação de energla livre è dada por

$$
\begin{aligned}
\Delta G & =-R T \operatorname{lnK} \\
& =-1,38 \log \mathrm{K}
\end{aligned}
$$

para uma temperatura ao redor de $298 \mathrm{~K}$ ( $\Delta \mathrm{G}$ em $\mathrm{kcal} / \mathrm{mol}$ ). A afinidade protônica è definida em termos de uma variação de ental pia.

$\Delta \mathbf{G}=\Delta \mathrm{H}-\mathrm{T} \Delta \mathbf{S}$

Portanto, para calculā-la seria necessärı conhecer a varlação 
de entropia no processo, a qual, contudo, é admitida como sendo zero nessas reações de transferência de próton. 58 Logo, obtëm-se a diferença de afintdades protônicas dos dois compostos. $\Delta G \simeq \Lambda H=A P(A)-A P(B)$

Para chegar na coṇđição de equilíbrio é em geral necessārio elevar a pressão até talvez $2 \cdot 10^{-4}$ Torr, o que corresponde a 40 colisões de um íon com moléculas neutras na cela de ressonância ciclotrônica de ions. Nessas pressões altas surge em muitos casos um problema, que é o da formação de dímeros protonados a par tir das molēculas protonadas, exemplificada pela equação

$\mathrm{AH}^{+}+2 \mathrm{~A}+(\mathrm{AHA})^{+}+\mathrm{A}$

No capitulo 4 foram estudados dimeros desse tipo nos $\mathbf{s i s t e m a s}$ das cetonas. As moléculas protonadas podem entrar ainda em outras reaçōes (veja o caso dos ālcoois, capítulo 6), mas de qual quer forma há um consumo das espécies protonadas em reaçōes para lelas, diferentes das do equilíbrio em questão, o qual, em conse quência, nunca é atingido. Por isso o método atè aqui descrito limita-se aos sistemas em que os fons moleculares protonados não reagem para dar ions terciārios. Hā no entanto outra maneira de conseguir o nūmero suficiente de colisões para haver equilỉbrio: em vez de aumentar a pressão, aumenta-se o tempo. Isto pode ser feito com a cela de aprisionamento (seção 2.4.1.) em conjunto com a técnica de operação pulsada. Registram-se separa damente as intensidades de $\mathrm{AH}^{+}$e $\mathrm{BH}^{+}$em função do tempo, como descrito em 2.4.3., atē as duas curvas nivelarem, 1 sto è, as intensidades não variarem mais. Calcula-se $\underline{K}$ como indicado acima. A vantagem é que è possivel trabalhar a pressões baixas $\quad\left(10^{-6}\right.$ Torr), nas quais dimeros protonados não são estabilizados. Porēm, quando 08 Ions moleculares protonados intervēm em outras reações 
bimoleculares rāpidas, tambēm com essa técnica não é possível oḅ ter resultados, pois as curvas de intensidade do sinal em função do tempo não nivelam.

Nessas medidas de equilibrio a diferença de afinidades protônicas dos dois compostos examinados não deve exceder $3 \mathrm{kcal} /$ mol. Isto corresponde a uma constante de equilíbrio já maior que 100, o que é em princípio o mäximo que se pode medir com certa precisão. Corresponde a preparar a amostra gasosa com as pressões parcias de A e B na proporção 10 : 1 e medir uma relação de inten sidades de sinais de $\mathrm{BH}^{+}$e $\mathrm{AH}^{+}$de $10: 1$.

Este mëtodo tem sido bastante empregado, 58,60 principal mente para medir basicidades relativas de compostos nitrogenados, cujos ions moleculares protonados geralmente não são multo reativos. Costuma-se obter diferenças de basicldade numa série de com postos, comparando, por exemplo, A com B e B com C; também se compara, se possivel, diretamente A com C, para ver se a diferença de basicidade entre A e C medida, concorda com a computada a partır das diferenças entre A e B e entre B e C. Geralmente ob-

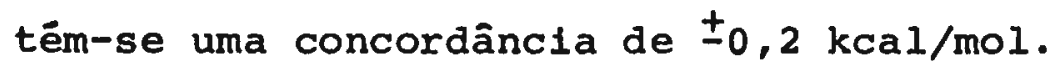

A afinidade protônica relaciona-se com outras grandezas termodinâmicas, o que pode ser visto pelo seguinte ciclo:

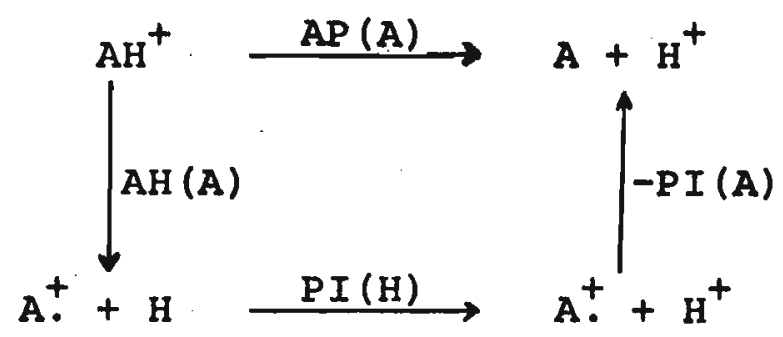

onde AP è a afinidade protônica, PI, o potencial de ionização e AH, a afinidade por hidrogênio, sempre da espécle indicada entre parênteses. 0 ciclo mostra que 
$A P(A)=-P I(A)+P I(H)+A H(A)$

Um ciclo análogo para a molécula B permite expressar o calor da reação 5.2 . como

$$
\begin{aligned}
\Delta H & =A P(A)-A P(B) \\
& =P I(B)-P I(A)+A H \cdot(A)-A H(B)
\end{aligned}
$$

O significado dessa equação serã visto mais adiante.

Medida a afinidade protônica de uma espécie $A$, ou se ja, o calor da reação 5.1., pode-se obter o calor de formação do ion $\mathrm{AH}^{+}$, desde que se conheça o calor de formação da molécula neu tra A; o calor de formação de $\mathrm{H}^{+}$é $366 \mathrm{kcal} / \mathrm{mol} .154$

$$
\Delta \mathrm{H}_{\mathrm{f}}\left(\mathrm{AH}{ }^{+}\right)=-\mathrm{AP}(\mathrm{A})+\Delta \mathrm{H}_{\mathrm{f}}(\mathrm{A})+\Delta \mathrm{H}_{\mathrm{f}}\left(\mathrm{H}^{+}\right)
$$

\subsection{Basicidades relativas}

Foi determinada a ordem de basicidade de alguns álcoois, ácidos, ësteres e cetonas, usando a técnica descrita na seçāo anterior, ou seja, vertficando em que sentido se dá a reação

$\mathrm{AH}^{+}+\mathrm{B} \rightleftharpoons \mathrm{BH}^{+}+\mathrm{A}$

Se a reação ocorre espontaneamente da esquerda para a direita, a basicidade de $\mathrm{B}$ è maior que a de $\mathrm{A}$ e, se ocorre da direita para a esquerda, a basicidade de $\mathrm{A}$ é maior que a de B. Desta forma, comparando as substânclas aos pares, fol possivel estabelecer uma ordem de basicidade.

A espectroscopia de ressonância ciclotrônica de ions permite facilmente verificar em qual sentido se dá a reação aci ma, atravēs da tēcnica de ressonâncla dupla, que fol discutida na 
seção 2.3.4.2. Trata-se de observar, por exemplo, o ion $\mathrm{BH}^{+} \mathrm{com}$ - oscilador marginal na frequêncla adequada para 1 sso e, ao mesmo tempo, irradiar o ion $\mathrm{AH}^{+}$com o oscilador de ressonância dupla, que deve ter uma frequência tal, que $\mathrm{AH}^{+}$esteja em resso nâncla no campo magnētico adequado para a observação de $\mathrm{BH}^{+}$. Es ta frequência é, usandø a förmula 2.3.:

$v_{2}=\frac{m_{1}}{m_{2}} v_{1}$

onde $v_{2}$ è a frequência do oscilador de ressonâncía dupla, $v_{1}$, a do oscilador marginal, $\mathrm{m}_{1}$ é a massa do ion $\mathrm{BH}^{+}$em untdades atômi cas e $\mathrm{m}_{2}$ a de $\mathrm{AH}^{+}$, em unidades atômicas. Se for observado um sinal de ressonância dupla negativo, o que equivale a um decrēscimo na intensidade do sinal de $\mathrm{BH}^{+}$, a reação é exotérmica da es querda para a direita e deve ocorrer espontaneamente nesse senti do (vide seçāo 2.3.4.2.). Logo, $A P(B)>A P(A)$. Em seguida inverte-se o procedimento, ou melhor, observa-se $\mathrm{AH}^{+}$e irradia-se $\mathrm{BH}^{+}$, acelerando-o. Se na primeira parte da experiêncla um sinal negativo foi observado, vārias possibilidades existem agora. Pode ser observado um sinal negativo tambëm, o que significa que na realidade a reação é praticamente termoneutra, ou seja, a afi nidade protônica de $A$ é quase igual à de $B$; neste caso não é pos sível dizer qual delas é maior e encontrou-se um sistema adequado para realizar um estudo de equilibrio, como descrito na seção anterior. Se na experiência de ressonância dupla for observado um sinal positivo, a reação é endotērmica da direita para a esquerda e o segundo oscilador forneceu a energia corresponden te à endotermicidade, de modo a fazer a reação ir nesse sentido, levando a um aumento na intensidade do sinal de $\mathrm{AH}^{+}$. Esta é uma situação um tanto confortante (sinal negativo num sentido, positivo noutro), pois permite afirmar com bastante certeza 
$A P(B)>A P(A)$, como ainda será visto melhor mais abaixo. Pode tam bém não ser observado sinal de ressonância dupla algum; neste caso a reação também é endotérmica da direlta para a esquerda, mas não é possivel fazer ela ir nesse sentido, acelerando $\mathrm{BH}^{+}$.' Conclut-se que $A P(B)>A P(A)$.

Fol mencionado na seção 2.3.4.2. que a experiência de ressonância dupla está sujeita a ser invalidada por efeltos ins trumentais, se não forem tomadas algumas precauçōes. ${ }^{39}$ o principal problema que eventualmente surge, è o de ions serem ejetados da cela ao aplicar o segundo oscilador, o que geralmente faz com que se observe um sinal de ressonância dupla negativo (vide seção 2.3.4.2.). Por isso um sinal negativo nos dois sentidos de reação è suspeito. o problema è reduzido, empregando campos de irradiação baixos. Também è conveniente trabalhar a correntes de emissão e pressões baixas, para ter poucos íons na cela e evitar os efeitos associados com cargas espaclais elevadas. A não observação de um sinal obviamente sempre pode em princípio decorrer de algum problema; por isso a obtençāo de sinal negativo num sentido e positivo noutro, é o resultado de ressonância dupla mais seguro.

Alēm dessas dificuldades com a ressonância dupla, há outra crîtica ${ }^{155}$ em relação à determinação de afinidades protôni cas na base da ocorrência ou não-ocorrência de reaçōes: existe a possibilidade de que a reação se dê, não pelo motivo de ser exo tẻrmica, mas pelo fato de o Ion reagente estar num estado excitado ou possuir excesso de energia cinētica. Essa posslbilidade po de ser reduzida, realizando experiências em função de pressão. ${ }^{151}$ Reglstram-se as Intensidades dos picos dos Ions $\mathrm{AH}^{+} \mathrm{e} \mathrm{BH}^{+}$(pro cesso 5.7.) numa dada pressão total, com dadas pressões parcials de $A$ e $B$; em seguida aumenta-se a pressāo total, mantendo a ra- 
zäo entre as pressões parciais de A e B, e registram-se novamente as intensidades e assim por diante. Se a reação se dá preferencialmente da esquerda para a direita, com aumento da pres são, a intensidade do sinal de $\mathrm{BH}^{+}$aumenta em relação à do sinal de $\mathrm{AH}^{+}$. Isto porque a pressões mais elevadas é maior o número de colisões entre Ions e moléculas, de modo que o sistema indica do pelo processo 5.7. chega mais próximo à situação de equilíbrio, o qual está deslocado no sentido do íon protonado da molécula mais bāsica. Deve-se lembrar que na mistura das substâncias neutras A e B, quando o tempo de reação é pequeno ou a pressão é baixa, as espēcies protonadas $\mathrm{AH}^{+}$e $\mathrm{BH}^{+}$sāo em geral formadas principalmente pelos ions moleculares de A e B ou por fragmentos dos mesmos, atravēs de reações de transferência de ' próton. Quando o tempo de reação aumenta, ou a pressão, o número de coll sões dos produtos $\mathrm{AH}^{+}$e $\mathrm{BH}^{+}$com moléculas neutras se torna apreciāvel; ocorrem reaçōes de transferência de próton desses íons para as molēculas, mas obviamente no sentido exotērmico; assim o ion protonado da molècula mais básica é formado preferencialmente, às custas do outro ion protonado, cujo sinal diminui em rela ção ao do primeiro. A vantagem de aumentar a pressão reside no fato de que tambēm aumenta o nümero de colisões não reativas;nes sas condições os ions relaxam qualquer excesso de energia e os processos observados são característicos de Ions no estado fundạ mental, com energia cinética térmica. Para afastar a possibili dade de estar observando ions excitados, é 1mportante que a atr 1 buição de afinldades protônicas também se basele em gráficos de abundâncias dos íons protonados em função de pressão.

Todavia, dependendo do sistema, tambëm esses estudos em função de pressão têm seus inconvententes. Como mencionado na seção 5.1., quando o número de colisōes aumenta, são estab1l1- 
zados dímeros protonados (vide reação 5.3.), que são espécies for madas com excesso de energia e que necessitam de uma colisão para relaxarem essa energia para não decomporem imediatamente. Então, considerando o processo 5.7 . a intensidade do sinal de $\mathrm{BH}^{+}$aumen ta ao aumentar a pressäo, se B for mais básico que A. Porém, se $\mathrm{BH}^{+}$formar um dímero $\mathrm{BHB}^{+}$. a pressōes elevadas, haverá consumo de $\mathrm{BH}^{+}$e a intensidade do sinal correspondente a $\mathrm{BH}^{+}$poderā até dimi nuir em relação à do sinal de $\mathrm{AH}^{+}$, fazendo crer que A è mais básí co que B.

Pelo exposto acima conclui-se que ordens de basicidade devem ser obtidas através de experiências de ressonância dupla, tọ mando as devidas precauções, isto é, trabalhando com campos de irradlação fracos e correntes de emissão baixas. Estas experiênclas devem ser complementadas por estudos em função de pressão, tendo-se a necessária cautela ao analisar os resultados, ou seja, è necessārio conhecer todas as reações que ocorrem no sistema da mistura de A com B. Alēm disso, se for concluído que a ordem de basicidade dos compostos A, B e C é, por exemplo A> B> 'C, porque ao comparar A com B e B com C fol obtido A>B e B>C, tam bém é conveniente comparar diretamente A com $C$, para que se tenha certeza de não encontrar uma inconsistência do tipo $A>B>C, A<C$. $\mathrm{Na}$ seção 5.4. todos os casos estudados serão examinados separadamente, mostrando-se os problemas de cada um com mals detalhe.

\subsection{Parte experimental}

o espectrōmetro usado foi descrito no capitulo 4 e aqui sō serão mencionadas as condições experimentals particulares às experiências concernentes às basicidades. A energla eletrônica ge ralmente fol de $15 \mathrm{eV}$; algumas vezes foram usadas energias maiores 
(até $45, \mathrm{eV}$ ), a fim de verificar se isto poderia causar alguma alteração nos resultados. Foi usada sempre a corrente de emissão mí nima compatível com uma relação sinal/ruido razoável; essa corren te, entretanto nunca excedeu $0,20 \mu \mathrm{A}$, tentando-se trabalhar, sempre que possivel com $0,05 \mu \mathrm{A}$. Nas experiências de ressonância dü pla o nivel de osçilação do segundo oscilador fol geralmente manti do abaixo de $10 \mathrm{mV} / \mathrm{cm}$; algumas vezes foi aumentado, para eventualmente achar um sinal muito fraco.

Os estudos em função de pressão foram conduzidos basicamente do seguinte modo: As duas substâncias foram introduzıdas separadamente na câmara de anālise, usando as duas entradas do espec trômetro. Geralmente foram obtidos pontos (intensidades dos picos dos ions moleculares protonados) a quatro pressões totais diferentes, uma sendo sempre o dobro da anterior: $0,50,1,0,2,0$ e 4,0 $10^{-5}$ Torr (pressões lidas diretamente no controle da bomba iôni ca). Para isso a pressão de uma das substâncias fol ajustada em $2,5 \cdot 10^{-6}$ Torr; em seguida foi introduzida a outra substância, ele vando-se a pressão assim até 5,0 $\cdot 10^{-6}$ Torr. As intensidades dos picos correspondentes aos Ions moleculares protonados foram registradas, varrendo o campo magnético. Em seguida a pressão parcial da primeira substância foi aumentada até se ter uma leitura (pressão total) de 7,5 $10^{-6}$ Torr no controle da bomba iônica; a pressão da segunda substância foi aumentada até leitura de 1,0 . 10 Torr; novamente foram registrados os picos de interesse. Depois disso foi introduzido mais da primeira substância, até leitura de $1,5 \cdot 10^{-5}$ Torr e, da segunda substância, até 2,0 $10^{-5}$ Torr; seguiu-se novo registro de intensidades, após o qual a pressão foi aumentada até $3,0 \cdot 10^{-5}$ Torr com a primeira substância e até $4,0 \cdot 10^{-5}$ Torr com a segunda; nessas condições foi obtido o último espectro. Portanto, a pressão total fol sucessivamente aumenta da, mas em cada mistura a pressão parcial de um composto era sempre 
igual à do outro, o que todavia não corresponde necessariamente à realidade, pois iguais eram apenas as leituras no controle da bomba iōnica e esse tipo de medidor tem uma sensibilidade dife rente para diferentes gases. Não foram feitas correções ou calibrações para 1sso. Em alguns casos achou-se mais conveniente pre parar num tubo a mistura dos dois compostos a serem examinados, e usar só uma das entradas do espectrômetro. Com isto a relação das pressões parciais dos dois compostos deve ter permanecido cons tante ao aumentar sucessivamente a pressão total da mistura. No tubo, os liquidos foram colocados em proporção tal que houvesse excesso do menos volätil, para conseguir pressões parciais de vapor sobre o líquido aproximadamente iguais; isto foi feito empiri camente, não se conhecendo na realıdade a proporção exata das duas substâncias. As intensidades dos sinais são simplesmente as amplitudes totais dos picos nos espectros registrados (lado positi vo mais lado negativo da derivada). Não foram feitas as corre ções indicadas na seção 2.3.4.1., para transformar intensidades de sınais em correntes iônicas, pois no presente caso só interessavam as tendências verificadas nas intensidades dos sinais ao aumentar a pressão, 1sto é, queria-se ver qual dos picos corres pondentes a ions moleculares protonados aumentava em relaçấo ao outro.

Foram utilizados os seguintes compostos, sendo indicada entre parênteses a origem de cada um: ácido fórmico (Braun),ăcido acético (Fisher), äcido acético-d 4 (Stohler), metanol (Baker), metanol-d 4 (Merck), etanol (Reagen), etanol-d 6 (Merck),formiato de metila (Eastman), formiato de etila (BDH), acetato de me tila $(\mathrm{BDH})$, acetato de metila-d 6 (Merck), acetato de etila (Baker), acetona (Fisher), butanona (Fisher) e pentanona-3 (Eastman). De todos estes compostos só o ácido fórmico requereu umà 
purificação adicional: foi destilado com coluna de fracionamento (ponto de ebulição: $99-101^{0} \mathrm{C} / 699$ Torr). Os compostos deuterados foram mantidos em balões (FIGURA 4.2.).

\subsection{Resultados}

Na TABELA 5.1. tem-se um resumo de todas as compara ções feitas, isto è onde aparece um $\mathrm{x}$, o composto da coluna vertí cal foi examinado em conjunto com o da linha horizontal, para ver qual deles è mais bãsico. Nesta tabela os compostos jã estão em ordem crescente de afinidades protônicas. Nota-se que, a não ser nos extremos da tabela, todo composto fol comparado pelo menos com dois de afinidade protônica menor e com dois de afinidade protônica maior. Em nenhum caso foram encontradas inconsistências. Em continuação cada uma das misturas estudadas serã discutida com maiores detalhes.

1) ăcido förmico/metanol. Observou-se nesse sistema a reação $\mathrm{HCOOH}_{2}^{+}+\mathrm{CH}_{3} \mathrm{OH} \rightarrow \mathrm{CH}_{3} \mathrm{OH}_{2}^{+}+\mathrm{HCOOH}$

$\mathrm{m} / \mathrm{e} 47 \mathrm{~m} / \mathrm{e} 33$

Como, porém, metanol protonado reage com moléculas neutras de metanol para dar êter metilico protonado, ${ }^{156} \mathrm{CH}_{3} \mathrm{OHCH}_{3}{ }^{+}$, que também tem relação $\mathrm{m} / \mathrm{e}=47$, foi usado metanol perdeuterado, $\mathrm{CD}_{3} \mathrm{OD}$, para que o pico desse éter não coincidisse com o de $\mathrm{HCOOH}_{2}{ }^{+}$. Na mistú ra de substâncias deuteradas com não-deuteradas, a situação se complica,pols a cada espécie química correspondem fons de várias massas; assim, no caso, as espécies de interesse são: $\mathrm{CD}_{3} \mathrm{OH}_{2}{ }^{+}(\mathrm{m} / \mathrm{e}$ 36), $\mathrm{CD}_{3} \mathrm{OHD}^{+}(37), \mathrm{CD}_{3} \mathrm{OD}_{2}^{+}(38), \mathrm{HCOOH}_{2}^{+}(47), \mathrm{HCOOHD}^{+}$(48) e $\mathrm{HCOOD}_{2}{ }^{+}(49)$. Alêm disso, $\mathrm{m} / \mathrm{e} 36$ è $\mathrm{CD}_{3} \mathrm{OD}^{+}$e m/e 47 é HCOOD $\mathrm{H}^{+}$. Por 


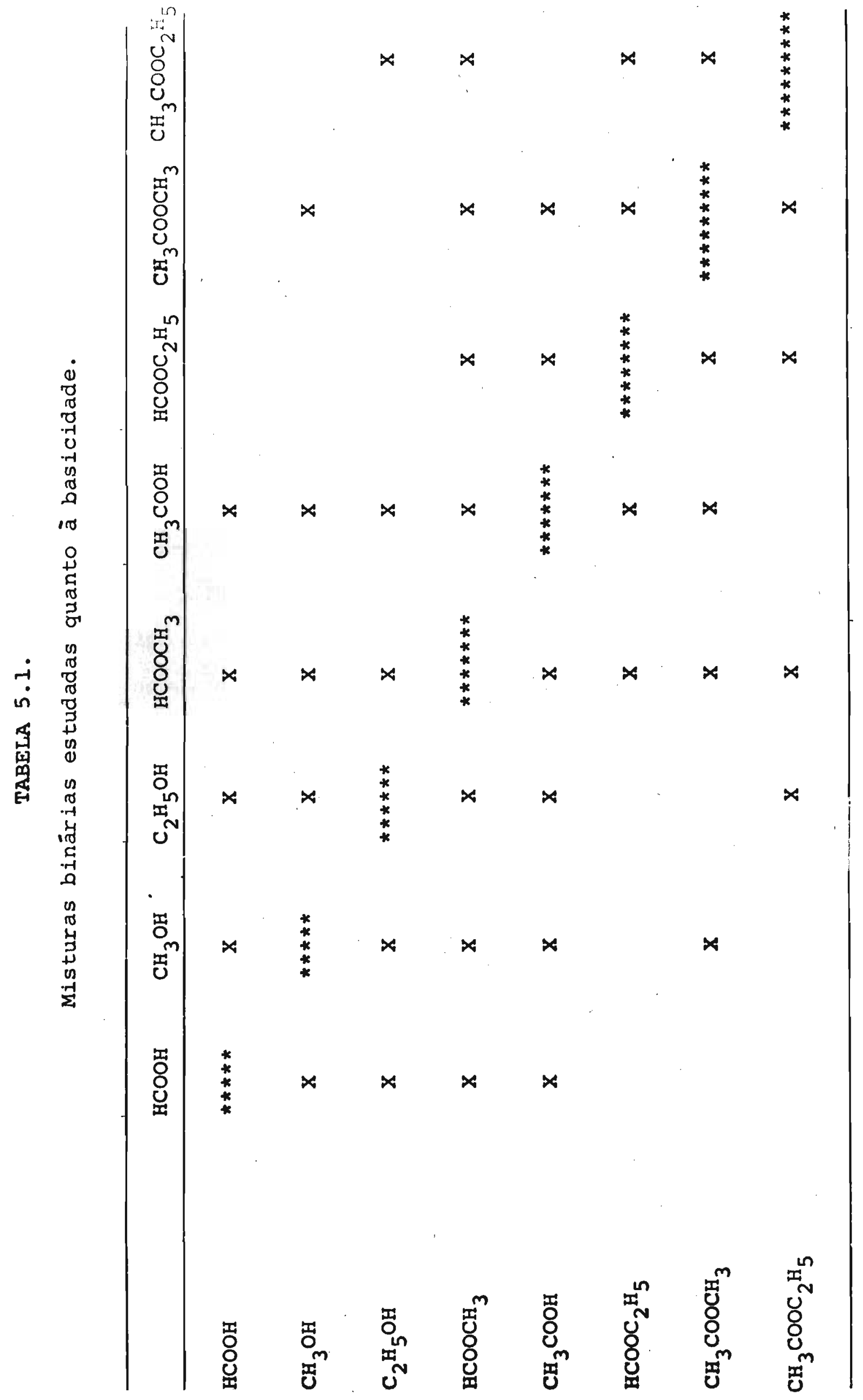


isso os estudos em função de pressão puderam ser apenas qualitatí vos. Observou-se que o conjunto de picos 36,37 e 38 aumen tou bastante em relação ao conjunto 47,48 e 49 com aumento da pressão (inicialmente os primeiros picos foram todos menores que os últimos, depois maiores). Isto indicou que metanol è mais bāsico que ácido förmico: Os íns de m/e 36,37 e 38 reagem todos para darem os éteres metílicos protonados, mas como são justamen te os picos correspondentes a esses ions que crescem e, como àc1do förmico protonado não reage nesse sistema (vide capítulo 6), 0 resultado foi conclusivo. Ressonância dupla, realizada a 2,3 - $10^{-5}$ Torr, com as pressões parcials de ăcido e álcool aproximadamente iguais, mostrou que ocorrem as reações

$$
\begin{aligned}
& \mathrm{HCOOH}_{2}{ }^{+}+\mathrm{CD}_{3} \mathrm{OH} \\
& \mathrm{HCOOH}_{2}{ }^{+}+\mathrm{CD}_{3} \mathrm{OD} \\
& \mathrm{OH}_{2}{ }^{+}+\mathrm{HCOOH}
\end{aligned}
$$$$
\mathrm{HCOOHD}+\mathrm{CD}_{3} \mathrm{OH} \rightarrow \mathrm{CD}_{3} \mathrm{OH}_{2}^{+}+\mathrm{HCOOD}
$$$$
\mathrm{HCOOHD}++\mathrm{CD}_{3} \mathrm{OH} \rightarrow \mathrm{CD}_{3} \mathrm{OHD}^{+}+\mathrm{HCOOH}
$$$$
\mathrm{HCOOHD}+\mathrm{CD}_{3} \mathrm{OD} \rightarrow \mathrm{CD}_{3} \mathrm{OHD}^{+}+\mathrm{HCOOD}
$$

Os picos de $\mathrm{HCOOD}_{2}^{+}$e $\mathrm{CD}_{3} \mathrm{OD}_{2}^{+}$foram muito pouco intensos, não tendo sido possivel realizar experiências de ressonância dupla envolvendo os mesmos. Observando os ions protonados de metanol e irradiando os do ācido förmico, foram obtidos sinals negativos, in dicando que as reações se dão no sentido indicado; não fol possí vel obter sinais positivos, irradiando os Ions protonados do àlcool e observando os do ãcldo, ou seja, não fol possivel fazer com que a reação se dê no sentido inverso. De qualquer forma,res sonância dupla e variação de pressão provaram que a ordem de bas 1 cidade é $\mathrm{HCOOH}<\mathrm{CH}_{3} \mathrm{OH}$. 
2) àcido fórmico/etanol. A situação foi análoga à anterior, só que foi realmente imperativo usar etanol deuterado, $C_{2} D_{5}$ OD, pois do contrário os picos de ácido fórmico e etanol protonados teriam coincidido, pois ambos têm relação $\mathrm{m} / \mathrm{e}=47$. (No caso do metanol m/e 47, o éter, è um Ion terciário, e seu sinal não fol muito intenso). Os resultados também foram análogos aos ante riores: estudo em função de pressão, apenas qualitativo, e resso nância dupla indicando $\mathrm{HCOOH}<\mathrm{C}_{2} \mathrm{H}_{5} \mathrm{OH}$.

3) ácido fórmico/formiato de metila. A reação se dá no sentí do de protonação do éster,

$\mathrm{HCOOH}_{2}{ }^{+}+\mathrm{HCOOCH}_{3}+\left(\mathrm{HCOOCH}_{3}\right) \mathrm{H}^{+}+\mathrm{HCOOH}$

indicando $\mathrm{AP}(\mathrm{HCOOH})<\mathrm{AP}\left(\mathrm{HCOOCH}_{3}\right)$. Os resultados da experiência de variação de pressão encontram-se na TABELA 5.2. e na FIGURA 5.1.: ○ pico 61, $\left(\mathrm{HCOOCH}_{3}\right) \mathrm{H}^{+}$, aumentou em relação ao $47, \mathrm{HCOOH}_{2}^{+}$. Nos espectros o rúido diminuíu com aumento da pressão, pois a corren te de emissão foi mantida constante $(0,10 \mu \mathrm{A})$, de modo que a corrente iônica aumentou, levando a sinais mais intensos. A experiêncla fol realizada, usando mistura de 20 gotas de ácido e 5 gotas de éster num tubo; logo, não se conheclam as pressões parclais dos dols componentes nas várlas pressões totals. Fol reali zada outra experiência, com as duas substâncias em tubos distintos, introduzindo-as através das duas entradas do espectrômetro, mantendo depois as pressões parciais sempre uma lgual à outra. Os resultados das duas experiências foram praticamente 1guais. Na FIGURA 5.1. também aparece o espectro de ressonância dupla, tendo sido observado o ion 61 e Irradiado $\circ 47$, obtendo-se sinal negativo; não fol obtido sinal para a reação inversa. 


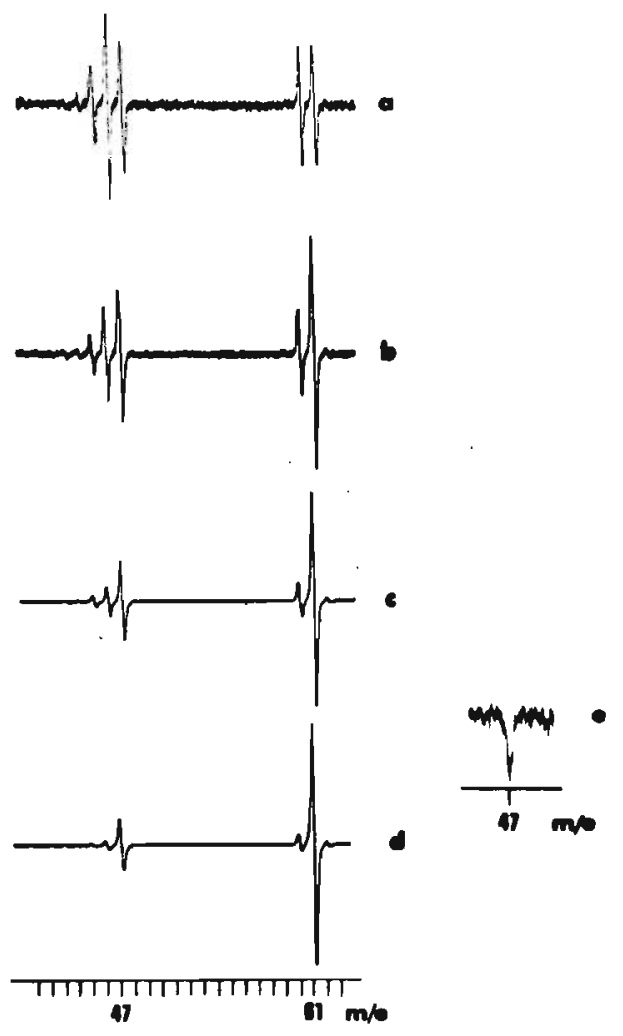

FIGURA 5.1. Espectros de massa da mistura de ácí do fórmico e formiato de metila en função da pressão total da mistura:a) $5,0 \cdot 10^{-6}$ Torr; b) $1,0 \cdot 10^{-5}$ Torr; c) $2,0 \cdot 10^{-5}$ Torr; d) 4,0 $10^{-5}$ Torr:

e) Espectro de ressonância dupla, na qual é observado o lon de m/e 61 e irradiado o de m/e 47; oscilador de ressonância dupla: pulsado entre 0 e $10 \mathrm{mV}$; pressão: $2 \cdot 10^{-5}$ Torr.

4) ācido förmico/ácido acētico. Os estudos foram realizados com um sistema de 20 gotas de ácido fórmico e 1 gota de ácido acético (resultados nas tabelas 5.2. e 5.3.) e também com as amostras. em tubos separados. A intensidade do pico $61, \mathrm{CH}_{3} \mathrm{COOH}_{2}{ }^{+}$, aumentou em relaçăo à do pico $47, \mathrm{HCOOH}_{2}{ }^{+}$, mas não de forma muito acentuada 
pois $\mathrm{CH}_{3} \mathrm{COOH}_{2}{ }^{+}$è consumido na formação do dímero protonado, $\left(\mathrm{CH}_{3} \mathrm{COOH}\right){ }_{2} \mathrm{H}^{+}$. Estes resultados e os de ressonâncla dupla (sinal negativo para a protonação de ácido acētico e nenhum sinal para a reação inversa), mostraram que $\mathrm{AP}(\mathrm{HCOOH})<\mathrm{AP}\left(\mathrm{CH}_{3} \mathrm{COOH}\right)$.

5) metanol/etanol. Este sistema apresentou problemas, pois tanto metanol, como etanol protonados formam os respectivos éteres protonados, sendo o éter dimetilico protonado formado pelo meta nol, isômero do etanol protonado. Se um dos ālcoois fosse deuterado, o problema da coincidência de picos seria resolvido, mas isto não foi feito, pois os picos dos éteres protonados eram bastante fracos, não interferindo apreciavelmente nos resultados do estudo em função da pressão, que indicou $\mathrm{AP}\left(\mathrm{CH}_{3} \mathrm{OH}\right)<\mathrm{AP}\left(\mathrm{C}_{2} \mathrm{H}_{5} \mathrm{OH}\right) .0$ resultado de ressonância dupla nada provou, pois apenas revelou' que o Ion 47 provém do 33, o que é correto, por $\mathrm{CH}_{3} \mathrm{OH}_{2}^{+}(\mathrm{m} / \mathrm{e} 33)$ reage com metanol para dar o éter protonado $\left(\mathrm{CH}_{3}\right)_{2} \mathrm{OH}^{+}(\mathrm{m} / \mathrm{e} 47)$, 156 mas não significando necessariamente que $\mathrm{CH}_{3} \mathrm{OH}_{2}^{+}$também trans fira um próton para etanol, dando $\mathrm{C}_{2} \mathrm{H}_{5} \mathrm{OH}_{2}^{+}(\mathrm{m} / \mathrm{e} 47)$. Não foi dada maior atenção a esse sistema, porque as afinidades protôni cas de metanol.e etanol jā eram conhecidas. 143

6) metanol/formiato de metila. Estes dois compostos foram intro duzidos separadamente no espectrômetro e trabalhou-se em condi ções de pressões parciais iguais. A experiêncla de ressonância dụ pla forneceu um sinal negativo para a transferêncla de um próton de metanol protonado para formlato de metila e não forneceu sinal para a reação inversa. Isto indicou $\mathrm{AP}\left(\mathrm{CH}_{3} \mathrm{OH}\right)<\mathrm{AP}(\mathrm{HCOOCH})_{3}$, - que foi confirmado pelos estudos em função de pressão TABELA 5.2.). Poder-se-ia pensar que o aumento do pico 61 , $\left(\mathrm{HCOOCH}_{3}\right) \mathrm{H}^{+}$, em relação ao płco $33, \mathrm{CH}_{3} \mathrm{OH}_{2}{ }^{+}$, não fol devido à transferência de prōton, mas ao consumo do Ion 33 na reação de formação de ēter 
dimet11ico protonado, $\mathrm{m} / \mathrm{e} 47$, uma reação que realmente ocorre. 156 Todavia, nos espectros obtidos não apareceu o pico correspondente a esse éter, certamente porque no sistema em questão a transferên cia de próton é muito mais rāpida que a reação de condensação,res ponsável pela formação de éter. Quando a pressão parcial do meta nol foi tornada muito maior que a do formiato de metila, apareceu um pico 47, pois nessas condições a colisão de um íon 33 com molé culas de metanol (levando à formação de éter protonado) è muito mals provável que a com moléculas de formiato de metila (que leva à formação de éster protonado).

7) metanol/ācido acētico. Neste sistema, estudado em condições de pressões parciais de ālcool e ãcido iguals, não existem proble mas de coincidência de picos, e os resultados de ressonância dupla indicaram que $\mathrm{AP}\left(\mathrm{CH}_{3} \mathrm{OH}\right)<\mathrm{AP}\left(\mathrm{CH}_{3} \mathrm{COOH}\right)$, pelo fato de ter sido obtido um sinal negativo para a reação

$$
\mathrm{CH}_{3} \mathrm{OH}_{2}^{+}+\mathrm{CH}_{3} \mathrm{COOH}+\mathrm{CH}_{3} \mathrm{COOH}_{2}^{+}+\mathrm{CH}_{3} \mathrm{OH}
$$

e nenhum sinal para a reação inversa. Os resultados da experiência de variação de pressão corroboraram os de ressonância dupla, mas isto pode ter sido acidental, pois ambos os Ions intervëm em reações paralelas em considerāvel extensão: $\mathrm{CH}_{3} \mathrm{OH}_{2}{ }^{+}$forma éter dí metilico protonado ao reagir com metanol, e acetato de metila pro tonado ao reagir com ācido acētıco (vide capitulo 6) e $\mathrm{CH}_{3} \mathrm{COOH}_{2}{ }^{+}$ forma o dimero protonado ao reagir com ácido acétıco e o mencionado acetato ao reagir com metanol.

8) metanol/acetato de metila. Ressonância dupla provou que $\mathrm{AP}\left(\mathrm{CH}_{3} \mathrm{OH}\right)<\mathrm{AP}\left(\mathrm{CH}_{3} \mathrm{COOCH}_{3}\right)$ (sinal negativo no sentido de transfe rêncla de próton para o acetato; nenhum sinal no outro sentido). Em condições de pressões parclals iguais o pico de $\mathrm{CH}_{3} \mathrm{OH}_{2}{ }^{+}$foi 
sempre muito menor que o de $\left(\mathrm{CH}_{3} \mathrm{COOCH}_{3}\right) \mathrm{H}^{+}$, mesmo a pressões mu1to baixas; isto já foi uma indicação de que o èster è multo mais băsico que o álcool. Não apareceu $\circ$ pico de $\left(\mathrm{CH}_{3}\right)_{2} \mathrm{OH}^{+}$que pode ria ser formado por $\mathrm{CH}_{3} \mathrm{OH}_{2}{ }^{+}$e dificultar a interpretação dos resultados das experiências de variação de pressão.

9) etanol/formiato de metila. Fol obtido sinal de ressonância dupla negatıvo no sentido de protonação do éster e sinal posit vo no sentido de protonação do etanol; logo, esta última reação é endotérmica, mas ocorre, se o reagente (formiato de metila protonado) é acelerado (nivel do segundo oscilador: $1 \mathrm{mV} / \mathrm{cm}$ ). Portanto, $\mathrm{AP}\left(\mathrm{C}_{2} \mathrm{H}_{5} \mathrm{OH}\right)<\mathrm{AP}\left(\mathrm{HCOOCH}_{3}\right)$; as afinldades protônicas devem estar prōximas, pois foi possivel fazer a reação ir no senti do endotérmico. Os resultados do estudo em função de pressão es tão na TABELA 5.2. e mostram que o plco de $\left(\mathrm{HCOOCH}_{3}\right) \mathrm{H}^{+}$aumentou em relação ao de $\mathrm{C}_{2} \mathrm{H}_{5} \mathrm{OH}_{2}{ }^{+}$; porém, $\mathrm{C}_{2} \mathrm{H}_{5} \mathrm{OH}_{2}{ }^{+}$é em princíplo reativo, formando o éter dimetílico protonado, cujo pico na presente experiência contudo não apareceu.

10) etanol/ácido acético. Ressonância dupla mostrou

que $\mathrm{AP}\left(\mathrm{C}_{2} \mathrm{H}_{5} \mathrm{OH}\right)<\mathrm{AP}\left(\mathrm{CH}_{3} \mathrm{COOH}\right)$ (s Inal negatıvo para formação de $\mathrm{CH}_{3} \mathrm{COOH}_{2}{ }^{+}$ e positivo para formação de $\mathrm{C}_{2} \mathrm{H}_{5} \mathrm{OH}_{2}{ }^{+}$), mas este fol o único caso em que a experiência de variação de pressão não confirmou este re sultado. E que $\mathrm{CH}_{3} \mathrm{COOH}_{2}^{+}$e $\mathrm{C}_{2} \mathrm{H}_{5} \mathrm{OH}_{2}^{+}$são muito reativos nesse sistema, ambos sendo responsāveis pela formação de $\left(\mathrm{CH}_{3} \mathrm{COOC}_{2} \mathrm{H}_{5}\right) \mathrm{H}^{+}$ (vide capitulo 6), além de o primeiro formar um dímero protonado e o segundo, um éter protonado. Por 1sso só o resultado de ressonância dupla pôde ser considerado.

11) etanol/acetato de etila. A diferença de afinidades protôni cas è muito grande; $\operatorname{AP}\left(\mathrm{C}_{2} \mathrm{H}_{5} \mathrm{OH}\right)<\operatorname{AP}\left(\mathrm{CH}_{3} \mathrm{COOC}_{2} \mathrm{H}_{5}\right)$; só fol consegu生 do um sinal de ressonâncla dupla negativo e, nos espctros de 
ressonância simples, o pico de $\left(\mathrm{CH}_{3} \mathrm{COOC}_{2} \mathrm{H}_{5}\right) \mathrm{H}^{+}$foi sempre muito mais intenso que o de $\mathrm{C}_{2} \mathrm{H}_{5} \mathrm{OH}_{2}{ }^{+}$.

12) formiato de metila/ácido acētico. Como os dois compostos tèm mesma massa molecular, um deles teve que ser deuterado. Fol usado ãcido acético-d 4 , podendo-se então esperar as seguintes reações

$\left(\mathrm{HCOOCH}_{3}\right) \mathrm{H}^{+}+\mathrm{CD}_{3} \mathrm{COOH} \rightarrow \mathrm{CD}_{3} \mathrm{COOH}_{2}^{+}+\mathrm{HCOOCH}_{3}$

m/e $61 \quad \mathrm{~m} / \mathrm{e} 64$

$\left(\mathrm{HCOOCH}_{3}\right) \mathrm{H}^{+}+\mathrm{CD}_{3} \mathrm{COOD} \rightarrow \mathrm{CD}_{3} \mathrm{COODH}^{+}+\mathrm{HCOOCH}_{3}$

$\mathrm{m} / \mathrm{e} 61 \quad \mathrm{~m} / \mathrm{e} 65$

$\left(\mathrm{HCOOCH}_{3}\right) \mathrm{D}^{+}+\mathrm{CD}_{3} \mathrm{COOH} \rightarrow \mathrm{CD}_{3} \mathrm{COODH}^{+}+\mathrm{HCOOCH}_{3}$

$\mathrm{m} / \mathrm{e} 62 \mathrm{~m} / \mathrm{e} 65$

$\left(\mathrm{HCOOCH}_{3}\right) \mathrm{D}^{+}+\mathrm{CD}_{3} \mathrm{COOD} \rightarrow \mathrm{CD}_{3} \mathrm{COOD}_{2}^{+}+\mathrm{HCOOCH}_{3}$

m/e $62 \quad$ m/e 66

Ressonância dupla fol felta só com os picos mais intensos, ou seja, fol observado o ion de m/e 65 e irradiados os de m/e 61 e $\mathrm{m} / \mathrm{e} 62$ obtendo-se dois sinais negativos; também fol observado - de m/e 61 e irradiados os de m/e 64 e m/e 65 , obtendo-se dois sinais positivos. Por causa dessas reações paralelas, é preciso, nos estudos em função de pressão, ver se a soma dos picos dos ions de $\mathrm{m} / \mathrm{e} 64,65$ e 66 cresce ou decresce em relação à soma dos picos dos ions de $\mathrm{m} / \mathrm{e} 61 \mathrm{e} 62$. Porēm, $\mathrm{m} / \mathrm{e} 64$, além de corresponder à espécie $\mathrm{CD}_{3} \mathrm{COOH}_{2}{ }^{+}$, é princtpalmente $\mathrm{CD}_{3} \mathrm{COOD}^{+}$, o Ion molecular do ácido acético deuterado; por 1 sso o pico de $\mathrm{m} / \mathrm{e} 64$ não foi incluido nas somas. Tambēm deve-se lembrar que 
ácido acético protonado forma um dímero protonado. Mesmo assim a soma dos picos dos íon de m/e 65 e 66 cresceu em relação à soma dos picos dos ions de m/e 61 e 62 (TABELAS 5.2. e 5.3.). Logo, $\mathrm{AP}\left(\mathrm{HCOOCH}_{3}\right)<\mathrm{AP}\left(\mathrm{CH}_{3} \mathrm{COOH}\right)$.

13) formiato de metila/formiato de etila. Os resultados dos estudos em função de pressão encontram-se na TABELA 5.2. e também sob forma de gräfico na FIGURA 5.2., indicando que $\mathrm{AP}\left(\mathrm{HCOOCH}_{3}\right)$ < AP ( $\left.\mathrm{HCOOC}_{2} \mathrm{H}_{5}\right)$, ○ que fol confirmado por ressonância dupla. Um

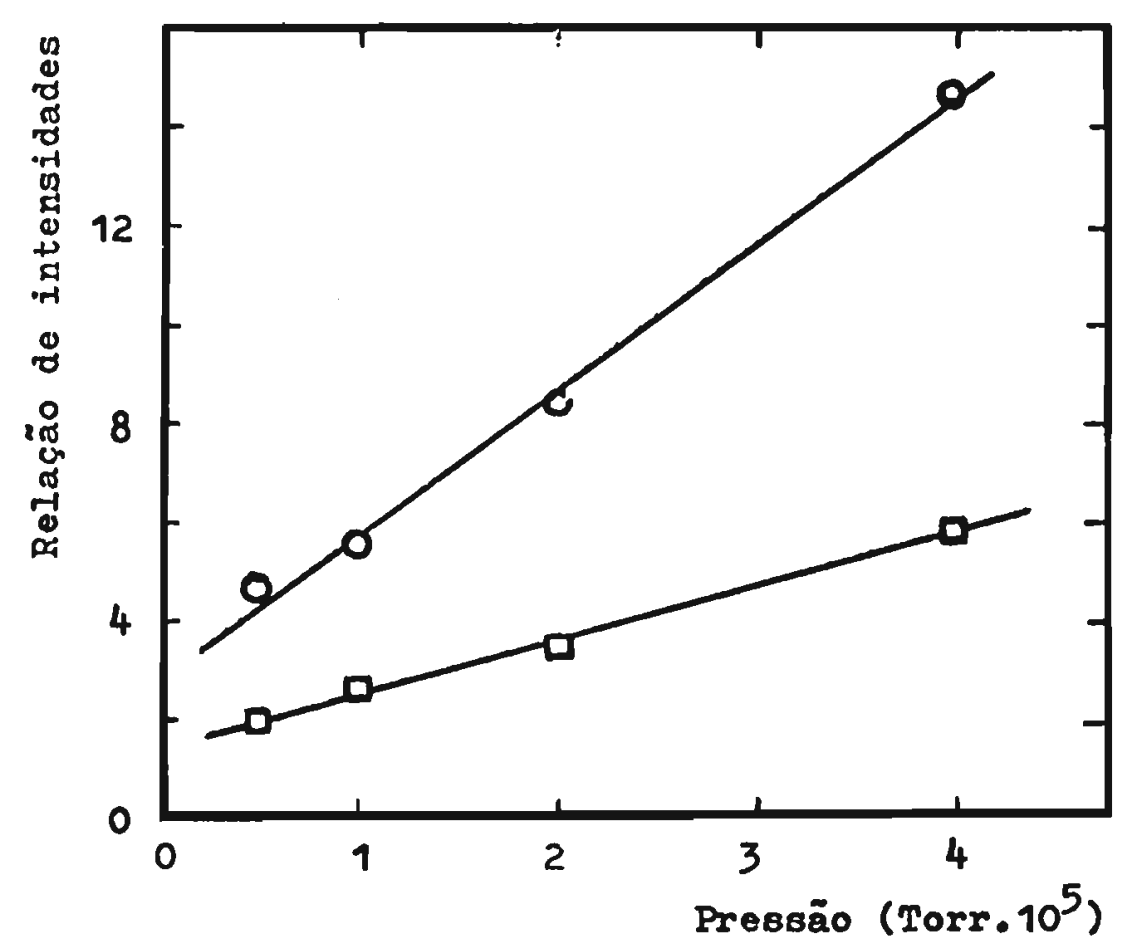

FIGURA 5.2. Relações de intensidades de picos de íns protonados:

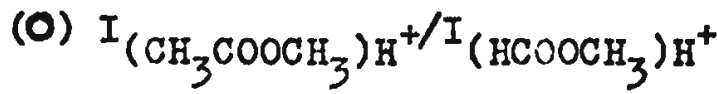

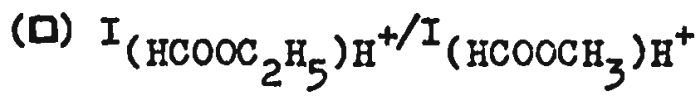


sinal de ressonância dupla positivo para a reação de formação de formiato de metila protonado só foi conseguido a $45 \mathrm{eV}$ de e nergia de ionização(sinal negativo para a reação inversa foi oḅ tido a $15 \mathrm{eV}$ ), mas isso provavelmente só foi devido ao fato de nessa energia mais elevada as intensidades dos sinais serem maiores, e não devido ao fato de espécies excitadas reagirem. No gráfico da FIGURA 5.2. foi possível traçar uma reta pelo conjunto dos quatro pontos obtidos, mas isto,apesar de ser o ca so na maioria dos outros sistemas investigados, não deve em princípio ser esperado, pois os processos clnéticos que ocorrem no sistema não bastante complexos (veja mais abaixo).

14) formiato de metila/acetato de metila. Os sinais de resso nância dupla positivo e negativo obtidos indicaram que $\mathrm{AP}\left(\mathrm{HCOOCH}_{3}\right)<\mathrm{AP}\left(\mathrm{CH}_{3} \mathrm{COOCH}_{3}\right)$. Os estudos em função de pressão foram realizados com um sistema de 15 gotas de formiato de meti la e 25 gotas de acetato de metila num tubo e, numa segunda experiência, usando as duas entradas do espectrômetro e mantendo Iguais as pressões parciais dos dois componentes. Ambos os resultados estão na TABELA 5.2. (por esses resultados vê-se agora que na primeira experiência a pressão parcial de acetato foi me nor que a de formiato, pois as relações de intensidades obtidas for am menores do que na segunda experiêncta).Na FIGURA 5.3. es tão os espectros da primeira experiência e os de ressonância dụ pla, e, na FIGURA 5.2. também está o grä́fico referente à segunda experiêncla.

15) formiato de metila/acetato de etila. Só fol realizada a ex periência de ressonância dupla, sendo que os sinais negativo e positivo obtidos indicaram AP $\left(\mathrm{HCOOCH}_{3}\right) \& \mathrm{AP}\left(\mathrm{CH}_{3} \mathrm{COOC}_{2} \mathrm{H}_{5}\right)$. 


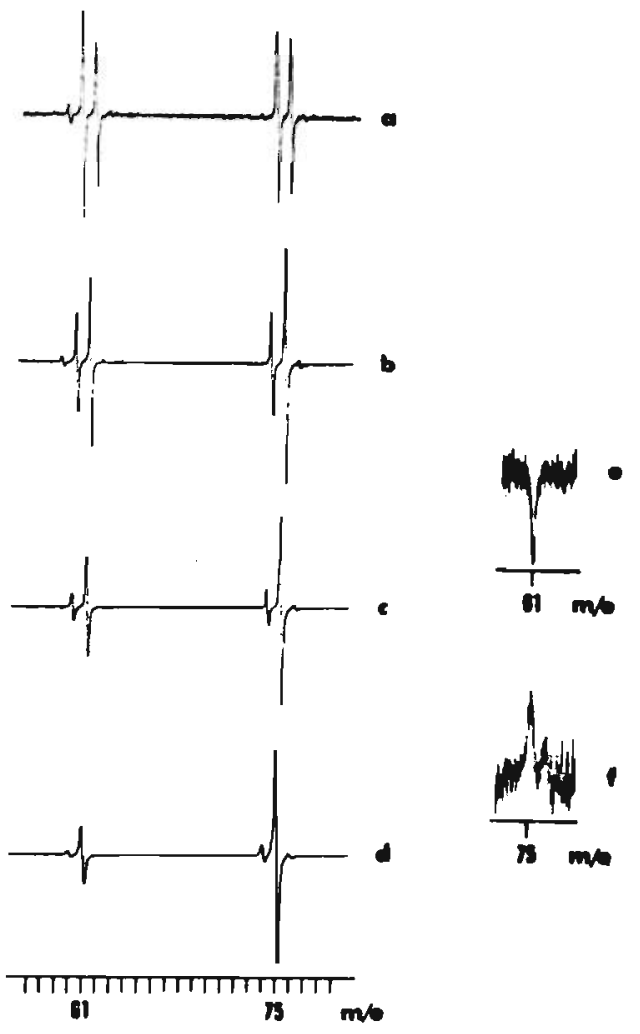

FIGURA 5.3. Espectros de massa da mistura de formiato de metila e acetato de metila em função da pressão total da mistura (pressões parciais iguals em cada caso) : a) $5,3 \cdot 10^{-6}$ Torr; b) $1,0 \cdot 10^{-5}$ Torr; c) $2,0 \cdot 10^{-5}$ Torr; d) $4,0 \cdot 10^{-5}$ Torr. Espectros de ressonância dupla; e) observado o ion de $\mathrm{m} / \mathrm{e} .75$ e irradiado o de m/e 61; oscilador de resso nância dupla: pulsado entre 0 e $10 \mathrm{mV}$; f) observado 0 ion de $\mathrm{m} / \mathrm{e} 61$ e irradiado o de m/e 75; oscilador de resso nância dupla: pulsado entre 0 e $20 \mathrm{mV}$.

16) ácido acëtico/formiato de etila. O sinal de ressonância dụ pla, negativo,para a transferência de pröton do äcldo para o éster indicou que $\mathrm{AP}\left(\mathrm{CH}_{3} \mathrm{COOH}\right)<\mathrm{AP}\left(\mathrm{HCOOC}_{2} \mathrm{H}_{5}\right)$. Os estudos em função de pressão aparentemente corroboraram este resultado, mas deve-se 
lembrar que $\mathrm{CH}_{3} \mathrm{COOH}_{2}{ }^{+}$é consumido na reação de formação do dímero protonado, se bem que em pequena extensão. Trabalhou-se com mistura de 30 gotas de ācido e 2 de éster.

17) ácido acético/acetato de metila. Valem as considerações do sistema anterior, tendo-se obtido $\mathrm{AP}\left(\mathrm{CH}_{3} \mathrm{COOH}\right)<\mathrm{AP}\left(\mathrm{CH}_{3} \mathrm{COOCH}_{3}\right)$.

18) formiato de etila/acetato de metila. Novamente os dois com postos têm a mesma massa molecular; por isso o acetato de metila foi usado na forma deuterada. Ocorrem as reações:

$$
\begin{array}{cc}
\left(\mathrm{HCOOC}_{2} \mathrm{H}_{5}\right) \mathrm{H}^{+}\left(\mathrm{D}^{+}\right)+\mathrm{CD}_{3} \mathrm{COOCD}_{3}+ & \left(\mathrm{CD}_{3} \mathrm{COOCD}_{3}\right) \mathrm{H}^{+}\left(\mathrm{D}^{+}\right)+\mathrm{HCOOC}_{2} \mathrm{H}_{5} \\
\mathrm{~m} / \mathrm{e} 75(76) & \mathrm{m} / \mathrm{e} 81(82)
\end{array}
$$

Nos estudos em função de pressão foi observado o aumento da soma dos picos dos íons de m/e 81 e 82 em relação à soma de m/e 75 e 76. Na ressonância dupla obteve-se sinal negativo ao observar 81 e irradiar 75 e nenhum sinal ao irradiar 76 e, sinal positivo, ao observar 75 e irradiar 81 e nenhum sinal ao 1rradiar 82 . 0 pico 76 foi pouco intenso no espectro de ressonância simples,mas - 82 fol bastante intenso, comparãvel ao 81 . Conclusão: AP ( $\mathrm{HCOOC}_{2} \mathrm{H}_{5}$ ) \& $\mathrm{AP}\left(\mathrm{CH}_{3} \mathrm{COOCH}_{3}\right)$.

19) formiato de etila/acetato de etila. Foi executada apenas a experiência de ressonância dupla, tendo-se obtido sinals positivos e negativos, indicando que $\mathrm{AP}\left(\mathrm{HCOOC}_{2} \mathrm{H}_{5}\right)<\mathrm{AP}\left(\mathrm{CH}_{3} \mathrm{COOC}_{2} \mathrm{H}_{5}\right)$.

20) acetato de metila/acetato de etila. Foram obtidos sinais de ressonância dupla positivo e negativo (FIGURA 5.4.) e os estudos de variação de pressão foram realizados com mistura 1 : 1 dos dois compostos liquidos num tubo e, por simples conveniência da época, usando acetato de metila-d $d_{6}$ num balão e acetato de etila num tubo. (Neste caso foram mantidas iguals as pressões parcials 


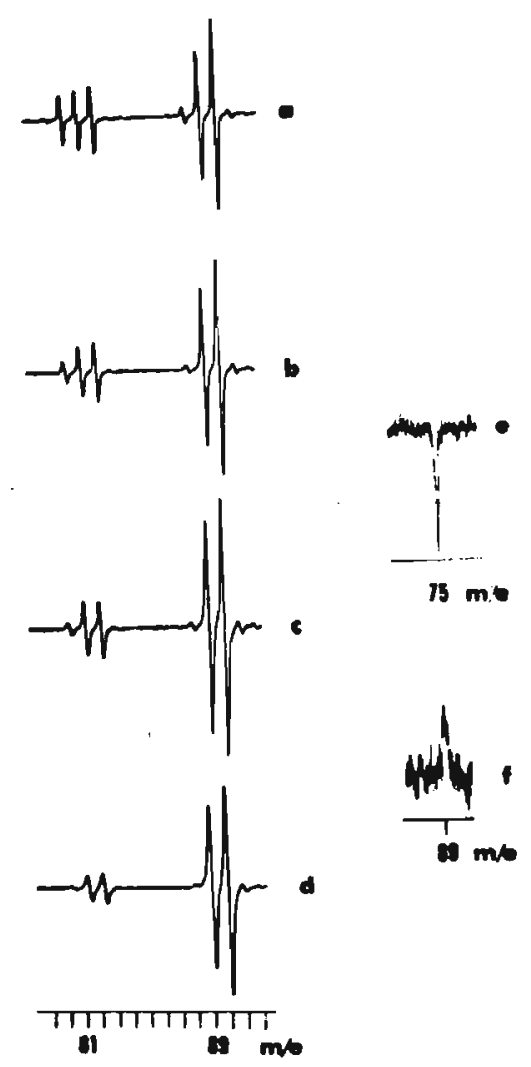

FIGURA 5.4. Espectros de massa da mistura de acetato de metila-d 6 e acetato de etila em funçäo da pressão total da mistura (pressöes parciais iguais em cada caso) : a) $5,0 \cdot 10^{-6}$ Torr; b) $1,0 \cdot 10^{-5}$ Torr; c) $2,0 \cdot 10^{-5}$ Torr; d) $4,0.10^{-5}$ Torr. Espectros de ressonância dupla da mistura de acetato de metila e ace tato de etila: e) observado o ín de $\mathrm{m} / \mathrm{e} 89$ e irradiado o de $\mathrm{m} / \mathrm{e} \mathrm{75;} \mathrm{osci-}$ lador de ressonância dupla: pulsado entre 0 e $6,2 \mathrm{mV} ; f)$ observado 0 Ion de $\mathrm{m} / \mathrm{e} 75$ e irradiado o de m/e 89; og lador de ressonâncla dupla: '. pulsado entre 0 e $10 \mathrm{mV}$.

dos dois componentes. FIGURA 5.4. Também fol repetida a experi ência de ressonâncla dupla com o acetato deuterado, mas os compostos foram usados numa proporção em termos de pressão tal, que 
os picos de $\left(\mathrm{CD}_{3} \mathrm{COOCD}_{3}\right) \mathrm{D}^{+}$e $\left(\mathrm{CH}_{3} \mathrm{COOC}_{2} \mathrm{H}_{5}\right) \mathrm{D}^{+}$fossem aproximadamente iguais: nestas condições os picos de $\left(\mathrm{CD}_{3} \mathrm{COOCD}_{3}\right) \mathrm{H}^{+}$e $\left(\mathrm{CH}_{3} \mathrm{COOC}_{2} \mathrm{H}_{5}\right) \mathrm{H}^{+}$ foram muito pequenos, não permitindo a execução da experiència de ressonância dupla.) Os resultados indicaram que $\mathrm{AP}\left(\mathrm{CH}_{3} \mathrm{COOCH}_{3}\right)$ $<\operatorname{AP}\left(\mathrm{CH}_{3} \mathrm{COOC}_{2} \mathrm{H}_{5}\right)$.

Juntando os resultados individuais dessas vinte compara f̧ões, obtēm-se a seguinte ordem crescente de basicidades:

$\mathrm{HCOOH}<\mathrm{CH}_{3} \mathrm{OH}<\mathrm{C}_{2} \mathrm{H}_{5} \mathrm{OH}<\mathrm{HCOOCH}_{3}<\mathrm{CH}_{3} \mathrm{COOH}<\mathrm{HCOOC}_{2} \mathrm{H}_{5}<$

$$
<\mathrm{CH}_{3} \mathrm{COOCH}_{3}<\mathrm{CH}_{3} \mathrm{COOC}_{2} \mathrm{H}_{5}
$$

Considerações a respeito dessa sequência serão feltas na seçăo 5.5. As tabelas que seguem mostram os resultados numéricos das experiências de variação de pressão. Na TABELA 5.2. estão os sís temas para os quais existem dados nas pressões $0,50,1,0,2,0$ e $4,0 \cdot 10^{-5}$ Torr; na TABELA 5.3. estão os sistemas para os quais se dispōem de dados a outras pressões.

Näo deve ser dado muito valor aos número em s1, que aparecem nestas tabelas, pois para tirar conclusões quantitativas destes resultados é necessārio conhecer em detalhe a cinética nes ses sistemas; as reações que ocorrem são muitas. Não hã apenas transferência de prōton entre as espēcies relacionadas nas tabelas, mas em geral os próprios ions moleculares e os fragmentos destes são capazes de transferir um próton para as moléculas neu tras, formando as espécies protonadas em questão. o que interes sa, é observar as tendências, isto é, verificar qual o pico que cresce em relação ao outro com aumento da pressão. 0 pico que cresce corresponde ao Ion protonado da molécula de maior basicida de, pois, a pressōes mals elevadas, o sistema se aproxima mais 
TABELA 5.2 .

Relaçōes entre intensidades de sinais de espécies protonadas em funçāo de pressāo de uma série de misturas binārias

\begin{tabular}{|c|c|c|c|c|c|}
\hline \multirow[b]{2}{*}{ sistema } & \multirow[b]{2}{*}{ espécles protonadas } & \multicolumn{4}{|c|}{ pressão $\left(\times 10^{5}\right.$ Torr $)$} \\
\hline & & 0,50 & 1,0 & 2,0 & 4,0 \\
\hline $3^{a}$ & $\left(\mathrm{HCOOCH}_{3}\right) \mathrm{H}^{+} / \mathrm{HCOOH}_{2}^{+}$ & 0,9 & 1,8 & 2,6 & 4.7 \\
\hline $4^{b}$ & $\mathrm{CH}_{3} \mathrm{COOH}_{2}^{+} / \mathrm{HCOOH}_{2}^{+}$ & - & 0,5 & 0,6 & 0,9 \\
\hline $5^{a}$ & $\mathrm{C}_{2} \mathrm{H}_{5} \mathrm{OH}_{2}^{+} / \mathrm{CH}_{3} \mathrm{OH}_{2}^{+}$ & 2,0 & 2,5 & 3,7 & 4,8 \\
\hline $6^{a}$ & $\left(\mathrm{HCOOCH}_{3}\right) \mathrm{H}^{+} / \mathrm{CH}_{3} \mathrm{OH}_{2}^{+}$ & 4,6 & 6,3 & 7,5 & 9,4 \\
\hline $7^{a}$ & $\mathrm{CH}_{3} \mathrm{COOH}_{2}^{+} / \mathrm{CH}_{3} \mathrm{OH}_{2}^{+}$ & 3,2 & 3,6 & 4,6 & 5.6 \\
\hline $8^{a}$ & $\left(\mathrm{CH}_{3} \mathrm{COOCH}_{3}\right) \mathrm{H}^{+} / \mathrm{CH}_{3} \mathrm{OH}_{2}^{+}$ & 7,2 & 18 & 18 & 34 \\
\hline $9^{a}$ & $\left(\mathrm{HCOOCH}_{3}\right) \mathrm{H}^{+} / \mathrm{C}_{2} \mathrm{H}_{5} \mathrm{OH}_{2}^{+}$ & 1,6 & 2,0 & 3,2 & 6,1 \\
\hline $10^{a}$ & $\mathrm{CH}_{3} \mathrm{COOH}_{2}^{+} / \mathrm{C}_{2} \mathrm{H}_{5} \mathrm{OH}_{2}^{+}$ & 2,5 & 2,6 & 2,0 & 2,1 \\
\hline $11^{a}$ & $\left(\mathrm{CH}_{3} \mathrm{COOC}_{2} \mathrm{H}_{5}\right) \mathrm{H}^{+} / \mathrm{C}_{2} \mathrm{H}_{5} \mathrm{OH}_{2}^{+}$ & 9,7 & 14 & 16 & 28 \\
\hline $12^{a, b, c}$ & $\mathrm{CH}_{3} \mathrm{COOH}_{2}+/\left(\mathrm{HCOOCH}_{3}\right) \mathrm{H}^{+}$ & - & 0,7 & 0.8 & 1,0 \\
\hline $13^{a}$ & $\left(\mathrm{HCOOC}_{2} \mathrm{H}_{5}\right) \mathrm{H}^{+} /\left(\mathrm{HCOOCH}_{3}\right) \mathrm{H}^{+}$ & 1,9 & 2,6 & 3,4 & 5,8 \\
\hline $14 a$ & $\left(\mathrm{CH}_{3} \mathrm{COOCH}_{3}\right) \mathrm{H}^{+} /\left(\mathrm{HCOOCH}_{3}\right) \mathrm{H}^{+}$ & 1,1 & 1,4 & 1,9 & 3.5 \\
\hline $14 \mathrm{~b}$ & & 4,6 & 5,5 & 8,4 & 15 \\
\hline 16 & $\left(\mathrm{HCOOC}_{2} \mathrm{H}_{5}\right) \mathrm{H}^{+} / \mathrm{CH}_{3} \mathrm{COOH}_{2}^{+}$ & 0,3 & 0,3 & 0,4 & 0.6 \\
\hline 17 & $\left(\mathrm{CH}_{3} \mathrm{COOCH}_{3}\right) \mathrm{H}^{+} / \mathrm{CH}_{3} \mathrm{COOH}_{2}^{+}$ & 1,6 & 4,3 & 7,6 & - \\
\hline $18^{a, d}$ & $\left(\mathrm{CH}_{3} \mathrm{COOCH}_{3}\right) \mathrm{H}^{+} /\left(\mathrm{HCOOC}_{2} \mathrm{H}_{5}\right) \mathrm{H}^{+}$ & 4,1 & 6.7 & 11,4 & 17,3 \\
\hline $20^{a, e}$ & $\left(\mathrm{CH}_{3} \mathrm{COOC}_{2} \mathrm{H}_{5}\right) \mathrm{H}^{+} /\left(\mathrm{CH}_{3} \mathrm{COOCH}_{3}\right) \mathrm{H}^{+}$ & 2,5 & 3,4 & 4,2 & 6,7 \\
\hline
\end{tabular}

a) Pressão parcial do componente $A$ igual à do $B$ nas diversas pressōes.

b) Dados em outras pressōes na TABELA 5.3.

c) A relação de intensldades è na realldade

$\left[\mathrm{CH}_{3} \mathrm{COOH}_{2}^{+}+\mathrm{CH}_{3} \mathrm{COOHD}{ }^{+}\right] /\left[\left(\mathrm{HCOOCH}_{3}\right) \mathrm{H}^{+}+\left(\mathrm{HCOOCH}_{3}\right) \mathrm{O}^{+}\right]$.

d) A relação de intensidades é na realidade $\left[\left(\mathrm{CD}_{3} \mathrm{COOCD}_{3}\right) \mathrm{H}^{+}+\left(\mathrm{CD}_{3} \mathrm{COOCD}_{3}\right) \mathrm{D}^{+}\right] /\left[\left(\mathrm{HCOOC}_{2} \mathrm{H}_{5}\right) \mathrm{H}^{+}+\left(\mathrm{HCOOC}_{2} \mathrm{H}_{5}\right) \mathrm{D}^{+}\right]$.

e) A relação de intensıdades é na realıdade $\left[\left(\mathrm{CH}_{3} \mathrm{COOC}_{2} \mathrm{H}_{5}\right) \mathrm{H}^{+}+\left(\mathrm{CH}_{3} \mathrm{COOC}_{2} \mathrm{H}_{5}\right) \mathrm{D}^{+}\right] /\left[\left(\mathrm{CD}_{3} \mathrm{COOCD}_{3}\right) \mathrm{H}^{+}+\left(\mathrm{CD}_{3} \mathrm{COOCD}_{3}\right) \mathrm{D}^{+}\right]$. 
do equilíbrio, que sempre está deslocado para o ion protonado da molécula mais bãsica.

TABELA 5.3 .

Relações entre Intensidades de sinais de espēcies protonadas em função de pressão de duas misturas binārias.

\begin{tabular}{|c|c|c|c|c|c|c|}
\hline \multirow{2}{*}{ sistema } & \multirow{2}{*}{ espëcies protonadas } & \multicolumn{3}{|c|}{ pressão $\left(\times 10^{5}\right.$} & \multicolumn{2}{|c|}{ Torr; } \\
\hline & & 1,0 & 2,0 & 3,0 & 4,0 & 8,0 \\
\hline 4 & $\mathrm{CH}_{3} \mathrm{COOH}_{2}{ }^{+} / \mathrm{HCOOH}_{2}{ }^{+}$ & 0,5 & 0,6 & - & 0,9 & 1,4 \\
\hline $12^{a}$ & $\mathrm{CH}_{3} \mathrm{COOH}_{2}^{+} /\left(\mathrm{HCOOCH}_{3}\right) \mathrm{H}^{+}$ & 0,7 & 0,8 & 0,9 & 1,0 & - \\
\hline
\end{tabular}

a) Vice nota c da TABELA 5.2 .

Foi obtida tambēm a ordem de afinidades protônicas de algumas das cetonas estudadas no capítulo 4, ou seja, da acetona, da butanona e da pentanona-3. As cetonas foram comparadas duas a duas, usando as duas entradas de amostra do espectrômetro. Nos estudos em função de pressão, cujos resultados estão na TABELA 5.4., foram mantidas iguais as pressões parclais das duas ceto nas. Na ressonância dupla as pressōes foram ajustadas de modo que as intensidades dos picos dos ions moleculares protonados fos sem aproximadamente iguais. Os resultados indicaram que a ordem de basicidade è

$\mathrm{CH}_{3} \mathrm{COCH}_{3}<\mathrm{CH}_{3} \mathrm{COC}_{2} \mathrm{H}_{5}<\mathrm{C}_{2} \mathrm{H}_{5} \mathrm{COC}_{2} \mathrm{H}_{5}$

Os Ions protonados das cetonas são bastante reativos; reagem com moléculas neutras de cetonas, formando dimeros protonados (vide capitulo 4 ). 
TABELA 5.4 .

Relações entre intensidades de sinais de espēcies protonadas em função de pressão em alguns sistemas binários.

\begin{tabular}{crrrr}
\hline espécies protonadas & pressão & $\left(\times 10^{5}\right.$ Torr $)$ \\
& 0,50 & 1,0 & 2,0 & 4,0 \\
$\left(\mathrm{CH}_{3} \mathrm{COC}_{2} \mathrm{H}_{5}\right) \mathrm{H}^{+} /\left(\mathrm{CH}_{3} \mathrm{COCH}_{3}\right) \mathrm{H}^{+}$ & 2,8 & 4,4 & 5,7 & 7,8 \\
$\left(\mathrm{C}_{2} \mathrm{H}_{5} \mathrm{COC}_{2} \mathrm{H}_{5}\right) \mathrm{H}^{+} /\left(\mathrm{CH}_{3} \mathrm{COC}_{2} \mathrm{H}_{5}\right) \mathrm{H}^{+}$ & 2,0 & 3,1 & 4,2 & 5,4 \\
$\left(\mathrm{C}_{2} \mathrm{H}_{5} \mathrm{COC}_{2} \mathrm{H}_{5}\right) \mathrm{H}^{+} /\left(\mathrm{CH}_{3} \mathrm{COCH}_{3}\right) \mathrm{H}^{+}$ & 4,9 & 7,1 & 7,3 & 13 \\
\hline
\end{tabular}

$$
\left(\mathrm{R}-\mathrm{CO}-\mathrm{R}^{\prime}\right) \mathrm{H}^{+}+\mathrm{R}^{\prime \prime}-\mathrm{CO}-\mathrm{R}^{\prime \prime} \rightarrow \mathrm{RR}^{\prime} \mathrm{CO} \ldots \ldots \mathrm{H}^{+} \ldots \ldots O C \mathrm{R}^{\prime \prime} \mathrm{R}^{\prime \prime}
$$

Como explicado antes, reações paralelas dos ions protonados dificultam a interpretação dos resultados dos estudos de variação de pressão. Devido à facilidade com que a reação de formação de dîmeros protonados se dá nas cetonas, este é um problema mais sério nestes compostos do que nos ésteres estudados antes. Todavia, pá rece que os estudos em função de pressão não foram maiormente afe tados por isso, pois as tendências de aumento das relações de intensidade foram claras. Na TABELA 5.5. são comparadas as intensi dades dos picos dos dimeros protonados com as dos ions molecula res protonados.

Para combinar a sequência de basicidades das cetonas com a obtida anteriormente, de ésteres, ācidos e ālcools, tentouse localizar a acetona na escala de basicidades dada por esses compostos, se é que a afinidade protônica da acetona calsse no in tervalo de afinidades protônicas coberto por esses compostos. Os sinais de ressonância dupla obtidos,positivo e negativo, e o estu 
TABELA 5.5 .

Relações entre intensidades de sinais de dimeros protonados e íons moleculares protonados em sistemas cetônicos, em função de pressão.

\begin{tabular}{|c|c|c|c|c|}
\hline \multirow{2}{*}{ sistema } & \multirow{2}{*}{ espécies protonadas } & \multicolumn{2}{|c|}{ pressão $\left(x 10^{5}\right.$} & \multirow{2}{*}{$\begin{array}{l}\text { Torr) } \\
4,0\end{array}$} \\
\hline & & 1,0 & 2,0 & \\
\hline acetona & $\left(\mathrm{CH}_{3} \mathrm{COCH}_{3}\right)_{2} \mathrm{H}^{+} /\left(\mathrm{CH}_{3} \mathrm{COCH}_{3}\right) \mathrm{H}^{+}$ & 0,05 & 0,2 & 0,5 \\
\hline butanona & $\left(\mathrm{CH}_{3} \mathrm{COC}_{2} \mathrm{H}_{5}\right)_{2} \mathrm{H}^{+} /\left(\mathrm{CH}_{3} \mathrm{COC}_{2} \mathrm{H}_{5}\right) \mathrm{H}^{+}$ & 0 & 0,08 & 0,3 \\
\hline pentanona-3 & $\left(\mathrm{C}_{2} \mathrm{H}_{5} \mathrm{COC}_{2} \mathrm{H}_{5}\right)_{2} \mathrm{H}^{+} /\left(\mathrm{C}_{2} \mathrm{H}_{5} \mathrm{COC}_{2} \mathrm{H}_{5}\right) \mathrm{H}^{+}$ & 0 & 0,1 & 0,3 \\
\hline
\end{tabular}

do em Iunção de pressão, indicaram claramente que $\mathrm{AP}\left(\mathrm{HCOOC}_{2} \mathrm{H}_{5}\right)$ < $\operatorname{AP}\left(\mathrm{CH}_{3} \mathrm{COCH}_{3}\right)$. Quando a acetona foi comparada com acetato de metila, os estudos em função de pressão indicaram que $\mathrm{AP}\left(\mathrm{CH}_{3} \mathrm{COCH}_{3}\right)<$ $\mathrm{AP}\left(\mathrm{CH}_{3} \mathrm{COOCH}_{3}\right)$, porque a intensidade do sinal de $\left(\mathrm{CH}_{3} \mathrm{COCH}_{3}\right) \mathrm{H}^{+}$dimi nuiu em relação ao de $\left(\mathrm{CH}_{3} \mathrm{COOCH}_{3}\right) \mathrm{H}^{+}$com aumento da pressão, porém, esse resultado não é conclusivo, pois $\left(\mathrm{CH}_{3} \mathrm{COCH}_{3}\right) \mathrm{H}^{+}$è gasto também 'na formação do dimero protonado da acetona. Na experiênctá de ressonância dupla foi obtido um sinal negativo em ambos os sent1 dos dà reação de transferência de próton.

$$
\left(\mathrm{CH}_{3} \mathrm{COCH}_{3}\right) \mathrm{H}^{+}+\mathrm{CH}_{3} \mathrm{COOCH}_{3} \rightleftharpoons\left(\mathrm{CH}_{3} \mathrm{COOCH}_{3}\right) \mathrm{H}^{+}+\mathrm{CH}_{3} \mathrm{COCH}_{3}
$$

Isto é em geral tomado como uma indicação de que a reação é termo neutra, 72 e que, no caso $\mathrm{AP}\left(\mathrm{CH}_{3} \mathrm{COCH}_{3}\right) \simeq \mathrm{AP}\left(\mathrm{CH}_{3} \mathrm{COOCH}_{3}\right)$. A acetona também fol comparada com o acetato de etila, tendo-se encontra do que a afinidade protônica da cetona é menor que a do éster. 
Na seção seguinte as ordens de basicidade obtidas serão discutidas com maior detalhe, será feita uma comparação com dados de literatura, quando possível, e serão apresentadas algumas caracteristicaś gerais no que diz respeito a afinidades protônicas em compostos da mesma classe.

\subsection{Afinidade protônica e potencial de ionização}

Empregando o mētodo de equilïbrio descrito na seção 5.1., Bowers ${ }^{157}$ obteve valores bastante precisos, dentro de 0,2 kcal/mol, para as afinidades protônicas de vārias aminas e,conhe cendo os potenciais de ionização dessas aminas, pôde mostrar,atra vés da equação 5.4 ., que afinidades por hidrogênio são aproximada mente constantes numa série homóloga. A TABELA 5.6. mostra uma das séries de aminas estudadas por Bowers e os valores das afinidades por hidrogênio encontradas, dando uma idéla da constância das mesmas.Se, na reação 5.7., A e B forem dols compostos homólo gos, a variação de entalpia dessa reação será a diferença entre os

TABELA 5.6 .

Afinidades por hidrogênio numa série de aminas homólogas. 157

aminas

metilamina

etilamina

n-propilamina

n-butilamina

isobutilamina

isopropilamina

sec-butilamina

terciobutilamina
AH (kcal/mol)

111,6

111,8

111,2

110,1

110,2

110,8

111,4

111,0 
potenciais de ionização de B e A (equação 5.5.) ou, pela equação 5.4., um gräfico das afinidades protônicas de uma sērie de compostos homólogos, em função dos respectıvos potenclais de ionização,será uma reta de coeficiente angular -1. Isto pode ser verificado qualitativamente na TABELA 5.7. para o caso dos deri vados carboxilicos e das cetonas estudadas. Os potenciais de io nização dos ácidos e dos ésteres são de referência 158 e, os das cetonas, da referência 159. Trata-se de valores obtidos por espectroscopia de fotoelētrons, mas os valores tabelados não se referem aos potenciais de ionização verticais, mas aos adiabāticos. Verifica-se que a tendência nos potenciais de Ionização é de fato ó inverso da tendência das afinidades protônicas no caso dos compostos estudados (comparar a TABELA 5.7. com as sequências 5.8. e 5.9., seção 5.4.). Esta relação entre estas duas grandezas físicas foi notada tambēm em outros compostos.

TABELA 5.7 .

Potencla1s de ionização de ácidos, ēsteres e cetonas.158,159

composto PI $(\mathrm{eV})$

$\begin{array}{lr}\mathrm{HCOOH} & 11,33 \\ \mathrm{HCOOCH}_{3} & 10,85 \\ \mathrm{CH}_{3} \mathrm{COOH} & 10,70 \\ \mathrm{HCOOC}_{2} \mathrm{H}_{5} & 10,62 \\ \mathrm{CH}_{3} \mathrm{COOCH}_{3} & 10,33 \\ \mathrm{CH}_{3} \mathrm{COOC}_{2} \mathrm{H}_{5} & 10,24 \\ \mathrm{CH}_{3} \mathrm{COCH}_{3} & 9,71 \\ \mathrm{CH}_{3} \mathrm{COC}_{2} \mathrm{H}_{5} & 9,54 \\ \mathrm{C}_{2} \mathrm{H}_{5} \mathrm{COC}_{2} \mathrm{H}_{5} & 9,31\end{array}$


Admitindo que também os compostos carboxilicos da TABE LA 5.7. tenham afinidades por hidrogênio iguais, è possível calcular as afinidades protōnicas dos mesmos, usando a equação 5.4., desde que se conheça a afinidade protônica de um deles. Esta grandeza foi determinada para o ācido fōrmico por Franklin, 160 que achou $178,0 \mathrm{kcal} / \mathrm{mol}$. Assim, estão na TABELA 5.8. as afinidades protônicas calculadas para alguns dos compostos em estudo, usando o ácido fórmico como ponto de referêncla e os dados da TABELA 5.7 .

TABELA 5.8 .

Afinidades protônicas de compostos carbonilitcos.

AP (kcal/mol)

composto

$\mathrm{HCOOH}$

$\mathrm{HCOOCH}_{3}$

$\mathrm{CH}_{3} \mathrm{COOH}$

$\mathrm{HCOOC}_{2} \mathrm{H}_{5}$

$\mathrm{CH}_{3} \mathrm{COOCH}_{3}$

$\mathrm{CH}_{3} \mathrm{COOC}_{2} \mathrm{H}_{5}$ calculada

$(178,0)$ a

189,1

192,4

194,2

201,0

203,1 referência 143

175

188

188

198

202

205

a) As afinidades protônicas foram calculadas em relação a esse valor, tomado da referência 160 .

Simultâneamente com a publicação dos resultados desses estudos, ${ }^{140}$ Munson publicou uma lista de compostos com as respectivas afinidades protônicas, 143 determinadas pelo mētodo da observação de ocorrência ou não de uma reação (seção 5.1.) num espectrômetro de massa de tempo de vôo, usando fonte de alta 
pressão. Munson intercalou na sequência de compostos por ele es tudados uma série de compostos de afinidades protônicas já conhe cidas de modo que pudesse obter limites superiores e inferiores de afinidades protônicas para os outros compostos. Alguns desses valores foram incluídos na TABELA 5.8. para efelto de comparação. Deve-se lembrar que, devido ao método pelo qual foram obtidos, os valores da referêncla 143 têm um erro de \pm 2 a $\pm 5 \mathrm{kcal} / \mathrm{mol}$. Porém, também os valores calculados que aparecem nessa tabela, têm quatro algarismos significativos apenas porque os potencials de ionização empregados nos cãlculos foram dados com çuatro algarismos significativos, bem como a afinidade protônica do ãcido förmico, tomaāa como referêncla; mas nacaa se sabe a respeito das afinidades por hidrogênio, que foram supos tas constantes $e$, dependendo de quão boa essa suposição é, será maior ou menor o erro nas afinidades protônicas apresentadas. Pe la TABELA 5.6. vê-se que no caso das aminas as afinidades por h1 ạrogênio não variam mais do que $1.7 \mathrm{kcal} / \mathrm{mol}$. Na TABELA 5.9 . es tão as afinidades protônicas de mais alguns compostos relacionados com o presente trabalho, determinadas por Munson. A ordem de basicidade obtida é igual à das sequênclas 5.8. e 5.9.: portanto hå perfelta concordância entre as duas tẻcn1cas, ressonância ciclotrôntca de lons e fonte de alta pressão con detetor de tempo de vôo.

Usando os resultados apresentados na seção 5.4. podem ser escritas as seguintes ordens crescentes de basicidades: $: 63$ $\mathrm{HCOOH}<\mathrm{HCOOCH}_{3}<\mathrm{HCOOC}_{2} \mathrm{H}_{5}$ $\mathrm{CH}_{3} \mathrm{COOH}<\mathrm{CH}_{3} \mathrm{COOCH}_{3}<\mathrm{CH}_{3} \mathrm{COOC}_{2} \mathrm{H}_{5}$

e $\mathrm{HCOOCH}_{3}<\mathrm{CH}_{3} \mathrm{COOCH}_{3}$ $\mathrm{ClCOOC}_{2} \mathrm{H}_{5}<\mathrm{HCOOC}_{2} \mathrm{H}_{5}<\mathrm{CH}_{3} \mathrm{COOC}_{2} \mathrm{H}_{5}$ 
TABELA 5.9 .

Afinidades protônicas de alguns compostos ${ }^{143}$

compos to

AP (kcal/mol)

$\mathrm{HCOOH}$

175

$\mathrm{CH}_{3} \mathrm{OH}$

$182^{a}$

$\mathrm{C}_{2} \mathrm{H}_{5} \mathrm{OH}$

187

$\mathrm{CH}_{3} \mathrm{COOH}$

188

$\mathrm{C}_{2} \mathrm{H}_{5} \mathrm{COOH}$

$-190$

$\mathrm{HCOOCH}_{3}$

188

$\mathrm{CH}_{3} \mathrm{CH}_{2} \mathrm{CH}_{2} \mathrm{OH}$

189

$\left(\mathrm{CH}_{3}\right)_{2} \mathrm{CHOH}$

193

$\left(\mathrm{CH}_{3}\right)_{2} \mathrm{CHOHCH}_{3}$

$197^{b}$

$\left(\mathrm{CH}_{3}\right)_{3} \mathrm{COH}$

198

$\mathrm{HCOOC}_{2} \mathrm{H}_{5}$

198

$\mathrm{HCOOCH}_{2} \mathrm{CH}_{2} \mathrm{CH}_{3}$

198

$\mathrm{CH}_{3} \mathrm{COCH}_{3}$

202

$\mathrm{CH}_{3} \mathrm{COOCH}_{3}$

202

$\mathrm{CH}_{3} \mathrm{COOC}_{2} \mathrm{H}_{5}$

205

$\mathrm{CH}_{3} \mathrm{COOCH}_{2} \mathrm{CH}_{2} \mathrm{CH}_{3}$

205
a) valor da referêncla 161
b) valor da referêncla 162 
Vê-se que a basicldade de RCOOR' aumenta com o efeito indutivo +I tanto de $R$, como de $R^{\prime}$. Como se têm as sequências $\mathrm{HCOOCH}_{3}<$ $\mathrm{CH}_{3} \mathrm{COOH}$ e $\mathrm{HCOOC}_{2} \mathrm{H}_{5}<\mathrm{CH}_{3} \mathrm{COOCH}_{3}$, conclui-se que o efeito de $\mathrm{R}$ em au mentar a basicldade é maior que o de $R^{\prime}$. o efeito de $R^{\prime}$ prova velmente apenas reflete a polarizabilidade da molécula, pois, nos casos estudados, a af́inidade protônica de RCOOR' segue a polariza bilidade de $R^{\prime}$. Foi mostrado ${ }^{72}$ que carga positiva é estabilizada pela polarização de grupos grandes.

Neste estudo pôde mals uma vez ser mostrado como propriedades intrísecas de moléculas podem ser facilmente correlacio nadas de maneira esperada com certos efeitos ou grandezas. Mais especificamente, a ordem de basicidade de alguns ácidos e éstẹ res correlaciona com tendências de potenciais de Ionização, efeitos indutivos e polarizabilidades. No próximo capítulo será frequentemente feita referência aos resultados de basicidade. Para interpretar os resultados aí obtidos, basta conhecer ordens re lativas de basicidade; não hã necessidade dos valores absolutos das afinidades protōnicas. Deve ser mencionado que não è possí vel aplicar o método de equilíbrio, descrito na seção 5.1. , e que fornece valores muito precisos de afinidades protôntcas, aos com postos aqui estudados, pois esses compostos oxlgenados são na maior parte muito reativos, o que impede o estabelecimento de condições de equilíbrio. 


\section{REAÇÕES DE ESTERIFICAÇÃO}

Esterificação de ācidos carboxílıcos e hidrölise de ēsteres são reações que podem seguir vārios mecanismos. o reconhecimento desses mecanismos e o descobrimento dos fatores que fazem com que um ou outro mecanismo opere, foram iniciados já no século XIX. Victor Meyer, 164 em 1894, notara que com a maloria dos ácidos que tentava esterificar, obtinha rendimento ao redor de 908 em éster, mas alguns derivados do ácido benzóico forneciam o produto com rendimento sempre inferior a 10\%; fatores estéricos eram os responsáveis. Outros fatores foram sendo notados, ${ }^{165}$ tais como de estrutura de substituintes ligados ao grupo funcional e efeitos de solvente, até toda a multiplicldade de mecanismos ser reconhecida. 165

Por causa do interesse mecanístico dessas reações, resolveu-se então estudá-las em fase gasosa, usando a técnica de ressonância clclotrônica de íons. O conhecimento das propriedades intrísecas desses sistemas reacionais certamente contribui pa ra a compreensão de alguns aspectos fundamentais da química orgânica. Poder-se-ia esperar que a quimica de lons positivos em fase gasosa fosse anāloga às reações catalisadas por ācldos em solu §̧ão. De fato, em alguns casos as analogias foram encontradas,mas em outros, produtos diferentes dos conhecldos em solução são forma dos.

Os resultados desse trabalho foram comuntcados perante a American Chemical Society em Chicago, ${ }^{166}$ e a Academia Brasileira de Ciênctas em são Paulo 167 e, enviados para publicação ao Journal of the American Chemical Society. 168 
Inicialmente será feita uma breve revisão dos mecanismos de esterificação catalisada por ācidos, propostos parà as reações em solução. Embora este seja um assunto bem conhecido, ele será aqui apresentado, a fim de servir como um marco de refe rêncla para as reações descritas nas seções 6.6. a 6.8.

\subsection{Reações em solução}

A hldról1se de ésteres pode ser catalisada por ácidos ou bases. 169

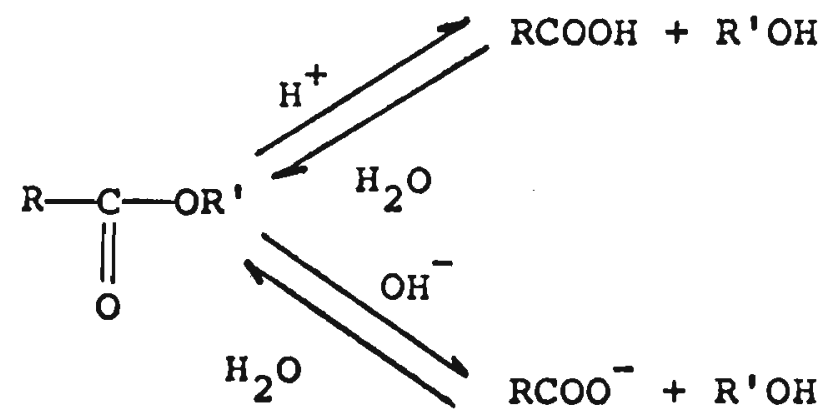

Na catálise bāsica a espécie que ataca è $\mathrm{OH}^{-}$, um reagente nucleō filo muito forte; esta reação è chamada de saponificação e forma-se o sal do ácldo. Ácidos catalisam a reação, tornando o car bono carbonilico mais positivo, de modo que o grupo OR' saia mals facilmente. Ambas as reações são de equilíbrio, de modo que só são praticáveis quando se consegue deslocar o equilíbrio para a direita. Quando se forma o sal do ácido carboxilico è justa mente isto o que acontece; assim, a hidrólise de ésteres para fins preparativos é sempre felta em solução básica.

Ingold classificou a hidrölise de èsteres (e a forma fão dos mesmos, pols são reações reversiveis que têm o mesmo mecanismol de acordo com olto mecanismos, dependendo de se a reaf̧ão é catalisada por ácldos ou por bases, è unimolecular ou bimo lecular, ocorre com ruptura das ligações acila-oxigênio ou alqui la-ox1gên1o. 165,169 Como neste capitulo serão descritas reaçōes 
entre ions positivos e moléculas, que podem ser consideradas como anālogas às reações catalisadas por ăcldos, só estas serão discutidas aqui. Na TABELA 6.1. estã a classificação dos meca nismos de catálise ácida segundo Ingold. Pela tabela, a notação de Ingold deve ser facilmente compreensivel.

No caso da catālise ácida, os processos não são apenas reversiveis, mas tambēm simétricos, isto é, os mecanismos de formação de éster são exatamente os mesmos da hidrólise, exceto que $\underline{H}$ substitui $R$. Isto $j a ́$ havia sido mostrado por Lapworth em 1904. ${ }^{165}$ As transferências de próton internas podem não ser diretas, mas dar-se através do solvente.

Dos oito mecanismos propostos por Ingold, só seis foram realmente observados. Dos mecanismos envolvendo catálise por ácldos não é conhecido $\circ{ }_{A L}{ }^{2}$, que implicaria em água ser um agente nucleóf1lo numa reação $\mathrm{s}_{\mathrm{N}} 2$.

As reações catalisadas por ácidos podem ser explica das na maioria dos casos pelo mecanismo ${ }_{A}{ }^{\prime}{ }^{2}$, que envolve ruptura da ligação acila-oxigênio, para o que existem as seguintes evidências: 1) hidaólise com $\mathrm{H}_{2}{ }^{18} \mathrm{o}$ resulta em ${ }^{18} \mathrm{o}$ no äcido e não no àlcool;

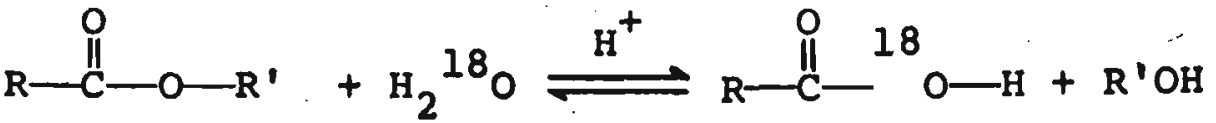

2) ésteres com $R^{\prime}$ assimétrico dão álcoois com retenção de configuração; 3) se R' é alililco, rearranjo alilico não ocorre; se $R^{\prime}$ é neopentilico; também não ocorre rearranjo; tudo isto indica que a ligação $O-R$ ' não é quebrada. As reações são de pr $\underline{1}$ meira ordem, independentemente em substrato, água e ácido. A reatividade de ésteres (no caso de hidrölise) e ácidos (no caso de esteriflcação) é controlada pela necessldade de passar através 


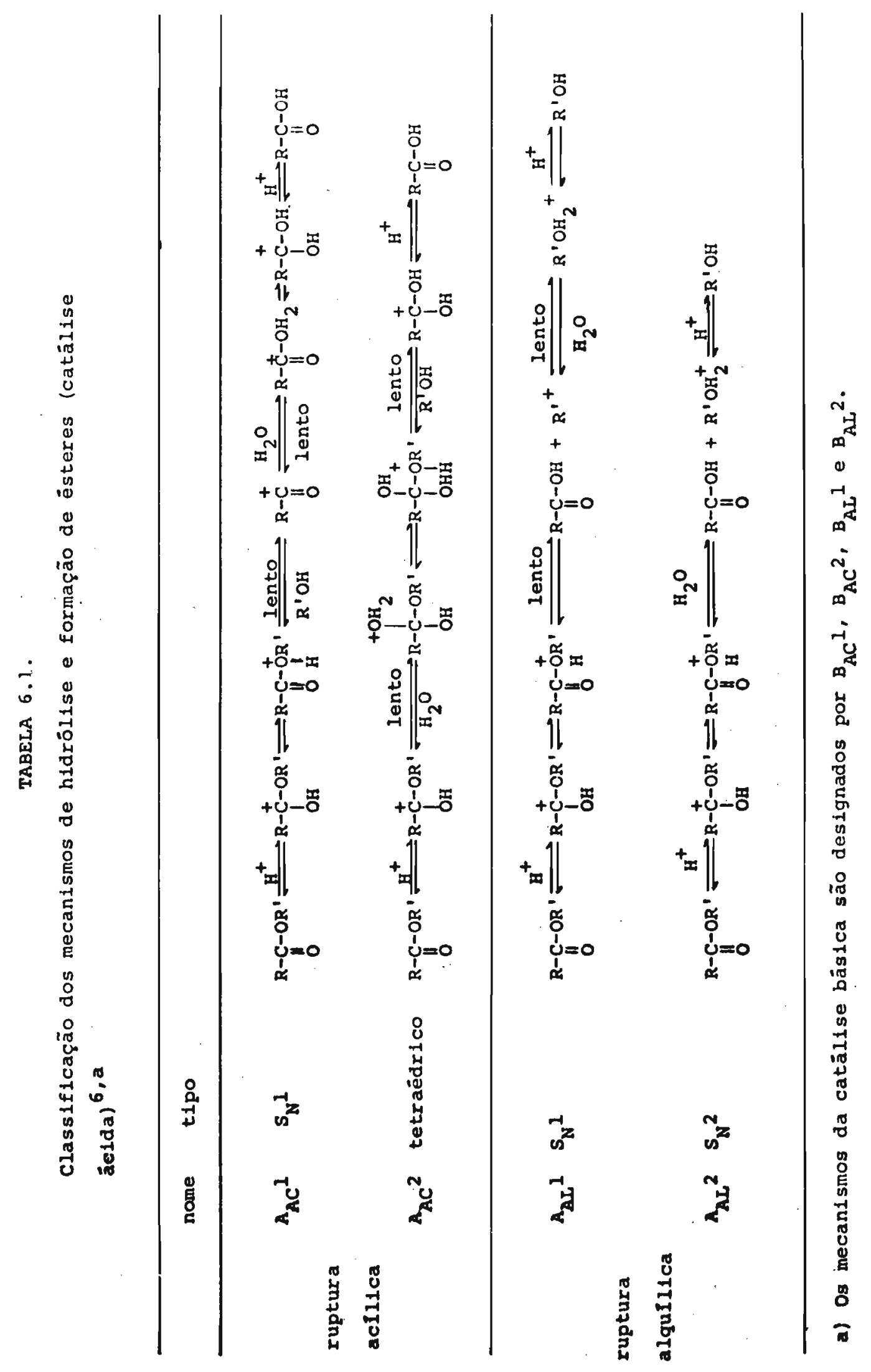


de um intermediário com um carbono tetraédrico no grupo funcional. 170 se o grupo carbonila tiver grupos volumosos em volta de si, a reação pode ser muito lenta. Assim a esterifícação de $\mathrm{CH}_{3} \mathrm{COOH}$ com etanol é mais de 2000 vezes mais rápida que a de $\left(\mathrm{CH}_{3} \mathrm{CH}_{2}\right)_{2} \mathrm{CHCOOH}$.

O mecanismo $A_{\dot{A} C^{l}}$ só é encontrado quando $\underline{R}$ é muito volumoso, a ponto de o ataque bimolecular ser impedido estericamente. só se dã em solventes ionizantes.

Os mecanismos que envolvem a ruptura da ligação alquilaoxigênio são $A_{A L}{ }^{1}$ e $A_{A L}{ }^{2} \cdot A_{A L}{ }^{1}$ ocorre quando $R^{\prime}$ pode formar um Ion de carbōnio estável, isto é quando $R^{\prime}$ é um grupo alquila terciário, alila, benzila, etc. $A_{A L}{ }^{2}$ nunca foi observado.

Transesterificação è uma reação que permite transfor-mar um éster em outro.

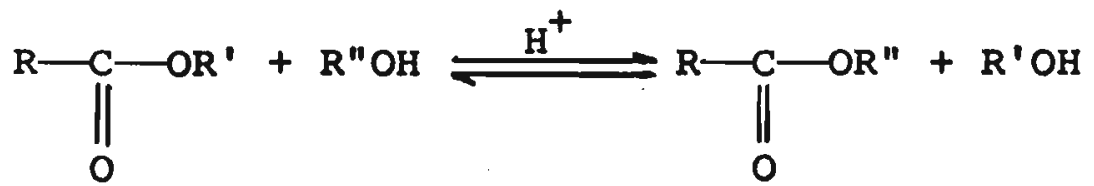

Tem-se um equį̣lbrio, que precisa ser deslocado na direção deseja da. Os mecanismos são Idênticos aos da hidrólise de èsteres, exceto que ROH substitul HOH. Envolvem ruptura da ligação acilaoxigênio, pols quando rompe a ligação alquila-oxigên1o, os prodụ tos são äcido e êter.

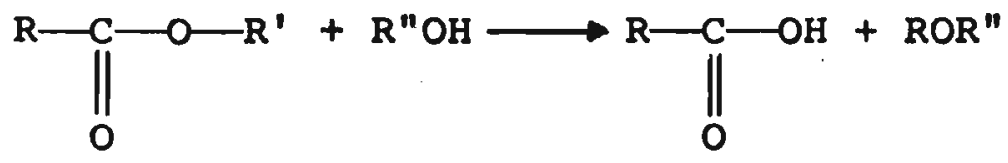

Por isso tentativas de transesterificação frequentemente falham, quando $R^{\prime}$ é grupo terclár10, pols esse tipo de substrato geralmen te reage com ruptura da ligação alquıla-oxigênło. 169 
6.2. Parte experimental

O fato de esterificação e hidrólise envolverem a particlpação de espécles iônicas, sugere que essas reações devam ser em princípio sensiveis à participação do solvente. Esse efeito pode ser eliminado e as caracteristicas intrinsecas desses processos desvendadas, se, em fase gasosa, forem estudadas reações anālogas. Esse foi justamente o objetivo do presente trabalho. Fol estudada a química de ions positivos de misturas de ácidos, ālcoois e ésteres $e$, as reações que ocorrem podem ser vistas como correspondentes às reações catalisadas por ácidos.

Mais espectficamente, as reações examinadas foram:

$\mathrm{RCOOH}_{2}^{+}+\mathrm{R}^{\prime} \mathrm{OH}+\left(\mathrm{RCOOR}^{\prime}\right) \mathrm{H}^{+}+\mathrm{H}_{2} \mathrm{O}$

$(\mathrm{RCOOR}) \mathrm{H}^{+}+\mathrm{R}^{\prime \prime O H} \rightarrow(\mathrm{RCOOR}) \mathrm{H}^{+}+\mathrm{R}^{\prime} \mathrm{OH}$

isto é, esterificação e transesterificação. A fim de verificar se, por exemplo, dado ácido reage com dado álcool, para produzir um èster (processo 6.1.), foram inicialmente obtidos separadamente os espectros de ressonância simples do ácldo, $\mathrm{RCOOH}, \mathrm{e}$ do álcool, R'OH, a diversas pressões. Isto foi necessārio, primeiro, para certificar-se da pureza dos compostos (a baixa pressão o espectro de ressonâncla simples pode ser comparado com espectros de massa da lite ratura), e, principalmente, para assegurar que um desses compos tos sozinho já não produzisse um ion de massa igual à do Ion cor respondente ao éster esperado. Isto é multo comum; em vários sistemas o próprio álcool forma um produto lônico 1sômero daquele que se espera; nesse caso um dos reagentes precisa ser deuterado. Isto será discutido com malores detalhes nas seções 6.6 .6 .7$. e 6.8. Em segulda foram obtidos espectros de ressonância simples 
de misturas de ácido e álcool (ouléster e álcool), com os dois compostos em várias proporções e a várias pressões totals, procu rando-se um pico no espectro que correspondesse ao éster protona do. No caso de obtenção de um produto, passou-se a Identificar os reagentes que levam à formação do mesmo, por meio de experiênclas de ressonância dupla. Este fol o esquema geral de traba2ho.

o espectrômetro de ressonância clclotrônica empregado fol descrito no capitulo $4 \mathrm{e}$ as condições experimentais são seme lhantes às dos capitulos 4 e 5, ou seja, em geral, a energia ele trônica fol de $15 \mathrm{eV}$, a corrente de emissão, menor que 0,20 $\mathrm{AA}$ e a amplitude do campo de rādio-frequência de ressonância dupla, menor que $10 \mathrm{mV} / \mathrm{cm}$. As pressões menclonadas são aproximadas; fo․ ram IIdas diretamente no controle da bomba 1ônica.

Foram usados os seguinte compostos: ācido förmico(Braun), ácido acético (Fisher), ācido acëtico-d 4 (stohler), äcido propanóico (BDH), metanol (Baker), etanol (Reagen); propanol-1 (Merck), propanol-2 (Reagen), butanol-1 (Carlo Erba), butanol- 2 (BDH), ālcool.terclobutilico (Fisher), pentanol-1 (Baker), formla to de metila (Eastman), formiato de metila-d ${ }_{3}$, formiato de etila (BDH), formiato de n-propila, formiato de 1sopropila, formiato de isopropila- $\mathrm{d}_{6}$, acetato de metila $(\mathrm{BDH})$, acetato de metila-d 6 (Merck), acetato de etila (Baker), trifluoroacetato de etila,clo roformiato de etila (BDH), propanotiol-2 (Baker) e cloreto de acetila (Allied). Formiato de metila-d ${ }_{3}$, formlato de n-propila, formiato de isopropila e formiato de isopropila-d $_{6}$ foram sintet1 zados pelo Dr. I. K. Blair e por P. C. Isolani. Trifluoroacetato de etila fol sintetizado ${ }^{171}$ a partir de $5 \mathrm{ml}$ de ācldo trifluoroacét1co (Carlo Erba), que iniclalmente foi dest1lado(62,8$63,2^{\circ} \mathrm{C} / \sim 700$ Torr), e $12 \mathrm{ml}$ de etanol (1sto corresponde a 3 mols 
de álcool para 1 mol de ácido); refluxou-se em presença de ácido sulfürico concentrado, procedendo-se depois da maneira usual 172 para extrair o éster, sendo recolhida a fração de faixà de ebuli ção $53,0-54,2^{\circ} \mathrm{C} / 200$ Torr, obtendo-se um rendimento global de 278 .

A fim de simplificar a apresentação das reações entre àcidos e álcoois e entre ésteres e álcoois, será feito primeiro um resumo das reações que ocorrem nos ácidos, álcoois e ésteres 1soladamente. Quase todas estas reações jã se achavam descritas na literatura, circunstâncla que facilitou os presentes trabaIhos envolvendo esterificação e transesterificação.

\subsection{Reações dos ācidos}

Ácido fórmico. o espectro (FIGURA 6.1.) è extremamen te simples: aparecem os fragmentos $\mathrm{CO}^{+}, \mathrm{HCO}^{+}$e $\mathrm{COOH}^{+}$, o Ion mole cular $\mathrm{HCOOH}^{+}$e o Ion molecular protonado $\mathrm{HCOOH}_{2}{ }^{+}$, formado pela transferêncla de um próton de algum dos outros ions para a molécula neutra de ácido fórmico. O problema è que frequentemente a parecem no espectro plcos correspondentes a ions de massas maiores que o do Ion molecular protonado; multas vezes foram encon trados picos que puderam ser atribuídos ao ācído acētico. Acredita-se não se tratar de impurezas contidas no prōprio ācido, mas que o ácido tenha sido impurificado no sistema de introdução de amostras do espectrômetro, pois a mesma alíquota apresentou es ses picos espürios em malor ou menor proporção em ocasiões dife rentes; alēm dis'so, fazendo uma espēcle de lavagem do sistema com a amostra, 1sto è, repetindo vārias vezes o processo de introduzir ácldo e bombeā-10 novamente, a Intensidade desses picos diminuiu sucessivamente. Possivelmente o äcido förmico tem a 


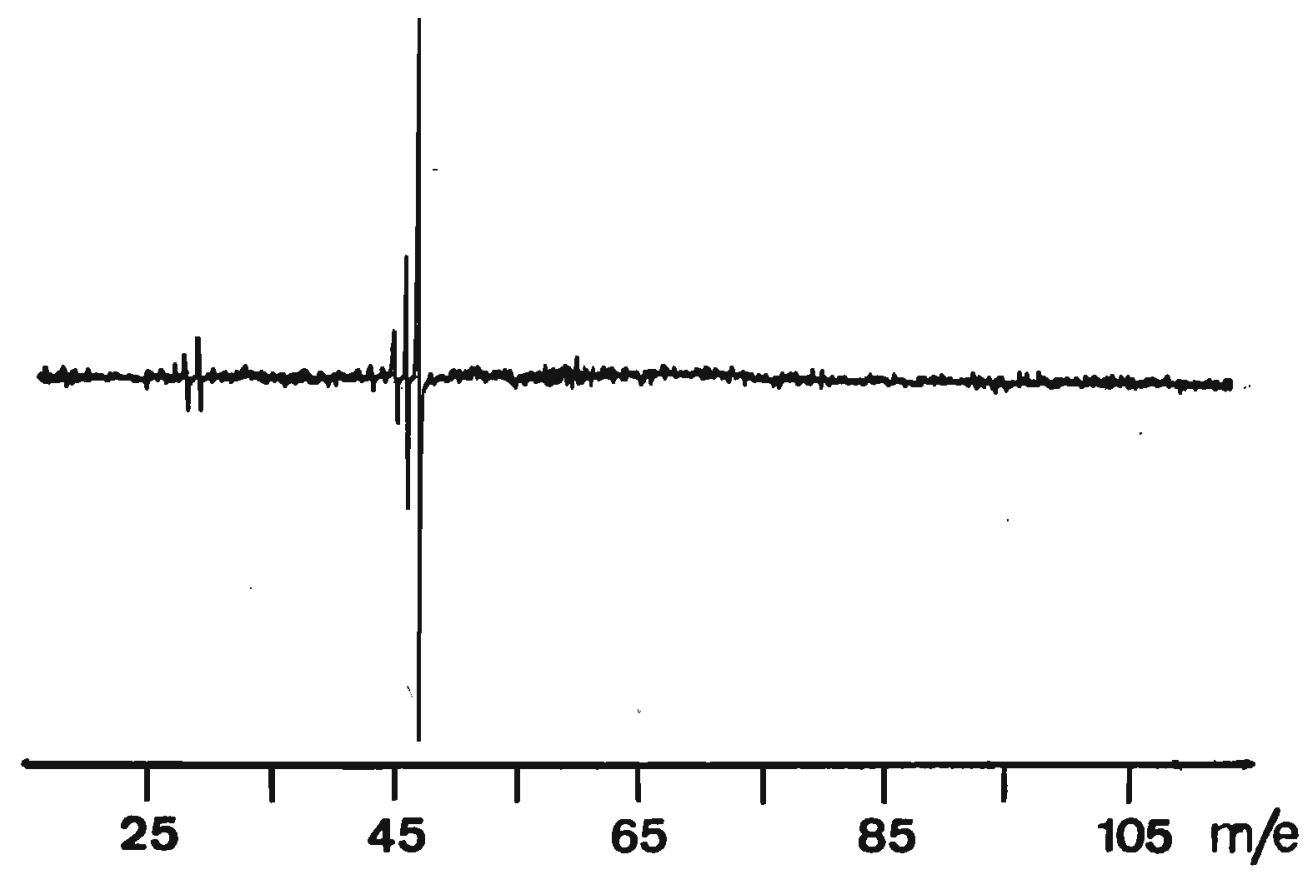

FIGURA 6.1. Espectro de massa de ácido fórmico.Pres são: $2,0 \cdot 10^{-5}$ Torr; energla eletrônica: $16,0 \mathrm{ev;}$ oscllador marginal: 153,8 $\mathrm{kHz}$.

propriedade de eluir facilmente substânclas adsorvidas nas paredes do sistema de introdução de amostras do espectrōmetro.

Ácido acētico. No espectro (FIGURA 6.2.) hả picos correspondentes ao fragmento $\mathrm{CH}_{3} \mathrm{CO}^{+}$, ao Ion molecular $\mathrm{CH}_{3} \mathrm{COOH}^{+}$, ao Ion molecular protonado $\mathrm{CH}_{3} \mathrm{COOH}_{2}{ }^{+} \mathrm{e}$, a dois Ions de relação massa/carga, respectivamente, 103 e 121. O primeiro Ion corresponde formalmente a $\left(\mathrm{CH}_{3} \mathrm{COOH}+\mathrm{CH}_{3} \mathrm{CO}\right)^{+}$, sendo que en ácido acét1co-d 4 surge um Ion de $\mathrm{m} / \mathrm{e} 110 ; \mathrm{m} / \mathrm{e} 121$ é o dimero protonado do ãcido acêtico.

Åcido propanōico. o espectro desse composto è mais com plicado; os principals picos, a uma pressão de $5 \cdot 10^{-6}$ Torr e 


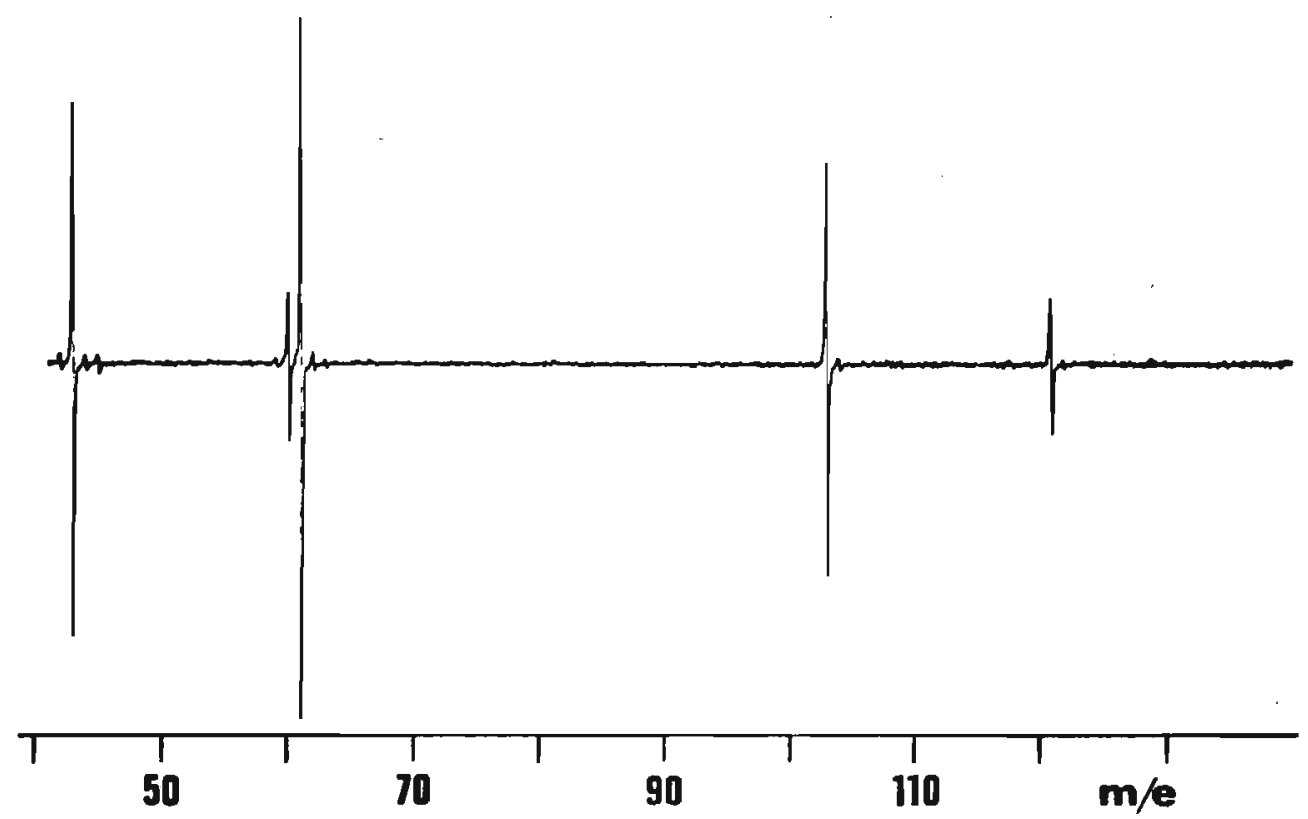

FIGURA 6.2. Espectro de massa de ácido acético.Pres são: $1,7 \cdot 10^{-5}$ Torr; energ1a eletrônıca: $20,0 \mathrm{eV}$; oscllador marginal 153,6 $\mathrm{kHz}$.

$15 \mathrm{eV}$ de energia eletrônica, correspondem a fragmentios de m/e $28,56,57$ e 73 e ao Ion molecular de m/e 74; além disso hã vārios picos menores. 173 Os Ions formados por reações desses frag mentos e do Ion molecular são o Ion molecular protonado (m/e 75) e Ions de m/e 129, 130 e 131; o Ion de m/e 131 fornece um pico intenso a uma pressão de $1,0 \cdot 10^{-5}$ Torr e corresponde formalmente a ácido propanölco mais o Ion $\mathrm{C}_{2} \mathrm{H}_{5} \mathrm{CO}^{+}(\mathrm{m} / \mathrm{e} 57)$; provavelmente é o Ion análogo ao de m/e 103 do ácido acético. Não fol verificado se o ãcldo propanölco forma um almero protonado (m/e 149). 


\subsection{Reações dos álcoois}

Metanol. As reações no metanol foram estudadas por He nis através de ressonância ciclotrônica de ions. 156 A balxa energia eletrônica, o único fragmento iônico é $\mathrm{CH}_{2} \mathrm{OH}^{+}$(m/e 31 ); 174 o Ion molecular é $\mathrm{CH}_{3} \mathrm{OH}^{+}$(m/e 32) e o ion molecular protonado, $\mathrm{CH}_{3} \mathrm{OH}_{2}^{+}(\mathrm{m} / \mathrm{e} 33)$. Este último ion reage com metanol para produzir éter dimetilico protonado (m/e 47).

H

$\mathrm{CH}_{3} \mathrm{OH}_{2}^{+}+\mathrm{CH}_{3} \mathrm{OH}+\mathrm{CH}_{3} \mathrm{OCH}_{3}+\mathrm{H}_{2} \mathrm{O}$

No metanol deuterado esse Ion tem $\mathrm{m} / \mathrm{e} 54$. Henis havia observado a inda uma sērle de outros ions de massas maiores:m/e 65, 79 e 97 , cujas estruturas todavia não confirmou. o Ion de m/e 65 è pouco abundante e deve corresponder ao dímero protonado de metanol. Os lons de m/e 79 e 97 não foram por nōs encontrados, mas, por outro lado foram-no lons de m/e 73, 103, 104 e 105 . No metanol deuterado aparecem picos relativos a ions de m/e 79, 112, 113, 114 e 115. O Ion de m/e 73 havia sido mencionado anteriormente, ${ }^{175}$ mas a or Igem de todas essas espécies é desconheclda. De qualquer maneira, a hipótese de contamınação da amostra na entra da do espectrômetro não pode ser excluía, apesar da conststên cla com que esses picos apareceram nos espectros do metanol. Co mo, porém, esses picos não interferiram nos presentes estudos,sen do as principais reações no metanol a protonação do mesmo (formação do ion de $\mathrm{m} / \mathrm{e} 33$ ) e a formação de éter protonado (m/e 47), a elucidação desses problemas não foi tentada.

Etanol. Os íons do espectro do etanol são: $\mathrm{CH}_{2} \mathrm{OH}^{+}(\mathrm{m} / \mathrm{e}$ 31), $\mathrm{CH}_{3} \mathrm{CHOH}^{+}(45), \mathrm{C}_{2} \mathrm{H}_{5} \mathrm{OH}^{+}(46), \mathrm{C}_{2} \mathrm{H}_{5} \mathrm{OH}_{2}^{+}$(47), $\mathrm{C}_{2} \mathrm{H}_{5}-\stackrel{\mathrm{OH}}{+}-\mathrm{C}_{2} \mathrm{H}_{5}(75)$ e $\left(\mathrm{C}_{2} \mathrm{H}_{5} \mathrm{OH}\right)_{2} \mathrm{H}^{+}(93)$. Futrel1 ${ }^{176}$ encontrou também um trimero proto nado e um Ion que corresponde a esse trímero com perda de água. 
Propanol-1. O espectro desse álcool é reproduzido na FIGURA 6.3. a uma pressão relativamente alta, de modo a favorecer o propanol protonado (m/e 61), o Eter dipropilico protonado (103) e o dimero protonado (121). Os outros Ions: $\mathrm{CH}_{2} \mathrm{OH}^{+}$(31), $\mathrm{C}_{3} \mathrm{H}_{7}^{+}(43), \mathrm{CH}_{3} \mathrm{CH}=\mathrm{OH}^{+}(45), \mathrm{C}_{2} \mathrm{H}_{5}{\mathrm{CH}=\mathrm{OH}^{+}}^{+}(59), \mathrm{C}_{3} \mathrm{H}_{7} \mathrm{OH}^{+}(60 ;$ é Ion molecular, que só está presente a pressões mals baixas que a indicada na FIGURA 6.3.), $\mathrm{C}_{3} \mathrm{H}_{7} \mathrm{OH}_{2}{ }^{+}(61),(73), \mathrm{C}_{3} \mathrm{H}_{7}-\mathrm{O}$......... $\mathrm{OH}_{2}^{+}$ (79), $\mathrm{C}_{3} \mathrm{H}_{7}-\stackrel{+}{\mathrm{OH}}-\mathrm{C}_{3} \mathrm{H}_{7}$ (103) e $\left(\mathrm{C}_{3} \mathrm{H}_{7} \mathrm{OH}\right) 2^{\mathrm{H}^{+}}$(121).

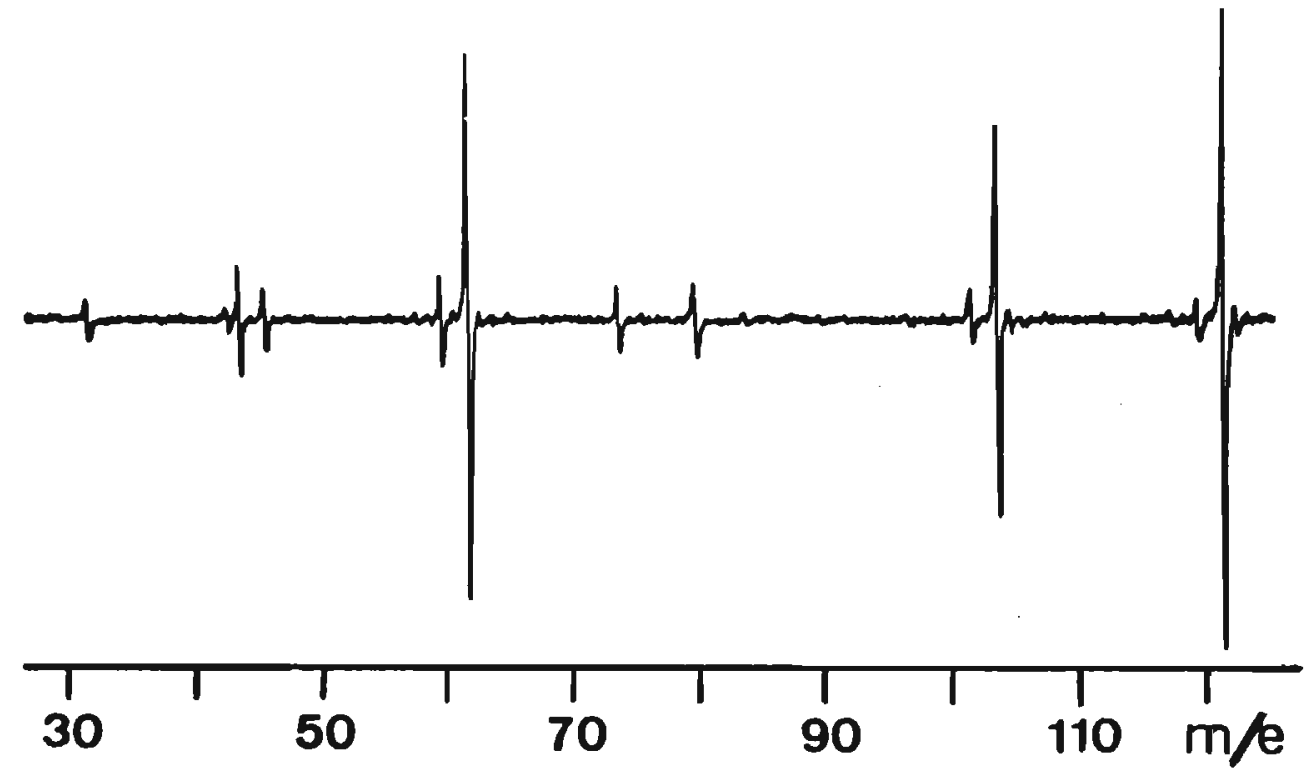

FIGURA 6.3. Espectro de massa de propanol-1. Pressão: $3 \cdot 10^{-5}$ Torr; energia eletrônica: $15,0 \mathrm{eV}$; oscilador marginal 153,6 kHz .

Propanol-2. Esse ālcool, ao contrārio do anterior, fol estudado por melo de ressonância ciclotrônica de Ions, estando os resultados descritos na literatura.177,178 os espectros dos do1s álcools são bastante semelhantes; no propanol-2 não apare- 
ce o fragmento $\mathrm{CH}_{2} \mathrm{OH}^{+}$, porque só há um hidrogênio no carbono $\underline{\alpha}$, mas aparecem três produtos iônicos adicionais, de m/e 69, 87 e 105. Segundo a classificação de Beauchamp, os principats Ions são: $\mathrm{CH}_{3} \mathrm{CH}=\stackrel{+}{\mathrm{O}} \mathrm{H}(45),\left(\mathrm{CH}_{3}\right)_{2} \mathrm{CHOH}_{2}^{+}(61),\left[\left(\mathrm{CH}_{3}\right)_{2} \mathrm{CH}\right]_{2} \mathrm{OH}^{+}$ (103), $\left[\left(\mathrm{CH}_{3}\right)_{2} \mathrm{CHOH}\right]_{2} \mathrm{H}^{+}(121)$, a lém de um trímero do qual fol eliminada água (m/e 163); picos. menores no espectros correspondem a $\mathrm{C}_{3} \mathrm{H}_{7}{ }^{+}$ (43), $\mathrm{C}_{2} \mathrm{H}_{4} \mathrm{O}^{+}(44), \quad \mathrm{CH}_{3} \mathrm{CH}=\mathrm{O} \ldots \mathrm{H}^{+} \ldots \mathrm{OH}_{2} \quad(63), \mathrm{C}_{5} \mathrm{H}_{9}^{+}$ (69), $\left(\mathrm{CH}_{3}\right)_{2} \mathrm{CH}-\mathrm{H} . \ldots \mathrm{H}^{+} \ldots \mathrm{OH}_{2}(79), \mathrm{CH}_{3} \mathrm{CH}=\stackrel{+}{\mathrm{OCH}}\left(\mathrm{CH}_{3}\right)_{2}$ (87), $\mathrm{CH}_{3} \mathrm{CH}=\mathrm{O} \ldots \mathrm{H}^{+} \ldots$ $\mathrm{OCH}\left(\mathrm{CH}_{3}\right)_{2}$ (105). Exceto aos de m/e 163 e 181, picos correspon dentes a todos esses Ions aparecem na FIGURA 6.4. O Ion de $\mathrm{m} / \mathrm{e}$ 59, $\left(\mathrm{CH}_{3}\right)_{2} \mathrm{COH}^{+}$, não fol observado a $13,5 \mathrm{ev} .174$

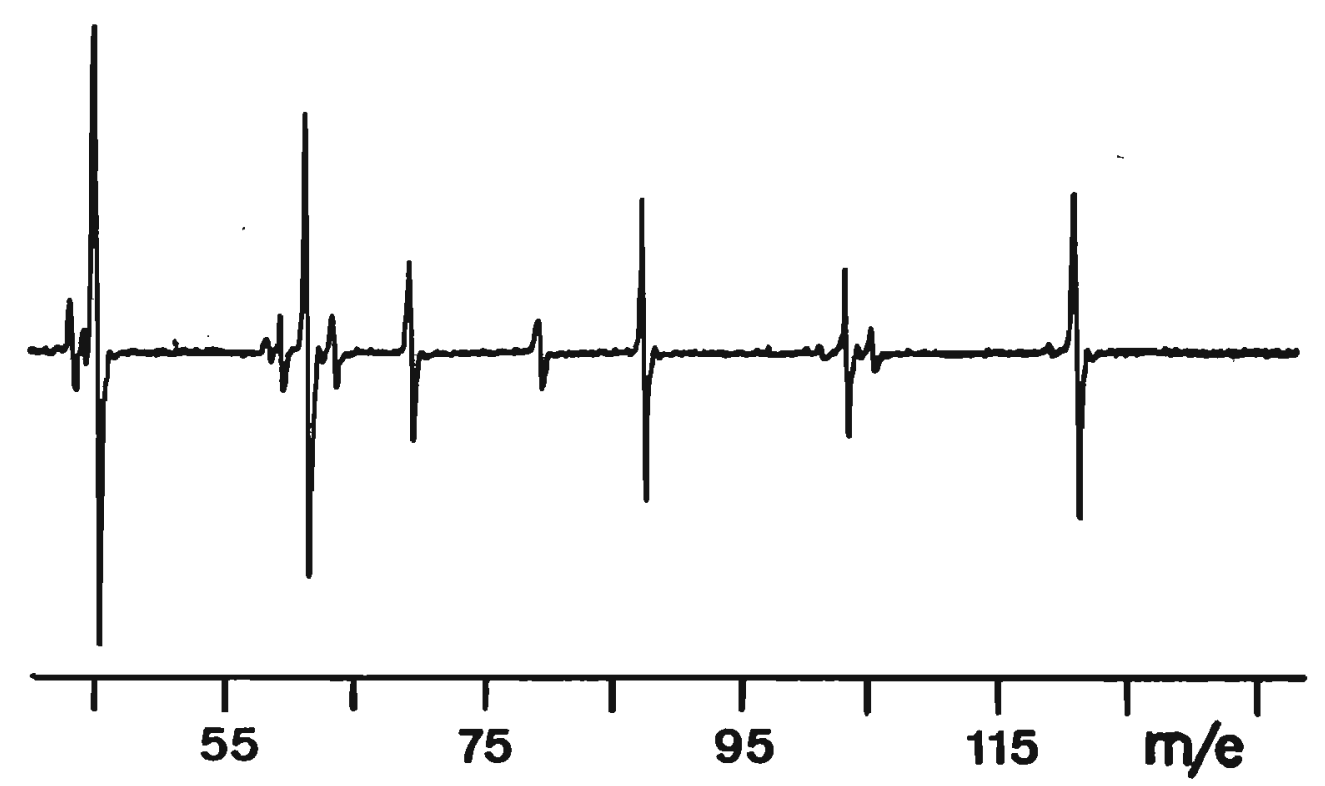

FIGURA 6.4. Espectro de massa de propanol-2. Pres são: 4,5 $\cdot 10^{-5}$ Torr; energla eletrônlca: $15,0 \mathrm{eV}$; oscilador marginal : $153,6 \mathrm{kHz}$.

Butanol-1. FIGURA 6.5. Neste espectro, obtido preg são balxa, aparecem os Ions de $\mathrm{m} / \mathrm{e} 31,41,42,43,55,56,57$, 


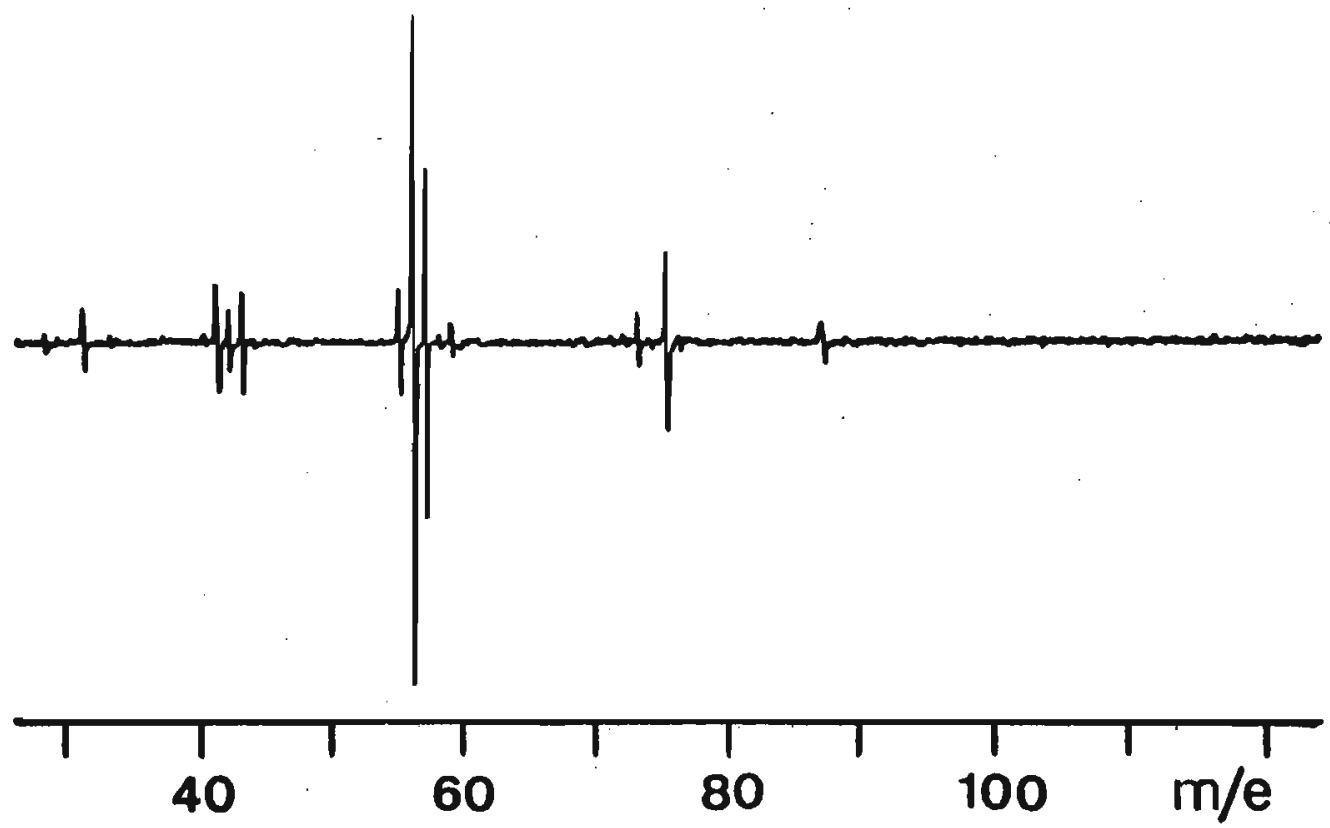

FIGURA 6.5. Espectro de massa de butanol-1. Pressão $1,1 \cdot 10^{-5}$ Torr; energ1a eletrônica: $15,0 \mathrm{eV}$; oscilador marginal: $153,6 \mathrm{kHz}$.

$59,73,75$ (molecular protonado) e 87. A pressões ma1s altas for am observados também lons de m/e 129, 131 (éter protonado) e 133. As reações entre Ions e moléculas de butanol-1 não estão descritas na literatura; por isso não se tentou atribulr estruturas a esses Ions.

Butanol-2. FIGURA 6.6. As reações que ocorrem nesse álcool estão descritas na literatura ${ }^{162}$ e os principals Ions são (de acordo com a referêncla 162): $\mathrm{CH}_{2} \mathrm{CHOH}^{+}(44), \mathrm{CH}_{3} \mathrm{CHOH}^{+}$ (45), $\mathrm{C}_{2} \mathrm{H}_{5} \mathrm{CHOH}^{+}$(59), $\mathrm{C}_{2} \mathrm{H}_{5} \mathrm{CH}\left(\mathrm{OH}_{2}\right) \mathrm{CH}_{3}^{+}(75), \quad\left(\mathrm{C}_{2} \mathrm{H}_{5} \mathrm{CHOHCH}_{3}\right)_{2} \mathrm{H}^{+}$ (149) e $\left(\mathrm{C}_{2} \mathrm{H}_{5} \mathrm{CHOHCH}_{3}\right)_{3} \mathrm{H}^{+}$(223); Ions, cuja corrente è menor que 108 da corrente 1ốnica total são: $\mathrm{CH}_{3} \mathrm{CHO} \ldots \mathrm{H}^{+} \ldots \mathrm{OH}_{2}$ 


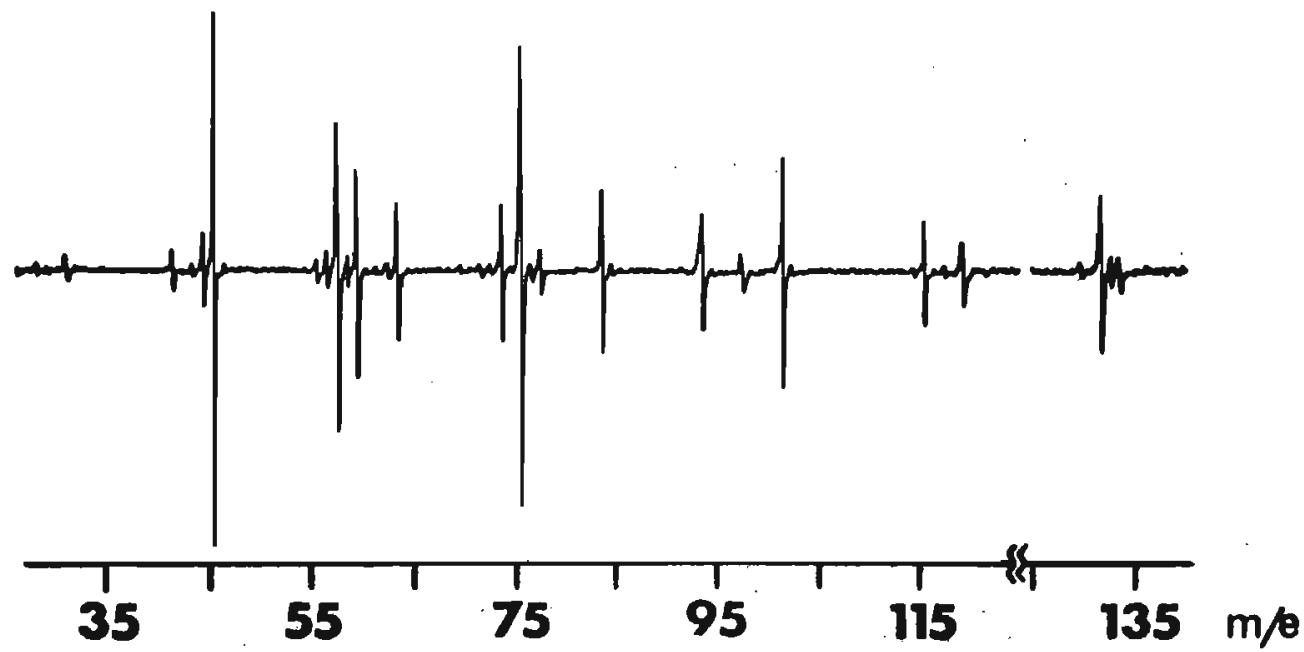

FIGURA 6.6. Espectro de massa de butanol-2. Pressão:4,0 $\cdot 10^{-5}$ Torr; energla eletrôni ca: $15,0 \mathrm{eV}$; osc1lador marginal:153,7 kHz. A escala de massa fol interrompida para facilitar o registro do espectro.

$\mathrm{C}_{6} \mathrm{H}_{11}+(83),\left(\mathrm{C}_{2} \mathrm{H}_{5}\right)\left(\mathrm{CH}_{3}\right) \mathrm{CH}-\stackrel{+}{\mathrm{O}} \ldots \mathrm{H}^{+} \ldots \mathrm{OH}_{2}(93), \mathrm{CH}_{3} \mathrm{CH}=\stackrel{+}{\mathrm{O}}-\mathrm{CH}\left(\mathrm{CH}_{3}\right)\left(\mathrm{C}_{2} \mathrm{H}_{5}\right)$ (101), $\mathrm{CH}_{3} \mathrm{CHO} \ldots \mathrm{H}^{+} \ldots \mathrm{H}_{-\mathrm{CH}}\left(\mathrm{CH}_{3}\right)\left(\mathrm{C}_{2} \mathrm{H}_{5}\right)$ (119), $\mathrm{C}_{4} \mathrm{H}_{9}^{+}(57), \mathrm{C}_{2} \mathrm{H}_{5} \mathrm{CHO} \ldots$ $\mathrm{H}^{+} \ldots \mathrm{OH}_{2}(77), \mathrm{C}_{7} \mathrm{H}_{13}{ }^{+}(97), \mathrm{C}_{2} \mathrm{H}_{5} \mathrm{CH}=$ ठ $-\mathrm{CH}\left(\mathrm{CH}_{3}\right)\left(\mathrm{C}_{2} \mathrm{H}_{5}\right)(115), \quad\left[\left(\mathrm{C}_{2} \mathrm{H}_{5}\right)\right.$ $\left.\left(\mathrm{CH}_{3}\right) \mathrm{CH}\right]_{2} \mathrm{OH}^{+}(131), \quad\left[\left(\mathrm{C}_{2} \mathrm{H}_{5}\right)\left(\mathrm{CH}_{3}\right) \mathrm{CH}\right]_{2} \mathrm{O} \ldots \mathrm{H}^{+} \ldots \mathrm{H}-\mathrm{CH}\left(\mathrm{CH}_{3}\right)\left(\mathrm{C}_{2} \mathrm{H}_{5}\right)(205)$. No espectro da FIGURA 6.6. há un pico relativo ao Ion de $\mathrm{m} / \mathrm{e} \quad 73$, $\left(\mathrm{C}_{2} \mathrm{H}_{5}\right)\left(\mathrm{CH}_{3}\right) \mathrm{C}=\mathrm{OH}^{+}, 174$ não mencionado na referêncla 162 , alēm de outros bem menores; não parece o piço do Ion de m/e 149, cuja existêncla, porêm, fol confirmada; não se tentou examinar o espectro de butanol até massas tão altas como 205 e 223. 
Alcool terciobutilico (2-metilpropanol-2). FIGURA 6.7. Este älcool foi estudado por Beauchamp. 139 os Ions para os quais estruturas foram atribuỉas são $\left(\mathrm{CH}_{3}\right)_{2} \mathrm{C}=\mathrm{OH}^{+}(59),\left(\mathrm{CH}_{3}\right)_{3} \mathrm{COH}_{2}^{+}$ (75), $\left(\mathrm{CH}_{3}\right)_{2} \mathrm{C}=\mathrm{O} \ldots \mathrm{H}^{+} \ldots \mathrm{OH}_{2}(77),\left(\mathrm{CH}_{3}\right)_{3} \mathrm{C}-\mathrm{H} \ldots \mathrm{H}^{+} \ldots \mathrm{OH}_{2}$ $\left(\mathrm{CH}_{3}\right)_{2} \mathrm{C}=0 . \ldots \mathrm{H}^{+} \ldots \mathrm{O}-\mathrm{C}\left(\mathrm{CH}_{3}\right)_{3}$ (133). Outros Ions que aparecem têm $\mathrm{m} / \mathrm{e} 57,\left(\mathrm{CH}_{3}\right)_{3} \mathrm{C}^{+}, 113,115,131$ (éter protonado) e 149 (d́lmero pro tonado, que não aparece na FIGURA 6.7.).

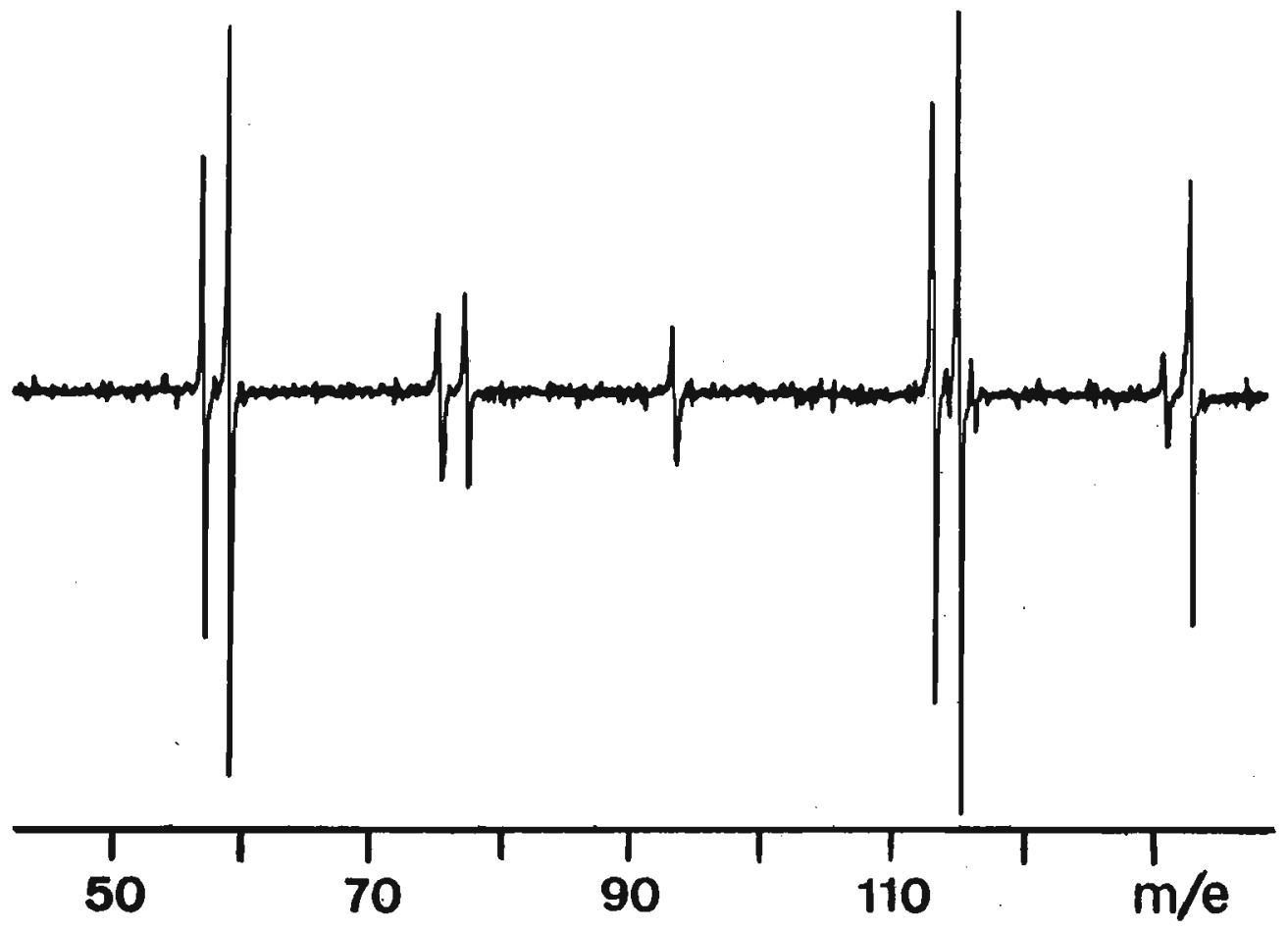

FIGURA 6.7. Espectro de massa de álcool terclobutí lico. Pressão: 4,0 $10^{-5}$ Torr; energia eletrônica: $15,0 \mathrm{eV}$; oscilador marginal: $153,6 \mathrm{kHz}$.

Pentanol-1. o espectro desse álcool è bastante complexo: $i^{174}$ como o espectro dos produtos de reações entre Ions e moléculas não consta na literatura, è diflcil saber se alguns dos Ions não são por acaso devidos a Impurezas. Os Ions que fornecem 
plcos razoavelmente intensos no intervalo de pressão de $4 \cdot 10^{-6}$ Torr e $1,0 \cdot 10^{-5}$ Torr e a $20 \mathrm{eV}$ de energía eletrônica, têm $\mathrm{m} / \mathrm{e}$ $31,40,41,42,43,55,56,57,59$ (é sempre o mals abundante), $69,70,71,75,77,87,89$ (Ion molecular protonado), 93, 101, $107,113,115,133$.

\subsection{Reações dos èsteres}

Ao contrário do que ocorre nos ácidos e nos álcoois, as reações que se processam nos ésteres são muito simples; geralmen te a úntca reação observada é a de protonação da molécula neutra do éster. Nos acetatos formam-se produtos de acetılação e dimeros protonados em reações anãlogas às encontradas nas cetonas (cá. pitulo 4), mas a extensão das mesmas è multo menor. A pressões altas o plco mais intenso é o do Ion molecular protonado; quanto malor a basicldade do ester, tanto menor a pressão em que esse plco começa a predominar. A fragmentação dos ésteres por impacto eletrônico de baixa energia não.é muito extensa. Um dos fragmentos que um èster RCOOR' produz è RCO ${ }^{+}$, que tem massa 29 nos formiatos e 43 nos acetatos; no formiato de metila, porém, não fol observado; no acetato de metila é o mals abundante a ba1xas pressões. O fragmento $O-R^{\prime+}$ não aparecé com esta estrutú ra, mas rearranja; ${ }^{179}$ é responsável pelos plcos 31 nos ésteres metillcos; nos ésteres etillcos o rearranjo tambẻm leva ao ion de $\mathrm{m} / \mathrm{e} 31$; nos ésteres 1sopropil1cos o lon tem m/e 45. 179 Outro fragmento é $\mathrm{OCOR}^{\prime}{ }^{+}$, que dá origem aos picos 59, 73 e 87 nos éste res metilicos, etilicos e propilicos, respectivamente. ${ }^{180}$ Um outro Ion que é devido a um rearranjo pode ser escrito formalmen te como $(\mathrm{RCOO}+2 \mathrm{H})^{+}, 180$ tem $\mathrm{m} / \mathrm{e}=47$ nos formlatos (não existe no de metila) e $\mathrm{m} / \mathrm{e}=61$ nos acetatos (não esiste no de metila); 
no trifluoroacetato de etila há um ion de $\mathrm{m} / \mathrm{e} 115,\left(\mathrm{CF}_{3} \mathrm{COO}+2 \mathrm{H}\right)^{+}$. $\mathrm{Na}$ referência 180 encontram-se os espectros dos ésteres aqui empregados (exceto os de cloroformiato de etila e trifluoroacetato de etila); há concordância qualitativa entre os picos mais intensos desses espectros e o que se observa em ressonância ciclotrônica de ions. A seguir os ésteres serão tratados separadamente.

Formiato de metila. A uma pressão de 5,0 $\cdot 10^{-6}$ Torr os únicos picos presentes no espectro correspondem aos ions de m/e 28, $31\left(\mathrm{HOCH}_{2}{ }^{+}\right), 17932,60$ (molecular), e 61 (molecular pro tonado), sendo esta também a ordem crescente das intensidades dos plcos. A pressões mais elevadas não surgiu nenhum plco novo; O do Ion de m/e 61 aumentou bastante.

Formiato de etila. Já a 5,0 $10^{-6}$ Torr o Ion de m/e 75, o Ion molecular protonado, é multo mais abundante que todos os outros, refletindo a afinidade protônica grande desse

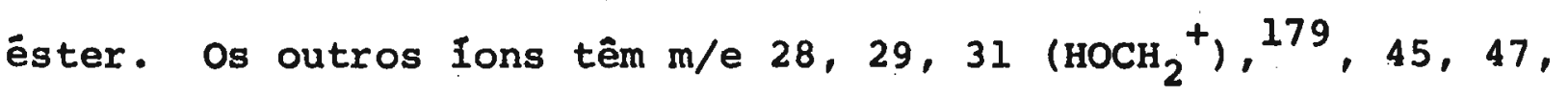
56,73 e 74 (molecular).

Formiato de n-propila. A pressão de $8,3 \cdot 10^{-6}$ Torr ó únicos picos apreciāveis são os dos lons de m/e 42 e 89 (molecular protonado); a pressões mais elevadas o Ion de m/e 89 predomina definitivamente., Outros Ions, que fornecem picos pouco Intensos, são os de $\mathrm{m} / \mathrm{e} 43,47,57,59$ e 71 . Note-se que não há pico correspondente ao Ion molecular (m/e 88).

Formlato de 1sopropila. Os princlpais plcos são devi dos aos Ions de m/e 42, $43\left(\mathrm{C}_{3} \mathrm{H}_{7}{ }^{+}\right), 45\left(\mathrm{HOCHCH}_{3}{ }^{+}\right)^{179} 73$ e 89 (molecular protonado); este ûltimo predomina largamente fá a $5,0 \cdot 10^{-6}$ Torr. Ions menos abundantes são os de m/e 41, 47, 59, $61,75,87$ e,a $3,0 \cdot 10^{-5}$ Torr aparece um Ion que dả origem a 
um pico razoavelmente intenso, de m/e 131 e que formalmente corresponde ao ion molecular (m/e 88), mals o fragmento $\mathrm{C}_{3} \mathrm{H}_{7}{ }^{+}(\mathrm{m} / \mathrm{e}$ 43). Portanto, neste èster ocorre uma outra reação, além das de protonação.

Cloroformiato de etila. A 7,0 $10^{-6}$ Torr os principais Ions no intervalo de 12 a 160 unidades de massa atômica. são os de m/e 28, 29, 64, 109 e 111. A 4,0 $10^{-5}$ Torr os fons de m/e 109 e 111 são muito mais abundantes que todos os outros; tra ta-se dos ions moleculares protonados, contendo, respectivamen te, ${ }^{35} \mathrm{Cl}$ e ${ }^{37} \mathrm{Cl}$; no espectro, a relação entre os plcos desses Ions é 3 : 1, o que está de acordo com a abundância natural dos dois 1sótopos de cloro. Outros picos que estão na proporção de 3 : 1 e que portanto devem conter cloro, são 64 e 66, 81 e 83, e 93 e 95; exceto o pico do Ion de m/e 64, todos os outros são muito pequenos. Além dos mencionados, aparecem picos relativos aos Ions de $\mathrm{m} / \mathrm{e} 45,62,63,65$ e 73. E possivel que alguns desses picos correspondam a impurezas.

Acetato de metila. A 5,0 $\cdot 10^{-6}$ Torr os principais Ions são $\mathrm{CH}_{3} \mathrm{CO}^{+}(\mathrm{m} / \mathrm{e} 43), \mathrm{CH}_{3} \mathrm{COOCH}_{3}^{+}$(74) e $\left(\mathrm{CH}_{3} \mathrm{COOCH}_{3}\right) \mathrm{H}^{+}$(75), sendo $\mathrm{CH}_{3} \mathrm{CO}^{+}$o mais abundante. No acetato de metila-d ${ }_{6}$ formamse os Ions deuterados correspondentes: $\mathrm{CD}_{3} \mathrm{CO}^{+}(46), \mathrm{CD}_{3} \mathrm{COOCD}_{3}^{+}$ (80) e $\left(\mathrm{CD}_{3} \operatorname{COOCD}_{3}\right) \mathrm{D}^{+}(82)$; existe o fon $\left(\mathrm{CD}_{3} \operatorname{COOCD}_{3}\right) \mathrm{H}^{+}$(81), mas seu pico épourco intenso; outro ion è o de m/e 62 e que no acetato de metila-do corresponde ao ion de m/e 59 e que é formado por fragmentação do Ion molecular do acetato de metila com expulsão do grupo metila ligado à carbonila; só aparece a balxas pressões. A pressões matores que $2 \cdot 10^{-5}$ Torr observam-se dois produtos 1ônicos de m/e 117 e 149; trata-se de acetato de metila acetilado, $\mathrm{CH}_{3} \mathrm{CO}^{+}\left(\mathrm{CH}_{3} \mathrm{COOCH}_{3}\right)$, e do dimero protonado desse ëster. Nos espectros 08 plcos desses Ions são extremamente 
pequenos", o que mostra que as reações de acetilação e de dimerização são muito lentas nos acetatos, ao contrário do que ocorre nas cetonas (vide capitulo 4), onde reações anãlogas são observa das.

Acetato de etila. Devido à afinidade protônica multo elevada do acetato de etila, o pico do ion molecular protonado (m/e 89) é muito mais intenso do que todos os outros, mesmo já a 5,0 $10^{-6}$ Torr. Outros Ions são os de m/e 43, 45, 61, 70, 73 e 88 (molecular); o íon de m/e 90 (acetato de etila protonado, contendo o isótopo ${ }^{13} \mathrm{C}$ ) dá origem a um pico apreciável. como produto de uma reação entre ions de acetato de etila e molécú las de acetato de etila, aparece um ion de $\mathrm{m} / \mathrm{e} 131$, $\mathrm{CH}_{3} \mathrm{CO}^{+}\left(\mathrm{CH}_{3} \mathrm{COOC}_{2} \mathrm{H}_{5}\right)$, um produto análogo aos que se conhecem das cetonas. A intensidade desse pico è maior que a do correspon dente ao Ion de m/e 117 no acetato de metila. Não fol verifica do se tambēm hã formação de um dímero protonado.

Trifluoroacetato de etila. Só foram observados os ions de m/e $29\left(\mathrm{C}_{2} \mathrm{H}_{5}\right.$ ?), $115\left(\mathrm{CF}_{3} \mathrm{COOH}_{2}{ }^{+}\right), 141$ e $143\left(\left(\mathrm{CF}_{3} \mathrm{COOC}_{2} \mathrm{H}_{5}\right)\right.$ $\mathrm{H}^{+}$). Veja o espectro da FIGURA 6.8. Não se pode afirmar que a única reação seja a de protonação, pois o espectro só fol varrido atè massa 190 (unidades atômicas); um produto do tipo encon trado nos acetatos descritos acima, teria massa 239. Porém, um ion nessa região do espectro não Irla interferir nas experi ênclas planejadas.

\subsection{Reações de esterificação}

Introduzindo separadamente ácıdo acētico e metanol no espectrômetro de ressonância clclotrônłca de Ions, o espectro de 


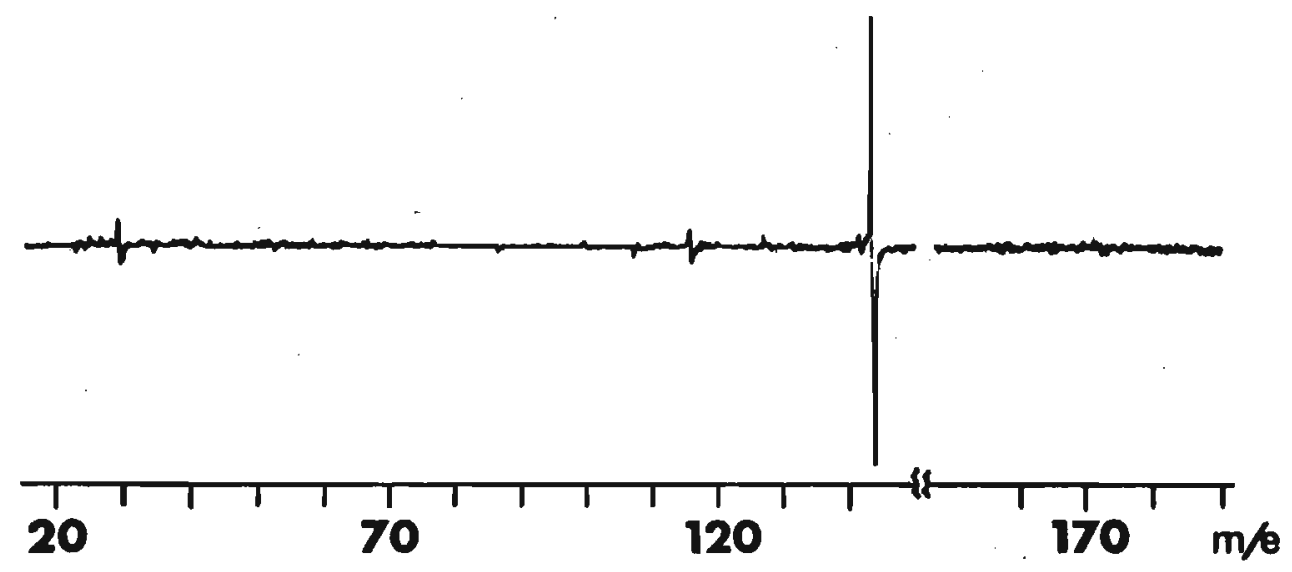

FIGURA 6.8. Espectro de massa de trifluoroacetato de etila. Pressão: 1,0 $10^{-5}$ Torr; energia eletrônica: 15,0 ev; oscila dor marginal: 113,2 kHz.

massa da mistura não é simplesmente a soma dos espectros das duas substânclas individualmente, mas revela a rápıda formação de um Ion com uma relação entre massa e carga igual a 75 e que corresponde a acetato de metila protonado. A FIGURA 6.9. mostra que, sob certas condlções, o produto 1ôntco de massa 75 pode ser o Ion que existe em malor proporção na cela. Esta reacão pode ser vista como anāloga ao processo catalisado por áci dos em solução.

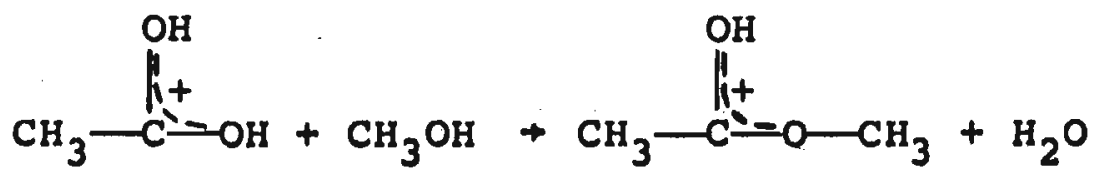

Pelo fato de os dols componentes da mistura serem introduzi dos através de entradas de amostra separadas no espectrôme tro, não há possibilidade de a formação de éster ocorrer na fase liquida, pois as substâncias sō entram em contato uma com a outra na câmara de alto vãcuo, a uma pressão da ordem de $10^{-5}$ 


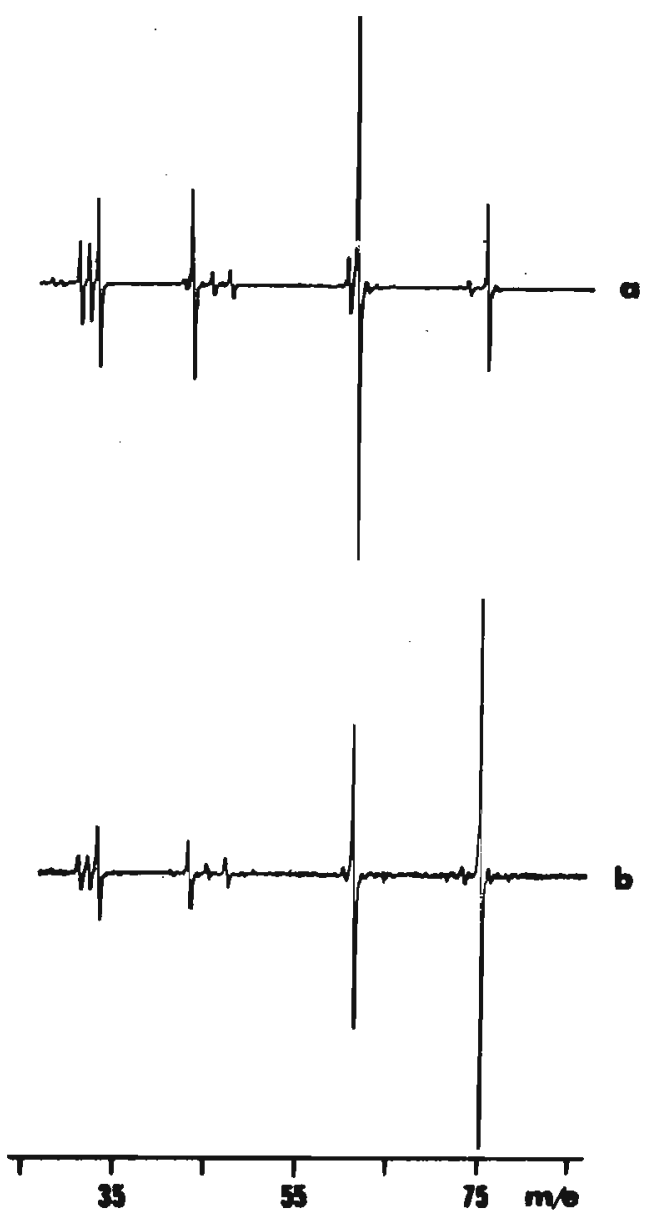

FIGURA 6.9. Espectros de massa de misturas de äc1do acético e metanol, nas quals ocorrem as reações

$$
\begin{aligned}
& \mathrm{CH}_{3} \mathrm{OH}_{2}^{+}(33)+\mathrm{CH}_{3} \mathrm{COOH}+ \\
& \left(\mathrm{CH}_{3} \mathrm{COOCH}_{3}\right) \mathrm{H}^{+}(75)+\mathrm{H}_{2} \mathrm{O} \\
& \mathrm{CH}_{3} \mathrm{COOH}_{2}^{+}(6 \mathrm{l})+\mathrm{CH}_{3} \mathrm{OH}+ \\
& \left(\mathrm{CH}_{3} \mathrm{COOCH}_{3}\right) \mathrm{H}^{+}(75)+\mathrm{H}_{2} \mathrm{O} \\
& \text { Pressões (em 10-5 Torr): a) ácido acé- } \\
& \text { tico: } 1,0 \text {; metanol: } 1,0 ; \text { b) ácido acé- } \\
& \text { tico: } 0,50 \text {; metanol: } 3,0 \text {. }
\end{aligned}
$$

Torr. Além disso, nunca se observou o pico do Ion molecular do ëster (m/e 74 no caso): de qualquer maneira, a reação em fase IIquida seria multo lenta sem a adição de ăcldo sulfúrico. 
Não se sabe se o ácido e o éster são realmente protona dos na posição indicada na reação 6.2. A formação de éster protonado tambēm se dá quando metanol protonado reage com o ácido.<smiles>CO[C+]=[C+]C(=O)O</smiles>

Isto fol mostrado por ressonância dupla; observando o éster protonado, obteve-se um sinal tanto do ácido protonado, como do álcool protonado, sendo aproximadamente lgual a contribuição dos dols para a formação do produto. Como ácido acético tem uma af nidade protônica maior que metanol (capitulo 5), a formação de Éster protonado por $\mathrm{CH}_{3} \mathrm{OH}_{2}^{+}$aparentemente compete com transfe rêncta de pröton.

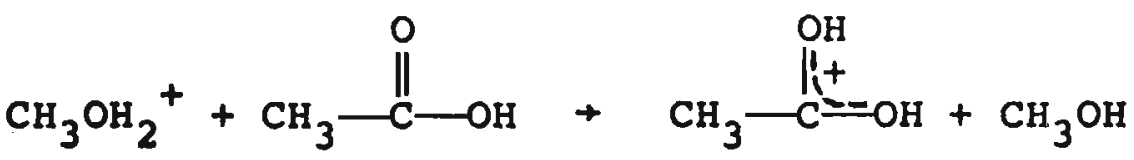

Pela FIGURA 6.9. e pela TABELA 6.2., onde a intensida de do pico do produto lônico é comparada com a intensidade doś plcos de álcool e ácldo protonados a vărias pressões e composições da mistura, verıflca-se que a reação è favoreclda por exces so de álcool, possivelmente pelo fato de os fragmentos iôni cos do álcool serem multo eficientes na protońação das espécies neutras.

Tudo o que fol dito para o caso do metanol, também vale para a reação de etanol com ácido acético, encontrando-se alguns resultados de intensidades relativas dos picos de reagentes e produtos na TABELA 6.2. O acetato de etila protonado tem $\mathrm{m} / \mathrm{a}$ $=89$.

Foram realizadas experiências com o intuito de medir as velocidades relativas das reações de ester1f1cação de ãcldo 
TABELA 6.2 .

Intensidades relativas dos picos das espécies tônicas envolvidas no processo de esterificação para vãrias composições e pressões. ${ }^{a}$

\begin{tabular}{|c|c|c|c|c|c|}
\hline $\mathrm{RCOOH}$ & $\mathrm{R}^{\prime} \mathrm{OH}$ & $\begin{array}{l}\mathrm{P}_{\mathrm{RCOOH}} \\
\left(\text { Torr } .10^{5}\right)\end{array}$ & $\begin{array}{l}\mathrm{P}_{\mathrm{R}^{\prime} \mathrm{OH}} \\
(\text { Torr.105) }\end{array}$ & $\mathrm{I}_{\mathrm{RCOOH}_{2}}^{+}$ & $\mathrm{I}_{\mathrm{R}^{\prime} \mathrm{OH}_{2}}{ }^{+}$ \\
\hline \multirow[t]{2}{*}{$\mathrm{CH}_{3} \mathrm{COOH}$} & $\mathrm{CH}_{3} \mathrm{OH}$ & 1,0 & 1,0 & 3,3 & 1,0 \\
\hline & & 0,5 & 2,5 & 0,55 & 0,17 \\
\hline \multirow[t]{2}{*}{$\mathrm{CH}_{3} \mathrm{COOH}$} & $\mathrm{C}_{2} \mathrm{H}_{5} \mathrm{OH}$ & 1,0 & 1,0 & 2,6 & 0,62 \\
\hline & & 0,3 & 2,7 & 0,38 & 0.27 \\
\hline \multirow[t]{3}{*}{$\mathrm{C}_{2} \mathrm{H}_{5} \mathrm{COOH}$} & $\mathrm{CH}_{3} \mathrm{OH}$ & 1,2 & 0,4 & 8,1 & 3,6 \\
\hline & & 0,5 & 1,5 & 3,5 & 5,8 \\
\hline & & 0,5 & 2,0 & 2,8 & 5,8 \\
\hline \multirow[t]{2}{*}{$\mathrm{C}_{2} \mathrm{H}_{5} \mathrm{COOH}$} & $\mathrm{C}_{2} \mathrm{H}_{5} \mathrm{OH}$ & 1,2 & 0,4 & 4,5 & 1,2 \\
\hline & & 0,7 & 2,1 & 1,6 & 1,3 \\
\hline \multirow[t]{2}{*}{$\mathrm{HCOOH}$} & $\left(\mathrm{CH}_{3}\right)_{2} \mathrm{CHOH}$ & 1,0 & 1,0 & 4,1 & 3,2 \\
\hline & & 2,0 & 2,0 & 1,1 & 2,1 \\
\hline
\end{tabular}

a) A intensidade relativa do produto iônico, (RCOOR') $\mathrm{H}^{+}$, fo1 Igualada a 1 em cada caso.

acētico com metanol e etanol. A comparação fol feita, mantendo constante a pressão de ácido acético perdeuterado, enquanto que a pressão parcial da mistura de metanol e etanol foi aumentada progressivamente e as intensidades dos dois produtos registradas no Intervalo de pressão de $1 \cdot 10^{-5}$ e $5 \cdot 10^{-5}$ Torr. 0 uso de $\mathrm{CD}_{3} \mathrm{COOD}$ fol necessário para separar o plco de acetato de 
metila protonado $(\mathrm{m} / \mathrm{e} 75)$ do de ëter dietilico protonado (m/e 75), um produto formado no próprio etanol (seção 6.4.). A pressão do ācido acētico fol mantida num valor baixo, menor que a dos álcoois. Metanol e etanol foram misturados em proporções volumētricas iguais num tubo. Com isso os produtos observados foram $\left(\mathrm{CD}_{3} \mathrm{COOCH}_{3}\right) \mathrm{H}^{+}$e $\left(\mathrm{CD}_{3} \mathrm{COOCH}_{3}\right) \mathrm{D}^{+}(\mathrm{m} / \mathrm{e} 78$ e 79), e $\left(\mathrm{CD}_{3} \mathrm{COOC}_{2} \mathrm{H}_{5}\right) \mathrm{H}^{+}$e $\left(\mathrm{CD}_{3} \mathrm{COOC}_{2} \mathrm{H}_{5}\right) \mathrm{D}^{+}(\mathrm{m} / \mathrm{e} 92$ e 93). Alguns esper tros dessa experiêncla acham-se na FIGURA 6.10. Nota-se que os picos dos lons de m/e 78 e 92 aumentaram com a pressão parcial. dos álcoois, permanecendo aproximadamente constante a relação entre eles (como existiu excesso de compostos não-deuterados, a intensidade dos picos dos ions de m/e 79 e 93 foi sempre menor que a dos de $\mathrm{m} / \mathrm{e} 78$ e 92). Isto indica que as duas reações se dão com velocidadesbastante prōximas. Deve-se ter em mente que se mediu a relação entre as velocidades de formação de acetato de metila e etila protonados, pois, como visto, cada um desses produtos é produzido atravēs de duas reações, a de ãcido acētico prọ tonado com álcool neutro e a de álcool protonado com ácido acétí co.

As reações de ãcldo propanóico com metanol e etanol são análogas ãs do ácldo acético. Observou-se que são bastante rápl das as reaçöes

$$
\begin{aligned}
& \mathrm{C}_{2} \mathrm{H}_{5} \mathrm{COOH}_{2}^{+}+\mathrm{CH}_{3} \mathrm{OH}+\left(\mathrm{C}_{2} \mathrm{H}_{5} \mathrm{COOCH}_{3}\right) \mathrm{H}^{+}+\mathrm{H}_{2} \mathrm{O} \\
& \mathrm{m} / \mathrm{e} 75 \\
& \mathrm{~m} / \mathrm{e} 89
\end{aligned}
$$

$$
\begin{array}{ll}
\mathrm{C}_{2} \mathrm{H}_{5} \mathrm{COOH}_{2}{ }^{+}+\mathrm{C}_{2} \mathrm{H}_{5} \mathrm{OH} & +\left(\mathrm{C}_{2} \mathrm{H}_{5} \mathrm{COOC}_{2} \mathrm{H}_{5}\right) \mathrm{H}^{+}+\mathrm{H}_{2} \mathrm{O} \\
\mathrm{m} / \mathrm{e} 75 & \mathrm{~m} / \mathrm{e} 103
\end{array}
$$



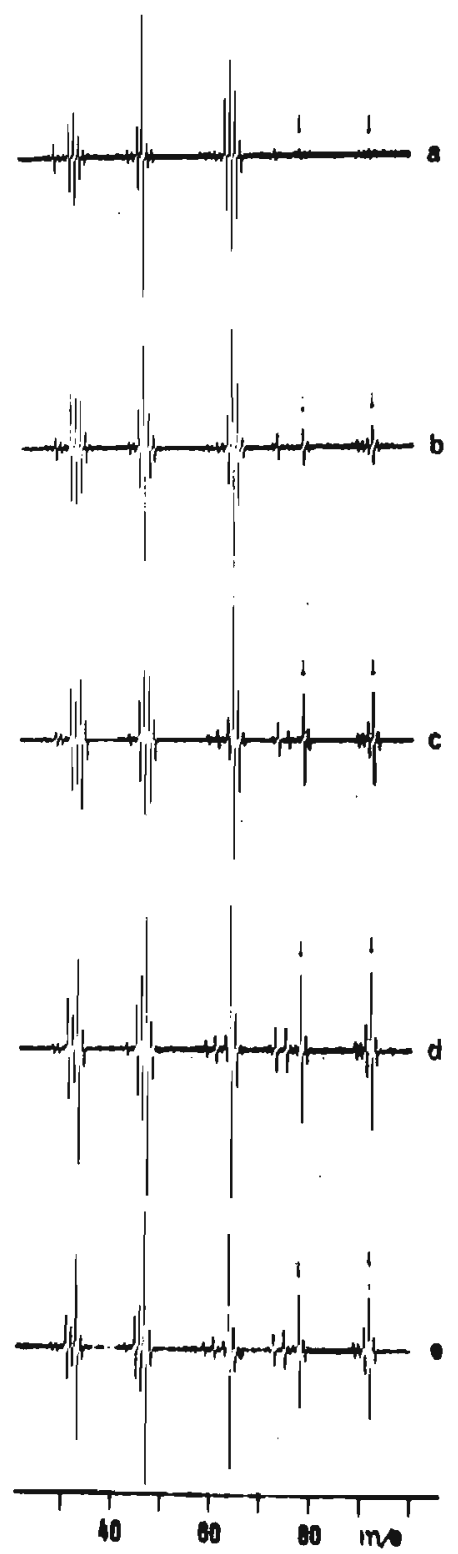

FIGURA 6.10. Espectros de massa de misturas de ác1 do acético-d 4 , metanol e etanol. Os èsteres formados são $\left(\mathrm{CD}_{3} \mathrm{COOCH}_{3}\right) \mathrm{H}^{+}(78)$ e $\left(\mathrm{CD}_{3} \mathrm{COOC}_{2} \mathrm{H}_{5}\right) \mathrm{H}^{+}(92)$. Pressão parcial do ácido: $5,0 \cdot 10^{-6}$ Torr. Pressão parcial (em $10^{-5}$ Torr) da mistura 1 : 1 em volume liquido de metanol e etanol: a) 0,50 ; b) 1,5 ; c) 2,5 ; d) 3,5 ; e) 4,5 .

Na FIGURA 6.11., onde é apresentado um espectro da mistura de áci do propanóico e metanol, vê-se que o pico do propanoato de metila protonado é razoavelmente intenso. Veja tambēm a TABELA 6.2. Os 

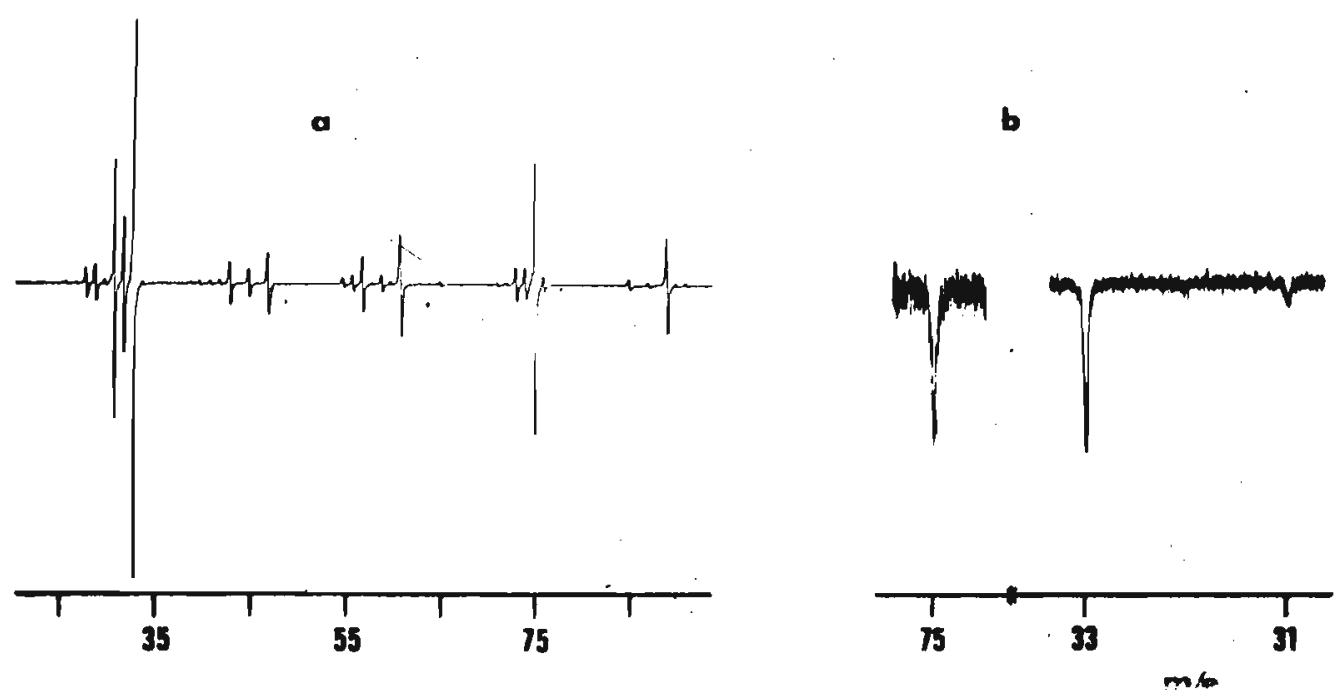

FIGURA 6.11. a) Espectro de massa da mistura de áct do propanóico $\left(0,5 \cdot 10^{-5}\right.$ Torr) e meta nol $\left(2,0 \cdot 10^{-5}\right.$ Torr $)$. b) Espectros de ressonância dupla: observado $\bigcirc$ Ion $\left(\mathrm{C}_{2} \mathrm{H}_{5} \mathrm{COOCH}_{3}\right) \mathrm{H}^{+}(\mathrm{m} / \mathrm{e} 89)$ e Irradia dos $\mathrm{C}_{2} \mathrm{H}_{5} \mathrm{COOH}_{2}^{+}(\mathrm{m} / \mathrm{e} 75), \mathrm{CH}_{3} \mathrm{OH}_{2}^{+}(\mathrm{m} / \mathrm{e}$ 33) e $\mathrm{CH}_{2} \mathrm{OH}^{+}$(m/e 31); oscilador de ressonância dupla: pulsado entre 0 e $10 \mathrm{mV}$.

espectros de ressonância dupla mostraram uma contribulção para $\left(\mathrm{C}_{2} \mathrm{H}_{5} \mathrm{COOCH}_{3}\right) \mathrm{H}^{+}$tanto de $\mathrm{C}_{2} \mathrm{H}_{5} \mathrm{COOH}_{2}^{+}$, como de $\mathrm{CH}_{3} \mathrm{OH}_{2}^{+}$; mals uma vez não Importa em qual dos reagentes o próton inicialmente está. A pequena contribulção do Ion de $\mathrm{m} / \mathrm{e} 31, \mathrm{CH}_{2} \mathrm{OH}^{+}$, um fragmento do me tanol (seção 6.4.), se deve ao fato de esse lon protonar uma das moléculas neutras, ácido propanọico ou metanol, sendo o produto dessa reação o reagente de esteriflcação; o que se observou, fol um sinal de ressonância dupla atravēs de duas reações consecutivas e duas reações paralelas. 


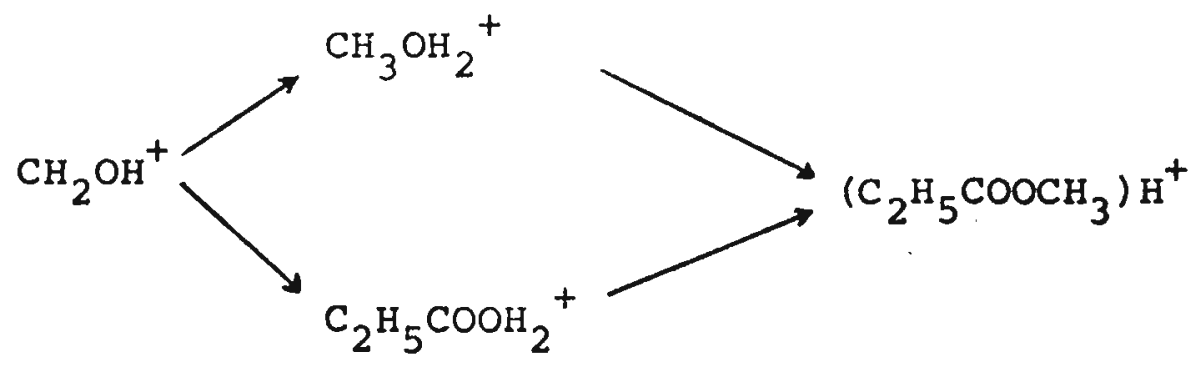

Nenhum outro íon do espectro forneceu um sinal de ressonância dupla com o propanoato de metila protonado.

Acido acético tambēm forma os ésteres correspondentes com propanol-2 (foi preciso usar ácido acético-d $4^{\prime}$ para deslo car o pico do acetato de isopropila protonado do pico de éter di-1sopropilico protonado, ambos aparecendo em massa 103; vide seção 6.4.), butanol-1 (o produto iônico tem m/e 117),ál cool terciobutilico (a reação é muito mais lenta que nos casos anteriores) e pentanol-1. Certamente o ácido acético também reage com outros álcools atravēs de reações entre Ions e moléculas em fase gasosa, mas foram apenas estes os casos examinados. Com os álcoois supertores a formação de ësteres protonados torna-se uma reação, de importância me nor, devido ao grande nümero de reações que ocorrem no próprio álcool, ou seja, entre fragmentos do álcool e moléculas neutras do álcool (seção 6.4.).

Acido fórmico comporta-se de modo diferente de ácido acético e ãcido propanóico no que diz respeito à esterificação com metanol e etanol; sua esterificação com estes álcools não fol 
observiuia. Naś condições das experiências de ressonância ciclotrônica de ions, o único processo encontradofolode transferêncla de próton, o que está de acordo com o fato de álcoois terem afinidades protônicas maiores que ācido fórmico (capitulo 5).

$\mathrm{HCOOH}_{2}^{+}+\mathrm{CH}_{3} \mathrm{OH} \rightarrow \mathrm{CH}_{3} \mathrm{OH}_{2}^{+}+\mathrm{HCOOH}$

A reação com etanol foi tentada, usando etanol deuterado, pois do contrário, o pico do produto esperado, $\left(\mathrm{HCOOC}_{2} \mathrm{H}_{5}\right) \mathrm{H}^{+}$, coincidi ria com o do ēter dietílico protonado, formado na reação de etanol protonado com etanol neutro (seção 6.4.). Com etanol-d 6 - pico do éter apareceu sob forma dupla, a massas 85 e 86, pois tem-se $\left(C_{2} D_{5}\right)_{2} \mathrm{OH}^{+}$e $\left(C_{2} D_{5}\right)_{2} \mathrm{OD}^{+}$, e o éster deveria fornecer picos em 80 e 81, o que não aconteceu. Entretanto, propano1-2 protona do reage com ācldo fórmico, bem como ácido fórmico protonado com propanol-2, dando um Ion de $\mathrm{m} / \mathrm{e}=89$, o qual provavelmente corresponde a formiato de isopropila protonado.<smiles>CC(C)O[C+]C(=O)OC(C)C</smiles>

Isto está ilustrado na TABELA 6.2. Esta esterificação também ocorre com butanol-2 e álcool terciobutilico, se bem que em extensão menor. Propanol-1 e butanol-l não reagem. Essa mudança drástica no comportamento se dã, apesar de as afinidades protôní cas desses álcoois serem alnda maiores que as de metanol e etanol. Isto sugere um mecanismo diferente nas reações do ácido förmico quando comparadas com as dos ácidos acético: e propanóico, mas para explicar 1sso (seção 6.9.) são necessãrios os resultados da seção 6.8 . 


\subsection{Ruações de transesterificação}

Reações de transesterificação não foram observadas em fase gasosa nas condições reinantes num espectrômetro de ressonân cia ciclotrônica de ions a pressões menores que $5 \cdot 10^{-5}$ Torr.

$$
\left.(\mathrm{RCOOR})^{\prime}\right) \mathrm{H}^{+}+\mathrm{R}^{\prime \prime O H} \nrightarrow\left(\mathrm{RCOOR}^{\prime \prime}\right) \mathrm{H}^{+}+\mathrm{R}^{\prime} \mathrm{OH}
$$

Esta conclusão basela-se numa sērie de experiências, relacionadas na TABELA 6.3. Várias das reações foram testadas em ambas as direções (por exemplo, acetato de metila + etanol e acetato de etila + metanol): se uma direção é endotérmica, a outra é exotērmica. Em nenhum caso foi encontrada a menor indlcação da exís tência de algum produto de transesterificação.

\subsection{Um novo tipo de reação}

A falta de reatividade dos sistemas relacionados na TA$B E L A$ 6.3. no que diz respeito às reações de transesterificação, é compensada por uma reação na qual āgua é eliminada. Trata-se de uma reação de condensação que se dá entre quase todos os ēsteres da TABELA 6.3. e os propanóis e butanóis, sendo que metanol e eta nol se caracterızam por não reagirem dessa manelra. A reação foi detectada primeiro com formiato de metila deuterado e propanol-2.

$\left(\mathrm{CH}_{3}\right)_{2} \mathrm{CHOH}_{2}^{+}+\mathrm{HCOOCD}_{3} \rightarrow \mathrm{HCO}_{2} \mathrm{CD}_{3} \mathrm{C}_{3} \mathrm{H}_{7}^{+}+\mathrm{H}_{2} \mathrm{O}$

Se tivesse sido usado $\mathrm{HCOOCH}_{3}$ em lugar de $\mathrm{HCOOCD}_{3}$, o produto, de m/e 103, não poderia ter sido distinguido do éter di-isopropilico protonado (seção 6.4.). Supõe-se que o produto tônico tenha uma estrutura do tipo de um acetal (I), embora uma estrutura do tipo 


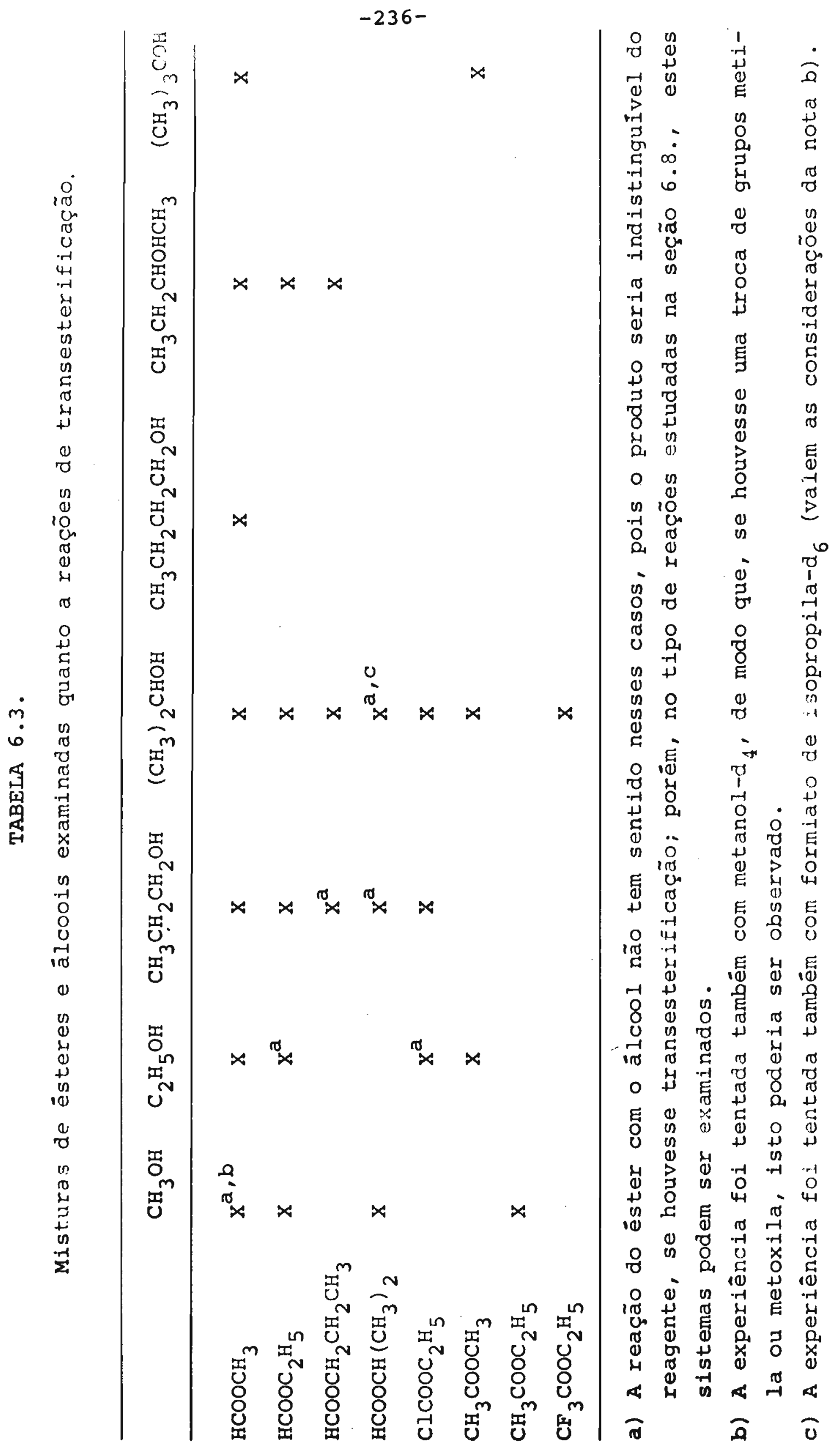


oxônto. (II) não possa ser excluída com base nas expertências rea lizadas (vide seção 6.9.).

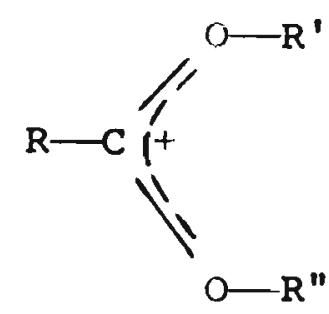

( I )

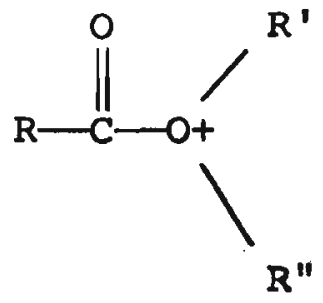

(II)

Todos os sistemas da TABELA 6.3. foram examinados quanto a essa reação e na TABELA 6.4. estão os sistemas nos quais a reação foi efetivamente observada. Na TABELA 6.5. as intensidades dos picos dos produtos iônicos $\mathrm{RCO}_{2} \mathrm{R}^{\prime} \mathrm{R}^{\prime \prime}$ são comparadas com as dos picos de ālcoois e ēsteres protonados a vārias pressões e composi Ções das misturas dos sistemas mais representativos. A comparação foi feita, envolvendo os picos de álcoois e ésteres protonados, porque experiências de ressonância dupla evidenciaram que nestas reações não importa aonde o prōton iniclalmente está: se no álcool, ou no éster. Portanto, o produto da reação 6.3. è ţambëm formado na reação

$$
\left(\mathrm{HCOOCD}_{3}\right) \mathrm{H}^{+}+\left(\mathrm{CH}_{3}\right)_{2} \mathrm{CHOH}+\mathrm{HCO}_{2} \mathrm{CD}_{3} \mathrm{C}_{3} \mathrm{H}_{7}^{+}+\mathrm{H}_{2} \mathrm{O}
$$

Na FIGURA 6.12. vê-se que houve formação de um Ion $\mathrm{m} / \mathrm{e} 131$ no sistema de formiato de n-propila e propanol-2 e, pelos espectros de ressonâncla dupla, que tanto propanol-2 protonado (m/e 61), co mo formiato de n-propila protonado (89) contribuem para a formação do produto. Esta situação è análoga àquela das reações de esterificação (seção 6.6.), onde a reação também pode ser iniclada tanto pelo ácido protonado, como pelo álcool protonado. 


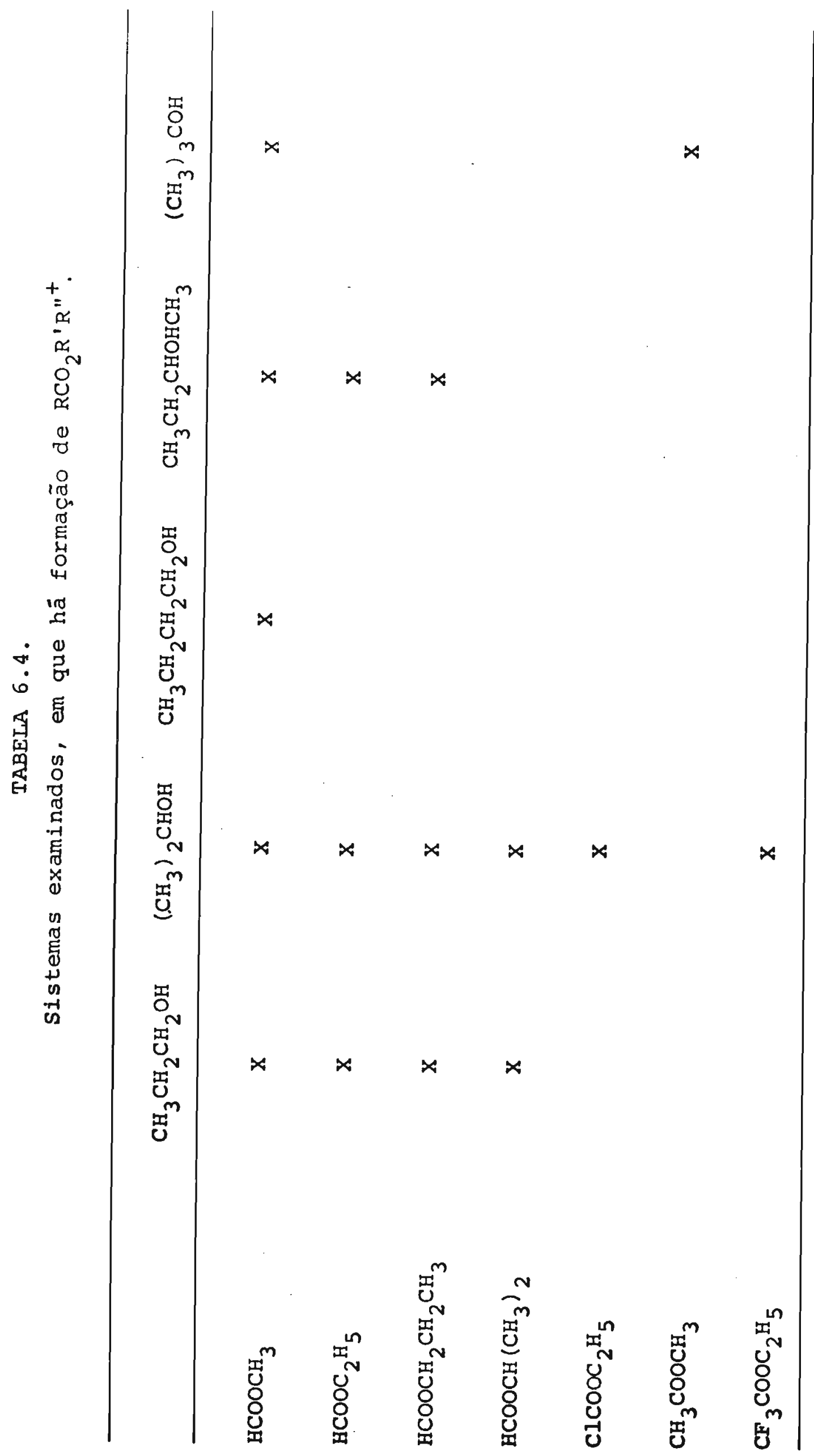


TABELA 6.5 .

Intensidades relativas dos plcos das espēcies iônlcas envolvidas na reaçāo de ésteres com álcools a vārlas composiçōes e pressōes. a

\begin{tabular}{|c|c|c|c|c|c|}
\hline RCOOR' & $\mathrm{R}^{n} \mathrm{OH}$ & $\begin{array}{l}\mathrm{P}_{\mathrm{RCOOR}} \\
\left(\text { Torr. } 10^{5}\right)\end{array}$ & $\begin{array}{c}\mathbf{P}_{\mathrm{R}^{\mathrm{N}} \mathrm{OH}} \\
\left(\text { Torr. } 10^{5}\right)\end{array}$ & $I_{R C O O R} H^{+}$ & $\mathrm{I}_{\mathrm{R}^{\prime} \mathrm{OH}_{2}}{ }^{+}$ \\
\hline \multirow[t]{2}{*}{$\mathrm{HCOOC}_{2} \mathrm{H}_{5}$} & $\mathrm{CH}_{3} \mathrm{CH}_{2} \mathrm{CH}_{2} \mathrm{OH}$ & 0,5 & 0,5 & 6,8 & 1,5 \\
\hline & & 0,5 & 2,3 & 1,6 & 1,2 \\
\hline $\mathrm{HCOOC}_{2} \mathrm{H}_{5}$ & $\left(\mathrm{CH}_{3}\right)_{2} \mathrm{CHOH}$ & 0,9 & 0,9 & 2,1 & 0,48 \\
\hline \multirow[t]{2}{*}{$\mathrm{HCOOCH}{ }_{2} \mathrm{CH}_{2} \mathrm{CH}_{3}$} & $\mathrm{CH}_{3} \mathrm{CH}_{2} \mathrm{CH}_{2} \mathrm{OH}$ & 0,5 & 0,5 & 16,5 & 4,3 \\
\hline & & 2,0 & 2,0 & 4,6 & 1,0 \\
\hline \multirow[t]{2}{*}{$\mathrm{HCOOCH}_{2} \mathrm{CH}_{2} \mathrm{CH}_{3}$} & $\left(\mathrm{CH}_{3}\right)_{2} \mathrm{CHOH}$ & 0,6 & 0,6 & 6,4 & 1,6 \\
\hline & & 2,0 & 2,0 & 2,4 & 0.57 \\
\hline $\mathrm{HCOOCH}\left(\mathrm{CH}_{3}\right)_{2}$ & $\left(\mathrm{CH}_{3}\right)_{2} \mathrm{CHOH}$ & 1,0 & 1,0 & 6,7 & 0,58 \\
\hline \multirow[t]{2}{*}{$\mathrm{ClCOOC}_{2} \mathrm{H}_{5}$} & $\left(\mathrm{CH}_{3}\right)_{2} \mathrm{CHOH}$ & 0,5 & 2,0 & 7,3 & 3,5 \\
\hline & & 2,0 & 2,0 & 1,9 & 2,4 \\
\hline \multirow[t]{2}{*}{$\mathrm{CF}_{3} \mathrm{COOC}_{2} \mathrm{H}_{5}$} & $\left(\mathrm{CH}_{3}\right)_{2} \mathrm{CHOH}$ & 1,0 & 1,0 & 2,5 & 0.66 \\
\hline & & 2,0 & 2,0 & 1,2 & 0,63 \\
\hline
\end{tabular}

a) A Intensidade relativa do produto $\left(R C O_{2} R^{\prime} R^{\prime \prime}\right)^{+}$fol 1 gualada a 1 em cada caso.

b) As Intensidades correspondem à soma dos plcos dos Ions contendo ${ }^{35} \mathrm{Cl}$ e 37 Cl. 

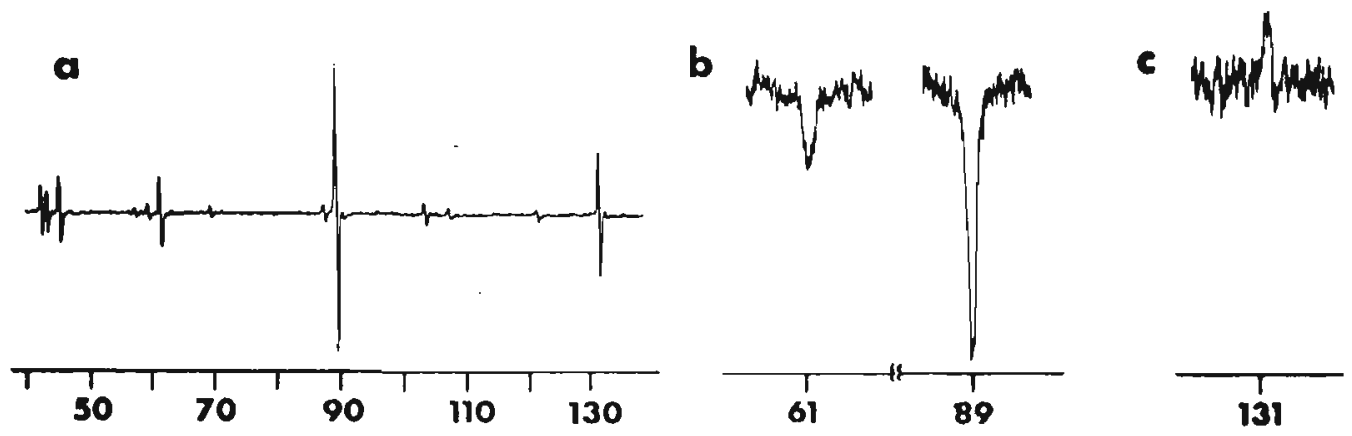

$\mathbf{m} / \mathbf{e}$

FIGURA 6.12. a) Espectro de massa da mistura de for miato de n-propila $\left(2,0 \cdot 10^{-5}\right.$ Torr $)$ e propanol-2 $\left(2,0 \cdot 10^{-5}\right.$ Torr $)$. Espectros de ressonância dupla: b) observa do $\circ$ ion $\mathrm{HCO}_{2}\left(\mathrm{CH}_{2} \mathrm{CH}_{2} \mathrm{CH}_{3}\right)\left(\mathrm{CH}_{3} \mathrm{CHCH}_{3}\right)^{+}(\mathrm{m} / \mathrm{e}$ 131) e irradiados $\left(\mathrm{CH}_{3}\right)_{2} \mathrm{CHOH}_{2}{ }^{+}$(m/e 61) e $\left(\mathrm{HCOOCH}_{2} \mathrm{CH}_{2} \mathrm{CH}_{3}\right) \mathrm{H}^{+}(\mathrm{m} / \mathrm{e} 89)$; oscilador de ressonância dupla: pulsado entre 0 e $10 \mathrm{mV} ; \mathrm{c}$ ) observado o Ion de $\mathrm{m} / \mathrm{e} \quad 89$ e irradiado o de $\mathrm{m} / \mathrm{e} 131$; oscllador de ressonância dupla: pulsado entre 0 e 20 $\mathrm{mV}$.

Um aspecto interessante dessas reações è que os produ tos 1ôn1cos $\mathrm{RCO}_{2} \mathrm{R}^{\prime} \mathrm{R}^{\prime \prime}$ podem decompor posteriormente à sua formação, com eliminação de espēcies neutras, cujas massas corres pondem a olefinas. Este processo é exemplificado pela reação 6.4 . para o caso do produto formado na reação 6.3 .

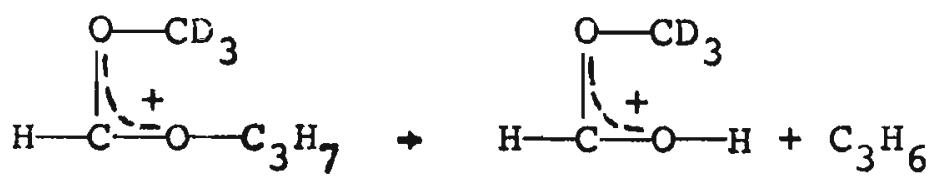

Não fol possivel averiguar se esta decomposição ocorre espontanea- 
mente na cela de ressonância ciclotrônica de íons, mas em todos os casos, acelerando o ion $\mathrm{HCO}_{2} \mathrm{CD}_{3} \mathrm{C}_{3} \mathrm{H}_{7}{ }^{+}$, isto é, comunicando-lhe $\mathrm{e}$ nergia cinética adicional, o processo 6.4. se torna favorável. Is to pode ser visto no caso do sistema da FIGURA 6.12.c, pelo sinal de ressonância dupla positivo; irradiando com o oscila dor de ressonância dupla o ion de m/e 131 e observando ao mesmo tempo o de m/e 89 (formiato de $\mathrm{n}$-propila protonado), verifi cou-se que a intensidade do sinal deste ültimo aumentou, indicando que o primeiro sofreu decomposição com formação de formiato de n-propila protonado. Apesar de ser obtido um dos reagentes de partida nessa decomposição (o éster protonado), não se trata da reação inversa da de formação.

Um fato notável é que a espécie que decompõe sempre o faz, expulsando o resto olefinico proveniente do álcool original. Esse comportamento é exemplificado pela sequência de reações 6.5 . e 6.6 .

$\left(\mathrm{CH}_{3}\right)_{2} \mathrm{CHOH}_{2}^{+}+\mathrm{H}-\mathrm{C}-\mathrm{C}-\mathrm{CH}\left(\mathrm{CD}_{3}\right)_{2}+\mathrm{O}-\mathrm{CH}-\mathrm{CH}\left(\mathrm{CD}_{3}\right)_{2}+\mathrm{H}_{2} \mathrm{O}$

$(6.5$.

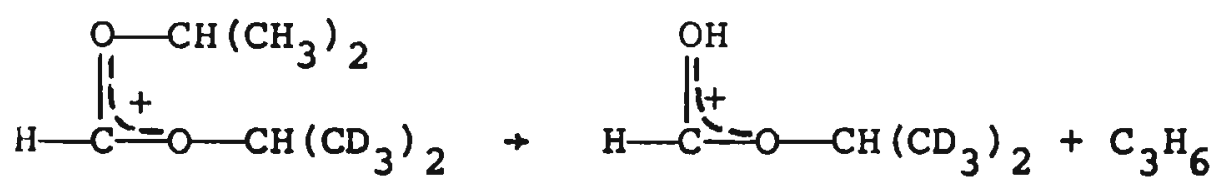

Se os grupos alquila do produto; da reação 6.5. fossem equivalen tes, uma vez que quimicamente são bem semelhantes, ao irradiar o Ion com um campo de rádio-frequência, tanto $\left(\mathrm{HCOOCH}\left(\mathrm{CD}_{3}\right)_{2}\right) \mathrm{H}^{+}$, $\mathrm{Co}-$ mo ( $\mathrm{HCOOCH}\left(\mathrm{CH}_{3}\right) \mathrm{H}^{+}$deveriam ter sido obtidos. Que isto não foi - caso pode ser visto na FIGURA 6.13., onde se observa a forma ção do produto de m/e 137 a partir dos Ions. de $\mathrm{m} / \mathrm{e} 61$, 

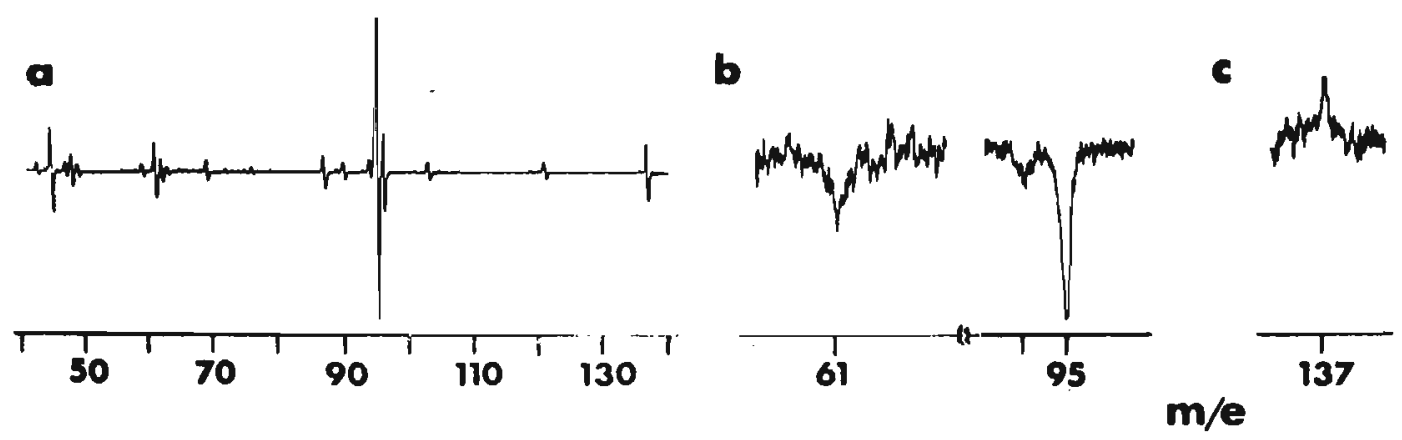

FIGURA 6.13. a) Espectro de massa da mistura de for miato de isopropila-d $6\left(2,0 \cdot 10^{-5}\right.$ Torr; e propanol-2 $\left(2,0 \cdot 10^{-5}\right.$ Torr $)$. Espec tros de ressonância dupla; b) observado 0 Ion $\mathrm{HCO}_{2}\left(\mathrm{CD}_{3} \mathrm{CHCD}_{3}\right)\left(\mathrm{CH}_{3} \mathrm{CHCH}_{3}\right)^{+}(\mathrm{m} / \mathrm{e}$ 137) e irradiados $\mathrm{HCOOCH}\left(\mathrm{CD}_{3}\right)_{2} \mathrm{D}^{+} \quad(\mathrm{m} / \mathrm{e}$ 96), $\mathrm{HCOOCH}\left(\mathrm{CD}_{3}\right)_{2} \mathrm{H}^{+}(\mathrm{m} / \mathrm{e} 95)^{2}$ e $\left.\left(\mathrm{CH}_{3}\right)_{2} \mathrm{CHOH}_{2}^{+}(\mathrm{m} / \mathrm{e} 6 \mathrm{l}) ; \mathrm{c}\right)$ observado 0 Ion de m/e 95 e irradiado o de m/e 137 .

$\left(\mathrm{CH}_{3}\right)_{2} \mathrm{CHOH}_{2}^{+}, 95,\left(\mathrm{HCOOCH}\left(\mathrm{CD}_{3}\right)_{2}\right) \mathrm{H}^{+}, \mathrm{e}, 96,\left(\mathrm{HCOOCH}\left(\mathrm{CD}_{3}\right){ }_{2}\right) \mathrm{D}^{+}$. Po rèm, irradiando o Ion de $\mathrm{m} / \mathrm{e} 137$ só um sinal positivo foi obtido no caso do ion de m/e 95 e, fixando o campo magnético de modo a poder observar um eventual ion de m/e.89 (ou 90), acelerando ao mesmo tempo o ion de $\mathrm{m} / \mathrm{e} 137$, nenhum sinal foi obtido. 0 Ion de m/e 96 tambēm não é formado na decomposição do de m/e 137. Es te tipo de decomposição foi observado em todos os sistemas da TABELA 6.4., tendo sido o resultado sempre o mesmo.

Nas FIGURAS 6.14. e 6.15. estão, a titulo de 1lustraf̧ão, os espectros dos sistemas trifluoroacetato de etila com pro panol-2 e acetato de metila com álcool terciobutilico, respecti- 

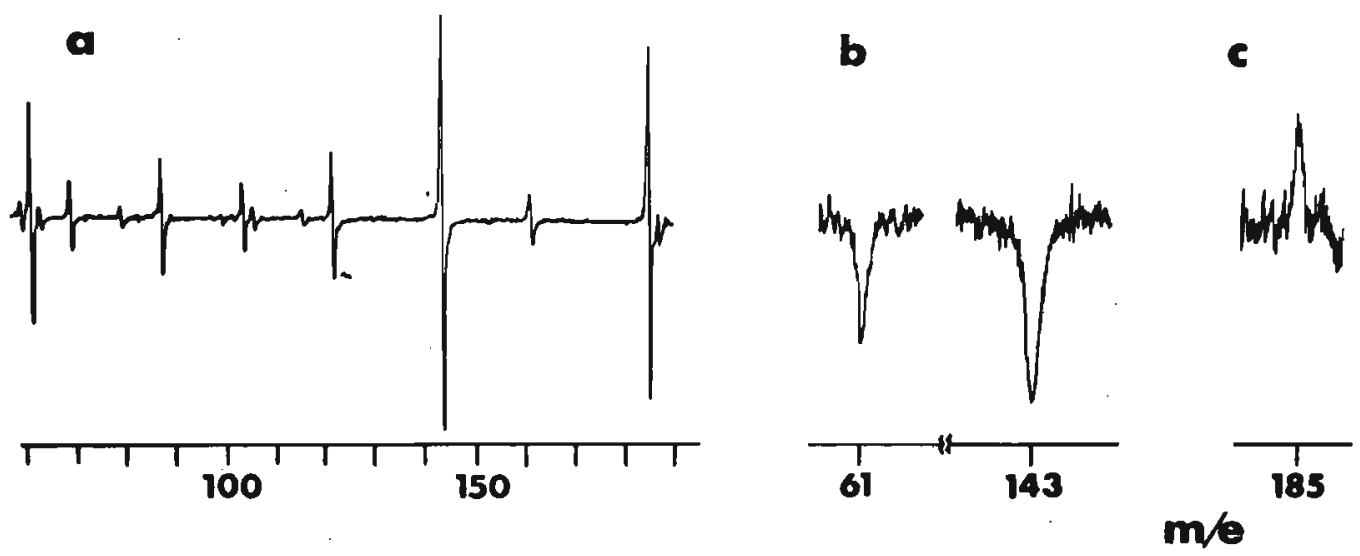

FIGURA 6.14. a) Espectro de massa da mistura de trí fluoroacetato de etila $\left(2,0 \cdot 10^{-5}\right.$ Torr $)$ e propanol-2 (2,0 $\cdot 10^{-5}$ Torr $)$. Espec tros de ressonância dupla: b) observado o Ion $\mathrm{CF}_{3} \mathrm{CO}_{2}\left(\mathrm{C}_{2} \mathrm{H}_{5}\right)\left(\mathrm{C}_{3} \mathrm{H}_{7}\right)^{+}(\mathrm{m} / \mathrm{e}$ 185) e irradiados $\left(\mathrm{CF}_{3} \mathrm{COOC}_{2} \mathrm{H}_{5}\right) \mathrm{H}^{+}$(m/e 143) e $\left.\left(\mathrm{CH}_{3}\right)_{2} \mathrm{CHOH}_{2}^{+}(\mathrm{m} / \mathrm{e} 6 \mathrm{l}) ; \mathrm{c}\right)$ observado do ion de $\mathrm{m} / \mathrm{e} 143$ e irradiado o de $\mathrm{m} / \mathrm{e} 185$.

vamente. Na primeira figura observa-se o ín de m/e 185, formado pelos lons de $\mathrm{m} / \mathrm{e} 61 \mathrm{e} \mathrm{m} / \mathrm{e} 143$. O Ion de m/e 161 corresponde a trifluoroacetato de etila ligado a $\mathrm{H}_{2} \mathrm{O}$ por uma ponte de hidro gênio; no prōprio propanol-2 existem Ions desse tipo (água ligada por ponte de hidrogênio a outra espécie qualquer; Ions de m/e 69 e 79), de modo que è de se esperar que também os forme ao rea gir com o trifluoroacetato. A reação de acetato de metila com àlcool terciobutilico fol estudada, empregando o acetato de meti la na forma deuterada, para que o produto, $\mathrm{CD}_{3} \mathrm{CO}_{2} \mathrm{CD}_{3} \mathrm{C}_{4} \mathrm{H}_{9}{ }^{+}$, tivesse m/e 137 e não coincidisse em massa com o éter diterciobutilico $(\mathrm{m} / \mathrm{e} 131$, vide seção 6.4.). O Ion de m/e 99 se deve a uma oụ tra reação entre acetato de metila e àlcool terciobutilico; tra- 


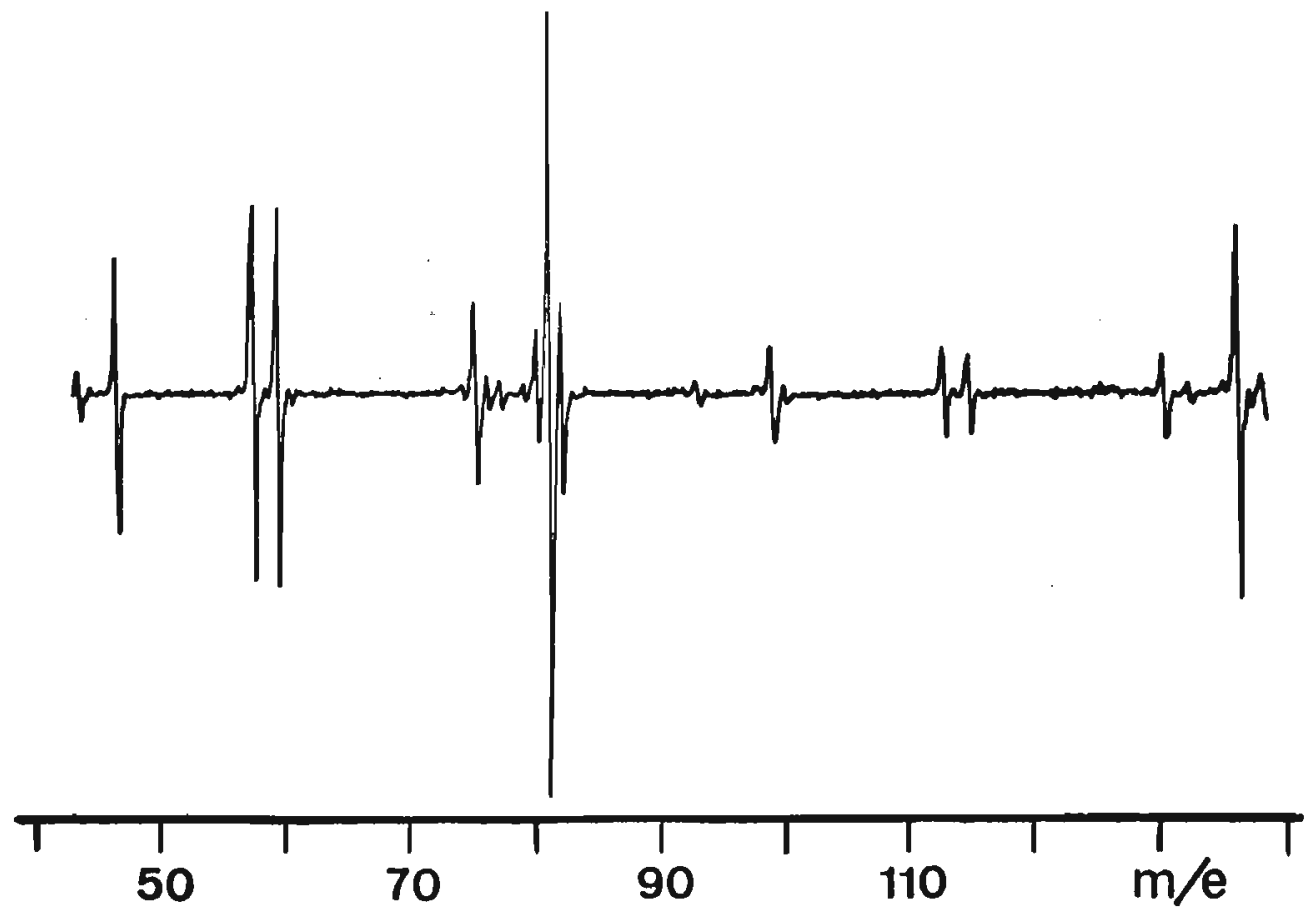

FIGURA 6.15. Espectro de massa da mistura de acetato de metila-d $6\left(2,0 \cdot 10^{-5}\right.$ Torr $)$ e álcool terciobutilico $\left(2,0,10^{-5}\right.$ Torr $) ;$ os Ions de interesse são $\left(\mathrm{CH}_{3}\right)_{3} \mathrm{COH}_{2}{ }^{+}$(m/e 75), $\left(\mathrm{CD}_{3} \mathrm{COOCD}_{3}\right) \mathrm{H}^{+}(\mathrm{m} / \mathrm{e} 8 \mathrm{l})^{2}$ e $\mathrm{CD}_{3} \mathrm{CO}_{2}\left(\mathrm{CD}_{3}\right)\left(\mathrm{C}_{4} \mathrm{H}_{9}\right)^{+}(\mathrm{m} / \mathrm{e} 137)$.

ta-se do éster ligado a água por ponte de hidrogênio.

\subsection{Termoguimica e mecanismos}

Tendo determinado a ordem relativa de afinidades protónicas de alguns dos ácidos, ésteres e álcools envolvidos nas reações atē aqui apresentadas e tendo também valores aproximados des sas afinidades protônicas em alguns casos (capítulo 5), è em prin ciplo possivel examinar os processos de esterificação e transeste rLflcação sob o aspecto termoquímico. As reações das seções 
6.6. e 6.7. podem ser representadas pela equação geral 6.7 .

$$
(\mathrm{RCOOR}) \mathrm{H}^{+}+\mathrm{R}^{\prime \prime O H} \rightarrow-(\mathrm{RCOOR}) \mathrm{H}^{+}+\mathrm{R}^{\prime} \mathrm{OH}
$$

A Eorma usual de escrever o calor de reação de 6.7., è através dos calores de formação das espécies que aparecem na equação:

$\Delta \mathrm{H}=\Delta \mathrm{H}_{\mathrm{f}}\left(\mathrm{RCOOR}^{\prime \prime} \mathrm{H}^{+}\right)+\Delta \mathrm{H}_{\mathrm{f}}\left(\mathrm{R}^{\prime} \mathrm{OH}\right)-\Delta \mathrm{H}_{\mathrm{f}}\left(\mathrm{RCOOR}^{\prime} \mathrm{H}^{+}\right)-\Delta_{\mathrm{f}}\left(\mathrm{R}^{\prime \prime} \mathrm{OH}\right)$

De acordo com a equação 5.6 , os calores de formação das espé cies protonadas podem ser escritos em termos dos calores de formàção das espécies moleculares correspondentes sem o próton, das afinidades protônicas dessas mesmas espēcies, e, do calor de for mação de $\mathrm{H}^{+}$, de modo que $\circ \Delta \mathrm{H}$ de 6.7 . fica:

$$
\begin{aligned}
\Delta H=\Delta H_{f}\left(R C O O R^{\prime \prime}\right)-A P\left(R C O O R^{\prime \prime}\right)+\Delta H_{f}\left(R^{\prime} O H\right)-\Delta H_{f}\left(R C O O R^{\prime}\right)+ \\
\\
\quad+A P\left(R C O O R^{\prime}\right)-\Delta H_{f}\left(R^{\prime \prime O H}\right)
\end{aligned}
$$

(Houve o cancelamento de $\Delta H_{f}\left(H^{+}\right)$.) De acordo com a equação 5.4 . e a suposição de afinidades hidrogeniônicas constantes nos homölogos de áciạos e ésteres, $\circ \Delta H$ da reação 6.7. toma finalmente .a forma:

$$
\begin{aligned}
\Delta H= & \Delta H_{f}\left(R C O O R^{\prime \prime}\right)+P I\left(R C O O R^{\prime \prime}\right)+\Delta H_{f}\left(R^{\prime} O H\right)-\Delta H_{f}\left(R C O O R^{\prime}\right)- \\
& -P I\left(R C O O R^{\prime}\right)-\Delta H_{f}\left(R^{\prime \prime O H}\right)
\end{aligned}
$$

Os calores de formação necessários para calcular o $\Delta H$ Indicado na equação 6.8. estão agrupàdos na TABELA $6.6 . ;$ os potenciais de Ionização estão na TABELA 5.7. Na TABELA 6.7. estão os resultạ dos dos cálculos, isto é os calores de reação dos diversos processos representados pela equação 6.7 . 
TABELA 6.6 .

Calores de formação de alguns ácidos, èsteres e ãlcoo1s. 181

compos to

$\mathrm{HCOOH}$

$\mathrm{CH}_{3} \mathrm{COOH}$

$\mathrm{HCOOCH}_{3}$

$\mathrm{HCOOC}_{2} \mathrm{H}_{5}$

$\mathrm{CH}_{3} \mathrm{COOCH}_{3}$

$\mathrm{CH}_{3} \mathrm{COOC}_{2} \mathrm{H}_{5}$

$\mathrm{H}_{2} \mathrm{O}$

$\mathrm{CH}_{3} \mathrm{OH}$

$\mathrm{C}_{2} \mathrm{H}_{5} \mathrm{OH}$
$\Delta \mathrm{H}_{\mathrm{f}}(\mathrm{kcal} / \mathrm{mol})$

$-90,48$

$-103,31$

$-83,7$

$-89$

$-99,2$

$-106,58$

$-57,796$

$-47,96$

$-56,19$

TABELA 6.7 .

Vàriação de entalpla nos processosa

$$
\left(\mathrm{RCOOR}^{\prime}\right) \mathrm{H}^{+}+\mathrm{R}^{\prime \prime O H} \longrightarrow\left(\mathrm{RCOOR}{ }^{\prime \prime}\right) \mathrm{H}^{+}+\mathrm{R}^{\prime} \mathrm{OH}
$$

\begin{tabular}{|c|c|c|c|c|c|c|c|c|}
\hline \multirow[t]{3}{*}{$\mathrm{R}^{\prime \prime}$} & \multicolumn{4}{|c|}{$R^{\prime}=H$} & \multicolumn{4}{|c|}{$\mathrm{R}^{\prime}=\mathrm{CH}_{3}$} \\
\hline & \multicolumn{4}{|c|}{$\mathbf{R}$} & \multicolumn{4}{|c|}{$\mathbf{R}$} \\
\hline & \multicolumn{2}{|c|}{ H } & \multicolumn{2}{|c|}{$\mathrm{CH}_{3}$} & \multicolumn{2}{|c|}{$\mathrm{H}$} & \multicolumn{2}{|c|}{$\mathrm{CH}_{3}$} \\
\hline $\mathrm{CH}_{3}$ & 14,1 & 14 & 14,3 & 14 & & & & \\
\hline $\mathrm{C}_{2} \mathrm{H}_{5}$ & 17 & 15 & 15,6 & 15 & 2 & 1 & 1,3 & 1 \\
\hline
\end{tabular}

a) Todos os valores dessa tabela são na realldade negativos e dados em $\mathrm{kcal} / \mathrm{mol}$; os da esquerda em cada quadro for am Calculados pela equação 6.8 . os da direlta, pela equação 6.9 . 
Existe outra maneira de escrever $\circ \Delta H$ da reação 6.7 . e que envolve energias de dissociação. Formalmente a reação 6.7 . pode ser considerada como o resultado da seguinte sequência de reações (em cada etapa é indicada a grandeza termoquímtca de interesse, sendo a energia de dissociação da ligação $X-Y$ represen tada por $D(X-Y))$.

$\stackrel{\mathrm{I}}{\mathrm{C}} \underset{+}{\stackrel{\mathrm{O}}{O} \mathrm{R}^{\prime}}+\mathrm{R}-\stackrel{\mathrm{O}}{\mathrm{C}}-\mathrm{OR}^{\prime}+\mathrm{H}^{+}$ $\operatorname{AP}\left(R C O O R^{\prime}\right)$<smiles></smiles>
$D\left(R C O-O R^{\prime}\right)$ $\mathrm{R}^{\prime O} \mathrm{O}-\mathrm{H}+\mathrm{R} " \mathrm{O} \cdot+. \mathrm{H}$ $D\left(R^{\prime \prime O}-H\right)$<smiles>[R7]O[13CH2][13CH2][13C]([R])=O</smiles>
$-D\left(R C O-O R^{n}\right)$

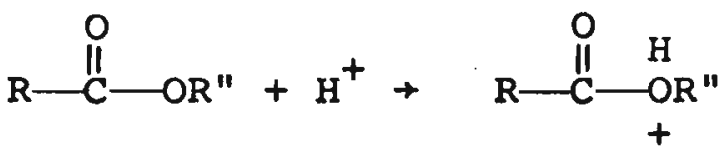
$-A P(R C O O R ")$ $\mathrm{H} .+. \mathrm{OR}^{\prime}+\mathrm{R}^{\prime} \mathrm{OH}$ $-D\left(R^{\prime} O-H\right)$

$$
\begin{aligned}
\Delta H= & A P\left(R C O O R^{\prime}\right)-A P\left(R C O O R^{\prime \prime}\right)+D\left(R C O-O R^{\prime}\right)-D\left(R C O-O R^{\prime \prime}\right)+ \\
& +D\left(R^{\prime \prime O}-H^{\prime}\right)-D\left(R^{\prime} O-H\right)
\end{aligned}
$$

As energias de dissociação empregadas no cálculo de valores de $\Delta H$ através da equação 6.9. encontram-se na TABELA 6.8. Os resultados dos cálculos, empregando a equação 6.9., estão na TABELA 6.7. As diferenças nos valores de $\Delta \mathrm{H}$ obtidos através das equações 6.8 . e 6.9 não são signiflcativas, pols deve-se ter em mente a aproximação feita nos cãlculos das afinidades protônicas (capitulo 5). 
TABELA 6.8 .

Energías de dissociação de algumas ligações em ãcidos, ésteres,ā coois e água. ${ }^{182}$

\begin{tabular}{|c|c|c|}
\hline composto $X Y$ & $D(X-Y)$ & (kcal/mol) \\
\hline $\mathrm{HO}-\mathrm{H}$ & & 119 \\
\hline $\mathrm{CH}_{3} \mathrm{O}-\mathrm{H}$ & & 102 \\
\hline $\mathrm{C}_{2} \mathrm{H}_{5} \mathrm{O}-\mathrm{H}$ & & 102 \\
\hline $\mathrm{HCO}-\mathrm{OH}$ & & $108^{a}$ \\
\hline $\mathrm{CH}_{3} \mathrm{CO}-\mathrm{OH}$ & & $109^{a}$ \\
\hline $\mathrm{HCO}-\mathrm{OCH}_{3}$ & & 94 \\
\hline $\mathrm{HCO}-\mathrm{OC}_{2} \mathrm{H}_{5}$ & & $90^{a}$ \\
\hline $\mathrm{CH}_{3} \mathrm{CO}-\mathrm{OCH}_{3}$ & & 97 \\
\hline $\mathrm{CH}_{3} \mathrm{CO}-\mathrm{OC}_{2} \mathrm{H}_{5}$ & & 96 \\
\hline
\end{tabular}

a) Valores calculados através de $D(X-Y)=\Delta H_{f}(X)+\Delta H_{f}(Y) \quad-$ $\Delta H_{f}(X Y)$, usando os seguintes calores de formação (kcal/mol): 182 OH $9,3, \mathrm{C}_{2} \mathrm{H}_{5} \mathrm{O}-6,7, \mathrm{HCO} 8, \mathrm{CH}_{3} \mathrm{CO}-4$, alēm dos da TABELA 6.6 .

Examinando a TABELA 6.7 ., nota-se que as reações de es teriflcação com metanol e etanol, tanto de ácldo fórmico, como de ácido acético, são exotérmicas, bem como as reações de trans esteriflcação dos ēsteres metilicos com etanol, sendo, porém, a exotermicidade bem menor nesse caso. Todavia, de todas essas reações, só são observadas as reações envolvendo o ácido acét1co. E Interessante também comparar uma reação de esterificação 
com uma, de transferência de próton, ambas envolvendo os mesmos reagentes.

$\mathrm{HCOOH}_{2}^{+}+\mathrm{CH}_{3} \mathrm{OH} H\left(\mathrm{HCOOCH}_{3}\right) \mathrm{H}^{+}+\mathrm{H}_{2} \mathrm{O}$ $\Delta \mathrm{H}=-14, \mathrm{lcal} / \mathrm{mol}$

$\mathrm{HCOOH}_{2}^{+}+\mathrm{CH}_{3} \mathrm{OH} \rightarrow \mathrm{CH}_{3} \mathrm{OH}_{2}^{+}+\mathrm{HCOOH}$ $\Delta \mathrm{H}=-1,0 \mathrm{kcal} / \mathrm{mol}^{160}$

Apesar de a primeira reação ser termodinamicamente mais favorā vel, è a segunda a que ocorre. Obviamente a primelra reação en volve um rearranjo eletrônico muito maior, o que a desfavorece. ${ }^{183}$

Pelo visto acima percebe-se que não basta a reação ser exotérmica para ser observada. Atentando para as reações de esterificação de ãcido fórmico e ãcido acético com metanol e etanol, todas exotërmicas, nota-se que elas ocorrem, se a afinidade protônica do ácido é maior que a do ãlcool. Este comportamen to é anālogo ao de reações de substituição nuclēofila em fase gasosa, envolvendo reagentes protonados, as quals ocorrem, se dois critērios são satisfeitos: a) a reação é exotérmica; b) a transferêncla de próton do substrato protonado para o reagente nu cleōfllo é endotérmica. ${ }^{184-186}$ Estes critérios foram estabelecidos pela primeira vez, ${ }^{184}$ ao ser observado o seguinte:

$\mathrm{CH}_{3} \mathrm{ClH}^{+}+\mathrm{H}_{2} \mathrm{O} \longrightarrow\left[\begin{array}{cc}\mathrm{CH}_{3}-\mathrm{Cl} \\ \\ \mathrm{H} \longrightarrow{ }_{\mathrm{H}}\end{array}\right]+\mathrm{H}_{3} \mathrm{O}^{+}+\mathrm{CH}_{3} \mathrm{Cl}$

$$
\mathrm{CH}_{3} \mathrm{CH}_{2} \mathrm{ClH}^{+}+\mathrm{H}_{2} \mathrm{O} \longrightarrow\left[\begin{array}{c}
\mathrm{CH}_{3}-\mathrm{CH}_{2}-\mathrm{Cl} \\
\\
\mathrm{H}
\end{array}\right.
$$


Essas quatro reações são exotērmicas, mas a ordem de basicidade dos compostos participantes ē $\mathrm{CH}_{3} \mathrm{CH}_{2} \mathrm{Cl} \times \mathrm{H}_{2} \mathrm{O}>\mathrm{CH}_{3} \mathrm{Cl}$, de modo que o primeiro complexo intermediärio decompõe com transferência do próton para $\mathrm{H}_{2} \mathrm{O}$, enquanto que o segundo decompõe, havendo trans ferência do próton para $\mathrm{CH}_{3} \mathrm{CH}_{2} \mathrm{Cl}$, O que possibilita um ataque nucleófilo ao cloreto de alquila por parte da áqua.

Mecanismos semelhantes podem ser escritos para as reações dos ácidos fórmico e acético com metanol, por exemplo.

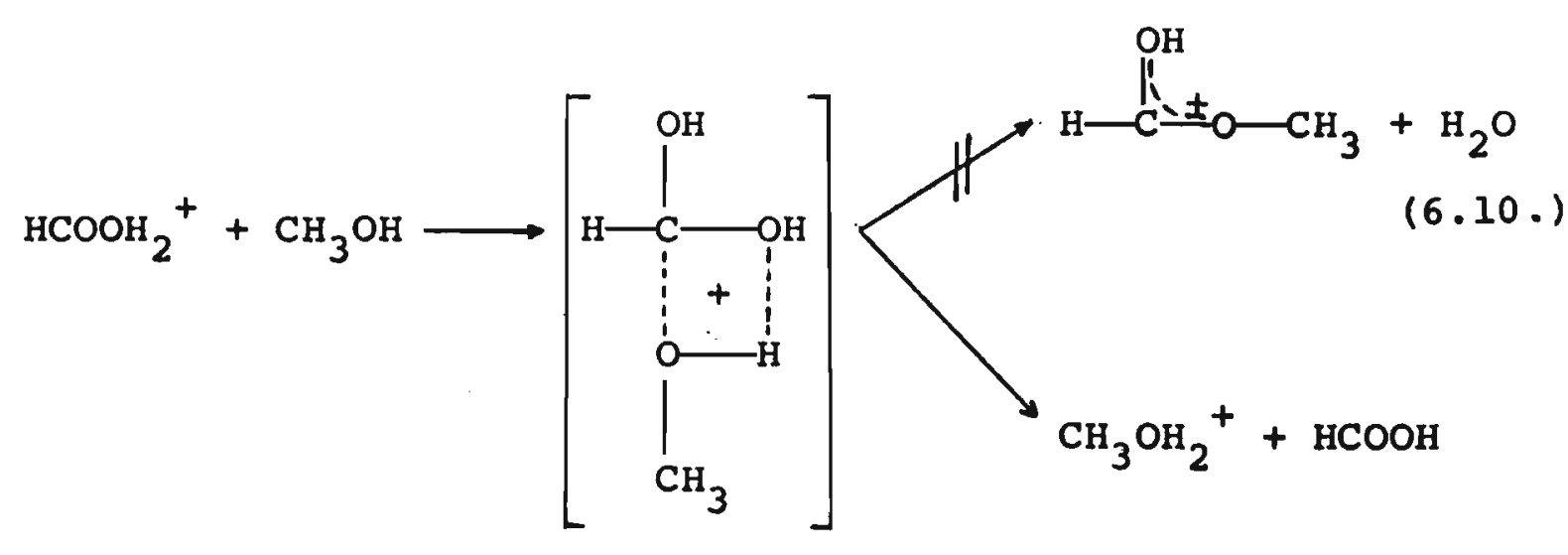

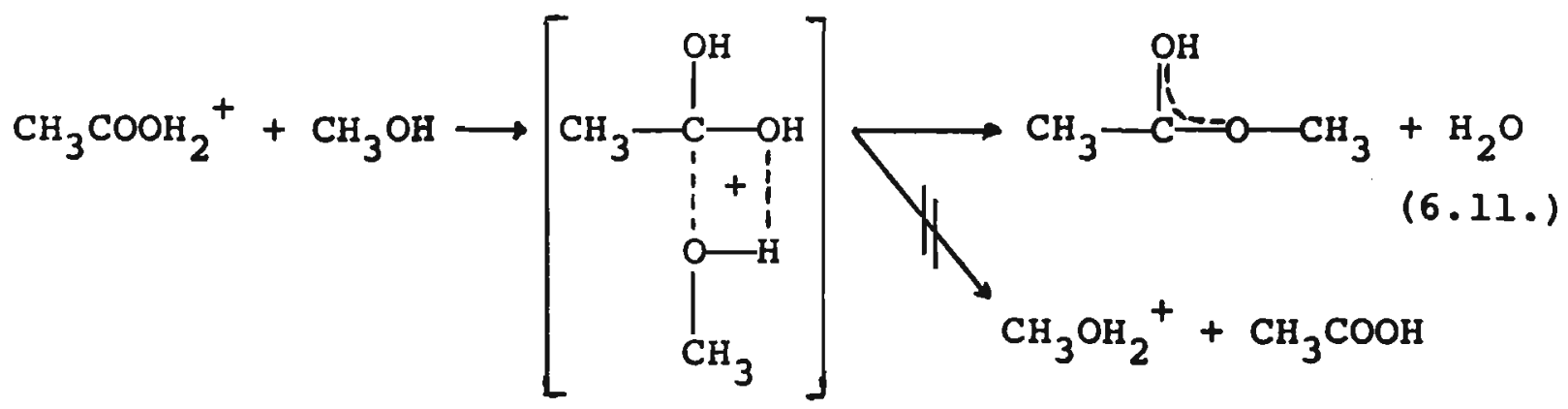

Deve-se notar que há diferença importante entre o mecantsmo aqui apresentado e o da referência 184 (reações dos clọ retos de alquila), com base nas quats os critérios de substituí ção nucleófila em fase gasosa foram desenvolvidos. A diferença consiste no seguinte: Nos cloretos o ataque nucléofilo se dá em 
carbono,saturado, enquanto que nos ácidos se dá num íon de carbô nio. No entanto, tudo indica que as regras sejam as mesmas:Quan do o reagente nucleófilo, isto é, o álcool, tem afinidade protônica menor que o substrato, isto é, o ácido, ocorre a reação de esterificação, pois a transferência de prōton do ālcool para o ácido è endotērmica; este è o caso do ācido acético, pois $\mathrm{AP}\left(\mathrm{CH}_{3} \mathrm{COOH}\right)>\operatorname{AP}\left(\mathrm{CH}_{3} \mathrm{OH}\right)$ (capitulo 5); no caso do ácido fórmico, $\operatorname{AP}(\mathrm{HCOOH})<\operatorname{AP}\left(\mathrm{CH}_{3} \mathrm{OH}\right)$, e só se obtém a transferência de próton.

A posição inicial do próton läbil (no ácido ou no ál cool) não deveria afetar o mecanismo, pois uma rápida transferên cia de próton é provável no complexo intermediário. De fato, é isto o que acontece quando metanol e etanol reagem com ácido acético, havendo, entretanto, mudança de mecanismo quando propa nol-2 e álcool terciobutilico reagem. Pouco depols de os resultados do presente trabalho terem sido enviados para Journal of The American Chemical Society, 168 Beauchamp, em comunicação partıcular, 187 relatou estudos de esterificação de ācido acético com metanol, etanol, propanol-2 e àlcool terciobutílico, empregando oxigênio-18. Experiências com esse isótopo obviamente permiti ram saber qual a ligação que se rompe na esterificação em fase gasosa, o que não pôde ser estabelecido através dos nossos dados. Além disso permitiram detectar dois mecanismos distintos, dependendo da posição inicial do próton lábil. Devido à relevân cia desses estudos para com os relatados nesse capitulo, os mesmos serão aqui discutidos.

Usando äcido acético com 21,48 de oxigênio-18, o produto iônico (acetato protonado) reteve $50 \pm 58$ de oxigênio marcado nas reações 6.12. e 6.13. Na reação 6.14., mais de 958 desse isótopo ficou retido no produto iônico. Isto fol explicado atra vés dos seguintes mecanismos: 
1) Prótọn lābil inicialmente ligado ao ácido:

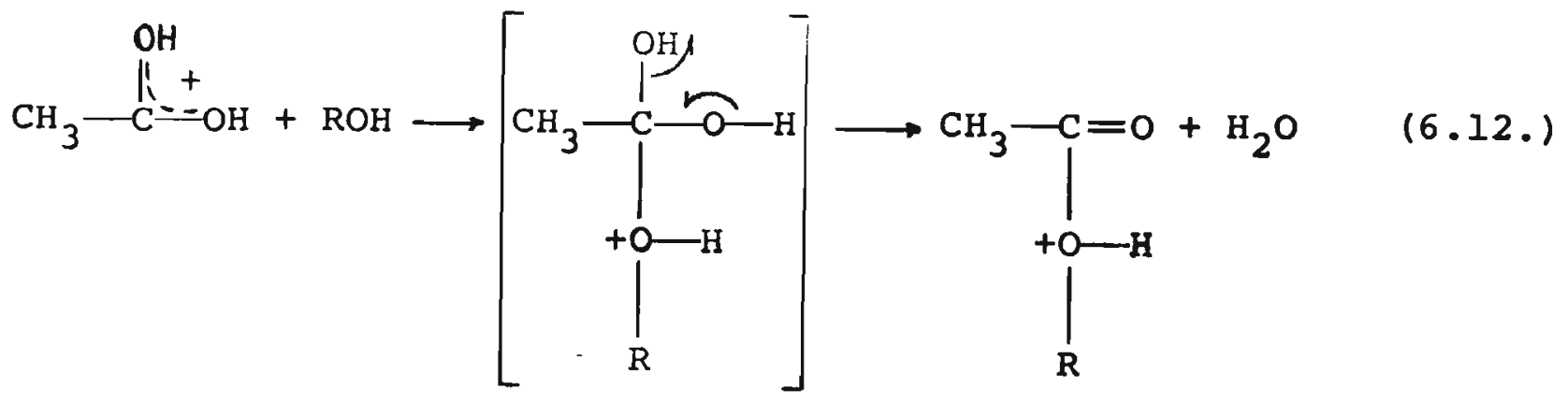

2) Próton lábil inicialmente ligado ao álcool:

$\mathrm{CH}_{3}-\mathrm{COOH}+\mathrm{ROH}_{2}^{+} \longrightarrow\left[\mathrm{CH}_{3}-\mathrm{CH}_{\mathrm{OH}}^{\mathrm{C}}\right]$

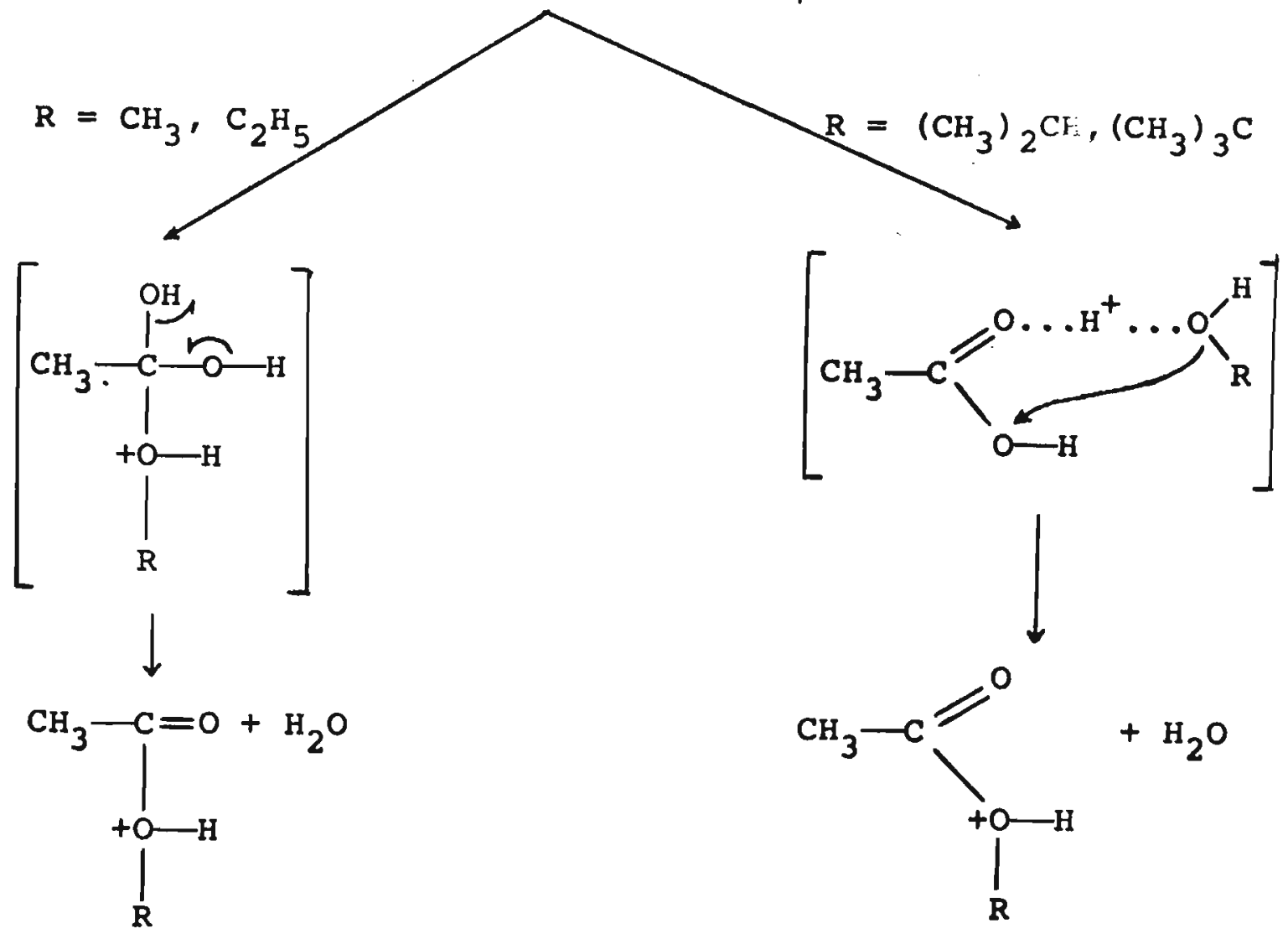

$(6.13$. 
Nas reações 6.12. e 6.13. qualquer um dos dois grupos OH do complexo intermediário pode sair com a água, de modo que estatisticamente $60 \%$ de oxigênio marcado permanece no produto. A forma de decomposição do complexo intermediārio nessas reações foi indicada de maneira diferente do que nas reações 6.10. e 6.11.,mas os dols processos não sạo na realidade distinguíveis. Hã rompị mento de uma ligação acila-oxigênio. Na reação 6.14. o oxigê nio da āgua provém do álcool, de modo que todo o ofigênio-18 existente no ácido aparece no produto iônico. Nenhuma ligação acila-oxigênio è rompida.

Foi visto na seção 6.6. que ãcido fórmico não esterifica com metanol ou etanol (o que foi racionalizado acima), fazendo-o, no entanto, com propanol-2, butanol-2 e álcool terciobutílico. Isto sugere uma mudança significativa no mecantsmo de reação ao passar para esses álcoois superiores. Um ataque nucleó filo, por exemplo de propanol-2 (protonado ou não), pode ser praticamente excluído, pois tal processo não é observado com os àlcoois de cadeia menor, apesar de propanol-2 ser em princípio um reagente nucleófilo melhor. Portanto, a estrutura do álcool parece ser um fator importante nesse mecanismo.

o fato de todos os formiatos reagirem com esses mesmos àlcoois superiores e não, com metanol e etanol, isto é, mostrando comportamento igual ao do ácido fórmico, sugere que o processo seja o mesmo quando reagem ésteres e ácido. o produto da reação de ácido förmico sempre teria a estrutura de un éster pro tonado, não sendo a reação distinguỉvel da de esteriflcação dire ta.

Produtos análogos aos descritos na seção 6.8. foram observados em estudos de ionização química.188,189 Usando metano como gās reagente, ${ }^{188}$ os seguintes Ions são capazes de iniciar 
uma reação: $\mathrm{CH}_{5}{ }^{+}, \mathrm{C}_{2} \mathrm{H}_{5}{ }^{+} \mathrm{e}_{3} \mathrm{C}_{5}{ }^{+}$. Quando $\mathrm{C}_{2} \mathrm{H}_{5}{ }^{+}$reage com um propanoato, supôs-se que possa haver um ataque ao grupo carboxila em qualquer um dos dois oxigênios, formando-se um complexo inter mediārio de estabilidade moderada.

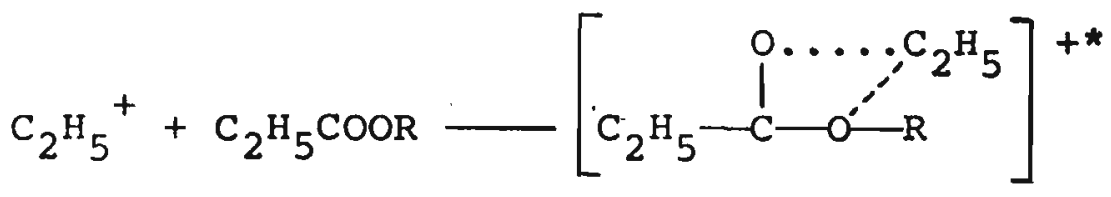

As linhas pontilhadas foram usadas para indicar ataque em qual quer um dos oxigênios; na publicação ${ }^{188}$ esse aspecto não foi dis cutido em detalhe. Este complexo pode então reaglr de várias maneiras. Em primeiro lugar, pode dissociar reversivelmente, for necendo os reagentes:

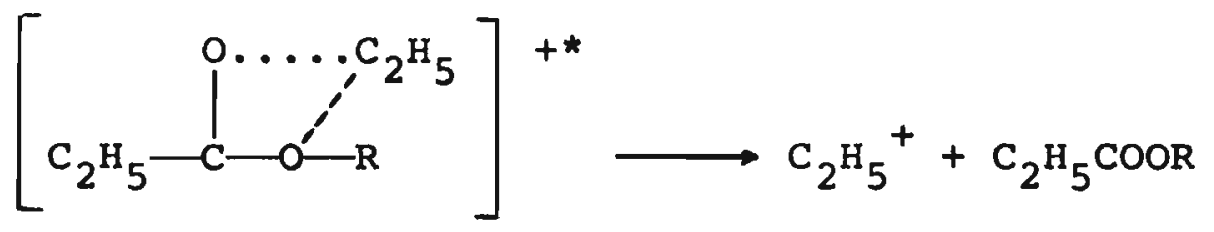

Pode colidir com uma espécie neutra a ser estabilizado:

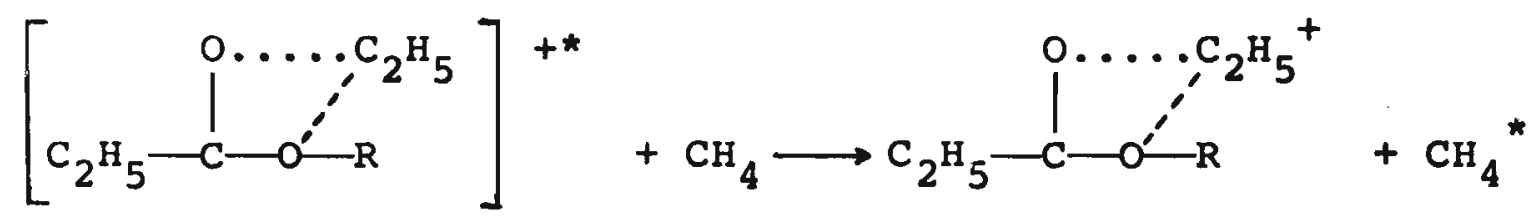

Pode eliminar etileno: esta reação corresponde à transferência de pröton entre os reagentes.

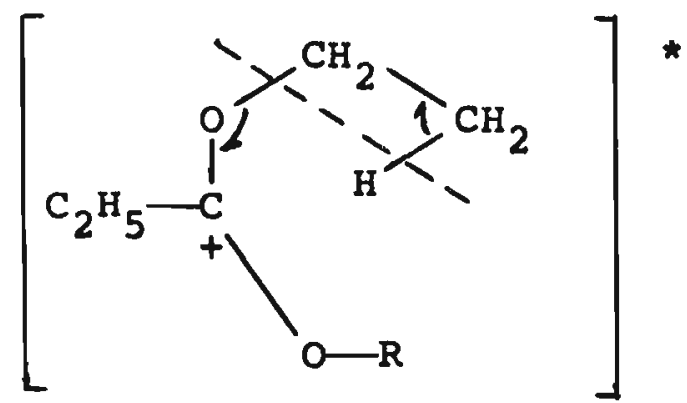

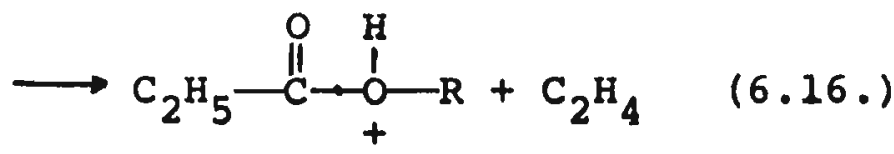

Se $\underline{R}$ for conveniente, pode haver eliminação da olefina apropriada. 


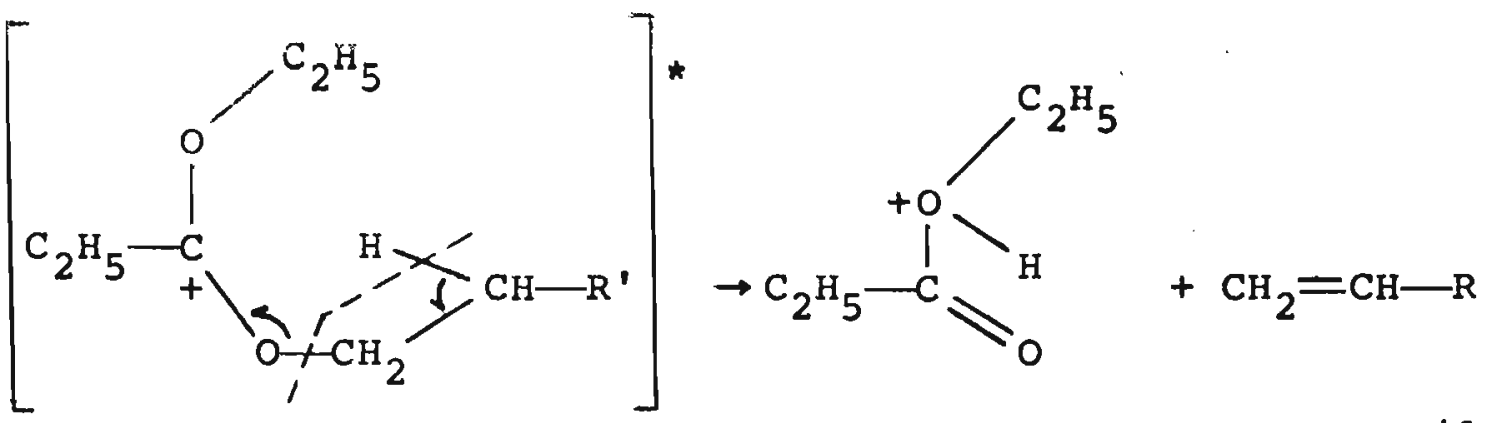

Nestas duas últimas reações o mecanismo foi escrito, supondo os dois grupos alquila ligados a oxigênios diferentes, mas mecanis mos equivalentes podem ser escritos para os grupos alquila liga dos ao mesmo oxigênio.

Essas reações, observadas num espectrômetro de massa, usando a técnica de ionização quỉmica, têm uma implicação inte ressante no presente caso. Se o tipo de produto mencionado na seção 6.8., análogo ao da reação 6.15., for decorrente de um atạ que de ion de carbônio, o seguinte mecanlsmo pode ser proposto para as reações da seção 6.8 .:

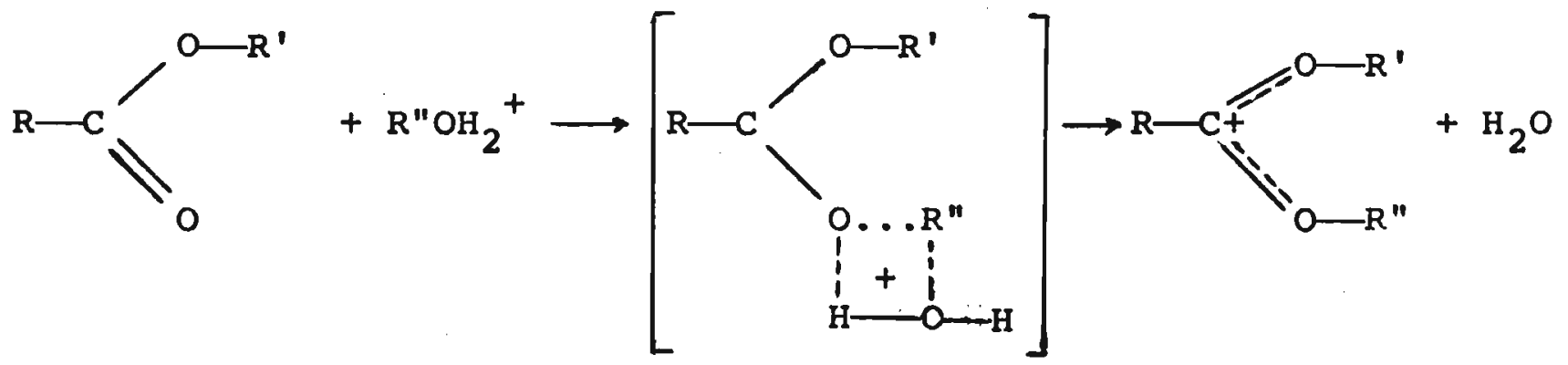

Esse Intermediário é obviamente pura especulação, mas pelo fato de só reagirem álcoois capazes de formar Ions de carbônio de certa es tabilidade (secundārios ou terciārios, mesmo que 1sto envolva um rearranjo), atravës de eliminação de água dos Ions moleculares pro tonados, parece que ataque de ion de carbônto e eliminação de água são importantes nessa reação. De fato, os espectros de ressonân - 
cia ciclotrônica de ions de metanol e etanol não apresentam picos correspondentes aos ions $\mathrm{CH}_{3}{ }^{+} \mathrm{e}_{2} \mathrm{H}_{5}{ }^{+}$, respectivamente, enquanto que nos espectros dos propanōis e butanóls $\mathrm{C}_{3} \mathrm{H}_{7}^{+}$e $\mathrm{C}_{4} \mathrm{H}_{9}{ }^{+}$, respectivamente, aparecem. Somente esses ūltimos álcoois reagem com ēsteres. Evidências mais diretas a favor ou contra esse mecanismo só poderiam ser obtidas com ésteres e älcools marca dos com oxigênio-18. Uma tentativa de substituir oxigênio por enxôfre, ou melhor, de realizar uma experiência com propanotiol2 em lugar de propanol-2, falhou, e o composto de enxofre mos trou-se em fase gasosa multo menos reativo que o composto corres pondente de oxigênio.

De acordo com o mecanismo proposto, o produto tem a estrutura de um acetal (I), mas uma estrutura de ion de oxônio(II) não pode ser excluída e, realmente, ambas foram postuladas como sendo possíve1s. 188

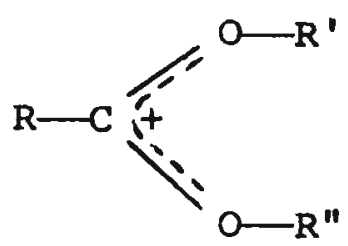

(I)

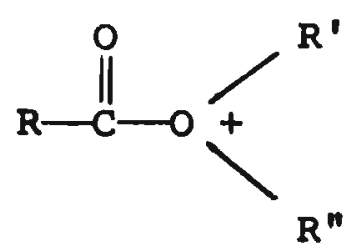

(II)

Considerações qualitativas em termos de deslocallzação de carga favoreceriam talvez a estrutura $I$, uma espécie normalmente encon trada nos espectros de ortoésteres. 190 Deve-se notar que nas duas estruturas os dois grupos alquila são equivalentes, o que todavia não corresponde às observações. Na seção 6.8 . foi mencionado que, irradiando o ion com uma rădio-frequêncla, ele decompõe, eliminando olefina, a qual sempre provëm do álcool que originalmente reagiu e nunca do grupo alquila jā existente no éster. Isto sugere que no produto iônico os grupos alquila man- 
tëm sua 'identidade (por exemplo, nas reações 6.5.e 6.6., $\mathrm{R}^{\prime}=$ $\mathrm{CH}\left(\mathrm{CH}_{3}\right)_{2}$ e $\mathrm{R}^{\prime \prime}=\mathrm{CH}\left(\mathrm{CD}_{3}\right)_{2}$, e não há mistura de hidrogênios e deutérios) e que a ligação recēm-formada não perde totalmente o excesso de energia vibracional, de modo que numa reação posterior é esta a ligação que rompe. Nas experiências de iontzação quími $\mathrm{ca}^{188}$ a pressão é muito maior que nas de ressonância ciclotrônica de Ions; por isso o produto iônico pode ter relaxado todo o exces so de energia vibracional, tornando-se os dois grupos alquila efe tivamente equivalentes. De acordo com essas idéias estão as reações 6.16. e 6.17., que mostram que sob condições de pressão alta o produto lônico decompõe, eliminando olefina tanto de um, como de outro grupo alquila.

Não existem na literatura dados adequados para caicular. os caiores das reações discutidas na seção 6.8. Fol encontrado apenas o calor de formação da espécie $\mathrm{HC}\left(\mathrm{OCH}_{3}\right)_{2}^{+}$, obtido por meio de medidas de potenclais de aparecimento: ${ }^{191} \Delta \mathrm{H}_{\mathrm{f}}\left[\mathrm{HC}\left(\mathrm{OCH}_{3}\right)_{2}^{+}\right]=$ $109 \mathrm{kcal} / \mathrm{mol}$. Empregando calores de formação da TABELA 6.6. e o calor de formação de $\mathrm{CH}_{3} \mathrm{OH}_{2}{ }^{+}$da referência $160(139,0 \mathrm{kcal} / \mathrm{mól})$,é possĩveí calcular o calor da seguinte reação hipotética:

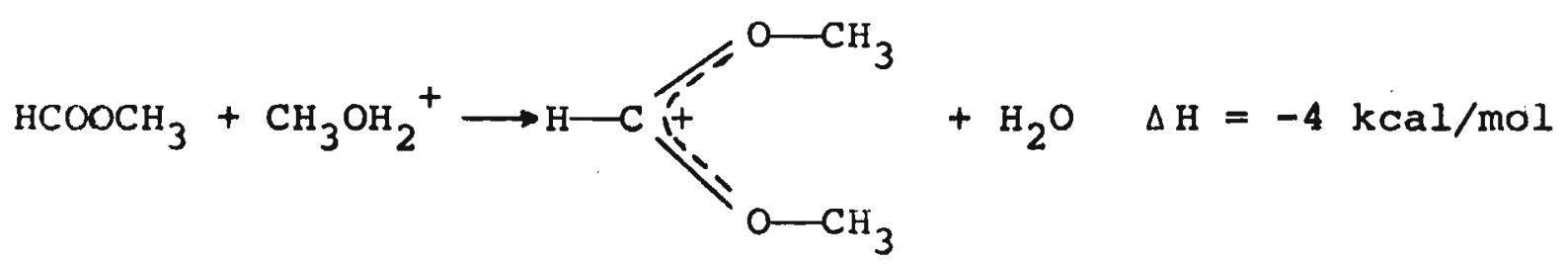

A reação é hipotētica, pois metanol não reage dessa maneira; sõ os álcoois a partır do propanol. Talvez a exotermicldade da reação seja maior que $4 \mathrm{kcal} / \mathrm{mol}$, pois o calor de formação de $\mathrm{HC}\left(\mathrm{OCH}_{3}\right)_{2}{ }^{+}$indicado é na realidade um limite supertor, mas de qualquer maneira, ela não ocorre. Logo, mais uma vez, as estrutú rasde álcool e éster parecem ter grande importância. 
- Propanol-2 não reage com acetatos, fazendo-o, no entanto, com formiatos, cloroformiatos e trifluoroacetatos (TABELA

6.4.). Logo, não são fatores estéricos que inibem a reação, mas um efeito indutivo -I (atração de elétrons) devido ao grupo liga do ao carbono carbonilico, favorece a reação. Por outro lado, acetatos reagem com álcool terciobutillco, que è mais básico que propanol-2; logo, a afinidade protônica maior do álcool pode compensar um fator desfavorāvel no èster. Mais uma vez as afinidades protônicas relativas dos reagentes desempenham um papel 1m portante na reatividade de compostos em fase gasosa.

Nesse capitulo foi mostràda a importâncla de estudos da quimica de Ions em fase gasosa para estabelecer uma correlação correta entre estrutura e reatividade Intriseca, mesmo para' as reações mats comuns em quimica. 
7. ESPECTROSCOPIA DE RESSONANCIA CICLOTRONICA DE IONS PULSADA

Os princípios básicos do espectrômetro de ressonância ciclotrônica de íons empregado nos estudos relatados nesta tese foram apresentados na seção 2.3.3. e, na seção 4.3., detalhes de construção e operação foram dados. Esse espectrômetro, fabrica do pela Varian, opera de forma continua e faz uso da cela de arraste de três regiões (FIGURA 2.5.). Na seção 2.4. foram discutí das as vantagens da operação pulsada e da cela de aprisionamento, de uma região só (FIGURA 2.8.); estas vantagens são: tempos de reação dos ions mais bem definidos e retenção dos ions por um tempo maior na cela. Houve por isso interesse em modificar o espectrömetro existente de maneira a poder operä-lo opcionalmente de forma pulsada. Um espectrômetro capaz de funcionar apenas desta forma pulsada foi fabricado durante algum tempo pela BFI Asso ciates (California, USA); atualmente a Dynaspec (California, USA, constrói um espectrômetro de ressonância clclotrônica de ions para operação continua e pulsada, que, porém, è dotado de uma cela um pouco diferente. 63

Houve sucesso nas modificações efetuadas no espectrôme tro. A relação sinal/ruído é por enquanto menor que a consegui da por outros. 52 Isto se torna problemático ao trabalhar com ions negativos, quando se têm correntes lônicas bem menores que no caso de Ions positivos; fol, contudo, possivel observar íns negativos primários. Outro problema è devido ao oscilador margi nal (FIGURA 2.1.), que possui no estāglo de āudio um filtro RC que degrada ligelramente o sinal de ressonância clclotrônica de Ions pulsada. Isto serä mostrado na seção 7.2. No entanto, al- 
guns aperfeiçoamentos simples podem ser realizados, que certamen te melnorarão o desempenho do espectrômetro. Isto tambēm será discutido na seção 7.2 .

Inicialmente será descrita a construção da cela de aprisionamento e em seguida, a de alguns circuitos elétricos necessários para a aplicạ̧ão dos pulsos nos diversos eletrodos da cela. O diagrama geral do instrumento modificado também será apresentado. Finalmente serão mostrados alguns resultados: espectros e curvas cinéticas. Esses resultados apenas comprovam o funcionamento do espectrômetro, mas não trazem informações quími cas novas que possam complementar ou ampliar os resultados men cionados nos capitulos 4,5 e 6 , pois, antes mais alguns aperfei çoamentos são necessārios. E por isso que essa modificação instrumental é apresentada como um último capítulo nesta tese.

\subsection{A cela de aprisionamento}

A cela de aprisionamento (FIGURA 2.8.) foi montada,pax tindo de uma cela de très regiões (FIGURA 2.5.), orıgınal Varian. Esta cela é constituía por placas de cobre prateadas, fixas e postes de cerâmica por meio de grampos. As placas que formam o coletor de ions foram simplesmente removidas. A separa ção entre as placas de arraste inferior e superior fol aumentada de $1,27 \mathrm{~cm}$ para $2,54 \mathrm{~cm}$; isto provavelmente aumenta o tempo pelo qual os ions podem ser aprisionados na cela, pois mais difi cilmente atingem as paredes da mesma. As placas de arraste supe riores das regiões fonte e analisadora foram ligadas mecanicamente e eletricamente; o mesmo foi feito com as placas inferio res; assim a cela passou a ter apenas uma região. 0 oscilador marginal fol ligado à placa inferior. Foram montadas tambēm 
duas placas terminais, de tela de arame (como essas placas fecham a cela, é conveniente que sejam perfuradas, para que não hạ ja um gradiente de pressão entre interior e exterior da cela).

o bloco do filamento foi substituido por um de nitreto de boro e dotado de uma grade; trata-se de uma placa de aço Inoxidável com um furo de $2 \mathrm{~mm}$ de diâmetro. Entre o bloco do filamento e a placa de aprisionamento foi colocada outra grade, de tela de arame (o mesmo material das placas terminais), em con tato com a placa de aprisionamento, para atenuar a penetração dos potenciais de grade e filamento na cela. Idêntica providência foi tomada do lado do coletor de elētrons.

\subsection{Circuitos de pulsos}

Foi visto na seção 2.4.2. que a espectroscopia de ressonância ciclotrônica de ions pulsada se baseia numa sequência de três pulsos (FIGURA 2.9.): pulso do feixe eletrônico, aplicado na grade de controle, para a formação de ions; pulso de deteć çäo, aplicado nas placas de aprisionamento, para por Ions de dada relação massa/carga em ressonância com o oscilador marginalie, pulso de destruição, aplicado na placa superior da cela, para interromper a faculdade de aprisionamento da cela e eliminar todos os íons. Porém, nesses eletrodos (grade, placas de aprisio namento e placa superior) estão tambēm tensões continuas; even tualmente são aplicadas ainda tensōes alternadas de alta fre quência, para experiências de ejeçäo de elétrons e de ressonân cla dupla. Então são necessārios circuitos que somem adequadamente pulso, tensāo contínua e tensāo alternada. Estes circui tos for am construídos e encontram-se esquematizados na FIGURA 7.1 . 

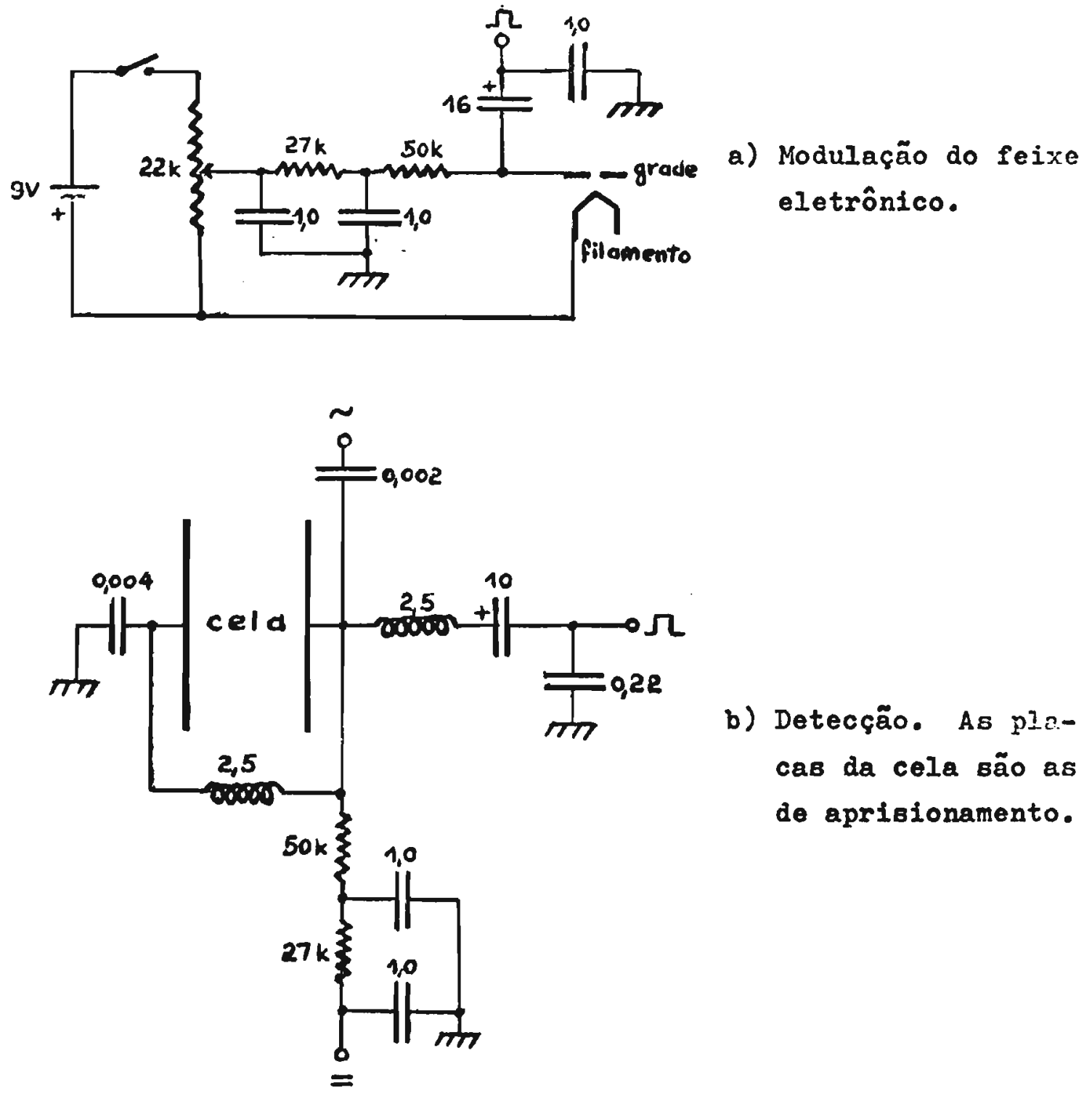

b) Deteç̧̃o. As placas da cela são as de aprisionamento.

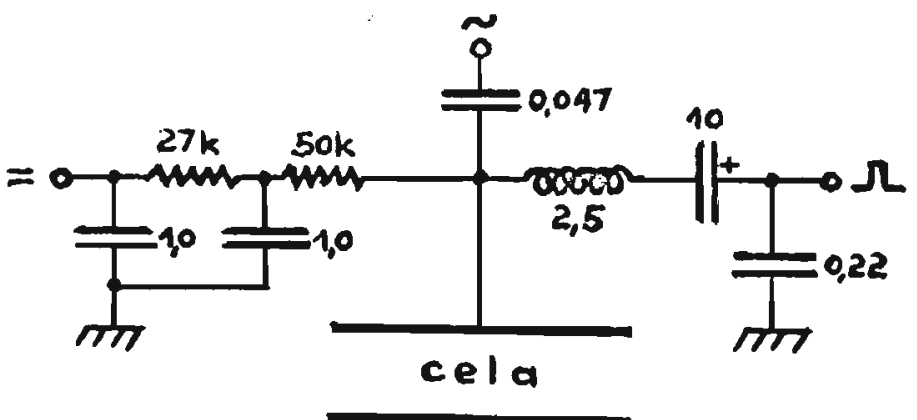

c) Destruição. $\mathrm{O}_{5}$ componentes eletrônicos estão ligados na placa superior da cela.

FIGURA 7.1. Circuitos de pulsos. Os valores de resistências, cepacitâncias e indutâncias são dados, respectivamente, em $\Omega, \mu F$ e $\mathrm{mH}$. Em $\underline{b}$ e os condensadores têm a polaridade adequada para a observação de lons positivos. 
A grade de controle è sempre colocada num

potencial mais negativo que o filamento, de modo a barrar o feixe de elétrons; periodicamente é pulsada para um potencial mais positivo, para a formação de ions. Entāo è conveniente tomar como referên cia do potencial da grade ofilamento e não, a "terra". Uma piIha de $9 \mathrm{~V}$ e um potenciōmetro de $22 \mathrm{k} \Omega$ (FIGURA 7.1.a) permitem va riar o potencial da grade entre 0 e $-9 \mathrm{~V}$ em relação ao filamento: o pulso (positivo) chega à grade através de un condesador eletro litico de $16 \mu \mathrm{F}$; esse condesador impede que a tensäo contínua fornecida pela pilha sofra uma queda através do gerador de pulsos (Tektronix, tipo 163; Tektronix, Inc., Beaverton, Oregon, USA); por sua vez, o pulso é impedido de chegar ao filamento (através da pilha) por uma resistência de $77 \mathrm{k} \Omega$. O condensador de $1 \mu \mathrm{F}$ na entrada do pulso elimina as componentes de Fourier de al ta frequência do pulso; estas componentes causam uma interfe rência no oscilador marginal, que, porém, não afeta o sinal registrado, mas afeta consideravelmente o traço no osciloscópio.Com este esquema è possivel ter pulsos com tempo de duração mínimo de $0,5 \mathrm{~ms}$. Nas experiências a grade é inicialmente colocada no potencial do filamento e a corrente através deste é ajustada para que se tenha a corrente de emissão desejada, lida no amperímetro ligado ao coletor de elētrons (quando a corrente de emissäo è intermitente, este amperímetro não indica o valor māximo desta, mas um valor médio). Em seguida aplica-se na grade um potencial de -7 ou $-9 \mathrm{~V}$ e um pulso positivo ao redor de $+12 \mathrm{~V}$, com uma duração entre 1 e $8 \mathrm{~ms}$; esses valores são adequados para a maioria das experiências.

Como fonte de tensão contínua das placas de aprisionamento é usada a fonte original do espectrômetro; assim o contro le dessa tensão é felto no painel do instrumento, com o potenciô 
metro normalmente usado para esse Eim. Para que o pulso de deteç̧äo possa ser aplicado, é intercalado na ligação dessa tensão à cela, o circuito da FIGURA 7.1.b. O pulso chañ às placas de aprisionamento por um condensador eletrolitico de 10 HF; por causa das duas bobinas, cuja finalidade será discutida logo a seguir, é muito importante eliminar do pulso as componentes de Fourier de alta frequência, pois, devido à auto-indução nas bobị nas, essas componentes criam tensöes de pico muito elevadas nos instantes de subida e descida do pulso. Para isto existe o condensador de $0,22 \mu \mathrm{F}$. Quando se examinam Ions negativos, elétrons térmicos tamieem são aprisionados na cela; muitas substân cias têm uma seção de choque de ionização por elétrons tërmí cos bastante grande; isto significa que ions negativos não são formados apenas durante o pulso na grade, mas durante todo o tem po de reação, o que dificulta a anālise cinētica dos resulta dos. Por isso ë frequentemente interessante ejetar esses elé trons da cela. Na seção 2.3.4.3. foi visto que Ions e, portanto tambēm elētrons, executam um movimento oscilatōrio na direção do campo de aprisionamento e que a amplitude dessa oscilação pode ser aumentáda a ponto de as espécies carregadas atı́ngirem os eletrodos da cela, sendo assim removidos da mesma. Para ejetar elétrons dessa maneira é preciso aplicar uma rádio-frequêncla (de àlguns megahertz nas condições usuais; vide equação 2.18.) nas placas de aprisionamento (em ambas, com a fase invertida, ou, em uma delas, constituindo a outra um "terra" para a rádio-frequência). Com o circulto da FIGURA 7.1.b existe essa possibilidade. A rảdio-frequência chega à placa de aprisionamento do lado do filamento por um condensador de $2 \mathrm{nF}$; uma indutância de 2,5 mH impede que essa tensão alternada chegue à placa de aprisionamento do lado do coletor, a qual constitui um "terra" para rádio-frequênclas de alguns megahertz devido ao condensador de 
$4 \mathrm{nF}$. A indutância de $2,5 \mathrm{mH}$ não impede a passagem do pulso; es te tem que chegar a ambas as placas de aprisionamento, enquanto que a rádio-frequēncia, só a uma delas. Os valores dos componentes deste circuito foram determinados empiricamente.

Finalmente, encontra-se na FIGURA 7.1.c um circuito se melhante para o pulso de destruição na placa superior da cela.Há a possibilidade de acoplar o oscilador de ressonância dupla a essa placa (atravēs do condensador de $47 \mathrm{nF}$ ); neste caso as frequências são mais baixas (centenas de kilohertz), mas uma indu tância de $2,5 \mathrm{mH}$ continua adequada para impedir que a rádiofrequência se perca através dos condensadores de entrada. A ten são contĩnua vem da fonte original do instrumento e è controla da pelo potenciômetro que, no caso da cela de três regiões, é usado para ajustar o potencial na placa inferior da região fonte. Geralmente o pulso de destruição tem uma amplitude de $+10 \mathrm{~V}$ (íons positivos) e uma duração de $5 \mathrm{~ms}$.

Somar pulso e tensão continua da maneira descrita, isto é, empregando condensadores, tem a desvantagem de a tensão contínua efetịvamente atuante depender de amplitude e duração do pulso. Em outras palavras: tem-se dado potencial positivo e soma-se a ele um pulso positivo; se a altura ou a largura do pulso forem aumentadas, o potencial aumentará. Esté problema não exis te se a soma é feita com amplificadores operacionais. 53 No caso dos circuitos da FIGURA 7.1. é preciso ter essa limitação em men te quando se experimentam diversas alturas de pulsos.

Os três circuitos da FIGURA 7.1. foram construídos como circuitos impressos e montados numa caixa metālica, dotada de conetores blindados (BNC) para a introdução dos diversos pulsos e rảdio-frequências. No espectrômetro original, as tensões aplicadas nas placas da cela de três regiões chegam à câmara de 
anālise por dois cabos que terminam em conetores de oito pinos, ligados à base da cela. Na modificação feita, esses cabos foram levados à caixa metálica mencionada acima, foram intercala dos os circuitos, sendo que da caixa saem dois novos cabos, que terminam em conetores de oito pinos e que são ligados à base da cela. Com essa montagem foi possível aproveitar os potenciómetrospara ajustar os potenciais nas diversas placas da cela de aprisionamento. Assim, o potenciômetro da tensão de aprisionamento continua controlando essa grandeza (positiva para ions positivos, negativa para ions negativos); o mesmo vale para o potenciômetro da tensão da placa inferior da cela (negativa para ions positivos, positiva para ions negativos), onde está ligado o oscilador marginal; o potencial da placa superior (negativo para Ions positivos, positivo para ions negativos) è controlado pelo potenciômetro da placa inferior da região fonte da cela de três regiões. Os dois potenciômetros das placas superiores da cela de três regiões tornaram-se inoperantes, pois controlam potenciais de polaridade não aproveitável na cela de' aprisionamento. Nesta cela existem placas terminals que, como têm polaridade oposta àquela dada pelos dois potenclômetros, requereram uma fonte adicional; foi usada uma pilha de $9 \mathrm{~V}$, uma resistência de $50 \mathrm{k} \Omega$, um potenciômetro de $22 \mathrm{k} \Omega$ e uma chave de dois polos e duas posições para poder ajustar esse potencial en tre 0 e $-3 \mathrm{~V}$ (ions positivos) ou entre 0 e $+3 \mathrm{~V}$ (ions negativos); vide a seção 2.4 .1 .

Deve-se notar que, devido ao movimento peculiar dos ions na cela de aprisionamento (seção 2.4.1.), não importa a po laridade do campo magnētico, isto é, não é necessário invertêlo ao passar de Ions positivos para ions negativos (veja tambēm a seção 4.3.); basta inverter os potenclais e os pulsos a- 
plicados nas placas da cela.

o pulso na grade è dado por um gerador Tektronix tipo 163; os pulsos de detecção e destruição, por geradores Tektronix tipo 161. Os geradores dos pulsos de formação de íons (na grade) e de destruição são ajustados de modo a dispararem respectivamente no inicio e no fim de uma base de tempo (dente de serra) gerada pela unidade tipo 162 da Tektronix. O gerador dos pulsos de formação de ions fornece concomitantemente com o pulso normal um outro pulso, de altura fixa $(+25 \mathrm{~V})$; esse pulso è usado para gatilhar uma base de tempo (igual ou ligeiramente menor, em termos de duração, que a da unidade tipo 162) num integrador 56 da PAR, modelo 160 (como esse pulso de $25 \mathrm{~V}$ iria destruir o circuito de entrada do integrador, um divisor de poten cial reduz o pulso para $1,8 \mathrm{~V}) .192$ Esse integrador por sua vez gera um pulso, exatamente durante o tempo em que também abre a sua janela e aceita o sinal detectado pelo oscilador marginal (o processamento do sinal pelo integrador foi explicado na seção 2.4.1.): o pulso do integrador gatilha o gerador do pulso de deteç̧ão. Logo, quando o pulso de deteç̧ão dispara, ions de certa relação massa/carga entram em ressonância, de modo a produzirem úm sinal, o qual alcança o integrador justamente quando a janela está aberta, podendo ser processado. o pulso de detecão pode disparar em qualquer instante da base de tempo; hã uma varredū ra automātica no integrador, que permite variar esse instante de acionamento do pulso ao longo da base de tempo. Essa varredu ra pode comandar o eixo $\underline{X}$ de um registrador $X Y$, entrando o sinal no eixo $Y$; dessa maneira registra-se diretamente uma curva cinética (intensidade do sinal em função do tempo). A FIGURA 7.2. mostra o circuito simplificado de geradores de pulsos e sistema de deteç̧ão. 


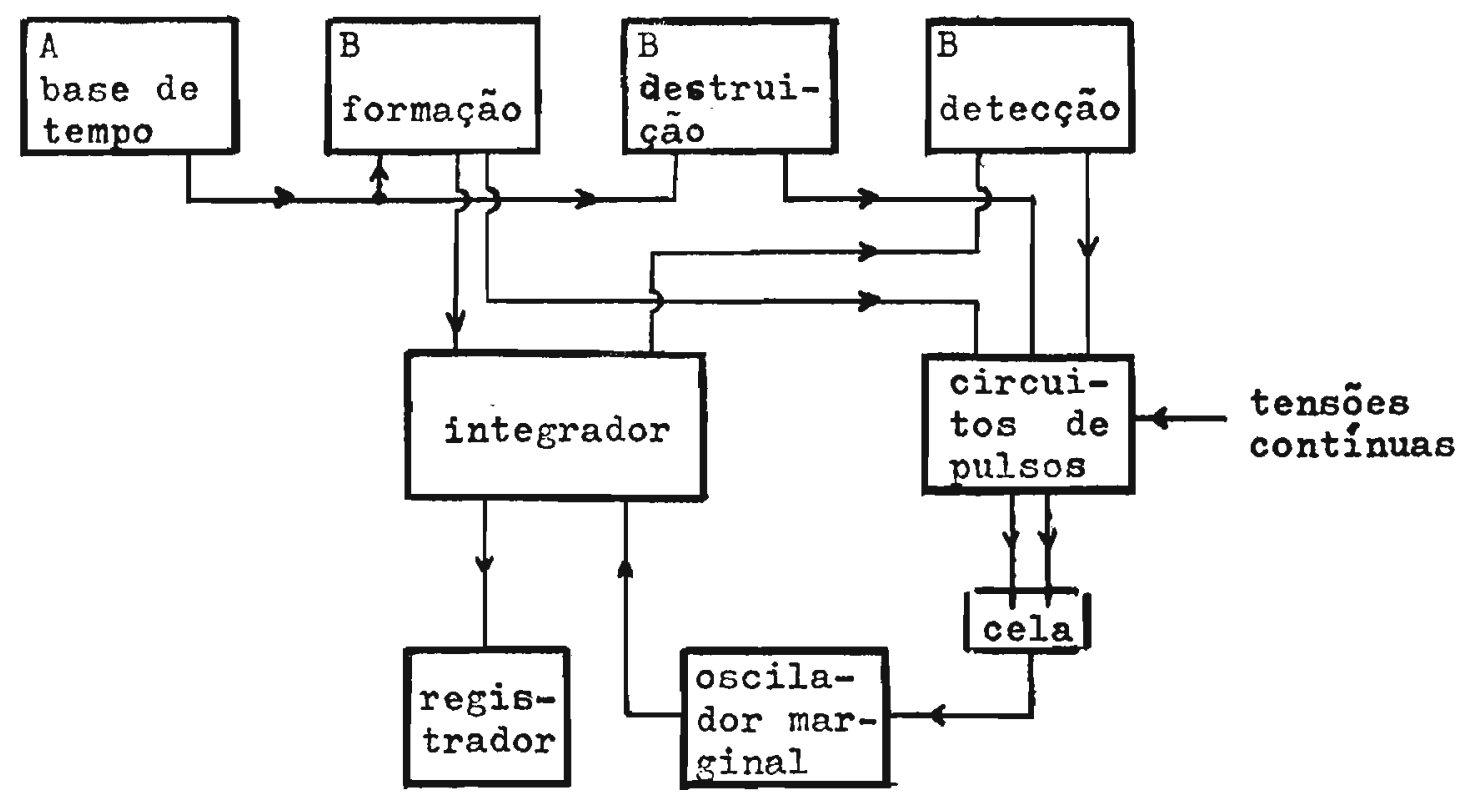

FIGURA 7.2. Esquema simplificado do espectrômetro de ressonância ciclotrônica de íns pulsada. A é um gerador de dente de serra; $\underline{B}$ são geradores de pulsos.

A FIGURA 7.3. mostra um traço de osciloscóplo de um sinal de ressonância ciclotrônica de ions pulsada. A varredura do osciloscópịo fol de $10 \mathrm{~ms} / \mathrm{cm}$ e a sensibilidade do elxo vertí cal, de $10 \mathrm{mV} / \mathrm{cm}$. o pulso de deteç̧ão teve uma duração de 4 ms. Observa-se que a intensidade do sinal cresce linearmente dú rante $4 \mathrm{~ms}$; o sinal não se reduz a zero instantaneamente logo a seguir, devido ao filtro RC no estáglo de áudio do oscilador marginal; por causa desse filtro também não aparece o batimento entre a frequência do oscilador marginal e a frequência ciclo trônica dos Ions ligeiramente afastados da situação de ressonân cla após o término do pulso de deteç̧ão. 52

Devido a componentes de Fourier de alta frequência no pulso de deteç̧ão, que podem ser eliminadas até certo ponto, é produzido um sinal errātico nos instantes inicial e final do 


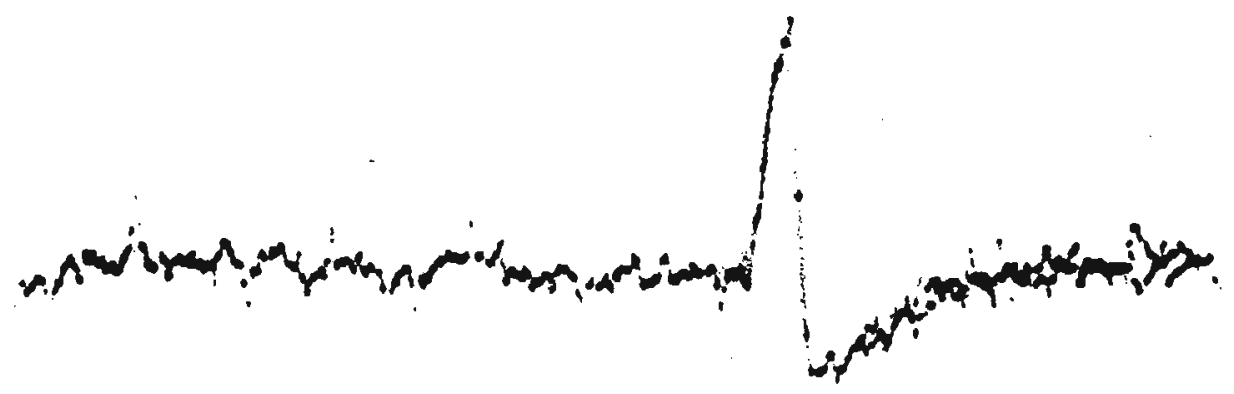

FIGURA 7.3. Sinal de ressonância ciclotrônica de ions pulsada de $\left(\mathrm{CH}_{3} \mathrm{COCH}_{3}\right) \mathrm{H}^{+}$. Atraso do pulso de deteç̧ão em relação ao de formação: $65 \mathrm{~ms}$; largura do pulso de deteç̧ão: $4 \mathrm{~ms}$. Osciloscōplo: vertical: $10 \mathrm{mV} / \mathrm{cm}$; horizontal: $10 \mathrm{~ms} / \mathrm{cm}$.

pulso. Isto aparece como ruído no sinal registrado. o ruído do final do pulso pode ser facilmente eliminado, se o tempo de abertura da janela do integrador for menor que a duração do pul so de detecçãọ. pois então a parte final do sinal não é processada. Porēm, eliminar o ruído do começo do pulso è mais difí cil, pois como descrito, é o pulso do integrador, coindidente com a abertura da janela, que aciona o pulso de detecção; logo, janela e pulso de deteç̧ão sempre coincidem no inicio (o térmí no pode ser variado independentemente). Então è preciso lançar mão de um esquema mals complicado, que constitul um dos a perfeiçoamentos ainda em vista, mencionados acima.

\subsection{Espectros e curvas cinēticas}

Na FIGURA 7.4. tem-se o espectro da acetona, registrado a $1,2 \cdot 10^{-5}$ Torr, Bendo varrido o campo magnëtico e mantido 


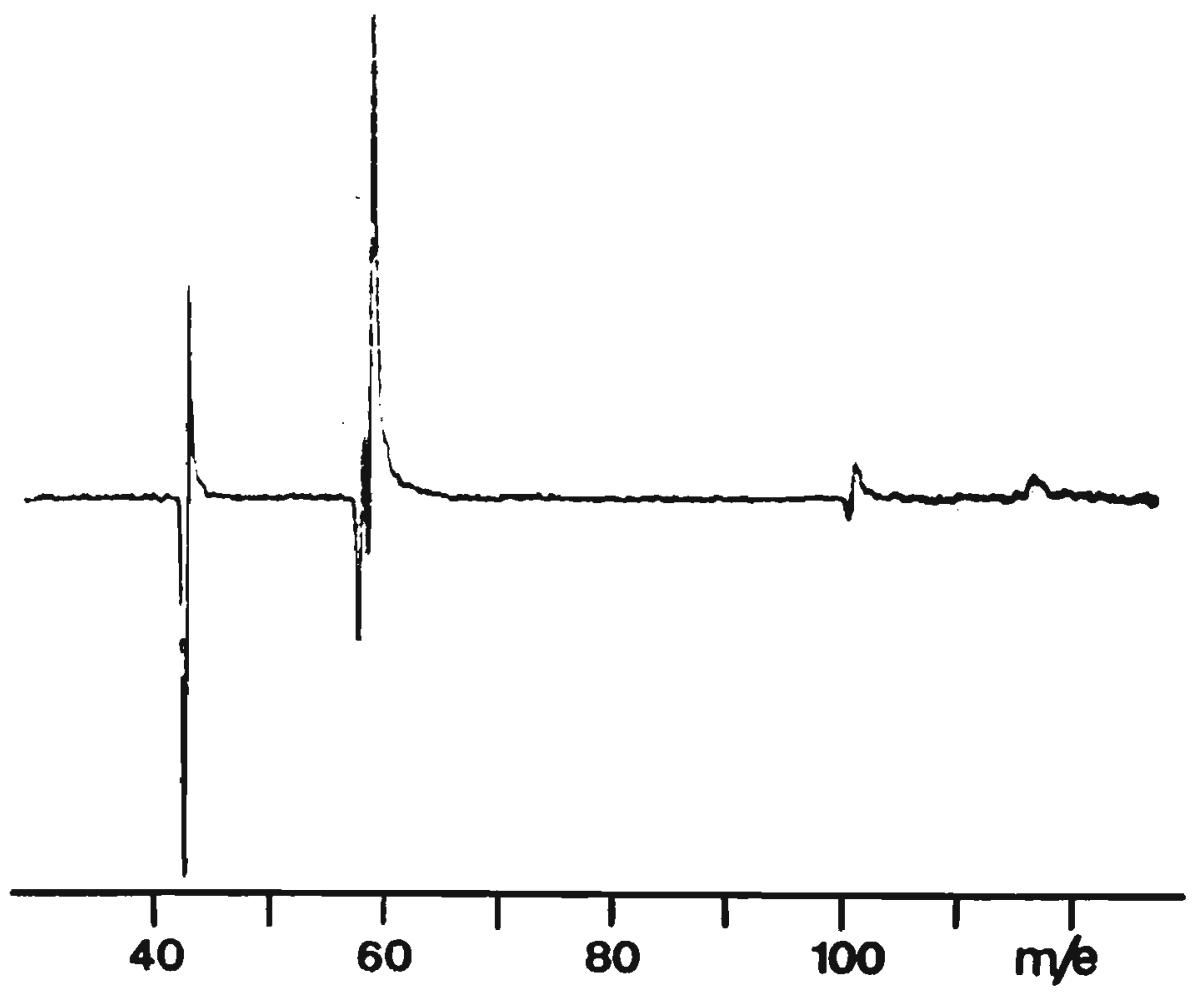

FIGURA 7.4. Espectro de massa da acetona. Energia eletrônica: $20 \mathrm{eV}$; pressão 1,2 $10^{-5}$ Torr; atraso do pulso de deteç̧ão em relação ao de formação; $8 \mathrm{~ms}$; oscila dor marginal: $153,6 \mathrm{kHz}$.

fixo o tempo de reação, ou seja, em cada ciclo, o pulso de deteç̧ão disparou $8 \mathrm{~ms}$ após o início do pulso de formação dos îons, que teve uma duração de $4 \mathrm{~ms}$; a largura do pulso de deteç ção fol de $4 \mathrm{~ms}$. Notarse que cada pico é precedido por um pico negativo, o qual tem sua origem no fato de, ao varrer o campo magnético, um ion entrar duas vezes em ressonância: a primeira vez no campo magnético correspondente ã tensão de aprisionamen to aplicada à cela durante o tempo de reação e, a segunda vez, no campo magnētico correspondente à tensão de aprisionamento dạ 
da pelo pulso de detecção (veja a equação 2.17. e a seção 2.4.2.). Quando há condições de ressonância pèla primeira vez, o ion absorve potência do oscilador marginal, mas o sinal não chega ao Integrador, pois a janela está fechada; durante o tempo de ativa ção do pulso de detecção, as condições de ressonância desapare cem; logo, tem-se um siṇal durante todo o tempo de reação e só não se tem sinal durante o tempo de detecção; como o acoplamento do estāgio de āudio do oscilador marginal é capacitivo, este desaparecimento do sinal é percebido como um sinal negativo, que então é processado pelo integrador. Quando o campo magnētico è tal que existam condições de ressonância quando a tensão de aprisionamento è a dada pelo pulso de detecção, não è observado sinal durante todo o tempo de reação, mas só durante o tempo de detecção; esse é o sinal de interesse e na medição das intensidades dós picos do espectro só é levada em conta a parte positiva dos mesmos. O pico negativo, que obviamente reduz a resolução do Instrụ mento, pode ser evitado com o oscilador marginal pulsado. 55

O espectro da FIGURA 7.4. pode ser comparado com o da FIGURA 4.9. O primeiro fol obtido a uma pressão ligeiramente me nor que o segundo $\left(1,2 \cdot 10^{-5}\right.$ e 2,0 $\cdot 10^{-5}$ Torr, respectivamente), mas o tempo de reação ( $8 \mathrm{~ms}$ ) foi certamente maior. Porém, no espectro obtido com a cela de aprisionamento notadamente o pico do ion de m/e 117 é extremamente pouco intenso. Por que? Foi visto que no caso de espectros obtidos com a cela de três regiões, para chegar a correntes tônicas, è preciso dividir as intensidades medidas pelas massas dos respectivos Ions (equação 2.21.), pelo fato de Ions mais pesados ficarem mais tempo na região analisadora e portanto terem reagido por mais tempo e absorverem mais potência. Com a cela de aprisionamento todos os Ions reagem durante tempos Iguals e são detectados por tempos iguals; 
logo, essa correção por causa dã massa não é aplicável; como, po rém a intensidade do sinal é dada pelo produto de corrente iôni ca e potência instantânea absorvida (seção 2.3.4.1.), sendo esta dada pela equação 2.12., é preciso multiplicar as intensidades dos picos pelas massas dos respectivos Ions, para obter correntes iônicas. Surge aqụi um fenômeno bastante interessante: enquanto que na ressonância ciclotrônica de ions contínua é preciso dividir as intensidades dos sinais por massa, è necessário multiplicá-las na ressonância ciclotrônica de ions pulsada. Na TABELA 7.1. encontram-se as correntes iônicas relativas dos Ions da acetona referentes às FIGURAS 7.4. e 4.9. Observa-se que as

TABELA 7.1 .

Correntes iônicas relativas dos íons da acetona, obtidas por res sonância ciclotrônica de. ions contínua e pulsada.

$\begin{array}{llllll}\mathrm{m} / \mathrm{e} & 43 & 58 & 59 & 101 & 117\end{array}$

$\begin{array}{llllll}\text { rc1 continua } & 0,373 & 0,145 & 0,398 & 0,052 & 0,032 \\ \text { rci pulsada } & 0,192 & 0,079 & 0,601 & 0,073 & 0,056\end{array}$

correntes dos ions reagentes foram menores na experiência da qual resultou a FIGURA 7.4., enquanto que as correntes iônicas dos produtos foram maiores; isto indica que na cela de aprisiona mento o tempo de reação fol maior ( $8 \mathrm{~ms}$; na cela de arraste esse tempo não è conhecido, mas provavelmente não excedeu 5 ms). Logo, apesar de o pico do Ion de m/e 117 ser extremamente pouco in tenso na FIGURA 7.4., corresponde a uma corrente iônica relativa maior que na FIGURA 4.9. Este é um aspecto de suma importân 
cla na espectroscopia de ressonância ciclotrônica de Ions, não tendo sido, ao que parece, suficientemente enfatizado. Como ge ralmente produtos lônicos têm massas maiores que os reagentes, é Importante estudar reações de ions com molēculas através de espectroscopia de ressonância ciclotrônica de Ions contínua,pois, apesar de não ser tão adequada à obtenção de dados cinéticos quantitativos, favorece produtos de massas elevadas por motivos inerentes à técnica. E por isso que no final da , seção 2.4.3. foi mencionada a conveniência de poder usar tanto a cela de três regiões, como a de aprisionamento.

Na FIGURA 7.5. encontram-se as curvas cinéticas dos Ions $\mathrm{CH}_{3} \mathrm{CO}^{+}(\mathrm{m} / \mathrm{e} 43)$ e $\left(\mathrm{CH}_{3}\right)_{2} \mathrm{COH}^{+}$(59) da acetona, registradas

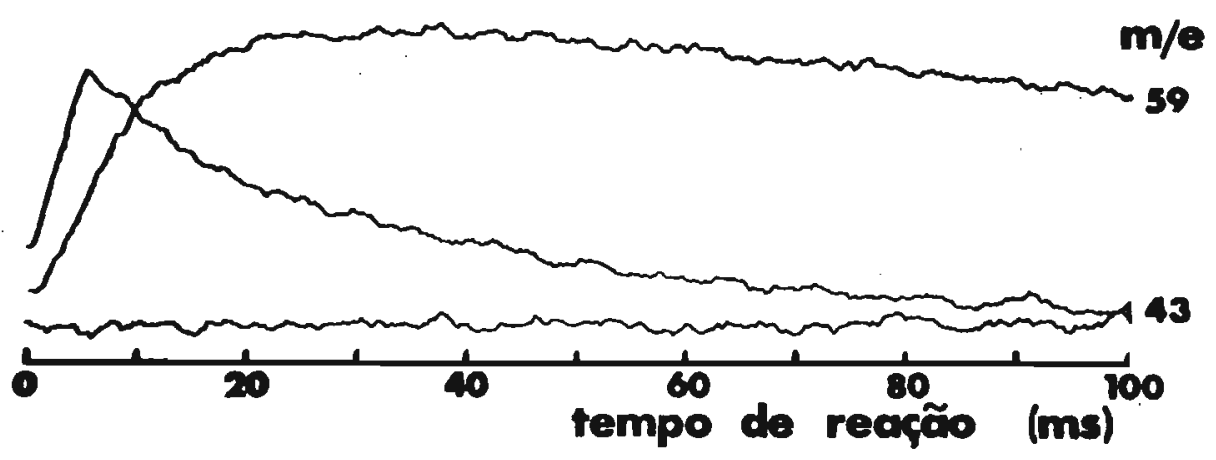

FIGURA 7.5. Curvas cinéticas dos íons $\mathrm{CH}_{3} \mathrm{CO}^{+}(\mathrm{m} / \mathrm{e}$ 43) e $\left(\mathrm{CH}_{3} \mathrm{COCH}_{3}\right) \mathrm{H}^{+}(\mathrm{m} / \mathrm{e} 59)$ em aceto na. Pressão: $6,4 \cdot 10^{-6}$ Torr.

a uma pressäo de 6,4 $10^{-6}$ Torr. Daremos a seguir as condições ex perimentais: pulso da grade: $5,0 \mathrm{~ms}$, $+12,5 \mathrm{~V}$; pulso de deteç̃ão: $4,0 \mathrm{~ms},+1,0 \mathrm{~V}$; pulso de destruição: $5,0 \mathrm{~ms},+10,0 \mathrm{~V}$; potencial de aprisionamento: $+0,50 \mathrm{~V}$; potencial da placa inferior da cela: $-0,50 \mathrm{~V}$; potenclal da placa superlor: $-0,70 \mathrm{~V}$; energla eletrôntca: 
$20,0 \mathrm{eV} ;$ tempo de registro do espectro: $5 \mathrm{~min}$; constante de tempo do integrador: $100 \mathrm{~ms}$. A linha base foi registrada, desli gando o pulso na grade. A intensidade do sinal do ion de $\mathrm{m} / \mathrm{e}$ 43 cresce durante os $5 \mathrm{~ms}$ de duração do pulso na grade e depois decresce exponencialmente; trata-se de um ion primário. A intensidade do sinal do îon de m/e 59 aumenta gradativamente às custas dos íons $\mathrm{CH}_{3} \mathrm{CO}^{+}(\mathrm{m} / \mathrm{e} 43)$ e $\mathrm{CH}_{3} \mathrm{COCH}_{3}^{+}$(58, não mostrado ); posteriormente a intensidade se reduz, pois o ion réage, forman do o dímero protonado (m/e 117). Que a curva do Ion de $\mathrm{m} / \mathrm{e} 43$ é realmente exponencial pode ser visto pela FIGURA 7.6., que

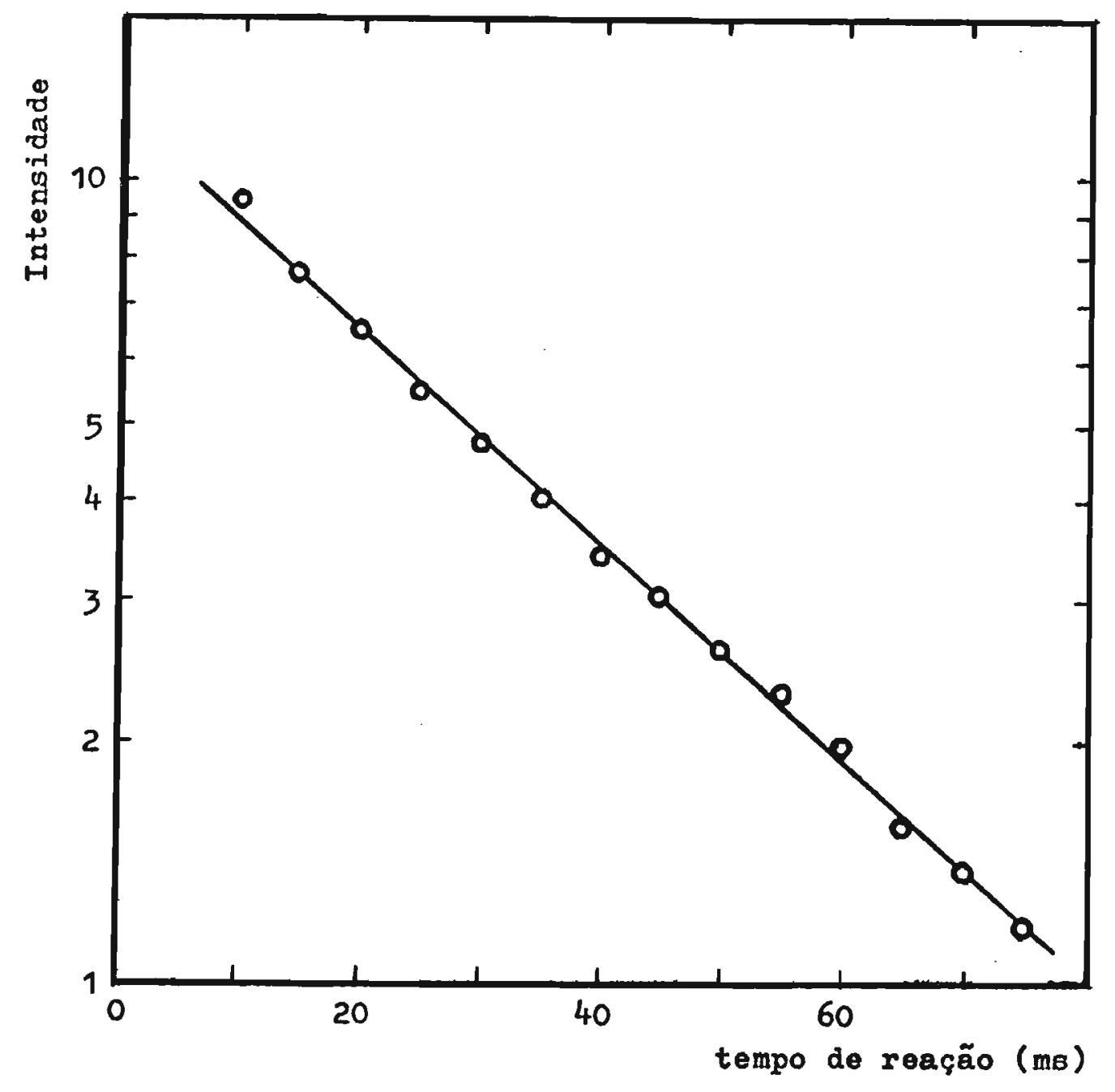

FIGURA 7.6. Logaritmo da intensidade do sinal de $\mathrm{CH}_{3} \mathrm{CO}^{+}$em acetona em função do tempo de reação. PresBão: $6,4 \cdot 10^{-6}$ Torr. 
mostra um grāfico de $\log I_{43}$ em função de $t$, sendo $I_{43}$ a intensi dade do sinal de $\mathrm{CH}_{3} \mathrm{CO}^{+}$. A abundância deste ion segue a lei cinētica

$\ln \frac{I_{43}}{I_{0,43}}=-n k t$

sendo $\mathrm{I}_{0,43}$ a intensidade do sinal de $\mathrm{CH}_{3} \mathrm{CO}^{+}$no Inf́cio da reação e $\underline{n}$, a densidade de moléculas neutras, relacionada com a pressão. Desse modo é possível calcular a partir do gráfico da FjGURA 7.6. a constante de velocidade de reação de $\mathrm{CH}_{3} \mathrm{CO}^{+}: \mathrm{k}=1,5 \cdot 10^{-10}$ $\mathrm{cm}^{3}$. molécula ${ }^{-1} \cdot \mathrm{s}^{-1}$. Na TABELA 4,2, encontra-se o valor determinado por Futrel1 ${ }^{108}$ para essa grandeza: $4,3 \cdot 10^{-10} \mathrm{~cm}^{3}$.mo lēcula ${ }^{-1} \cdot \mathbf{s}^{-1}$. No caso a pressão não fol calibrada (pressão lí da no controle da bomba: 1ônica)', mas também na referência 108 não há dados para poder avaliar o erro envolvido na medida.

Com estas experiências fol certamente possivel mostrar que a operação do espectrômetro de ressonância ciclotrônica de Ions sob forma pulsada é viável em nosso laboratórıo, pelo menos no caso de Ions positivos. E necessärlo agora aplicar a tēcni ca a algum problema químico conveniente. 
SUMARIO

A tēcnica de ressonância ciclotrônica de ions permite aprisionar numa cela adequada ions produzidos por impacto de elétrons sobre um gās a baixa pressão $\left(10^{-7}-10^{-4}\right.$ Torr $)$. Os ions são mantidos na cela por tempos de 3 a $10 \mathrm{~ms}$ e dessa maneira podem reagir com molēculas neutras do găs do qual provém ou, de algum outro gás introduzido no espectrômetro. Resultam dessas reações produtos tônicos, que frequentemente foram observados reagi rem novamente com molēculas neutras, dando origem a Ions terciārios. Todos os ỉons são detectados pela potêncla que absorvem de um campo de rádio-frequência conveniente, podendo ser registrado um espectro, no qual cada ín é caracterizado por sua massa, sendo a intensidade do pico correspondente proporcional à corrente tôni ca parcial do ion na cela: Contudo, a situação é tal que Ions de massa maior permanecem por tempos mais longos na cela, de modo a reagirem em maior extensão e absorverem maior potência do oscila dor de rádio-frequência. Essa discriminação de massa precisa ser levada em conta ao interpretar os espectros de ressonância ciclo trônica de lons e, para esclarecer a natureza das correções necessárias, as principais equações que descrevem o movimento dos Ions na cela foram deduzidas e discutidas na primeira parte deste traba 1ho. Tals equações sugerem uma série de experiências, que tornam a espectroscopia de ressonância ciclotrônica de ions uma técnica muito versātil. Estas experiências foram todas apresentadas na primeira parte, devendo-se salientar a experiência de ressonân cia dupla, que permite identificar de maneira inequivoca o pre cursor de algum produto Iônico, a experiêncla de ejeção de Ions, que permite remover seletivamente um Ion de dada espécie da cela, 
alēm de. experiências que visam a bbtenção de constantes de velocidade de reações de ỉons com molēculas.

E justamente esta última grandeza mencionada, a saber, a constante de velocidade de uma reação, a que pode ser com parada com valores calculados a partir de modelos teórtcos. Esses modelos baseiam-se em sua maiorla na interação do Ion, consi derado como carga puntiforme, com a molécula neutra de certa polarizabilidade e momento dipolar (modelo de polarização) ou, na fragmentação de um complexo intermediārio (modelos estatisticos). Os aspectos teōricos das reações entre Ions e molēculas em fase gasosa foram analisados e os modelos mencionados, discutidos, além de modelos chamados "diretos" maís apropriados para comparaçōes com resultados de experiências de felxes iônicos.

A espectroscopia de ressonâncla ciclotrônica de ions foi utilizada para o estudo de reações de acilação em cetonás, rea ções bastante gerais (foi verificado que ocorrem tambēm em outros sistemas carbonilicos) e que podem ser representadas pela equação

$\mathrm{RCOR}^{\prime+}+\mathrm{RCOR}^{\prime} \rightarrow \mathrm{RCO}^{+}\left(\mathrm{RCOR}^{\prime}\right)+\mathrm{R}^{\prime}$

Estudos de variação das correntes iônicas relativas de todos os Ions das cetonas, em função da pressão de cetona neutra, possibl taram a dedução de um mecanismo de formação desses íns acilados. Os resultados estão de acordo com um esquema no qual esse produto é formado pela fragmentação de um dimero intermediārio, para - qual se supõe exist1rem condições de estado estacionário. Esta fragmentação se dá de maneira anãloga à fragmentação dos Ions moleculares de cetonas em espectroscopia de massa usual, tratando-se então de uma fragmentação induzida por uma espécle neutra. 
A pressões elevadas, nas quais o dimero pode sofrer colisões nãoreativas e relaxar o excesso de energia Interna, o mesmo é estab1 11zado, fornecendo um pico no espectro. Cetonas de polarizabilidade mator têm uma afinidade malor para o grupo ac1la; isto foi concluido, quando foram observadas reações de transferêncla de grupos acila, como por exemplo a transferêncla de $\mathrm{CH}_{3} \mathrm{CO}^{+}$da cetona para a butanona num sistema formado pela mistura dessas duas cetonas.

Estudos de basicidade relativa de álcoois, ācidos,ēs teres e cetonas revelaram que há uma relação de proporcionalidade entre a basicidade desses compostos e seu potencial de iontzação. Isto havia sido mostrado anteriormente para o caso das aminas, por outros pesquisadores.

o conhecimento da basicidade de álcoois, ácldos e èsteres permitiu analisar reações de esterificação e transesterificação sob o ponto de vista termoquímico. Trata-se de reações entre moléculas protonadas das espēcles mencionadas, que podem ser consideradas anālogas às reações catalisadas por ācidos ém solução. o fạto de uma reação ser exotērmica não significa que .ela ocorra. Assim, fol observadoque ácido fórmico não é ester 1 í cado por metanol ou etanol nas condlções relnantes numa cela de ressonância ciclotrônica de Ions, enquanto qué ãcido acétíco o è. A ordem relativa de basicidades em fase gasosa fol determinada como sendo $\mathrm{HCOOH}+\mathrm{CH}_{3} \mathrm{OH}<\mathrm{C}_{2} \mathrm{H}_{5} \mathrm{OH}<\mathrm{CH}_{3} \mathrm{COOH}$. Dessa maneira os resultados estão de acordo com um ataque nucleófilo por parte do álcool no ácido protonado; porém, se este é menos básico que o âl cool, ocorre a transferêncla de prōton e não a esterificação. Rea ções de transesterificação não foram observadas de maneira alguma, mas uma outra reação entre ésteres a älcoo1s fol encontrada e que pode ser exemplificada pela equação 
$\left(\mathrm{CH}_{3}\right)_{2} \mathrm{CHOH}_{2}^{+}+\mathrm{HCOOC}_{3} \mathrm{H}_{7} \rightarrow \mathrm{HCO}_{2}\left(\mathrm{C}_{3} \mathrm{H}_{7}\right)\left(\mathrm{C}_{3} \mathrm{H}_{7}\right)^{+}+\mathrm{H}_{2} \mathrm{O}$

Esta reação só se dá com álcoois capazes de produzir ions de car bônio mais estáveis que os primārios; portanto metanol e etanol não reagem. o produto formado pode fragmentar novamente o que revelou que o grupo alquila proveniente do ālcool retém um exces so de energia na sua ligação, pois ra decomposição é esta a liga ção que rompe.

Em todos estes estudos, isto è, nos de acilação de cetonas e de esterificação, bem como nos estudos de basicidade, foi sempre salientada a importância de examinar essas reações em fase gasosa, pelo fato de serem reações mais simples, uma vez que se dão na ausência de solventes e portanto revelarem propriedades intrínsecas das espēcies envolvidas.

Finalmente foram descritas algumas modificações rẹa Ilzadas no espectrômetro de ressonância ciclotrônica de Ions, pa ra poder operä-lo de forma pulsada. Com isso é possível manter os ions por tempos maiores na cela (500 ms) e, o que è mals Importante, essẹs tempos podem ser definidos com grande precisão, - que torna viável a obtenção de resultados quantitativos (constantes de velocidade de reação) melhores. 


\section{SUMMARY}

Ions can be trapped for times as long as $10 \mathrm{~ms}$ by the combined action of magnetic and electric fields in the cell of an ion cyclotron resonance spectrometer. Despite the low operating pressure $\left(10^{-7}-10^{-4}\right.$ Torr $)$, the lons experience many collisions during this time, some of which may be reactive, lead ing to product ions. The ion cyclotron resonance spectrum thus displays a series of peaks corresponding to the various primary, secondary, and eventually tertiary ions; the peak helghts, after sultable mass correction, yield ion currents. The double resonance technique allows one to establish unamblguously the precursor tons of a given product ion, by accelerating the suspected reagent ions and examining the effect on the product Ion. Ions can also be selectively ejected from the cell, These techniques, which were described in this thesis after an outline of the basic principles of ion cyclotron resonance spectroscopy, allow one to unravel the gaseous ion chemistry in any chemical system.

Rate constants of ion-molecule reactions can be determined by Ion cyclotron resonance spectroscopy. The necessary equations, based on the equations relating measured peak intensities to ion currents, were derived and their limitations, as well as those of the experimental procedures for obtaining the input parameters for the expressions, were discussed. Rate constants can also be calculated theoretically and there are a few microscopic models which treat the collision of an ion with a polarizable neutral molecule (polarization model) or the uni molecular fragmentation of an intermediate complex (statistical models). Direct models, although more sultable for comparison 
with results from beam experiments, were presented together with the above mentioned models, and their importance for the interpretation of the basic aspects of ion-molecule chemistry was discussed.

The ion cyclotron resonance spectrometer was used to study an acylation reaction in ketones, which seems to be general for carbonyl compounds.

$\left.\mathrm{RCOR}^{\prime}+\mathrm{RCOR}^{\prime} \rightarrow \mathrm{RCO}^{+}(\mathrm{RCOR})^{\prime}\right)+\mathrm{R}^{\prime}$

Pressure plots of the ion currents. In ketones allowed us to propose a mechanism according to which the acylated ketones are formed by the fragmentation of an excited dimer ion, in a fashion analo gous to the fragmentation of ketone parent lons in ordinary mass spectroscopy. Steady state conditions prevall for the excited dimer, which can be stabilized at pressures high enough for the ion to collide with a neutral in a time short compared to his life time, thus relaxing excess energy. The acyl group can be trans ferred from a ketone of lower polarizability to one of higher polarizability; thus $\mathrm{CH}_{3} \mathrm{CO}^{+}$is for instance transferred from ace tone to butanone in a mixture of these two compounds, as detected by double resonance.

Relative proton affinities of alcohols, acids, esters, and ketones were determined and the results are in agreement with the assumption of constant hydrogen affinity within a homologous series, as has been shown previously for the- case of amines by others.

of particular interest is the following order of proton affinities: $\mathrm{HCOOH}<\mathrm{CH}_{3} \mathrm{OH}<\mathrm{C}_{2} \mathrm{H}_{5} \mathrm{OH}<\mathrm{CH}_{3} \mathrm{COOH}$. The positive ion spectra of mixtures of acetic acid with methanol or ethanol re 
vealed that this acid reacts with the alcohols yielding a protonated ester, in a process apparently analogous to the acid catalized esterification in solution. On the other hand, formic acid was found not to behave in this way, although the reactions are all exothermic. These results could be rationalized assuming that a nucleophilic attack takes place on the protonated acid by the alcohol. If the alcohol is more basic, only proton trans fer is observed. Transesterification reactions were not detected, but this failure was compensated by a reaction which all higher alcohols, namely those capable of producing a secondary or tertiary carbonium ion, undergo with the esters. This reaction can be exemplified by

$$
\left(\mathrm{CH}_{3}\right)_{2} \mathrm{CHOH}_{2}^{+}+\mathrm{HCOOC}_{3} \mathrm{H}_{7} \rightarrow \mathrm{HCO}_{2}\left(\mathrm{C}_{3} \mathrm{H}_{7}\right)\left(\mathrm{C}_{3} \mathrm{H}_{7}\right)^{+}+\mathrm{H}_{2} \mathrm{O}
$$

Although in this particular reaction both alkyl groups seem equi valent, they are not so with respect to internal vibrational ener gy; this was demonstrated by the decomposition reactions which the ionic products like the one in the reaction above undergo: the alkyl group originally in the alcohol is always eliminated.

$$
\text { All the reactions mentioned above, namely, acylation }
$$
of ketones, proton transfer, and esterification, show the impor tance of ion-molecule reaction studies in the gas phase, where the intrinsic properties of the reacting species can be examined, free from solvation effects. This point has been repeatedly stressed.

In a last chapter in this thesis the necessary modifications of the ion cyclotron resonance spectrometer, in order to operate it in a pulsed mode, were described. With this.kind of operation a bunch of lons is formed by a pulse of the electron beam and the lons react for a known period of time, after which 
they are removed from the cell. Kinetic studies can be more easily carried out in this way than in the conventional one.some preliminary results were shown. 


\section{REFERENCIAS}

1. J. D. Baldeschwieler, Science 159, 263 (1968); este artigo Eoi reproduzido em

J. D. Baldeschwieler, "Ion Cyclotron Resonance Spectroscopy", em "Carbonium Ions", vol. I, G. A. Olah, P. von R. Schleyer (editores), John Wiley \& Sons, New York, USA, 1968, p. 413

2. J. M. Riveros, "Determinação da Basicidade Relativa das Aminas por Ressonância Ciclotrônica de Ions", tese de livre-docêncla, Instituto de Química, Universidade de são Paulo,1970

3. J. D. Baldeschwieler, S. S. Woodgate, Accounts Chem. Res. 4, 114 (1971)

4. G. A. Gray, Adv. Chem. Phys. 19, 141 (1971)

5. J. D. Baldeschwieler, H. Benz, P. M. Llewellyn, Adv. Mass Spectrom. 4, 113 (1968)

6. J. M. S. Henis, Anal. Chem. $41(10), 22 A$ (1969)

7. J. L. Beauchamp, Ann. Rev. Phys. Chem. 22, 527 (1971)

8. G. C. Goade, R. M. O'Malley, A. J. Ferrer-Correla, K. R. Jennings, Chem. Brit. $\underline{7}, 12$ (1971)

9. J. H. Futrel1, "Ion Cyclotron Resonance Mass Spectroscopy", em "Dynamic Mass Spectrometry", vol. 2, D. Price (editor), Heyden \& Son, London, Inglaterra, 1971, p. 97

10. C. J. Drewery, G. C. Goode, K. R. Jennings, "Ion Cyclotron Resonance Mass Spectrometry", em "Mass Spectrometry, MTP International Review of Science, Physical Chemistry Series One, volume 5", A. Maccoll (editor), Butterworths, London, Inglaterra, e University Park Press, Baltimore, USA, 1972 , p. 183 
11. G.C. Goode, R. M. O'Malley, A. J. Ferrer-Correia, K. R. Jennings, Nature $\underline{227}, 1093$ (1970)

12. M. M. Bursey, comunicação particular

13. D. Wobscha11, J. R. Graham, Jr., D. P. Malone, Phys. Rev. 131,1565 (1963)

14. F. N. H. Robinson,. J. Sci. Instrum. 36, 481 (1959)

15. T. Coor, J. Chem. Ed. $\underline{45}$, A533 (1968)

16. T. C. O'Haver, J. Chem. Ed. 49, Al31 (1972)

17. W. T. Huntress, Jr., J. Chem. Phys. 55, 2146 (1971)

18. J. L. Beauchamp, J. Chem. Phys. 46, 1231 (1967)

19. M. B. Comisarow, J. Chem. Phys. 55, 205 .(1971)

20. R. C. Dunbar, J. Chem. Phys. 54, 711 (1971)

21. S. E. Buttrill, Jr., J. Chem. Phys. 50, 4125 (1969)

22. H. Sommer, H. A. Thomas, J. A. Hipple, Phys. Rev. $\underline{82,697}$ (1951)

23. H. Sommer, H. A. Thomas, Phys. Rev. 78,806 (1950)

24. N. W. Robinson, "The Physical Principles of Ultra-high Vacuum Systems and Equipment", Chapman and Hall, London, Inglaterra, 1968 , p. 27 e 111

25. G. Lewin, "Fundamentals of Vacuum Science and Technology", MCGraw-Hill, New York, USA, 1965, p. 112

26. D. Wobschall, Rev. Sc1. Instrum. 36, 466, (1965)

27. D. Wobschall, J. R. Graham, Jr., D. P. Malone, J. Chem. Phys. $\underline{42}, 3955(1965)$

28. D. Wobschall, R. A. Fluegge, J.R. Graham, Jx., J. Chem. Phys. 47, 4091 (1967)

29. J. I. Beauchamp, L. R. Anders, J. D. Baldeschwieler, J. Amer. Chem. Soc. 89,4569 (1967)

30. J. M. S. Henis, "Ion Cyclotron Resonance Spectrometry", em "Ion-Molecule Reactions", vol. 2, J. L. Franklin (editor), Plenum Press, New York, USA, 1972, p. 403 
31. J. L. Beauchamp, J. T. Armstrong, Rev. Sci. Instrum. 40, 123 (1.969)

32. R. P. Clow, J. H. Futrell, Int. J. Mass Spectrom. Ion Phys. $\underline{4}, 165$ (1970)

33. J. I. Brauman, K. C. Smyth, J. Amer. Chem. Soc. 91,7778 (1969)

34. K. C. Smyth, R. T. McIver, Jr., J. I. Brauman, R.W. Wallace, J. Chem. Phys. 54, 2758 (1971)

35. R. C. Dunbar, J. Amer. Chem. Soc. 93, 4354 (1971)

36. J. M. S. Henis, W. Frasure, Rev. Sci. Instrum. 39, 1772 (1968)

37. R. T. McIver, Jr., Rev. Sci. Instrum. 41, 126 (1970)

38. L. R. Anders, J. L. Beauchamp, R. C. Dunbar, J. D. Baldeschwie ler, J. Chem. Phys. 45, 1062 (1966)

39. G. C. Goode, A. J. Ferrer-Correia, K. R. Jennings, Int. J. Mass Spectrom. Ion Phys. ㅁ, 229 (1970)

40. B. S. Freiser, T. B. McMahon, J. L. Beauchamp, Int. J. Mass Spectrom. Ion Phys. 12, 249 (1973)

41. M. T. Bowers, D. D. Elleman, J. I. Beauchamp, J. Phys. Chem. 72, 3599 (1968)

42. M. T. Bowers, D. D. Elleman, J. Chem. Phys. 51, 4606 (1969)

43. M. L. Gross, J. Norbeck, J. Chem. Phys. 54, 3651 (1971)

44. M. T. Bowers, D. D. Elleman, J. King, Jr., J. Chem. Phys. 50, 1840 (1969)

45. V. G. Anicich, M. T. Bowers, Int. J. Mass Spectrom. Ion Phys. 11,329 (1973)

46. A. G. Marshal1, S. E. Buttrill, Jr., J. Chem. Phys. 52, 2752 (1970); para erros de impressão neste artigo, veja a referên cia 45 .

47. W. J. van der Hart, Chem. Phys. Letters, 23, 93 (1973)

48. A. G. Marshall, J. Chem. Phys. 55, 1343 (1971) 
49. T. B. McMahon, J. L. Beauchamp, Rev. Sci. Instrum. 42,1632 (1971)

50. D. L. Smith, J. H. Futrel1, Int. J. Mass Spectrom. Ion Phys. 10. 405 (1973)

51. R. T. McIver, Jr., Rev. Sci. Instrum. 41, 555 (1970)

52. R. T. McIver, Jr., R. C. Dunbar, Int. J. Mass Spectrom. Ion Phys. I, 471 (1971)

53. R. T. McIver, Jx., "Kinetic and Equilibrium Studies of Gas Phase Ionic Reactions Using Pulsed Ion Cyclotron Resonance Spectroscopy", tese de doutoramento, Universidade de Stanford, California, USA, 1971

54. T. E. Sharp, J. R. Eyler, E. Li, Int. J. Mass Spectrom. Ion Phys. 9 , 421 (1972)

55. R. T. McIver, Jr., Rev. Sci. Instrum., 44, 1071 (1973)

56. Este integrador è chamado de "boxcar integrator" na lingua in giesa.

57. G. M. Hieftje, Ana 1. Chem. $\underline{44}(7), 69$ A (1972)

58. M. T. Bowers, D. H. Aue, H. M. Webb, R. T. McIver, Jr., J. Amer. Chem. Soc. 93,4314 (1971)

59. R. T. Mcİver, Jr., J. R. Eyler, J. Amer. Chem. Soc. 93, 6334 (1971)

60. W. G. Henderson, M. Taagepera, D. Holtz, R. T. McIver, Jr., J. I. Beauchamp, R. W. Taft, J. Amer. Chem. Soc. 94, 4728 (1972)

61. R. T. McIver, Jr., J.A. Scott, J. M. Riveros, J. Amer. Chem. Soc. $\underline{95}, 2706(1973)$

62. R. T. McIver, Jr., J. H. Silvers, J. Amer. Chem. Soc. 95, 8462 (1973)

63. T. B. McMahon, J. I. Beaucharnp, Rev. Sc1. Instrum. 43, 509 (1972) 
64. R. E. Weston, Jr., H. A. Schwarz, "Chemical Kinetics", Pren tice-Hal1, New Jersey, USA, 1972, p. 21

65. C. R. Noller, "Chemistry of Organic Compounds", W. B. Saunders, Philadelphia, Pa., USA, 1966, p. 111

66. G. A. Olah, G. Liang, G. D. Mateescu, J. L. Riemenschneider, J. Amer. Chem. Soc. $\underline{95}, 8698$ (1973)

67. J. H. Futrell, T. O. Tiernan, Science 162, 415 (1968)

68. referência 64, p. 160

69. M. Henchman, "Rate Constants and Cross Sections", em "IonMosecule Reactions", vol.. I, J. L. Franklin (editor), Plenum Press, New York, USA, 1972, p. 101

70. P. J. Ausloos, prefácio, em "Advances in Chemistry Series 58", R. F. Gould (editor), American Chemical Soclety, Washington D. C., USA, 1966

71. J. E. Parker, R. S. Lehrle, Int. J. Mass Spectrom. Ion Phys. ㄱ. 421 (1971)

72. J. I. Brauman, J. M. Riveros, L. K. Blair, J. Amer. Chem. Soc. 93. 3914 (1971)

73. J. D. Payzant, A. J. Cunningham, P. Kebarle, Can. J. Chem. $\underline{50}, 2230 \cdot(1972)$

74. I. K. Blair, P. C. Isolani, J. M. Riveros, J. Amer. Chem. Soc. 95, 1057 (1973)

75. J. M. Riveros, A. C. Breda, I. K. Blair, J. Amer. Chem. Soc. 95, 4066 (1973)

76. E. W. McDaniel, V. Čermāk, A. Dalgarno, E. E. Ferguson, L. Friedman, "Ion-Molecule Reactions", Wiley-Interscience, New York, USA, 1970, p. 159

77. G. Gioumousis, D. P. Stevenson, J. Chem. Phys. 29, 294 (1958); para erros de 1mpressão neste artıgo, veja a referéncia $76, \mathrm{p} .14$ 
78. A. Henglein, "Kinematics of Ion-Molecule Reactions", em "Molecular Beams and Reaction Kinetics", Ch. Schlier (editor), Academic Press, London, Inglaterra, 1970, p. 148

79. J. V. Dugan, Jr., J. L. Magee, J. Chem. Phys.. 47, 3103 (1967)

80. T. Su, M. T. Bowers, J. Chem. Phys. 58, 3027 (1973)

81. T. Su, M. T. Bowers, Int. J. Mass Spectrom. Ion Phys. 12, 347 (1973)

82. C. E. Melton, "Principles of Mass Spectrometry and Negative Ions", Marcel Dekker, New York, USA 1970, p. 176

83. H. M. Rosenstock, M. Krauss, "Quasi-Equilibrium Theory of Mass Spectra", em "Mass Spectrometry of Organic Ions", F. W. Mclafferty (editor), Academic Press, New York, USA, 1963

84. A. L. Wahrhaftig, "Theory of Mass Spectra", em "Mass Spectrometry, MTP International Review of Science, Physical Chemistry Series One, volume 5", A. Maccoll (editor), Butterworths, London, Inglaterra, e University Park Press, Baltimore, USA, 1972 , p. 1

85. F. H. Field, J. I. Franklin, "Electron Impact Phenomena and the Properties of Gaseous Ions", edição revisada, Academic Press, New York, USA, 1970, p. 68

86. S. E. Buttrill, Jr., J. Chem. Phys. 52, 6174 (1970)

87. M. Vestal, A. L. Wahrhaftig, W. H. Johnston, J. Chem. Phys. 37. 1276 (1962)

88. W. A. Chupka, J. Chem. Phys. 30, 191 (1959)

89. J. G. Dillard, K. Draxl, J. L. Franklin, F. H. Field, J. T. Herron, H. M. Rosenstock, "Ionization Potentials, Appearance Potentials, and Heats of Formation of Gaseous Positive Ions", NSRDS-NBS 26 , U. S. Department of Commerce, National Bureau of Standards, USA, 1969 
90. M, T. Bowers, W. J. Chesnavich, W. T. Huntress, Jr., Int. J. Mass Spectrom. Ion Phys. 12, 357 (1973)

91. J. C. Light, J. Chem. Phys. 40, 3221 (1964)

92. L. S. Rodberg, R. M. Thaler, "Introduction to the Quantum Theory of Scattering", Academic Press, London, Inglaterra, 1970, p. 276

93. P. Pechukas, J. C. Light, J. Chem. Phys. 42, 3281 (1965)

94. J. C. Light, Discuss. Faraday Soc. 44,14 (1967)

95. P. M. Hierl, Z. Herman, R. Wolfgang, J. Chem. Phys. 53 , $660(1970)$

96. M. G. Holliday, J. T Muckerman, L. Friedman, J. Chem. Phys. 54, 1058 (1971)

97. B. H. Mahan, Accounts Chem. Res. 1, 217 (1968)

98. R. Wolfgang, Accounts Chem. Res. $\underline{3}, 48$ (1970)

99. B. H. Mahan, J. Chem. Phys. 55, 1436 (1971)

100. J. Diekman, J. K. MacLeod, C. Djerassi, J. D. Baldeschwieler, J. Amer. Chem. Soc: 91, 2069 (1969)

101. P. W. Tiedemann, J. M. Riveros, XXIV Reunião Anual da Sociedade Brasileira para o Progresso da Ciência, são Paulo, 1972, comunicação C-17

102. P. W. Tiedemann, J. M. Riveros, J. Amer. Chem. Soc. 95, 3140 (1973)

103. H. Budzikiewicz, C. Djerassi, D. H. Williams, "Mass Spectrometry of Organic Compounds", Holden-Day, San Francisco, USA, 1967, p. 129

104. A. G. Sharkey, Jr., J. L. Shultz, R. A. Friedel, Anal. Chem. 28, $934(1956)$

105. J. J. Beynon, G. R. Lester, R. A. Saunders, A. E. Williams, Trans. Faraday Soc. 57,1259 (1961)

106. M. S. B. Munson, J. Amer. Chem. Soc. 87, 5313 (1965) 
107. B. C. de Souza, J. H. Green, Aust. J. Chem. 18, 1153 (1965)

108. K. A. G. MaNeil, J. H. Futrell; J. Phys. Chem. 76, 409 (1972)

109. M. K. Hoffman, T. A. Elwood, T. A. Lehman, M. M. Bursey, Tetrahedron Letters 4021 (1970)

110. M. M. Bursey, T. A. Elwood, M. K. Hoffman, T. A. Lehman, J. M. Tesarek, Anal. Chem. 42, 1370 (1970)

111. M. M. Bursey, M. K. Hoffman, Can. J. Chem. 49, 3395 (1971)

112. S. A. Benezra, M. M. Bursey, J. Amer. Chem. Soc. 94, 1024 (1972)

113. T. A. Lehman, T. A. Elwood, M. K. Hoffman, M. M. Bursey, J. Chem. Soc. B, 1717 (1970)

114. G. Eadon, J. Diekman, C. Djerassi, J. Amer. Chem. Soc. 91 , $3986(1969)$

115. G. Eadon, C. Djerassi, J. Amer. Chem. Soc. 92, 3084 (1970)

116. G. Eadon, J. Diekman, C. Djerassi, J. Amer. Chem. Soc. 92 , $6205(1970)$

117. J. R. Hass, M. M. Bursey, D. G. I. Kingston, H. P. Tannenbaum, J. Amer. Chem. Soc. 94, 5095 (1972)

118. D. J. MCAdoo, F. W. McLafferty, J. S. Smith, J. Amer. Chem. Soc. $\underline{92}, 6343(1970)$

119. F. W. McLafferty, D. J. McAdoo, J. S. Smith, R. Kornfeld, J. Amer. Chem. Soc. 93, 3720 (1971)

120. G. Eadon, J. Amer. Chem. Soc. 94, 8938 (1972)

121. referência 25, p. 155

122. referêncla 25, p. 98

123. referência 25, p. 92, Veeco (Plainview, N. Y., USA), RG 75 P, controle RG-84 com desgassificação por bombardeamento de elètrons

124. referênc1a 25, p. 90. MKS Baratron (Burlington, Massachusetts, USA), sensor tipo $90 \mathrm{H}-\mathrm{IE}$ 
125. J., E. Dubois, M. Boussu, C. Lion, Tetrahedron Letters 829 (1971)

126. J. E. Dubois, B. Leheup, F. Hennequin, P. Bauer, Bul1.Soc. ch1m. Fr. 1150 (1967)

127. D. A. Shirley, "Organic Reactions", vol. VIII, John Wiley \& Sons, 1954, p. 28

128. A. I. Vogel, "A Text-Book of Practical Organic Chemistry", 3a. ed., Longmans, Green and Co., London, Inglaterra, 1966, p. 358

129. "Handbook of Chemistry and Physics", R. C. West (editor), The Chemical Rubber Co., Cleveland, Oh1o, USA, 52a. ed., $1971-1972$, p. C-415

130. P. P. Dymerski, R. C. Dunbar, J. Chem. Phys. 57, $\$ 049$ (1972)

131. L. Kevan, J. H. Futrell, J. C. S. Faraday II, 1742 (1972)

132. S. E. Buttrill, Jr., J. Chem. Phys. 58, 656 (1973)

133. C. A. Lieder, R. W. Wien, R. T. McIver, Jr., J. Chem. Phys. 56, 5184 (1972)

134. R. T. McIver, Jr., A. D. Barany1, enviado para Rev. Sc1. Instrum.

i35. J. A. Beran, L. Kevan, J. Phys. Chem. 73, 3860 (1969)

136. referência 129 , p. E-52

137. J. L. Beauchamp, S. E. Buttrill, Jr., J. Chem. Phys. 48 , $1783(1968)$

138. referêncla 103, p. 139

139. J. L. Beauchamp, J. Amer. Chem. Soc. 91, 5925 (1969)

140. P. C. Isolani, J. M. Riveros, P. W. Tiedemann, J. C. S. Faraday II, 1023 (1973)

141. J. P. Briggs, R. Yamdagni, P. Kebarle, J. Amer. Chem. Soc. 94, 5128 (1972) 
142. R. Yamdagni, P. Kebarle, J. Amer. Chem. Soc. 95, (1973)

143. J. Long, B. Munson, J. Amer. Chem. Soc. 95,2427 (1973)

144. A. E. Roche, M. M. Sutton, D. K. Bohme, H. I. Schiff, J. Chem. Phys. 55, 5480 (1971)

145. D. K. Bohme, R. S. Hemsworth, H. W. Rundle, H. I. Schiff, J. Chem. Phys. 58, 3504 (1973)

146. R. S. Hemsworth, H. W. Rundle, D. K. Bohme, H. I. Schiff, D. B. Dunkin, F. C. Fehsenfeld, J. Chem. Phys. 59, 61 (1973)

147. D. Holtz, J. L. Beauchamp, W. G. Henderson, R. W. Taft, Inorg. Chem. 10, 201 (1971)

148. M. Taagepera; W. G. Henderson, R. T. C. Brownlee, J. L. Beauchamp, D. Holtz, R. W. Taft, J. Amer. Chem. Soc. 94 , $1369(1972)$

149. P. Kriemler, S. E. Buttrill, Jr., J, Amer. Chem. Soc., 95, $1365(1973)$

150. S. Billets, H. H. Jaffē, F. Kaplan, Org. Mass Spectrom. I, $431(1973)$

151. D. Holtz, J. I. Beauchamp, J. R. Eyler, J. Amer. Chem. Soc. $\underline{92}, 704 \dot{5}(1970)$

152. W. A. Chupka, J. Berkow1tz, J. Chem. Phys. 54, 4256 (1971)

153. L. Friedman, B. G. Reuben, Adv. Chem. Phys. 19, 33 (1971)

154. referêncla 89, p. 14

155. M. De Pas, J. J. Leventhal, L. Friedman, J. Chem. Phys. 49 , $5543(1968)$

156. J. M. S. Henis, J. Amer. Chem. Soc. $\underline{90}, 844$ (1968)

157. D. H. Aue, H. M. Webb, M. T. Bowers, J. Amer. Chem. Soc. $\underline{94,} 4726(1972)$

158. D. A. Swelgart, D. W. Turner, J. Amer. Chem. Soc. 94,5592 (1972) 
159. B, J. Cocksey, J. H. D. Eland, C. J. Danby, J. Chem. Soc. B, 790 (1971)

160. S.-L. Chong, J. L. Franklin, J. Amer. Chem. Soc. 94, 6347 (1972)

161. M. A. Haney, J. L. Franklin, J. Phys. Chem. 73, 4328 (1969)

162. J. L. Beauchamp, M. C. Caserio, J. Amer. Chem. Soc. 94, $2638(1972)$

163. A ordem de basicldade $\mathrm{ClCOOC}_{2} \mathrm{H}_{5}<\mathrm{HCOOC}_{2} \mathrm{H}_{5}$ fol determinada por P. C. Isolani.

164. V. Meyer, Ber. 27, 510 (1894)

165. J. N. E. Day, C. K. Ingold, Trans. Faraday Soc. 37,686 (1941)

166. P. W. Tiedemann, J. M. Riveros, 166a. reuntão da American Chemical Society, Chicago, USA, 1973, comunicação Phys 67

167. J. M. Riveros, P. W. Tiedemann, Academia Brasileira de Ciências, São Paulo, sessão de 13 de novembro de 1973

168. P. W. Tiedemann, J. M. Riveros, J. Amer. Chem. Soc. 96 , 185 (1974)

169. J. March, "Advanced Organic Chemistry: Reactions, Mechanism, and Structure", McGraw-Hill, New York, USA, 1968, p. 309

170. J. B. Hendrickson, D. J. Cram, G. S. Hammond, "Organic Chemistry", 3a. ed., McGraw-Hill, New York, USA, 1970, p. 504

171. A. L. Henne, M. S. Newman, L. I. Quill, R. A. Staniforth, J. Amer. Chem. Soc. 69, 1819 (1947)

172. referêncta 128 , p. 382

173. G. P. Happ, D. W. Stewart, J. Amer. Chem. Soc. 74, 4404 (1952)

174. referência 103, p. 94

175. K. R. Ryan, L. W. Sieck, J. H. Futrell, J. Chem. Phys. 41 , $111(1964)$ 
176. L, W. Sieck, F. P. Abramson, J. H. Futrell, J. Chem. Phys . 45, $2859(1966)$

177. J. L. Beauchamp, R. C. Dunbar, J. Amer. Chem. Soc. 92, 1477 (1970)

178. T. A. Lehman, T. A. Elwood, J. T. Bursey, M. M. Bursey, J. L. Beauchamp, J. Amer. Chem. Soc. 93, 2108 (1971)

179. referência $103, \mathrm{p} .174$

180. A. G. Sharkey, Jr:, J. L. Shultz, R. A. Friedel, Anal. Chem. $\underline{31}, 87$ (1959)

181. referência 89 , p. 260

182. J. A. Kerr, Chem. Revs. 66, 465 (1966)

183. J. Hine, J. Amer. Chem. Soc. 94, 5766 (1972)

184. D. Holtz, J. L. Beauchamp, S. D. Woodgate, J. Amer. Chem. Soc. $\underline{92}, 7484(1970)$

185. D. Holtz, J. L. Beauchamp, Nature Phys. Sc1. 231, 204 (1971)

186. M. S. Foster, J. L. Beauchamp, J. Amer. Chem. Soc. 94,2425 (1972)

187. J. H. Cook, J. L. Beauchamp, enviado para publicação ao J ; Amer. Chem. Soc.

188. M. S. B. Munson, F. H. Field, J. Amer. Chem. Soc. 88, 4337 (1966)

189. W. A. Laurie, F. H. Field, J. Amer. Chem. Soc. 94, 2913 (1972)

190. referência 103, p. 268

191. R. H. Martin, F. W. Lampe, R. W. Taft, J. Amer. Chem. Soc. 88, $1353(1966)$

192. A base de tempo infciada no integrador é a que dita o tempo total de reação. Esta base de tempo poderia ser em principio usada para gatilhar os geradores dos pulsos de formação de Ions e de destrulção, não sendo necessārio o 
gerador de dente de serra da Tektronix tipo 162. Porém, - Integrador da PAR trabalha com tensōes menores que as unidades da Tektronix série-160, de modo que o primeiro è incapaz de gatilhar estas. Por 1sso tambēm è necessāria a redução de tensão ao gatilhar o integrador com o gerador de pulsos. 